University of Louisville

ThinkIR: The University of Louisville's Institutional Repository

Electronic Theses and Dissertations

8-2014

\title{
Globalizing literacies and identities : translingual and transcultural literacy practices of Bhutanese refugees in the U.S.
}

Tika R. Lamsal

University of Louisville

Follow this and additional works at: https://ir.library.louisville.edu/etd

Part of the English Language and Literature Commons

\section{Recommended Citation}

Lamsal, Tika R., "Globalizing literacies and identities : translingual and transcultural literacy practices of Bhutanese refugees in the U.S." (2014). Electronic Theses and Dissertations. Paper 789.

https://doi.org/10.18297/etd/789

This Doctoral Dissertation is brought to you for free and open access by ThinkIR: The University of Louisville's Institutional Repository. It has been accepted for inclusion in Electronic Theses and Dissertations by an authorized administrator of ThinkIR: The University of Louisville's Institutional Repository. This title appears here courtesy of the author, who has retained all other copyrights. For more information, please contact thinkir@louisville.edu. 


\title{
GLOBALIZING LITERACIES AND IDENTITIES: TRANSLINGUAL AND TRANSCULTURAL LITERACY PRACTICES OF BHUTANESE REFUGEES IN THE U.S.
}

\author{
By \\ Tika R. Lamsal \\ B.A., Tribhuvan University, Nepal, 1995 \\ M.A. in English (Literature), Tribhuvan University, Nepal, 1997 \\ M.A. in English (Rhetoric and Composition), University of Louisville, 2009
}

\begin{abstract}
A Dissertation
Submitted to the Faculty of the

College of Arts and Sciences of the University of Louisville in Partial Fulfillment of the Requirements

for the Degree of
\end{abstract}

Doctor of Philosophy

Department of English

University of Louisville

Louisville, Kentucky

August 2014 
Copyright 2014 by Tika R. Lamsal

All rights reserved 



\section{GLOBALIZING LITERACIES AND IDENTITIES: TRANSLINGUAL AND TRANSCULTURAL LITERACY PRACTICES OF BHUTANESE REFUGEES IN THE U.S.}

$$
\text { By }
$$

Tika R. Lamsal

B.A., Tribhuvan University, Nepal, 1995

M.A. in English (Literature), Tribhuvan University, Nepal, 1997

M.A. in English (Rhetoric and Composition), University of Louisville, 2009

A Dissertation Approved on

July 22,2014

by the following dissertation committee

\begin{tabular}{c}
\hline $\begin{array}{c}\text { Bruce Horner } \\
\text { Dissertation Director }\end{array}$ \\
\hline Min-Zhan Lu \\
\hline Bronwyn Williams \\
\hline David Anderson \\
\hline Cynthia Selfe
\end{tabular}




\section{DEDICATION}

This dissertation is dedicated to my parents:

\section{Durga Devi}

and

\section{Dadhi Ram Lamsal}

Whose belief in light of education and resilience has always inspired me to work hard and hope for the best 


\section{ACKNOWLEDGMENTS}

I express my utmost gratitude and thankfulness to all the participants from Bhutanese refugee community in the U.S. I wish I could name all of you here and express my individual earnest regard for your tireless cooperation, warm welcome, and stimulating conversations all the time I came to your homes, workplaces, and learning centers. I am deeply indebted to all of you for opening your homes and your hearts to me and sharing with me the stories of your life.

I am deeply thankful to Bruce Horner, the director of my dissertation for his loving and nurturing guidance. Without his careful guidance and dedication to this project, this dissertation could not be produced in this form. Bruce, special thanks for your generosity, support, time, and regular response to my emails during such a tough time in your family. I would like to thank the members of my committee, Min-Zhan Lu, Bronwyn Williams, David Anderson, and Cynthia Selfe for your time, invaluable suggestions, and deep insight in helping me shape this dissertation. I am deeply humbled by your inspiration and generous support to see me develop the project this far. I would like to express my special gratitude to Min-Zhan Lu, and Bronwyn Williams for your extensive intellectual and emotional support since the budding stage of this dissertation to help me shape it in the present form. You always went beyond the teacherly boundary to support me in any way you could in order to see me grow professionally and academically.

I am also thankful to Beth Boehm, the Dean of School of Interdisciplinary and 
Graduate Studies for providing me with Summer dissertation fellowship so I could devote more free time to complete this project. Thanks are also due to Susan Ryan, and Karen Kopelson, the former graduate directors of English Department, who constantly extended their support throughout my stay at $\mathrm{U}$ of $\mathrm{L}$.

I would also like to take this opportunity to remember with respect my gurus in Nepal, Shreedhar Lohani, and Abhi Subdedi, whose continuous support and encouragement pushed me further in pursuit of knowledge. I owe thanks to my friends and colleagues who regularly inspired me and pushed me towards the completion of this project. I am especially thankful to Iswari for his stimulating academic conversations in the course of conducting this research.

Heartfelt thanks to my teachers, staff, and friends at the Department of English who always welcomed me with warm hearts and guided me selflessly even during my emotional and academic journey throughout my seven-year stay at the university. My sincere regards to the Reading Group friends who patiently read my chapters and offered invaluable suggestions for improvement. I am highly impressed by their generosity and support in helping me accomplish this project.

Finally, I am indebted to my parents and siblings, who always saw a dream in me to lead them to the path of knowledge and education. My wife Renu and children Anusha and Arnav always reminded me that there is a life outside my dissertation and helped me stay sane and working. Special thanks to Renu who bent over backwards to make a successful co-traveler of me and led me to a right path out of innumerable curves of our life together for 15 years. I can't believe I'm done, finally!

July 15,2014 


\begin{abstract}
GLOBALIZING LITERACIES AND IDENTITIES: TRANSLINGUAL AND

TRANSCULTURAL LITERACY PRACTICES OF BHUTANESE REFUGEES IN

THE U.S.

Tika R. Lamsal
\end{abstract}

July 22, 2014

This critical ethnographic study explores how language and literacy shape the social identities and cultural practices of the Bhutanese refugees in the U.S., and how an understanding of their literate practices contributes to new conceptualizations of language and literacies research. Involving fifty-six Bhutanese refugees from a Midwest city, this study highlights linguistic and cultural resources utilized by the Bhutanese refugees at key literacy sites - such as an Elderly Care Center, mandatory ESL classes, weekly cultural and musical gatherings, men's and women's Kirtan (religious singing) groups, and youth online forums - for creating, changing, and transforming their linguistic, cultural, musical, and literate traditions. This study highlights and illustrates tensions between, on the one hand, dominant monolingualist views in the participants' notions about Bhutanese/Nepalese culture/language and traditions, and, on the other, their actual engagement in fluid, diverse, shifting, situated, and emergent practices. This dissertation contributes to the development of studies of immigrant literacies by articulating the effects of distinctions among immigrant groups (distinguishing between "voluntary" and refugee immigrants) and the effects of intra-group dynamics (by caste, 
gender, generation, and religious affiliation) on the specific literacy practices of members of immigrant refugee groups.

This dissertation is divided into five chapters. Chapter One, titled "In the Wor(1)ds of Language and Ethnicity: Literacies in Motion," introduces readers to Bhutanese refugee community and the development of their everyday literacy practices as they navigate across various geopolitical locales. In its discussion of the development of Bhutanese refugees' reading and writing practices as historically, culturally, politically, and religiously situated, the first part of this chapter also argues against the traditional notion of literacy as the cognitive achievement of people and their learning. The second part of this chapter situates the study in the context of scholarship in literacy studies, transcultural and translingual theories, and globalization and media studies.

Chapter Two, "The Outsider Within: Critical Ethnography and the Representation of Other," first explains the research methods for collecting data, interview processes, and the processes for interpreting and analyzing them, and the researcher's positioning. Then the chapter complicates a traditional notion of ethnography that reduces this research method to fieldwork and description and that treats ethnography as a study of the "other." Posing an alternative to traditional ethnography that accommodates critical voices and researchers' self-reflection, this discussion reviews scholarship that articulates issues on ethical representation and the use of critical ethnography in the context of the researcher's own positioning. A reflective analysis in the second part of this chapter stresses the role critical ethnography plays in invoking the processual and historical knowledge-making of the research participants as well as in helping document the researcher's own journey through knowledge. 
Chapter Three, "Literacies Across Borders: Remapping the Boundaries of Literacy and Language Practices," explores the literacy practices of the research participants as they migrate to various locales, and identifies the purpose of such practices in the transcultural and translingual contexts of their new home in the U.S. Observation, examination, and documentation of the everyday literacy practices of these refugees in the contexts of literacy sites as well as that of their homes and community demonstrate the ways in which the refugees utilize their literate practices to foster new understandings as well as to forge social networks while maintaining transnational connections. This section also analyzes identity as manifest in the language and literacy practices of these participants, especially by tracing the impact of multicultural, multimodal, and multilingual literacies on immigrant identities.

Chapter Four, "Globally Digital, Digitally Global: Multilingual and Multimodal Literacies in the Making," examines how the participants adopt multilingual literacy practices, especially through the use of digital new media in globalized contexts, to challenge monolingual and monomodal discourse on learning. Analysis of the emerging multilingual and multimodal literate practices of research participants across generations - elderly and middle-aged, and college-going adults - shows how these refugees utilize and negotiate their multilingual repertoires in the process of adjusting to a host country. This chapter focuses particularly on alternative language/culture source networks and their impact on refugee literate practices when interacting with mainstream society.

Chapter Five, which is titled "Resisting the Finality of Monolingual Closures: Implications for Pedagogy and Educational Research," summarizes and concludes the 
study, exploring its implications for the understanding and interpretation of emerging literate practices of minority communities like the immigrant refugees. The chapter concludes with a review of the study's limitations and directions for future research.

While most studies of out-of-school literacies treat formal and non-formal literacy practices as discrete entities, this study highlights continuities across these, forging a response to those who see literacy as a discrete cognitive practice that takes place mostly in the contexts of schooled reading and writing. Findings from the research indicate that the use of multiple languages, cultural resources, and new media have cultivated the Bhutanese refugees' literate practices in relation to race, gender, and nationality in a digitized and globalized context. Although focused on a Bhutanese refugee community, the findings of this study are relevant for educators who look for new ways to imagine academic experiences that are socially and culturally responsive. This study reflects the shifting socio-cultural dimensions of U.S. population, not only in terms of social diversity but also in relation to the political and cultural conflicts that underpin the refugees' lived experiences. 


\section{TABLE OF CONTENTS}

PAGE

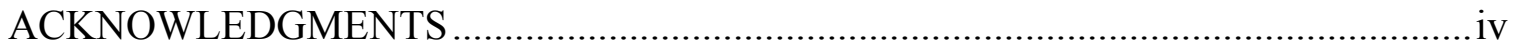

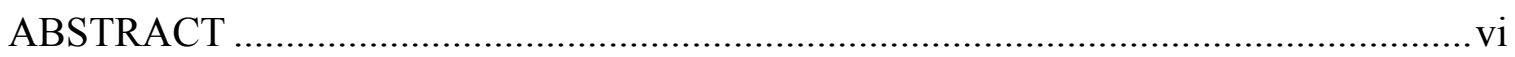

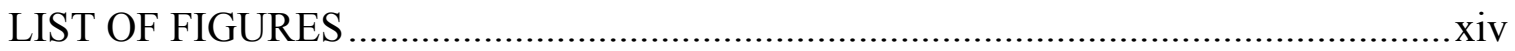

CHAPTER 1: IN THE WOR(L)DS OF LANGUAGE AND ETHNICITY: LITERACIES

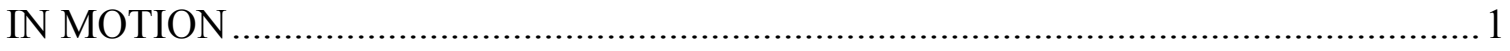

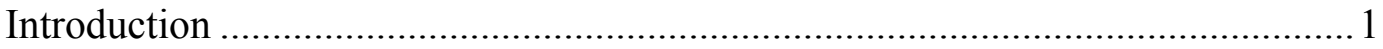

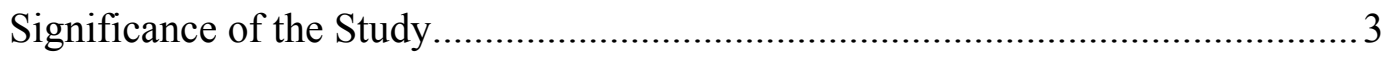

Literacy Practices and Literacies in the Plural ....................................................5

Bhutanese Refugees: Past and Present ………………................................ 8

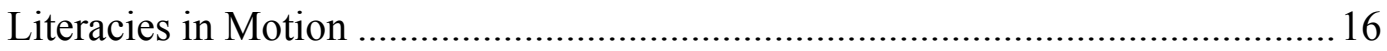

Recent Immigrants vs. Refugees .......................................... 19

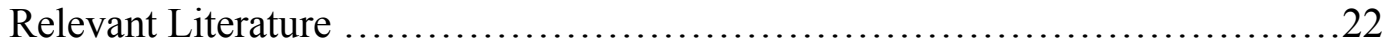

Literacies in Transcultural Contexts: Challenging the Autonomous Model ....23

Translingual Approaches to Literacy Learning ..............................33

Literacies in Globalized and Digitized Contexts ............................43

Research Questions ..................................................47

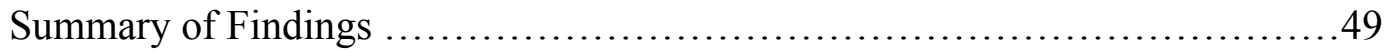

CHAPTER 2: THE OUTSIDER WITHIN: CRITICAL ETHNOGRAPHY AND THE

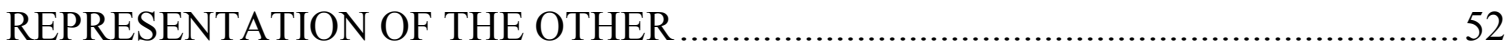


Introduction

Research Sites and Participants ................................................................... 53

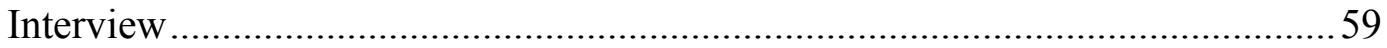

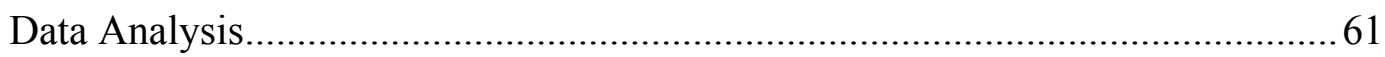

An Outsider within: My Positionality as a Researcher .......................................66

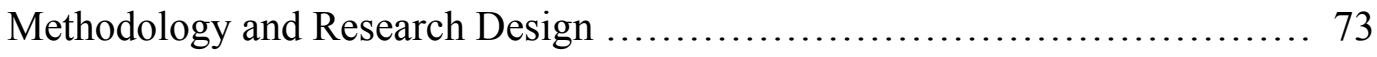

Ethnography and Representation of Other ........................ 75

Critical Ethnography and Critical Reflection ....................... 80

CHAPTER 3: LITERACIES ACROSS BORDERS: REMAPPING THE BOUNDARIES

OF LANGUAGE AND LITERACY PRACTICES ...................................................... 94

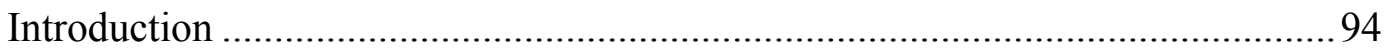

Construction of Identity across Diasporic Borders .......................................... 96

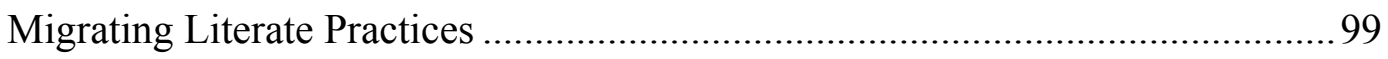

Literacies in Everyday Contexts ...................................... 107

Literacy Practices at the Elderly Care Center ........................... 108

Multicultural and Multilingual Literate Practices of the Elderly Refugees . 110

Mandatory vs. Motivational Citizenship Classes ....................... 116

Learning through Physical Exercise, Yoga, and Games ................ 122

“He Don’t Speak English; Don’t Talk to Him in English”: Conflictual Practices

of Production and Circulation of Languages in the U.S. ................... 124

Multilingual vs. Monolingual Teaching Practices at ESL Classrooms ....... 127

"No Bees No Honey; No English No Money": Challenging the Assimilationist 
Approach

Music, Arts, and Culture Group (Triveni): Mobility of Cultural Literacy in

Imaginary Homelands 140

Sponsors of Literacy: Schools as Ideological Apparatuses .................... 148

Literacies for Belongingness and Citizenship ............................ 152

Intra-Community Dynamics: Outsiders within ......................... 162

CHAPTER 4: GLOBALLY DIGITAL, DIGITALLY GLOBAL: MULTILINGUAL

AND MULTIMODAL LITERACIES IN THE MAKING 173

Introduction 173

Literacies beyond School Classrooms: Changing Technologies of Communication 177

Multilingual Repertoires among Refugee Youth …………………………....... 185

Converging Literacies across Digital Spaces ...................................................2204

Religious Literacy and Transnational Identities ............................ 215

Women and Learning: Gendering Work and Literacy ....................... 222

Everyday Discourse of Self-Making through New Media Literacies ........... 231

CHAPTER 5: RESISTING THE FINALITY OF MONOLINGUAL CLOSURES:

IMPLICATIONS FOR PEDAGOGY AND EDUCATIONAL RESEARCH.................239

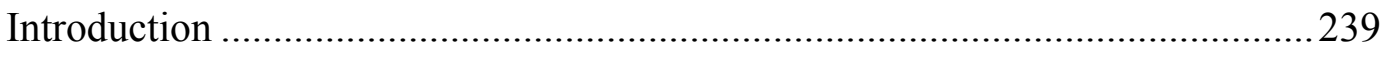

Discursive Rhetorics, Dynamic Literacies: Contribution to the Field .................241 Implications for Classroom Pedagogy: My Position as a Writing Teacher ..243 Intra-community Dynamics as Mediating Practices......................................2249

Literacies for Nationhood .............................................251 
Multiliteracies in the Making: Fluid and Emergent Literacy Practices ... 252

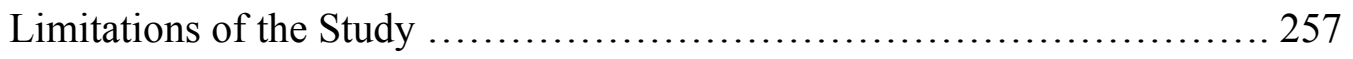

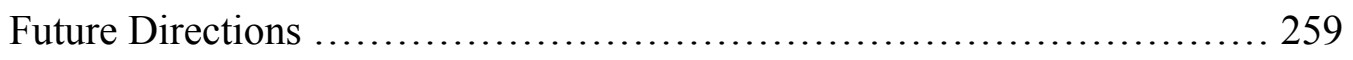

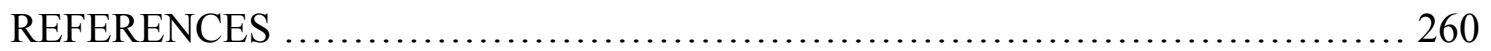

\section{APPENDICES}

APPENDIX A: INTERVIEW PROTOCOL ................................. 281

APPENDIX B: ETHNOGRAPHIC ESSAY ASSIGNMENT ...................... 283

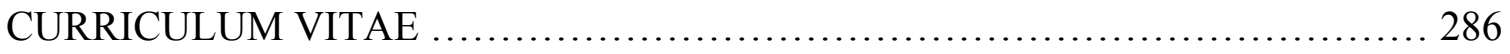




\section{LIST OF FIGURES}

$\begin{array}{ll}\text { FIGURE PAGE } & \text { PAR }\end{array}$

1.1. Map of Bhutanese Refugee Camps in Eastern Nepal ......................... 16

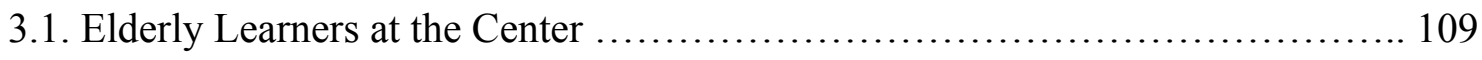

3.2. Balgopal's Manuscript .............................................. 143

3.3. Mahesh's Poem ................................................... 158

3.4 Balgopal's Ghazal in Nepali ....................................... 160

4.1. Binaya's Writing Sample ............................................ 183

4.2. Facebook: Multiple Languages in Action .............................. 191

4.3. Priya and Her Group Facebook Interface ............................. 192

4.4. Priya's Writing Sample ........................................... 197

4.5. Binu and Her Friends' Song Script ...................................... 220 


\section{CHAPTER I}

\section{IN THE WOR(L)DS OF LANGUAGE AND ETHNICITY: LITERACIES IN MOTION}

The Globe shrinks for those who own it; for the displaced or the dispossessed, the migrant or refugee, no distance is more awesome than the few feet across borders or frontiers.

- Homi Bhabha (1992)

I usually write in both Nepali and English, and have also been running an online forum for discussing cultural and academic issues among a younger generation of Bhutanese refugees in

the US. However, when I write for my classes in college, the professors always penalize my grades saying that I write in a different English, and that my grammar is bad. I don't know what that means, but I sometimes feel frustrated and worry that I can't succeed academically.

- Bijaya, born in

Bhutan in 1990

You know, even in America there is a different treatment to we less educated and working refugees than to those who are suited booted and speak better English. More educated among us

work as translators and speak for us, and we never have our say when we go to government offices and other workplaces. Our supervisors in the workplaces also say that we should learn

American English, American manners, and behave like them to get better opportunities.

-Mukti, born in

1977 in Bhutan

\section{Introduction}

Bijaya's and Mukti's stories of facing differences in academic institutions and workplaces represent the stories of most of the Bhutanese refugees in the U.S. The Bhutanese refugees' literacy practices have been punctuated by various cultural, political, economic, and linguistic conflicts they encountered in both their birth country and the countries of resettlement. While refugees become the subjects of norms, rules, and 
systems within institutional constraints as prescribed by sponsors of literacy (Brandt, 1998), they also explore ways to improvise and negotiate their literacy practices as well as cultural identities in the globalized context. "Recession, relocation, immigration, technological change, governmental retreat all can," according to Brandt, "condition the course by which the literate potential develops" (p. 173). Such literate potential develops beyond the constraints put upon these refugees by the sponsors, whereby people's process of self-formation occurs mostly outside of those institutional webs of power relations. The Bhutanese refugees' transnational and transcultural identities across various locations of their resettlement are rooted in transborder geopolitics and transregional fluidities of migration. The absence of national identity and the lack of solidarity with their birth state have deeply implicated the refugees into cross-border discourse as envisioned by Anzaldua (2002), who critiques the national discourse and produces a discourse about vernacular internationalism.

In light of theories of postcolonial migration, and multicultural, multimodal, and multilingual literacies, this study aims to uncover and examine literacy practices of the Bhutanese refugees in the U.S. by attending to the learning experiences of past and present generations of families whose literacy practices are shaping and shaped by their encounters with various cultural and geographical locales of their migration, ranging from their country of origin, Bhutan, to the refugee camps in Nepal to the U.S. My study of the literacy practices of Bhutanese refugees can be reflective of the shifting sociocultural dimensions of the U.S. population, not only in terms of social diversity but also in relation to the political and cultural conflicts that underpin recent immigrants' lived experiences in the country of their origin as well as their country of resettlement. While 
most ethnographies studying out-of-school literacies treat in-school and beyond school literate practices as discrete entities (Graham, 1980), this study highlights continuities across these learning spaces, forging a response to those who see literacy as a discrete cognitive practice that takes place mostly in the contexts of schooled reading and writing.

This study will also offer a perspective to look at literate practices of a community that is totally new to the context of U.S. immigrants. Although previous studies have demonstrated that utilizing culturally and linguistically diverse approaches to school instructions helps minority students improve their literate experiences, what these studies overlook is the fact that strategies that work in one community cannot necessarily be transferred to other communities where cultural and linguistic patterns may be completely different (Foster, 1992). Herein lies the significance of ethnography, which, according to Geertz (1973), is “a thick description" (pp. 9-10), whose aim is to adapt a semiotic system of culture in the context of research writing. Culture, in this sense, "is not a power, something to which social events, behaviors, institutions, or processes can be causally attributed; it is a context, something within which they can be intelligibly that is thickly - described" (Geertz, 1973, p. 14).

\section{Significance of the Study}

Recent decades have witnessed a considerable increase in the research of minority communities' literacy practices beyond school classrooms. Street's (1984) ideological model of literacy through ethnographies of different meanings out of people's lived experiences has received scholarly attention in the literacy practices of peripheral and marginalized groups in society, leaving direct implications to school literacy. While Street's (1984) ideological model of literacy challenged skills-based cognitive 
orientations to literacy, Moss's (1994) study legitimized the non-standard literacy practices of minority communities, and Rose's (1989) conceptions of literacy established the significance of community literacies by examining the intersections between home and school literacies. Barton and Hamilton's (1998) study of "vernacular" literacies of Lancaster communities has been widely received in literacy studies. Similarly, Gregory and Williams's (2000) research on two communities in Spitalfields and London presents an "intergenerational study of living, learning, and reading as it has taken place throughout the twentieth century in homes, clubs, churches, synagogues, mosques, theatres, and of course, the school classrooms" (p. xv). The publication of a special issue of Harvard Educational Review in 2001, by including ethnographic studies of different immigrant communities' literacy practices, also suggests the importance given to peripheral, and immigrant education by U. S. academic institutions.

However, literacy practices of immigrant refugees are undertheorized in the field of rhetoric and composition, paving the way for traditional assumptions to dominate the discourse. Some of the existing studies on immigrants and refugees focus mostly on Hispanic, African-American, European, and Southeast Asian immigrants (e.g., Guerra, 1998; Heath, 1983; Ong, 2003; Duffy, 2007). Most of these studies on immigrant and refugee literacies demonstrate how these minority communities adapt their literacy practices in light of adverse racial relations (Duffy, 2007); cultures clashing and languages colliding in schools, workplaces, and other institutional settings (Guerra, 1998); global capital flow (Prendergast, 2008), and home-country conflicts (Blommaert, 2010). Despite these studies' highlights on the shifting literacy practices of immigrants in globalized contexts, the concepts of literacies from cross-cultural, translingual, and 
transnational human rights perspectives among immigrant refugees are noticeably undertheorized.

The purpose of this research is to study how the refugees use reading and writing in various academic and non-academic contexts. The research helps promote an understanding of literacy practices and values as well as educational needs and strengths of recent immigrants and refugees. By investigating ideologies about literacy practices and language learning in relation to the views and experiences of the Bhutanese refugees, this study helps us better understand the ways that those refugees are positioned and position themselves within a specific educational, and cultural context in the U.S. as opposed to that of other immigrants.

In the first part of this chapter, I introduce the topic of this study and also offer a general background about the Bhutanese refugees in both Bhutan and Nepal before their arrival in the U.S. Then I focus on specific differences between recent immigrants and refugees in terms of their social, cultural, and linguistic status in the U.S. The next section highlights relevant theories of literacy, language, and cultural studies in relation to globalization and new media that help ground this study into translingual, transcultural, and multimodal research contexts. I will conclude this chapter with a summary of major findings from this study.

\section{Literacy Practices and Literacies in the Plural}

In this study, I use literacy practices in the sense of what Street (2001b) posits as "attempts both to handle the events and the patterns around literacy and to link them to something broader of a cultural and social kind" (p. 11, emphasis in the original). This mode of literacy, according to Street, underlies an ethnographic perspective, which 
encourages us to not only talk to the people and listen to their stories but also to link their "immediate experience out to other things that they do as well"; literacy practices thus refer to "this broader cultural conception of particular ways of thinking about and doing reading and writing in cultural contexts" (p. 11). I consider literacies as fluid and dynamic practices situated in different domains, expressing relations of power that are historically situated within political, social, economic, and cultural contexts (see Street, 1984; Gee et al., 1996; Barton et al., 1999). Along the same line, I talk about literacies in the plural for the purpose of what Martin-Jones and Jones (2000) call a "critique of the asocial, a-historical skill/ability understanding to reading and writing” (p. 4) related to what Street $(1984,2001)$ called the autonomous view of literacy. Concomitant to this view of literacy are resources of literacy in terms of what Brandt (2001) refers to as literacy learning and literacy development. While literacy learning attends to the learning activities beyond "school settings or formal study," literacy development means "the accumulating project of literacy learning across a lifetime, the interrelated effects and potentials of learning over time" (pp. 6-7). In my discussion of literacy practices of the Bhutanese refugees, I will use both of these resources of literacy based on the above definitions by Brandt.

In addition to those references regarding literacy practices, my definition of literacy is also informed by Pennycook's (2010) concept of language as a local practice. Pennycook develops a linguistic theory of practice where he defines language not as a system but as a practice. By practice he means "bundles of activities that are organized into coherent ways of doing things" (p. 25). The activities of reading, writing, and participating in social and cultural events that individuals engage in everyday contexts are 
"in a sense, the new discourse, the new way of describing that level of mediating social activity where we do things both because we want to and along lines laid down by habit, propriety, cultural norms or political dictates. It is therefore useful to explore the mesopolitical space of practice that lies between the local and the global” (p. 23). This is a more useful conceptualization of literacies in everyday context, where individuals reinvigorate their learning experiences by connecting everyday language use with other daily activities. The important point about practice, according to Pennycook, is that "it sits between these levels, between Big-D discourse (the abstractions of worldview) and little-d discourse (everyday language use) and asks how they connect, how this mesopolitical level organizes local activity in relation to broader social, cultural or historical organization" (p. 123). The accounts of Bhutanese refugees' literacy practices illustrate how, as Brandt (2001) states in Literacy in American Lives, literacy practices are complex practices that

complicate treatments of literacy as merely a set of technical, drillable, portable skills. They display instead the complex social and cultural orchestrations that even the simplest acts of reading or writing entail. They also invite interrogation into the implications of literacy in the maintenance of racism, sexism, and other undemocratic interests. (p. 8)

Offering insights into the development of literacies across socio-cultural contexts, as Luke (2003) points out, is one of the main goals of current literacy research. Such contexts demand particular attention as ways to counteract the homogenizing force of current literacy studies in the context of U.S. universities. Ethnographic research that studies minority communities, such as those represented by the Bhutanese refugees, is instrumental because "much of the literature on multiculturalism tends to treat all multilingual 'ethnicities' of a piece, without due attention to social class, location, and 
history" (Street, 2001). This study, therefore, focuses on emergent, situated, and discursive characteristics of the literacy practices in relation to the Bhutanese refugees in the U.S.

\section{Bhutanese Refugees: Past and Present}

Out of a total of 75,651 Bhutanese refugees resettled in the U.S. today (as of March 2014) ${ }^{1}$, around 4,500 are currently residing in Louisville, Lexington, and a couple of other locations in Kentucky. And approximately 3,200 among them are living in the city of this research, which I call Panorama City for the purpose of this study. These refugees started to migrate to the U.S. since early 2008 after the U.S. government in 2006 originally offered to resettle 60,000 Bhutanese refugees for third-country resettlement out of 107,000 total population in the refugee camps in Nepal. The refugees spent nearly two decades in the refugee camps in Nepal before coming to the U.S.

Bhutan is a small landlocked (also India-locked with India bordering on all sides of Bhutan except the north, which borders China) Himalayan monarchical state in South Asia. Culturally a diverse state, Bhutan inhabitants include Drukpa in the north and west, Sarchop in the east, and Lhotshampas (ethnic Nepalese) in the south, three main cultural populations in Bhutan, and there are also other small minorities. Although the statistics regarding the total populations and ethnic groups are highly contested due to the Bhutanese government's unwillingness to share the exact configuration of its nationals, most of the scholars in Bhutan and South Asia studies agree that it has approximately one

\footnotetext{
1 According to an online news portal, Nepalnews.com, by March 2014, the U.S. has resettled the largest number of Bhutanese refugees (75,651), followed by Canada (5,778), Australia (4,819), Denmark (852), Norway (550), and Netherlands (326), respectively. (published on March 26, 2014, and retrieved on June 26, 2014 from http://www.nepalnews.com/index.php/news/32647-88,000-Bhutanese-refugees-resettled-in third-countrie )
} 
million inhabitants consisting of the three broad linguistic groups (Hutt, 1996; Giri, 2005). According to Giri (2005),

First, the practitioners of Lamaist Buddhism and Dzongkha-speaking (an offshoot of the Tibetan language) Ngalung people, including the monarchy, form about 18 per cent of the total population and occupy northwestern Bhutan. Second, the Sarchhop group of Indo-Burmese origin living in the eastern region, constitute around 33 per cent of Bhutan's total inhabitants. They also practice a Lamaist form of Buddhism and speak a similar language that is spoken in the Arunachal state of India. Ngalung and Sarchhop peoples are often collectively called 'Drukpas'. However, it is clear that 'Drukpa' is used without a clear delineation of whom the term applies to. In fact, the word 'Bhutanese' is associated almost exclusively with the 'Ngalung' ruling group. Third, Nepali-speaking Lhotshampa people, who are largely Hindus, make up about 43 per cent of Bhutan's total population. (p. 345)

The government of Bhutan started colonizing ethnic Nepalese people's linguistic and cultural domains since the declaration of its "one nation, one people" policy, Driglam Namzha, in 1989 that required all Bhutanese people to follow the dress and language codes of Drukpa culture (mainstream Bhutanese culture). Hari K. Chhetri (2013), who also worked as a high-ranking government official in the Foreign Ministry of the Royal Government of Bhutan for more than a decade, describes Driglam Namzha as "the $17^{\text {th }}$ century theocratic etiquettes based on Buddhist concepts and central to Drukpa society. It prescribed the professed Bhutanese etiquette of how to conduct certain religious ceremonies and regulated [sic] a wide range of other forms of behavior from how to walk, sit, eat and dress to how to behave in the presence of superiors including the mandatory use of national dress and the Dzongkha," the national language of Bhutan (p. 77). This policy also terminated the use of Nepali language from school instructions (Hutt, 1996) in southern Bhutan, an area of subliminal nationalism and unresolved conflicts. When Bhutanese people of Nepali origin, who mostly lived in southern Bhutan, 
and were called Lhotshampas, waged war during the late 1980s and early 90s against the government measures to eliminate Lhotshampas' racial, cultural, and linguistic identity, the government started arresting, torturing, and even killing some of the protesters. It was such ethnic violence and government persecution that forced the Lhotshampas to flee their country to take refuge in the eastern part of Nepal.

I was a college student back in the early 1990s, when Bhutanese refugees were being forced to leave their country and driven to the refugee camps in eastern Nepal. Being from the eastern part of Nepal and staying close to the refugee camps for five years before I headed to Kathmandu for my Master's degree, I had a chance to closely observe the activities, daily life situations, and predicament of the refugees in the camps. As a college student in Damak Multiple Campus, which is hardly four kilometers away from the largest refugee camp in Beldangi, Jhapa, I used to very often visit the camp and sometimes even participate in some of the camp activities. As an outsider to the camp, I often saw the outer part of their life, Nepali and Hindi music blaring in a crescendo around the camp, young boys and girls involved in football (soccer) matches in the evenings in the open field nearby the camp, children running around, playing, crying, and the elderly people strolling outside their bamboo huts, talking to each other and enjoying the kids' play in the surroundings. However, I was always intrigued by the seemingly unperturbed but deeply wounded life the refugees in these meagerly sustained camps were living. Only sometimes did some news of persecution and atrocities meted out to them by the Bhutanese regime trickle through some of the tea-shop conversations I used to overhear during my occasional visits to a small tea and snacks stall nearby the camp, which was run by my cousins. I wanted to find out more about the causes of the refugees' 
displacement, their experiences, and the ways they were trying to adjust to this new environment. As soon as I graduated college, I headed to Kathmandu for my Master's. And my desire to explore more into the life experiences and literate practices of Bhutanese refugees in my own hometown hibernated for a long time until I found out that the Bhutanese refugees were being resettled to several other countries including the U.S. I found it a pleasant coincidence that they were resettled in a number of around 3,000 in the same city where I was pursuing my $\mathrm{PhD}$. This offered me an opportunity to revitalize my long-cherished desire to further research the day-to-day literate practices and the experiences of these refugees by observing their resettlement processes and consequent challenges in their new home.

As expressed by almost all of my Bhutanese refugee participants in the U.S. and as illustrated by several studies (see Hutt, 1996, 2003, 2005; Napoli, 2011; Zeppa, 1999; Chhetri, 2013), the ethnic Nepalese living in the southern part of Bhutan for "seven generations" ${ }^{2}$ suddenly became refugees in the early 1990s as a result of the Bhutanese government's strategic policies to eliminate the Lhotshampas, the ethnic Nepalese living in southern Bhutan, from its territorial and cultural map. With a forceful implementation of constrictive legislation, such as the 1988 Census, and Driglam Namzha, a policy of one nation one people, in the South in 1989, the government of Bhutan enforced the law necessitating the ethnic Nepalese for mandatory procurement of landholding and citizenship documents by making 1958 a cut-off year. The census that was conducted only in southern Bhutan in 1988 had started to categorize Nepalese families into seven

\footnotetext{
2 A cultural expression typical to Bhutanese-Nepalese and other Nepalese communities to indicate a long span of time like ages. See Michael Hutt's book Unbecoming citizens: Culture, nationhood, and the flight of refugees from Bhutan (2003) for details on the Lhotshampas' culture, history, citizenship status, and flight to the refugee camps in Nepal.
} 
different categories from F1 to F7. Only those who were registered as F1 were entitled to Bhutanese citizenship, and others were labeled non-citizens and were decreed to leave Bhutan. Thousands of ethnic Nepalese who had been living in Bhutan for generations were thus labeled non-citizens under allegations that they didn't have the required documents prior to 1958 to make them citizens. To add insult upon injury to the disappointed southerners, the government announced the closure of Nepali pathashalas (Nepali medium schools) and removed Nepali from school curricula in the south. This practice of discriminating against a particular ethnic group based on their language aligns exactly with monolingualist ideology that insists on linking national civic and ethnic identity with a single language and culture, and all conceived as unchanging, internally uniform, and discrete from others. Compounding dismay upon disappointment, the government made it mandatory for all the ethnic Nepalese to wear Gho and Kira (Bhutanese national dresses for men and women, respectively), which were too heavy to be worn on the humid plains of southern Bhutan.

In her memoir of Bhutan where she taught as a Canadian English teacher during the late 1980s, Zeppa (1999) included several incidents of the ongoing ethnic conflict between her southern Nepali students and the campus administration. In her account of one of such incidents that she encountered while teaching in Sherubtse College in eastern Bhutan, Zeppa (1999) remembered how her Nepali students from southern Bhutan were treated by the college administration, and how they were forced to change their ways of celebrating Hindu-based cultural events on campus. When they were barred from 
observing Durga puja ${ }^{3}$ by wearing Nepali dress, the Nepali students from the south became very worried about their identity and status in their own birth land because, as one of the students complained with Zeppa, the government and the college administration "don't want us to be Nepali anymore ... . We have to wear their dress and speak their language. We can no more be who we are" (Zeppa, 1999, p. 190). Although, as an outsider, she could not directly enquire about the "Situation", Zeppa recalls how she deeply felt about the government persecution against her Nepali students from the south, with night patrols on campus, room checks each evening, arrests, and disappearances: "They are taken at night. Arrested, gone, delivered to Thimpu (capital city of Bhutan) for questioning .... This is the most frightening thing" (p. 194).

Such strategic assault and persecution by the Bhutanese government targeting the ethnic Nepalese in the south triggered disappointments and organized resentments in the beginning, which, by September 1990, took the form of a movement of the Lhotshampas for democracy and human rights. This movement mostly emerged as a response to the government measures to eliminate the Lhotshampas' cultural, linguistic, national, and religious traces and render them non-citizens in their own country. Although the Lhotshampas presented their concerns to the government through their representatives in the beginning by writing a petition, the government only turned a deaf ear to those demands and started to reprimand and arrest the people's representatives from the south. To oppose such government measures, the Lhotshampas organized some mass protests and gatherings that turned violent for some time in almost all of the southern districts of Bhutan. The protesters took to the streets and voiced slogans for their basic cultural,

${ }^{3}$ An observance of a Hindu festival that falls around October/November and is considered to be the greatest festival among Hindus in the Nepali community. During this cultural festival, devotees, clad in their traditional Nepali dresses, worship the Goddess Durga, and offer blessings to the devotees. 
social, linguistic, and religious rights. The government took this as an opportunity to wage war against most of the Lhotshampas by declaring them Ngolops, anti-nationals and terrorists.

The government persecution against the Lhotshampas turned more violent and oppressive, as it deployed army and police in the southern villages to beat and arrest innocent villagers, raid their houses at night, rape the women, torch their houses and cattle, and even kill them sometimes in the name of crossfire or through torture in the temporary prisons housed in the former school premises. Recounting a touching story about Chandra and Laxmi, a Bhutanese refugee couple now residing in a resettled community in Tucson, Arizona, as ethnic Nepalis running away from persecution from the Bhutanese regime, Napoli (2011) offers an account of how

Schools in the south, where the largest settlements of ethnic NepaleseBhutanese lived, were shut down and turned into prisons, ending educational opportunities for children. Men were rounded up and sent to those prisons, often without being charged with a crime. Women were raped by the Bhutanese military. Houses were torched. People were classified according to the government's perception of the authenticity of their citizenship; some were deemed 'real' Bhutanese, others in the same family as 'non-national'. (p. 272)

Having spent a couple of years in Bhutan as a journalist trainer, Napoli feels betrayed by the apparently unperturbed kingdom of thunder dragon, for "It was nearly impossible to imagine that those gorgeous mountains, steeped in natural beauty and spiritual wonder, could be the backdrop for such events" (p. 272). It was only after her repeated visits to the resettled Bhutanese refugees in Tucson, Arizona in 2010 that meanings of some of the events that she had witnessed during her 2006-07 stay in Bhutan as a volunteer to help Kuzoo radio staff started to dawn on Napoli: 
And it deciphered what I'd witnessed since I'd first traveled to Bhutan: The notice on the wall at Kuzoo forbidding radio jockeys from playing foreign songs on the air - meaning music from Nepal. The fact that someone had once spurned the advance of a nice-looking boy at the station 'because he was half-Nepali.' A star teenage golfer unable to get a passport to attend a tournament in Vietnam for which he'd qualified because he wasn't 'really' a citizen, despite having been born in and grown up in Bhutan. (2011, p. 274)

The Lhotshampas then had no other options but to flee their country and take refuge in any other surrounding country. Despite the immediate Indian states bordering Bhutan, the Bhutanese refugees were not offered any shelter by India and were instead forced to go to Nepal by Indian security forces. The refugees then were compelled to live a very miserable and non-human life on the banks of rivers in eastern Nepal until United Nations High Commissioner for Refugees (UNHCR) intervened in 1991 to help them settle in seven different refugee camps in the eastern part of Nepal. The Bhutanese refugees thus spent nearly two decades in these refugee camps before the third country resettlement process started under the leadership of the U.S. in 2006. The refugees thus started to leave the refugee camps in Nepal for third country resettlement from early 2008. Although some of the Bhutanese refugees are also resettled in some European countries, the largest numbers of them (more than 80,000 by June 2014) have been resettled in the U.S.

In the face of such atrocities and persecution adopted by the Bhutanese regime to eliminate the ethnic, linguistic, religious, and cultural traces of nearly a one third of its own citizens, Napoli (2011) further observes that the widely trumpeted concept of GNH (Gross National Happiness) pioneered and championed by the Center for Bhutan Studies and initiated by the $4^{\text {th }}$ king of Bhutan way back in 1972 belies the very notion of happiness amongst half of its own ethnic citizens: 
At the first annual Gross National Happiness USA conference in Vermont in June, 2010, a peaceful protest was waged by a half dozen or so Nepalese-Bhutanese who'd crammed in a car and driven all night from their new home base of Atlanta. Hoping to counteract any adoration of the country that had rejected them, they declared, 'There is no Gross National Happiness in Bhutan.' When a conference attendee asked the keynote speaker, the visiting Bhutanese secretary of GNH, how people could be treated so badly, he refused to answer. He hadn't been brought here to discuss politics; he'd been brought here to talk about how the Bhutanese were responding to world-wide interest in how they measured well-being. (p. 274)

Despite the obvious cultural, political, religious, and social fragmentation that the

Bhutanese refugees have experienced since their eviction from Bhutan in the 1990s, most of them appear to have come to terms with the current circumstances of their lives in the

\section{U.S.}

Figure 1.1. Map of Bhutanese Refugee Camps in Eastern Nepal (Source: IOM - International Organization for Migration)

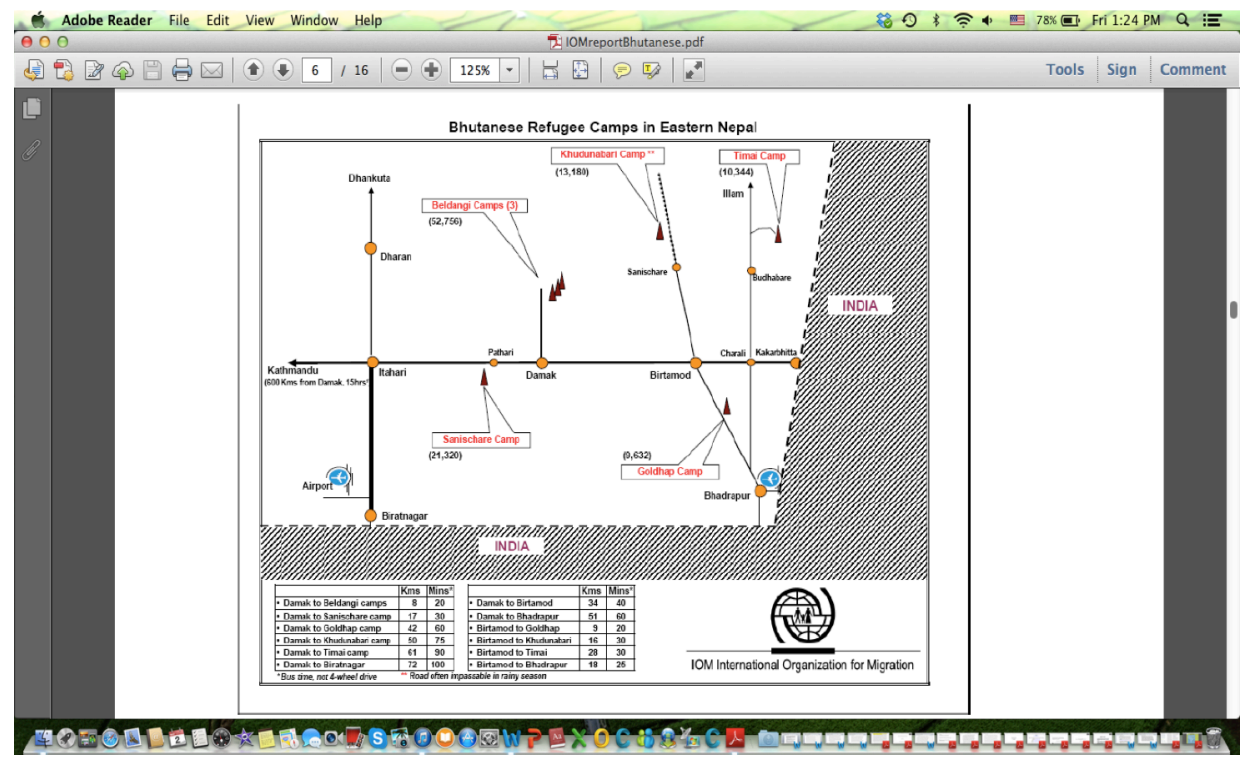

\section{Literacies in Motion}

During their stay both inside and outside of their homeland, Bhutanese refugees'

literacy practices mostly seem to be both constitutive of and constituted by the patterns of 
cultural, social, and historical mobility, characterized largely by the experiences of inclusion and exclusion in various geopolitical locations. "The dynamics of presenceabsence, inside-outside, included-excluded," according to Nyers (2006), "are never perfectly symmetrical or consistent" (p. xiii). Moreover, as Nyers adds, "refugees are allocated characteristics - speechlessness, invisibility, passivity - that are the obverse of the sovereign identity of citizenship" (p. xiv). For example, when the UNHCR resettled them temporarily in the refugee camps of Nepal, the Bhutanese refugees apparently seemed to integrate with the Nepalese people because of their similarities in terms of language, culture, and other behavioral patterns. However, the refugees were never welcomed within their social, cultural, and educational trajectories by the Nepali community due to the formers' label as "refugees." As a result, they never got to realize the sense of belongingness, sovereignty, and citizenship due to several nation states' perceptions of them as ethnic Nepalese in Bhutan, and as refugees in both Nepal and in the U.S. In various locations to which they moved, from their home country to the countries of resettlement, the Bhutanese refugees were always characterized by their homelessness, invisibility, passivity, and speechlessness. This study is an attempt to offer them a platform to raise their voices and help them render their identity as more assertive, visible, and in the making in the host country.

Despite their deep-seated confrontation with the Bhutanese regime, Bhutanese refugees established in the refugee camps in Nepal a different education system that was informed and shaped more by their home institutional academic values than by the Nepali educational system. Their schooled literacy still followed the traces of their home culture in a strange land while their "socio-cultural literacy practices" (Street, 2006, p. 37) were 
influenced by several other factors due to their "mix" with the Nepali patterns of life around the refugee camps. The daily experiences of Bhutanese refugees, their dislocation from the homeland, their generational fractures in the process of migrating from one nation to the other offer a unique perspective to see immigrants' literate practices in the context of globalized migration. Thus, Bhutanese refugees' history of repeated migrations makes the study of their experience a promising site for further understanding immigrant literacy practices.

Along the same line, Bhutanese refugees continue to undergo experiences of exclusion in their new home in the U.S. in the sense of eliminating the features of their previous linguistic and cultural repertoires that are deemed to be socially undesirable. As one of the recent studies shows, Bhutanese refugees are always pressured to learn "standard" English and communication practices by doing away with their "thick accent," and also by learning "American ways of life" (Shrestha, 2011). The refugees are thus under pressure to conform to dominant American linguistic and cultural values because the literacy sponsors always stress the "American ways" of living by reinforcing the dominant values at the cost of the refugees' linguistic and cultural differences. The refugees become more vulnerable culturally and linguistically compared to other recent immigrants also because unlike other immigrants, the experiences of immigrant refugees are not the consequences of their choices but that of their compulsion, characterized mostly by their need to conform to the principles and values of the sponsors of literacy that work mostly in tandem with the interests of the host countries. 


\section{Recent Immigrants Vs. Refugees}

There are some similarities and differences between other recent immigrants and refugees in terms of their status, identity, and literacy practices. In my discussion of the recent immigrants, I have in mind those "voluntary" legal, not so-called "illegal," immigrants, since the latter do not have the characteristics I identify in this study with non-refugee immigrants. Both of these communities - recent immigrants, and refugees become economic immigrants in their host country seeking work and a better life for themselves and their families. Both of them experience new cultures and languages. They are often ethnic minorities who might face open discrimination or other forms of hostility due to their social, cultural, and linguistic differences from the mainstream culture, regardless of their immigration status. Although the refugees come to a new home after facing the oppressive regime's brutal treatments in their birth country that may be radically different from the experiences of other immigrants, they undergo similar experiences of exoticization and "otherness" experienced by other immigrants for a long time.

While both refugees and other recent immigrants migrate to a different state from their birth country for the purpose of resettlement, the other immigrants opt for this opportunity voluntarily, looking for better standards of living. The refugees, on the other hand, are forced to leave their country on account of their political, ethnic, religious, and social differences. As an immigrant minority, to take from Ogbu's (1988) classification, these refugees enjoy a better position for the time being in terms of their newly granted status, while at the same time they differ from the recent immigrants in that their coming to the U.S. is not voluntary and therefore is more restrictive. Although they seem to enjoy 
a better position due to their refugee status as they receive permanent residence and become eligible to receive welfare assistance for a certain time as soon as they arrive in the U.S., unlike those legal immigrants not considered refugees, who must wait at least five years to be eligible for those privileges (Balgopal, 2000), the refugees also undergo an experience of humiliation and denigration by the dominant groups due to their subordinate status as "refugees" in their home country as well as in the country of their resettlement. Moreover, those who migrate from the Third World for better opportunities and life styles in the West are the ones who leave their countries for professional and economic reasons and therefore are not persecuted in their own countries as the refugees are. These non-refugee immigrants may be the national elites in their home countries with privileges in terms of wealth, education, and culture, for their empowerment in their home countries may have entitled them with certain privileges, such as the learning of the metropolitan languages, access to better education, and resources to negotiate the paper work of the nation-states, enabling them to leave their countries and settle in the West. Despite their privileged status and better educational opportunities in their home countries, they might have migrated to a First World country for gaining better cultural capital, educational degrees, and experiences.

In the meantime, while the other immigrants can return to their home country as per their wishes, the refugees cannot do so due to the "well-founded fear of persecution" (U.S. Immigration and Naturalization Service, 1997, p. 27), and therefore remain as permanent exiles. However, the refugees' contact with the home country continues through "memorabilia, symbolism, and ruminations, such as 1) observance of rituals, religious practices, and festivals; 2) adherence to the native language and communication 
patterns; 3) practice of ethnic values through customs and behavioral and attitudinal codes; and 4) familial, fraternal, and other ethnic group and interpersonal relationships" (Mayadas \& Segal, 2000, p. 209).

Unlike most of the immigrants, refugees carry a burden of facing differences more vehemently and also using English differently. For example, most immigrants migrate to the U.S. as skilled workers for financial opportunities by virtue of which they already master some level of proficiency in written and spoken English. Here, I am writing about current legal immigrants, vs. those without legal standing. Those legal immigrants may fare better in the workplace and host society as most of them render their language and literate practices saleable due to their upbringing to some elite class in their home country. The refugees, however, are far less likely to embody such skills and proficiency because of which they have to struggle more in almost all the activities they engage in, ranging from visits to government offices, to clinics, to their workplaces. Moreover, the refugee badge of their identity lurks behind them everywhere they go, further stigmatizing their behaviors, cultural and literate practices.

By focusing on the issues of immigrant refugees' differential identity, and literacy practices from that of other immigrants', I argue against common views of refugees as purely lacking, rather than as having important literacy and language resources. I have also explored in my study as to how the purpose of literacy becomes to dominate and to marginalize others (Gee, 1992), and how literacy practices enable people to resist the dominant practices and work towards bringing change, demonstrating the ways literacy becomes a complicated set of skills and practices and cultural understandings, and practical deployments. 
In my dissertation, I focus attention on the situated construction of literacy practices by examining the specific ways that the refugees in the study take up, resist, or negotiate discourses about literacy, language, and the place of refugees in U.S. society. Doing so helps me illustrate the ways historical structures and individual literacies are mediated by local practices and sponsors of literacy. In conducting this research, I utilized ethnographic methods, such as participant observation, interview, collection and analysis of cultural artifacts, and the close analysis of cultural practices and languages in use.

\section{Relevant Literature}

Many scholars in recent decades have defined literacy along the lines of sociocultural dimensions to suggest its break from the traditional model that treats it as a practice of learning and writing in a certain educational milieu, i.e. school settings. Such a traditional model, which literacy scholars and historians of education like Graham (1980) advocate, considers literacy "primarily as a cognitive enterprise," and limits it merely to "the ability to read, communicate, compute, develop independent judgments and take actions resulting from them" (Graham, 1980, p. 127). This view of literacy, however, fails to see how literacy is not simply acquired in school and how it is equally influenced by other social, cultural, and economic contexts in the community the students come from. Critiquing such a cognitive model of literacy, those who advocate the ideological model of literacy (Street, 1984, 2006; Barton and Hamilton, 1998) challenge it as an autonomous model that considers the practices of learning as skill-based and cognitive to argue in favor of multicultural, multilingual, and multimodal literacies. 
In the following sections on transcultural, translingual, and multimodal literacies, I critically analyze some relevant studies that have shaped the discourse on literacies in recent times. Then I critique some of the studies in light of the theories of literacy and language to argue that new perspectives to literacy learning should be developed in order to account for the literacy practices of recent immigrants and refugees because their learning experiences reflect not only their involvement in preserving and acting upon their prior cultural and academic practices but their active engagement in reshaping and asserting an agency over those emerging literacy practices in the context of their resettlement in their host country.

\section{Literacies in Transcultural Contexts: Challenging the Autonomous Model}

Since the studies of literacy took a social turn in the 1970s and 80s, literacy scholars have tried to uncover the ideological nature of traditional models of literacy. They conceptualize literacy practices not in terms of universal and autonomous skills of reading and writing based on cognitive and behavioral patterns of learning but on people's experiences of learning in relation to their social, cultural, political, and economic as well as local communicative practices. The dominant definition of literacy in the academy until the 70's was based on whether or not people possessed coding or decoding skills of written texts. Such skills were supposed to be universal ones based on learners' cognitive competence. This traditional view of literacy focused on the ability to produce written texts and understand them, which gave birth to a long-standing divide between oral and written language. In that line, Ong (1982) claimed that oral cultures cannot develop sophisticated uses of language and that having a written language advances a culture. This tendency of privileging one form of literacy over many others helped in perpetuating the dominance of Western models of literacy as the only 
legitimate form, thus reducing the literacy practices of many other societies and groups of people to illiteracy.

However, other literacy scholars complicated this view of literacy by suggesting the inevitability of socio-cultural influences in people's practices of reading and writing. Freire (1970) poses a challenge to the traditional cognitive view of literacy when he asserts that pedagogy can be liberating if it truly enables the oppressed to name the world for themselves rather than merely imposing the knowledge of the dominant group. Freire thus offers a political perspective to see literacy as involving critical political knowledge, whereby people participate in the ideological domain of education. According to Freire, the oppressed must become literate in the true word, which he defines in terms of work or praxis, and they can do this by naming the world, an act of creation that in turn changes the world (p. 87). Therefore, liberating education consists of acts of cognition, and critical, cultural understandings, not transfers of information. Teaching from generative themes drawn from the lives of the students can lead to critical consciousness as the students come to understand the situation in which they live, gain the power to name it, and see the possibility of changing it themselves. In this sense, literacy can be defined as the people's ability to recognize their situation within the world and their ability to recognize the existence and value of their empirical knowledge, which is culturally situated rather than cognitively patterned.

Street (1984) develops this sociocultural model of literacy further when he highlights the difference between autonomous and ideological models in his discussion of literacy and demonstrates how the autonomous model is deeply ideological. The former, according to Street, tends "implicitly to privilege and to generalize the writer's own conceptions and practices, as though these were what 'literacy' is" (p. 2). Such an etic 
approach to literacy promoted by autonomous model stands in sharp contrast to an ideological model, which takes into account "the specific social practices of reading and writing" (p. 2). Stressing the significance of socialization processes, the ideological model of literacy "concentrates on the overlap and interaction of oral and literate modes rather than stressing a 'great divide"' (p. 3). In his discussion of the ideological model of literacy, Street challenges the assumptions of the autonomous model of literacy that literacy is a technical, objective, neutral, and cognitive entity, and analyzes the contradictions and problems such assumptions lead to.

Street (2006) further clarifies the ideological model of literacy, which, as a social practice approach to literacy, establishes that cultural and ideological assumptions become inherent to people's learning experiences and that literacy is "always embedded in socially constructed epistemological principles" (p. 23). Similarly, the crux of NLS (New Literacy Studies), according to Street, is that literacy is not an issue of measurement or of skills but that of social practices that vary from one context to another (p. 21). Literacy as such becomes a social practice based on social contexts and relations of people's lived experiences as opposed to cognitive practices of knowledge making that are mainly attributed to individual developmental processes of learning. As Street (1984) shows in his ethnographic research he conducted among the Cheshmeh people in Iran in the late 1970 's, the idea of literacy as a social practice hinges on social relations people build with each other along with their learning experiences. For example, the "tajers," or the fruit contractors in Cheshmeh village in Iran, according to Street, were able to transfer their "maktab" literacy to commercial practices later on as they started to be interested in buying fruits with the village people and selling them in the city. Doing so helped them 
not only to transfer their maktab literacy to their business, but also to establish social relations with Chesmeh people in a way to forward their own business interests, whereby literacy developed at the ideological level, "a social construction of reality embedded in collective practice in specific social situations" (p. 12). It is on the foundation of social relations between tajers and the local farmers in the context of social and economic transactions that literacy functions in this community. If we look closely at the literacy practices of Cheshmeh people, we notice that the social in their context refers to economic practices and their working conditions.

Similarly, Barton and Hamilton (1998), in their study of literacy practices of one community in Lancaster, England, offer us a glance into the social and cultural contexts of learning. They argue that literacy practices are "patterned by social institutions and power relationships, and some literacies become more dominant, visible, and influential than others" (pp. 10-11). By the same token, such literacy practices are "purposeful and embedded in broader social goals and cultural practices" (p. 11). As a set of social practices inferred from events that are mediated by written texts, literacy, as it is manifested in the contexts of the research participants in this study, may serve multiple functions in any given activity. Out of many examples and references Barton and Hamilton mention in this study, I find one particular event to be more interesting in that it shows how school literacy becomes implicated in students' socioeconomic status and home environment. It seems to be common for Lancaster children to go to various schools and keep on changing them very often depending on class and educational backgrounds of their family, for "Lancaster's complex historically and politically induced muddle of two single-sex grammar schools, along with different Catholic and Anglican 
schools, made for some difficult decisions" (p. 199). Going to a grammar school in Lancaster becomes a matter of prestige and pride for students and their family. Those who can't participate in the competing models of grammar school education system have to feel alienated and sometimes humiliated. Diane was one such parent who felt powerless in the face of a school decision to send her disabled son to a special school, despite his abilities to perform well, by ignoring her son's abilities and her own knowledge of him as a parent (p. 203). Diane knew that her son, Eddie, was quite able to learn any kinds of skills as he showed in his home and outside school, but school standards assessed him to be fit only for a special school. This particular incident serves as an example to illustrate how students' out-of-school skills, which Street $(1984 ; 2006)$ calls "hidden literacy skills," go unaccounted for by the educational system guided by the principles of the autonomous model of literacy.

Street (1984) maintains that hidden literacy skills develop in conflictual relationship with schooled literacy, which is based more on the autonomous model of learning. Schooled literacy becomes a particular form of literacy without which people are labeled as illiterate despite their reading and writing skills. On the other hand, hidden literacy skills, according to Street, are "seldom addressed in schools" (p. 222). So, the job of teachers and researchers investigating literacy practices is to make explicit what is hidden in the society, and create an awareness among students about how hidden skills contribute to people's meaning making practices in relation to schooled literacy (p. 223). The latter, however, is deemed to be an official form of literacy that helps social improvement and social mobility, and which, according to Graff (1991), only perpetuates 
the literacy myth that literacy of itself can contribute to people's progress, social order, and restraint (p. 31).

Like Freire, Street, and Graff, Auerbach (1989) points out the need to look at students' work in the context of their life and a complex set of home culture resources that sometimes takes priority over formal education inculcated in school environments. Giving an example of Rosa, who is a mother, worker, and an adult student in a school, Auerbach underscores the complicated relationship between home environment and school learning. Rosa has several responsibilities as a mother, wife, cook, member of an extended family and community to prioritize at home before school work, so she is not always able to complete her formal work assigned by the school in a way the school literacy demands. Rosa, however, becomes committed to her education as she sees its importance in her life; in the meantime, she asks her teacher to look at her schoolwork in the context of her life and understand a complex relationship between her school life and home contexts (pp. 165-66). The acquisition of literacy skills as such should be seen in its context and uses (Heath, 1983; Street, 1984), and literacy becomes meaningful to the students only to the extent that it relates to daily realities and helps them to act on them (Freire, 1970), whereby a teacher's role extends beyond what happens to school life and reaches to students' life out of school so as to help us see the relationship between school literacy and home environment. For this, Auerbach (1989) proposes an alternative formulation, which, as she argues, helps school teachers address students' housing, education, work, and health by making explicit their uses in students' home life, and also exploring and acknowledging them in classroom. Here, literacy becomes a tool for 
addressing these issues and cultural differences by perceiving them as strengths and resources, which can bridge the gap between home and school (p. 176).

Highlighting the interdisciplinary nature of literacy, Basu, Maddox, and Robinson-Pant (2009) suggest that literacy is embedded in power relations; as people become aware of the dominant ideology and work towards redefining it in the course of their reading and writing practices, they also find ways to align with literacy practices, which involve the reworking of power relations rather than supporting or rejecting them in totality. Recognition of embedded power relations thus enables students to understand literacy as an activity to be accounted for not on the basis of individualized cognitive knowledge, but on the basis of ideological and cultural contexts that undergird people's lived experiences.

Some other literacy scholars have studied literacy as a source of domination and oppression (Stuckey, 1991). This approach to study literacy practices examines literacy not as a study of reading and writing behaviors of people as an objective cognitive science, but as a (re)conceptualization of social, cultural, and historical contexts, which offers people ways to unravel the "political and economic interests of those imparting it [literacy]" (Street, 1995). Being literate in this sense also means being able to respond to the opposite set of symbols and coercive practices used by the dominant institutions or a regime to suppress the marginalized communities and their values. Thus, if institutions can "control people by controlling their literacy," Daniell (1999) argues, it is also possible for "individuals and groups to use literacy to act either in concert with or in opposition to this power" (p. 406). Literacy practices thus become mostly embedded in broader social, cultural, and historical practices and are "patterned by social institutions 
and power relationships, and some literacies are more dominant, visible, and influential than others" (Barton \& Hamilton, 2000, p. 8).

A transcultural approach to literacy helps promote this model of learning by stressing the need to build on and acknowledge people's prior experiences in terms of their differences and distances rather than dismissing them as irrelevant on linguistic and cultural grounds. This approach is also informed by Appadurai's (1996) notion of the adjectival "cultural" instead of culture as a noun. According to Appadurai, "If culture as a noun seems to carry associations with some sort of substance in ways that appear to conceal more than they reveal, cultural the adjective moves one into a realm of differences, contrasts, and comparisons that is more helpful" (p. 12, emphasis the writer's). Calling it more a centrifugal approach of inclusivity than a centripetal method, Mingolo and Schiwy (2002) suggest that transculturation is "a necessary concept to think all kinds of social and political relations of forces in a transnational world" (p. 252). I am interested in exploring a transcultural approach to literacy because, as Trahar (2005) postulates in his research in the context of higher education teaching, transculturalism is a stage "beyond interculturalism where a common and different culture emerges from the dialogue of the transcultural spaces between teachers and students" (Trahar cited in Robinson-Pant, p. 18). While culturally based approaches offer us insights into the situated nature of reading and writing, they can do little "to delineate the historical relationships that have shaped the very practices being described" (Duffy, 2007, p. 9). According to Duffy, such limitations of culturally based approaches may result in reproduction of literacy practices that "may end up being represented as though they were self-generating, a product of unique cultural characteristics rather than an outcome of 
historical and often violent contacts between peoples of unequal power" (p. 9). A transcultural approach to literacy takes us beyond this cultural approach to account for conflictual and emerging historical constructs of literacy that have shaped the experiences of reading and writing of the Bhutanese refugees. This approach also sheds light on significant cultural differences between culturally specific academic discourses and the cultural gaps that need to be bridged when doing cross-border and multilingual research (see Helms et al., 2005; Muller, 2007).

The use of a transcultural model thus offers us a way to better understand and recognize people's transcultural spaces in a way to analyze their cultural differences based on historical contexts, as Robinson-Pant (2005) believes, differently from how a cross-cultural model does. Referring to the research on international students in British higher education, Robinson-Pant suggests that the cross-cultural model bears the risk of reifying the cultures of international students by stabilizing them as "other," and reinforcing the gap between the dominant and the dominated by looking at them in binary terms. Giving an example of how international students themselves succumb to such binary of cross-cultural relations, she points out that "students are often eager to generalize about 'their' culture, referring to 'we Saudi Arabians,' rather than emphasising that even within [our] seminar group, individual Saudi students from differing backgrounds often hold contrasting beliefs" (p. 12). Along the same line, drawing attention to the impossibility of comparing one culture with another as binary oppositions, Bhabha (1994) argues, "The very concepts of homogeneous national cultures, the consensual or contiguous transmissions of historical traditions, or 'organic' ethnic communities - as the grounds of cultural comparativism - are in a profound 
process of redefinition" (p. 5). A transcultural approach further allows us to see cultural differences as emergent and fluid, opening up interrogatory and identitarian space, which, according to Bhabha, means "the interstitial passage between fixed identifications [which] opens up the possibility of a cultural hybridity that entertains difference without an assumed or imposed hierarchy" (p. 4). Such an identitarian space Bhabha envisions also takes into account the intricacies of globalization and affects the movement of refugees and migrant workers.

Despite the significance of reading and writing in current conversations, literacy is mostly characterized by its complex relationships between individuals and institutions in a given setting than its being resident in cognition. As Barton and Hamilton (1998) argue, "Literacy practices are patterned by social institutions and power relationships, and some literacies become more dominant, visible, and influential than others.... [They] are purposeful and embedded in broader social goals and cultural practices" (p. 7). Similarly, other scholars like Street (1984, 1993; Gregory \& Williams, 2000) have extended the notion of literacy beyond the realm of reading and writing to incorporate a range of meaning making practices, aligning literacies against any monolithic and autonomous notion of literacy (Street, 1993, p. 9). Literacies are thus not only social practices, or ways of using written texts that are bound up in social processes which locate individual action within social and cultural processes (Martin-Jones \& Jones, 2000, p. 4), but also ways of participating in larger social and cultural discourses that can be defined as systems of behaving, interacting, valuing, thinking, believing, and often reading and writing that are accepted as instantiations of particular roles by specific groups of people (Gee et al., 1996). Literacies as such are deeply embedded in the socio- 
cultural, historical, and political contexts, and in people's responses to such contexts through their participation and sometimes even through resistance.

\section{Translingual Approaches to Literacy Learning}

The traditional, monolingual model of language learning makes a false assumption about the notion of language competence, which is based on the myth of the native speaker. It assumes that the target of language learning is to achieve native-like or near-native competence. But it fails to acknowledge the fact that neither there are any universal conventions of 'standard' (native) English nor are they stable (even if there are any). In other words, it believes that language is a fixed, stable, and neutral entity. Hence, the ideology of "standard English" has become a norm in students' literacy practices, irrespective of their socio-cultural, and geo-political differences.

However, the forces of globalization and cross-cultural contact have made it inevitable for rhetoric and composition to more seriously address differences in language and culture in its treatment of literacy and learning. As Matsuda (2002) points out, the increasing demographic shift in the faculty and student population in US colleges and universities in recent decades has in fact led to a shift in expectations of what is the norm. Such change, Matsuda notes, arises "as a result of institutions actively recruiting students and scholars with various socioeconomic backgrounds as well as, by implication, linguistic and cultural backgrounds" (p. 194). The Conference on College Composition and Communication realized this shift and initiated its effort with its 1974 resolution, SRTOL (Students' Right to Their Own Language), as a way to address differences in students' language and culture by recognizing and affirming students" "right to their own patterns and varieties of language - the dialects of their nurture or whatever dialects in 
which they find their own identity and style." Despite its seemingly progressive move in the context of 1970s, SRTOL, however, has left some fissures in its recognition of students' right to their own language, providing the education system with sufficient grounds to maintain the privileged status of EAE (Educated American English) in a new way. By calling differences among dialects in a given language as "always confined to a limited range of surface features that have no effect on what linguists call deep structure, a term that might be roughly translated as 'meaning"' (SRTOL, 1974, p. 6), the resolution has left new ways for educators to endorse EAE in classroom situations because it (the resolution) dismisses the issues of differences and diversity as superficial features, rendering them neutral in the process of meaning-making. By the same token, this assumption implies that the teaching of meaning is separate from its social, cultural, and historical contexts. This also suggests that composition stands above the conflictual grounds of dialectal differences and meaning-making processes, paving the way for the education system to maintain its transcendence over social, cultural, and historical power struggle.

Another way the education system has been used to maintain the dominance of native speaker norms in the academy is through what Matsuda (1999) calls the disciplinary division of labor. He notes that as ESL grew as a profession, some believed that a division of labor was necessary because ESL students required teachers with special training in order to serve their particular needs (p. 784). Matsuda argues that because ESL students are often required to take mainstream freshman composition courses as well as professional writing in addition to their ESL writing courses, that interdisciplinary cooperation between composition and TESL is necessary for ESL 
students' success, which includes writing programs that employ or train writing instructors who are prepared to address the needs of ESL student writers. Along the same line, Matsuda (2006) in another seminal article postulates that the college composition course has functioned historically to "contain" linguistic (and henceforth, social) differences while socializing students to dominant linguistic norms. Composition, then, has evolved around the "myth of linguistic homogeneity - the tacit and widespread acceptance of the dominant image of composition students as native speakers of a privileged variety of English" (p. 638). Consequently, the myth of linguistic homogeneity has excluded those who display stronger forms of linguistic difference that resist normalization through containment and socialization, like speakers of non-standard dialects and second language writers. This history explains why composition has failed to develop a coordinated response to the increasing numbers of diverse language speakers in first year composition classrooms.

Along the same line, Horner and Trimbur (2002) expose the dominant "cultural logic" behind linguistic imperialism while also revealing its presence in arguments against such domination (p. 595). They shed light on the problems arising due to reductive monocultural and monolingual measures adopted by U. S. universities to attribute non-native speakers' language difference to their cultural identity. In the English Only movement and in the history of U.S. college composition, the authors see a "tacit language policy of unidirectional English monolingualism" rooted in reified and reductive notions of language, identity, and culture (p. 594). They argue that an idealized notion of a normative, standard English that arises from "universalist" and "ethnicist" approaches to language has become a "guiding assumption" in both national language 
policy and U.S. writing instruction (pp. 615-616). The authors highlight the insidious sense of "inevitability" that attaches to developing cultural logics that serve the needs of the powerful (p. 595). Their argument, however, becomes less encompassing in that it doesn't sufficiently give voice to the cultural and linguistic differences that the international non-native speaking students bring to U.S. universities.

These students' writing also manifests what Guerra (2008) calls an "alternative discourse[s]" they bring to a different culture from their diverse home culture. Such approach, as Guerra points out citing Kells, also pushes educators towards becoming more serious for the better understanding of cultural diversity, whereby the students enhance their "ability to write: 'Appropriately (with an awareness of different conventions); Productively (to achieve their desired aims); Ethically (to remain attendant to the communities they serve); Critically (to learn to engage in inquiry and discovery); and Responsively (to negotiate the tensions caused by the exercise of authority in their spheres of belonging)"' (p. 299, emphasis writer's). Such intercultural interference in writing helps these students bring their cultural strengths to negotiate their translingual and transcultural identity in a different academic institution. Guerra (1997) in another article points out that if we are to support minority students and the "democratization of education," we must "challenge the ways in which a discourse community itself is currently defined and preconstructed" (p. 250). Citing Delpit, he suggests that students must learn the ways in which "authoritative discourse" is constructed in academic discourse communities, but "we must be careful not to reify the idea of an academic discourse community by presenting it as a closed, unchanging entity that demands such strict allegiance to its conventions that all persons who enter it must be born again, must 
leave behind the discourse strategies and expectations they learned elsewhere" (p. 252). Guerra's approaches thus pave the ways towards better understanding of the issues of cultural and identitarian differences of non-native English students, by offering us ways to see academic discourse as emergent and fluid, hence subject to revision for the inclusion of issues of language and cultural diversity.

Pennycook's (2008) work on language difference has served to deconstruct the norm of English as a native language, questioning the way in which it is frequently envisioned as a "monolingual enterprise" of linguistic dominance (p. 34). He says that English "is always a language in translation" meaning that it is not an "entity on its own" (p. 34). Rather, English constitutes and co-constitutes meaning in relationship to other languages, which are similarly unstable and dependent upon other codes, and language varieties that feed into and out of them. Every language and dialect is its own semiotic system developed against and working with other linguistic systems that it encounters. So, the ideology of the native speaker becomes baseless against the backdrop of English being a part of the flow of different varieties of English used for communicative and academic purposes across the world. For Pennycook, this flow of languages "in and out of each other is the norm across the world" (p. 42). Pennycook's idea becomes instrumental to see how culture and identity also become emergent and fluid in the same way language itself is always in translation.

Issues of students' differential identity can also be fostered in relation to their practice of a different variety of English as a part of their cultural inflection in their writing. Canagarajah (2011), in his discussion of translanguaging - which involves shuttling between the languages brought by the other to co-construct meaning - offers us 
ways to challenge the native speaker assumption and deal with the issue of identity through language practices. He draws from Kramsch's notion of symbolic competence as a way of constructing a favorable condition for language negotiation, which, according to Canagarajah, offers the "possibility of resisting conventions and renegotiating contexts for alternate identities and meanings" (p. 15). Referring to the example of Buthainah, an international student in his class, Canagarajah argues that academic conventions are not rigid and static; instead, they are open to negotiation (pp. 23-24). His concluding point in this essay is that his promotion of translanguaging in class has helped the non-native speakers like Buthainah to come up with reflective and critical awareness of their language choices. Canagarajah also wants us to move away from what he calls "normbased" or "form-based" notions of error and adopt a "practice based orientation to developmental stages in translanguaging" (p. 9). As Canagarajah (2006) argues in another essay, "rather than focusing on correctness, we should perceive 'error' as the learner's active negotiation and exploration of choices and possibilities" (p. 593), warning that "not every instance of nonstandard usage by a student is an unwitting error; sometimes it is an active choice motivated by important cultural and ideological considerations. The assumption that multilingual students are always bound to err in a second language denies them agency" (p. 609).

Students' communicative practices based on their home culture and language resources thus contribute to their identity formation and literacy development, enabling them to construct, reposition, and represent their identity in cross-cultural and crosslanguage contexts. Lam (2000), in her discussion of a Chinese L2 student's formation of identity through multimodal communicative practices, demonstrates how English- 
language learners might employ a variety of available representational resources to design new identities and communities and create new meanings and representations of reality. She asserts that our attention to design is essential "at a time when articulating one's voice can involve the complex orchestration of multiple modalities through electronic media within a growing diversity of linguistic and cultural affiliations" (p. 461). Fox (1994) similarly accounts for the problems invited by native speaker ideology in imposing Western values upon what she calls the "world majority students." She highlights the need to challenge such ideology in terms of multicultural students in the U.S. when she suggests that "it would not be a good idea to assume that anyone who comes from abroad, or worse, anyone whose last name is Wong or Das Gupta or Hernandez must have a particular writing or thinking style, or must be affected by cultural differences to the same degree or in the same way as other world majority students, or even at all" (pp. 110-11). In line with Fox, Williams (2003) criticizes this uniform model of student identity, which conforms to the ideological values of the institution, when he says that "Part of the ideological agenda of the first-year composition course" becomes to "introduce and indoctrinate new students into the values privileged by the institution" (p. 590). This kind of cultural and linguistic generalization of nonnative speakers of English, as discussed by Lam, Fox, and Williams, arises from the monolingual and monocultural tendency to reify students' identity based on their home culture and native language origin.

Horner and $\mathrm{Lu}$ (2007) challenge this tendency to reify non-native speakers' language and identity, drawing on World Englishes scholarship that recognizes both variations within and across languages and works against English-only policies that "treat 
language and identity as fixed, linked and uniform, and that treat fluency in standardized English, thus understood, as either a valid mark of national identity or a key that unlocks the doors to global opportunity" (p. 145). They compare and contrast eradicationist, second language, and accommodationist approaches to language difference with the multilingual approach, one that provides opportunities for engaging meaningfully with students as "living-English" users who have agency over their own heterogeneous, situated writing practices. However, such differences cannot be meaningful for students unless they are realized and seen in terms of what Mohanty (1994) calls conflict, struggle, and threat of disruption. According to Mohanty, talking about other's difference in terms of language and culture is not one of merely acknowledging difference; rather, "the more difficult question concerns the kinds of difference that are acknowledged and engaged. Difference seen as a benign variation, for instance, rather than as conflict, struggle, or the threat of disruption, bypasses power as well as to suggest a harmonious, empty pluralism" (p. 146).

Like Fox, and Horner and Lu, Young (2004) indicates the problem of attributing language to the cultural and regional identity of learners when he says that the problem that remains in the scenario is the "problem of equating language with identity, which means that we must continue to exaggerate the differences not only between races but between languages in order to make the differences stick" (p. 705). As Young suggests, distinctions between black and white languages merely echo or reinforce unnecessary distinctions between the races. Stratification of language into cultural dialects, as some of the language scholars have indicated in their discussions, mirrors racial, class, and gender stratifications. These constructs group people together reductively, engender hierarchies, 
and create performative tropes of identity that reproduce distinctions between groups.

Due to widening contexts of learning engineered by the forces of globalization, it is “increasingly inappropriate to make simple identifications of students' languages and to categorize and place them in courses of instruction according to such identifications" (Horner, 2006, p. 571). In the globalized context, people's educational practices also hinge on pluralized domains of linguistic repertoires, whereby "multilingual competence emerges out of local practices where multiple languages are negotiated for communication" (Canagarajah, 2011). Writing in multilingual trends provides students with a linguistic agency capable of facilitating a resistant pedagogy in the face of institutional constraints that label their differences as deficiencies. According to Horner et al. (2011), a translingual approach to the teaching of writing "sees difference in language not as a barrier to overcome or as a problem to manage, but as a resource for producing meaning in writing, speaking, reading, and listening” (p. 73). As such, a translingual approach to literacy offers us ways to better understand the issues of identity and culture. Matsuda's (2002) remarks about the need to address such linguistic and cultural difference as changing and emergent become relevant in this context, as he talks about the need to address multicultural and multilingual differences as a two-way traffic. He points out that "we need to recognize that when multilingual and multicultural writers enter the US academy, they are not the only ones who need to learn the conventions and assumptions of US academic discourse practices; everyone in the US academy needs to reassess their assumptions about discourse practices in the academy as they come in contact with unfamiliar discourses" (p. 194). In other words, the onus for learning differences in culture and language goes to both students and teachers in the U.S. 
academy, suggesting that learning of language, culture, and identity is a bilateral process.

Besides transcultural and postcolonial issues, I find translingual practices to be crucial in accounting for the development of literacy practices among Bhutanese refugees in the U.S. Such a translingual approach to research, as Crane, Lombard, and Tenz (2009) argue, "implies looking across or beyond different languages to capture the meanings produced by the research process, rather than seeing meaning as static and attached to language. It also means understanding that even in monolingual research contexts, the production of meaning is a contingent and continual process of refinement and reflection" (p. 45). As I study translingual relations to literacy, I want to use the notion of repertoires as an intersecting point between a particular language community and literacy practices attached to the community based on their use of repertoires in the sense of what Blommaert and Backus (2011) call "the means of language" (p. 4). Repertoires in this sense become an amalgam of multiple sources of language and other learning practices that people adopt. Such use of repertoires is precipitated, according to Blommaert and Backus, by superdiversity - tremendous diversifying of diversity - as a response to the changing nature of immigration, labor, and education along with the rise of the internet and mobile telephones, especially after the end of the Cold War world order.

Against the backdrop of such repertoires, I seek to study how people's literacy practices make inroads to their means of language, and whether such literacy practices help them to articulate their differences through language. The study of literacy within linguistic domains of people becomes more relevant in the context of the refugees, who have found ways to create their identity based on their language choices that are informed by their literacy practices in the past as well as in the present. For this, I have examined 
some relevant research to see how U. S. academic institutions have dealt with the issues

of differences in language, especially the differential language resources of the immigrant refugee population. I believe that such examination has offered me a critical insight into the relationship between people's language resources and their literacy practices.

\section{Literacies in Globalized and Digitized Contexts}

Globalization in its macroscopic connotation disperses ideological and cultural influences across communities, nations, and regions as an expansion of Westernization and modernization in terms not only of culture but also of language, education, and flow of capital. In my use of the impact of globalization on the transnational migration of the Bhutanese refugees, I mostly draw impetus from Giddens's (1994) concept of globalization. According to Giddens, globalization "is not a single process but a complex mixture of processes, which often act in contradictory ways, producing conflicts, disjunctures, and new forms of inequality" (p. 5). Globalization thus attends to ethnic nationalisms in recent times, which are "associated with the disintegration of supranational states and the emergence of a post-industrial global economy" (Richmond, 2002, p. 708). Pointing out the gulf created by globalization between the privileged elites and the locally disenfranchised people, especially from the developing countries, Bauman (1998) illustrates how the latter are marred by the spirit of cultural hybridization fetishized by globalization, resulting in "an almost complete communication breakdown between the learned elites and the populus" (p. 102, emphasis the writer's). The culturally disempowered people, such as refugees and other labor migrants, can thus hardly reap any economic benefits of globalization that are much touted in the globalized bazaar of the post-industrial economy, resulting in deeper economic disparities and inequalities 
between the privileged elites and refugees and migrant workers.

Such problems caused by globalization can be better addressed through what West (1990) calls "the new cultural politics of difference." In trying to view the problem of globalization from the perspective of the new cultural politics of difference, this perspective can contribute "to trash the monolithic and homogeneous in the name of diversity, multiplicity, and heterogeneity; to reject the abstract, general, and universal in light of the concrete, specific, and particular; and to historicize, contextualize, and pluralize by highlighting the contingent, provisional, variable, tentative, shifting, and changing" (West, 1990, p. 93). As the problems cut through the existing practices of globalization, the new cultural politics of difference offers one of several alternative ways to look at the literacy practices of refugees and recent migrants, which are mostly overlooked in the globalized context. As Hardt and Negri (2000) concur, "a specter haunts the world and it is the specter of migration. All the powers of the old world are allied in a merciless operation against it, but the movement is irresistible" (p. 213).

Much of the work on globalization transdisciplinarily conducted within various disciplines, such as anthropology, sociology, and critical and social theory agree on the need to recognize the multiplicities of identities and geographies brought forth by transnational migration and to respect the cultural and language resources the refugees and recent migrants bring with them in their new home (see Hannerz, 1996). The globalization theorists and interdisciplinary scholars, such as Appadurai (1996), and Gupta and Ferguson (2002), critique the segregated enclave of anthropological fieldwork and advocate a more inclusive theoretical tool that can account for the migrants and refugees and the various flows traveling with them across various locales of their 
migration.

Critiquing the concept of globalization theorized only in terms of cultural imperialism, Inda and Rosaldo (2002) argue that globalization, more than merely a cultural domination of the South by the North, refers to the "intensification of global interconnectedness, suggesting a world full of movement and mixture, contact and linkages and persistent cultural interaction and exchange" (p. 2). Refugees and immigrants thus, unhinged from particular localities, openly transcend specific territorial boundaries, for, as Inda and Rosaldo further claim, "uprooting of culture is only half the story of globalization. The other half is that the deterritorialization of culture is invariably the occasion for the reinsertion of culture in new time-space contexts" (p. 11). Such reinsertion, as Pennycook (2010) would argue, is recontextualization that helps the refugees repurpose their learning experiences in the new context, and, in turn, reshape that context. Such recontextualization of cultural and linguistic resources offers a perspective to interrogate the challenges of globalization by allowing us to envision the purpose of literacy practices in taking into account the multiplicities of disciplinary, ethnic, cultural, historical, national or geographic origins.

Furthermore, learners are more likely to shuttle between their home cultural practices and schooled literacy practices in the process of learning, collapsing the boundaries between schooled and unschooled sets of skills. Schools themselves become informed and influenced by hidden literacy skills in society as they bring moving image media, performances, and cultural models from outside of the school walls and use them as resources for teaching. Such resources include multimodal forms of learning that contribute to students' learning process sometimes in a more effective way than formal 
teaching of school literacy does. As Cope and Kalantzis (2010) argue, the global spread of the new media has fundamentally changed the ways in which people learn: "Control by others has become self-control; compliance has become self-imposed. New media are one part of this broader equation. The move may be primarily a social one, but the technology has helped us head in this general direction" (p. 91). We can also see the examples of multimodal forms of learning reshaping the literacy practices of school kids in Street's (2006) study. For example, the minority kids in schools in California in Street's study show their achievement through drawing of pictures like an Aztec warrior and pyramid, bird, and other features representing their hidden social skills. Joaquin's iconography, as Street illustrates through the visual manifestation of this drawing, represents the boy's cultural world, whereby he creates deeper social and cultural meanings by associating them with his work of art (p. 35), suggesting that his learning arises out of the cultural features of his background, which provide him more agency in his writing than the schooled literacy skills do. However, in cases like Joaquin's painting, such multimodal features are quickly erased because of the teacher's lack of awareness of such alternative modes as learning resources for students. Moreover, issues in the use of such alternative modes may not be limited to the use of a particular mode but, rather, whether or not any particular modal configuration is treated as subject to user agency. Such specific effects of media practices, as Horner and Selfe (2013) point out in their working paper, are dependent on training and the user agency rather than as resources in themselves. According to Horner and Selfe (2013), "It is the training (in composition, performance, listening) that 'affords' these effects, not the technologies of production as ordinarily defined" (p. 15). That is, more traditional school modalities are not in 
themselves a barrier but, rather, the orientation students are asked to take toward these. Drawing could, conversely, be just as limiting for drawers if the modes are taught with a disposition that there is only one correct way to draw.

In light of the above definitions and discussions of literacy, these theoretical perspectives have infused a critical edge to the conceptions of literacy in this study. They help me see literacy practices not as a set of rules and cognitive practices to be measured through universal standards but as practices that are embedded in broader social goals and cultural practices (Street, 1993). Knowledge of these theories and definitions of literacy makes me more aware of the need to see literacy as a culturally situated discourse dealing with learners' social, cultural, historical, political, economic, and multimodal contexts of learning. I have utilized such knowledge of literacy practices in this study as these approaches have helped me explore in detail various modes of learning that the Bhutanese refugees in the U.S. are engaged in. Similarly, as many of the participants in this study have expressed, there lies a possibility for the members of this community to not only build on their prior literacies for succeeding in the new context but also to assert an agency over their newly developing literacy practices in the contexts of the U.S.

\section{Research Questions}

This study seeks to respond to these conceptualizations of literacies by examining how refugees' literacy practices build on their previous literate experiences and are transformed after their arrival in the U.S. It also sheds light on the field's need to attend to the significance of cross-border movements in shaping the literacy practices of refugees. The aim of this study is to meet that challenge by describing and investigating how Bhutanese refugees' encounter with conflict, violence, and humanitarian crises in 
their home country as well as in the countries of resettlement has shaped the development of their literate practices. Their case offers us a unique illustration of identity construction through an intersection of language, literacy, and the use of technology in their struggle to materialize nationhood in the conflictual context of what Appadurai (1996) calls "deterritorialization."

How does literacy develop in minority cultures like refugees? What are the forces that constitute the literacy experiences of such cultures in the twenty-first century? How do the sponsors of literacy mediate the learning practices of such minority cultures? These questions demand further exploration in relation to the minority cultures like recent South Asian immigrant refugees in American society. I have used the above questions as guiding research questions in my dissertation in order to address the gap between larger immigrant cultures on the one hand and refugee cultures on the other. Bhutanese refugees' cases will provide valuable temporal, cultural, social perspectives on literacy learning and practices that are mostly informed by postcoloniality, migration, and translingual practices in globalized contexts and that are shaped by daily experiences of learning. I echo Street (2001b) to assert that this study "has a task to do in making visible the complexity of local, everyday, community literacy practices and challenging dominant stereotypes and myopia" (p. 7). In my discussion of these issues in relation to the literacy practices of the Bhutanese refugees in the U.S., in this dissertation, I particularly focus on the following questions:

1) How do immigrant refugees navigate their social, cultural, political, and linguistic spaces in the new country they arrive in? 
2) How are literacy practices implicated in our constructions of identity, perceptions of reality, and exertions of power inside and outside of the community?

3) How do refugees' cultural, linguistic, and literacy practices differ from those of other recent immigrants? How do the refugees negotiate and assert agency in order to create new literacy practices and appropriate or transform existing literacy practices and cultures building on their prior experiences?

4) How do their multilingual and cross-cultural literacy practices contribute to (or hinder) immigrants' learning process in the new educational environment? How do they help (or not help) them negotiate their transcultural, and transnational identity in a new home?

5) What are the intra-community dynamics within the Bhutanese refugees in terms of their experiences of learning, living, and transitioning to different locations of their migration?

6) What can educators do, in light of the government and institutional hidden assumptions, toward helping immigrant refugees' learning experiences in U. S. universities and beyond?

\section{Summary of Findings}

My two-year long ethnographic research with the Bhutanese refugees in Panorama City has produced many intriguing findings. Here, I will only highlight some dominant themes of such findings and talk in more detail about them in the following chapters. As they were persecuted by their own birth country for their cultural, linguistic, religious, and ethnic differences, conditions associated with refugee status and literal alienation from mainstream national ideology led the Bhutanese refugees to commit more 
to their language, culture, religion, and collective identity as Bhutanese refugees with Nepali origin in the U.S. As a result, reading and writing practices within and outside the community became increasingly political (for citizenship rights, learning about politics at home and abroad), religious, linguistically and cross-culturally motivated, and economic (for adjustment).

On the surface, the Bhutanese refugees' adoption of literacy practices for such purposes in the U.S. would suggest a stabilization of identity and cultural practices. However, in fact, it represents a change in these political, religious, cultural, linguistic, and economic practices in relation to their reading and writing; these practices would not have the same valence if they were not the subjects of persecution in their country of origin. This changing practice in the new context helps us see the clearly always emerging status of their identity and language practices with claims to and belief in a stability and discrete character to these. Most of the literacy events they organized within as well as outside their community linked the Bhutanese refugees in the U.S. spiritually, culturally, and financially to both Bhutan and the U.S., also encouraging them to assert their translingual and transcultural identities in a new diaspora.

Whether through increased awareness of enhancing reading and writing activities, promoting cultural practices, and learning a new language in the U.S., or through their active participation in literacy events inside and outside the community, Bhutanese refugees became more collectively involved in their community and encountered changes in their material conditions and living styles. In the process of their transition and adjustment to U.S. society, not only did they imitate and learn from the new communities and contexts but created and changed the existing literacy practices and those contexts as 
new Bhutanese-Nepalese cultures and identities, which I call transcultural and translingual identities, in the U.S. Through their participation and active engagement in language and literacy programs run both inside and outside their community, the Bhutanese refugee participants not only improved their language and literacies they needed to succeed in the new contexts but also brought changes in their living conditions. Despite their hardships and challenges due to their status as "refugees" compared to other recent immigrants, the Bhutanese refugees showed their perseverance and resilience against all odds in order to succeed in all aspects of their life in the U.S.

The diversity within the community (intra-community dynamics) became another important finding of this research that helps challenge some of the existing conceptualizations of literacy learning that seek to identify literacies of peoples based on their regional and national origins or identities instead of treating their literacy practices as specific, situated, and emergent practices. In other words, the attachment the Bhutanese refugees might have to their seemingly uniform and stable identity and literacy/language practices is itself a change from the meaning such practices might have had had they not been the subjects of persecution in Bhutan. So, while manifestation of such practices in their daily life might seem like a stabilization of identity and literacy/language/cultural practices, such practices in the context of the U.S. in fact represent a transformation. For example, the way they speak Nepali and observe religious and cultural ceremonies in the U.S. carries a different meaning for the people inside as well as outside their community from what it might have in Bhutan or in Nepal. I will discuss these findings in detail with examples and illustrations from my data sources in Chapters 3 and 4 . 


\title{
CHAPTER II
}

\section{THE OUTSIDER WITHIN: CRITICAL ETHNOGRAPHY AND THE REPRESENTATION OF THE OTHER}

\author{
Difference, yes, but difference \\ Within the borders of your homelands, they say \\ White rule and the policy of ethnic divisions.
}

(Trinh T. Minh-ha, 1991)

The issue of local perspectives ... is a technical problem to be overcome. My story gives space for the opposite approach. What if we paid more attention to incompatible data sets? In other words, what if we took a look at the ways social position, genre, and practical knowledge shape the data we gather? Instead of erasing incompatibility, we need to find out where it makes a difference.

(Anna Tsing, 2005)

There is no essential ethical value to a researcher's decision to put the personal into ethnographic research or to get it out. Rather, the ethics of such decisions must be examined in relation to the particular conditions of work informing the research project, including the scale and goal of the project, the nature of the contract between the researcher and the informants, and the kinds of dominant modes of research methodology, textual representation, and reader response active on the social and historical horizon.

(Min-Zhan Lu, 2004)

\section{Introduction}

In this chapter, I describe the research methods I've used for this study and explain with examples the process and rationale behind my selection of sites and participants from the Bhutanese refugee community. Next, I discuss the limitations and weaknesses of these research methods in relation to my positionality as a researcher. Finally, I also detail the methods of data collection and interpretation by highlighting the relevance of these ethnographic methods to the theoretical concerns that guided this study. I hope that in addition to foregrounding issues of power, status, and relations 
between the researcher and the participants, ethnographic methods will also help emphasize concerns about ethics of representation and other practical issues that must be considered in ethnographic research when working with communities that are politically, culturally, and economically marginalized and oppressed.

The challenge of ethnographic research lies in whether it can address the issues of existing power relationships between the researcher and the participants and ethics of representation as a way to enhance an understanding of research as a work produced with the community members. Ethnography as a form of qualitative research engages the knowledge and expertise of all the participants in a way to write research "not only about the other, but for the other," as Sullivan (1996, p. 106) suggests. This liberal gesture Sullivan suggests, however, is problematic, for I believe that ethnographic research is conducted not for the Other but with the Other in a way to co-construct knowledge through the participation of both the researcher and the participants. In my discussion in the second part of this chapter, I will explain the issues of reflection, education, participation, and ethical representation by drawing on theories of qualitative research, and then explore the ways critical ethnography addresses these issues in a more useful way. I will then argue that knowledge of critical ethnography helps me to share the research process with the Bhutanese refugees in a way to make my study more engaging, meaningful, and participatory.

\section{Research Sites and Participants}

The study involved fifty-six Bhutanese refugees currently living in Panorama City. The participants in the beginning were selected through what Bernard (1988) calls "snowball" sampling (pp. 97-98) to represent both sexes from various ethnic, religious, 
educational, and professional backgrounds (students, working mothers, low-wage workers, professional employees, indigenous and lower-caste members within the Bhutanese refugee community, elderly citizens, administrative workers, etc.). Despite my familiarity with the refugees for so long, my selection of the participants in the beginning months of my research was limited by my access and references of my friends. While most of the participants were selected based on suggestions from my acquaintances from the refugee community, I went further beyond snowball sampling later, as I was able to befriend more people in the course of my participation and volunteering in several community events. I then decided to choose other participants based on my observation and belief regarding their representations of various facets of Bhutanese community practices.

As a speaker of their native language and as someone also from South Asia, I regularly visited members of the Bhutanese refugee community in Panorama City and attended their cultural, educational, and social gatherings since their resettlement in the City in 2008. I regularly visited research sites (7 different locations in Panorama City where they were resettled) and collected data. I drove around these locations very often for observation, participation, fieldnotes, interviews, organization and management of various community events, and offered volunteering services to the community in order to reciprocate their participation in my study. Visiting these research sites frequently helped enhance the quality of my study, as I was able to establish closer relationships with research participants and elicit quality information pertaining to my research. As I was also involved as an ethnographer in offering volunteering services to the community people by driving them to hospitals, government offices, and other job appointments and 
also by being involved in organizing community events and settlement process, I believe that my participation in those events and other volunteering services to the community helped to benefit the community and reciprocate their participation. In the meantime, I believe that my familiarity with their sociocultural and linguistic contexts helped me develop a good research relation with the community.

In this study, out of fifty-six in total, I discuss research with thirty-one participants: twenty-two males and nine females, with ethnic backgrounds, including Brahmin, Dalit, and Indigenous, with socioeconomic levels in Bhutan ranging from impoverished to upper middle class, and with educational backgrounds spanning self-learning of alphabets at home to the completion of $\mathrm{PhD}$ degree in Bhutan and Nepal. All of the Bhutanese refugee participants in this study hail from southern Bhutan and the refugee camps in Nepal, who arrived in the U.S. between 2008 and 2013. Although this study is not representative of the literacy practices of all the Bhutanese refugees in the U.S., it offers valuable insights into these diverse participants' transnational literacy practices in globalized and digitized contexts.

Table 2.1 provides a brief summary of the participants, with their ethnic, religious, educational, and linguistic backgrounds. Although this study involves fifty-six participants from the Bhutanese refugee community in Panorama City, it is also informed and shaped equally by the informal conversations and regular visits to and observations of scores of other members from the community. Of the total participants, thirty-five were male and twenty-one female. Although thirteen participants in my study said they followed Christianity as their religion, the overall ratio of the Bhutanese refugees that follow Christianity is much smaller. According to a CDC update ("Summary," 2008), a 
large majority of the Bhutanese refugees are Hindus (60\%), followed by Buddhists (27\%), Kirats, followers of an indigenous animist religion (10\%), and Christians (1-7\%). Similarly, the ratio of the Dalit population is much smaller than the one that appears in my study.

A large majority of the Bhutanese refugees are multilinguals. As shown in Table 2.1, forty-eight people out of fifty-six could speak two or more languages. Most of them could proficiently communicate in Nepali, English, and Dzongkha, the national language of Bhutan, and also had a good knowledge of Hindi, the Indian national language, which is dominant in most parts of South Asia.

For those who were educated in Bhutan, the medium of instruction was English, and they had to also learn Dzongkha and Nepali as two other languages, the national language and mother tongue for Lhotshampas (Nepali-speaking southern people), respectively. Although the majority of the participants were high school and college graduates, a significant number of them had non-formal education either through community initiatives or self-learning, helping them develop their literate practices outside the walls of formal schools. A lot of them with such non-school background, who called themselves "only literate," learned to read and write for religious or commercial purposes. As most of them were farmers and produced crops for sale in Bhutan, they learned to read and write so they could keep track of their transactions and run the household business. Five of such participants in my study were self-taught that way, either because they didn't have access to school when they were growing up, or because they were not allowed to attend school, such as working daughters at home. Even five other participants, who called themselves "illiterate", were learning to read and write at 
Literacy Centers or ESL and Citizenship Classes in both their first language (i.e. Nepali) as well as in English at the time of this study. I will provide more detailed discussion on their backgrounds and literacy development in Chapters 3 and 4.

Most of the participants I interviewed worked in food packaging plants and other factories in Panorama City. As better-educated people, only eight of the participants worked either as literacy workers ${ }^{4}$ (teaching ESL and citizenship classes for the refugee communities at the resettlement agencies and Elderly Care Centers), or as interpreters and caseworkers across various domains of public life, such as resettlement agencies, courts, hospitals, and social security offices. Although most of the Bhutanese refugees between the ages $25-49$ were high school and college graduates, certification issues prevented them from working in their respective professions. Lack of formal education and English language skills were major barriers to employment for most of those between ages 50-82, although most of them received informal education (reading religious books in their first language, doing basic calculations necessary to run household business, and writing their names) in the refugee camps in Nepal, and the country of their origin, Bhutan.

Table 2.1. The Participants

\begin{tabular}{|l|l|l|l|l|l|l|l|}
\hline $\begin{array}{l}\text { No. } \\
\text { Total: } \\
56\end{array}$ & $\begin{array}{l}\text { Age } \\
\text { Group }\end{array}$ & Sex & $\begin{array}{l}\text { Racial } \\
\text { Identity }\end{array}$ & Religion & $\begin{array}{l}\text { Language(s) } \\
\text { Spoken }\end{array}$ & Education & $\begin{array}{l}\text { Born } \\
\text { in }\end{array}$ \\
\hline 12 & $15-24$ & & & & & & \\
\hline 33 & $25-49$ & & & & & & \\
\hline 11 & $50-82$ & & & & & & \\
\hline & & & & & & & \\
\hline 35 & & Male & & & & & \\
\hline
\end{tabular}

${ }^{4}$ By literacy workers, I mean those members of the refugee community who have had at least a college or university degree and who have actively worked in the community, both in Nepal and in the U.S. either by teaching/running some literacy classes or by promoting literacy learning of the community by utilizing community resources. 


\begin{tabular}{|c|c|c|c|c|c|c|}
\hline 21 & Female & & & & & \\
\hline 42 & & Brahmin* & & & & \\
\hline 10 & & Dalit** & & & & \\
\hline 4 & & Indigenous $* * *$ & & & & \\
\hline & & & & & & \\
\hline 42 & & & Hindu & & & \\
\hline 13 & & & Christian & & & \\
\hline 1 & & & Kirat & & & \\
\hline & & & & & & \\
\hline 8 & & & & One & & \\
\hline 4 & & & & Two & & \\
\hline 24 & & & & Three & & \\
\hline 19 & & & & Four & & \\
\hline 1 & & & & Five & & \\
\hline & & & & & & \\
\hline 5 & & & & & Illiterate $* * * *$ & \\
\hline 5 & & & & & Literate $* * * * *$ & \\
\hline 7 & & & & & Primary & \\
\hline 6 & & & & & Middle & \\
\hline 15 & & & & & High & \\
\hline 11 & & & & & Bachelor's & \\
\hline 6 & & & & & Master's & \\
\hline 1 & & & & & Ph.D. & \\
\hline & & & & & & \\
\hline 50 & & & & & & Bhutan \\
\hline 6 & & & & & & Nepal \\
\hline
\end{tabular}

*By Brahmin, I mean those who belong to upper caste in Hindu categorization and are considered to be privileged.

**By Dalit, I mean those who belong to lower caste in Hindu categorization and are considered to be underprivileged.

***By Indigenous, I mean those who hail from Mongolian heritage and are underprivileged.

****By Illiterate, I mean those who can't read and write in any language and who never had schooling.

*****By Literate, I mean those who can read and write in their first language and who are self-taught.

While my research among the Bhutanese refugees primarily took place at familial

settings, such as home and workplace, I also followed the participants to the community

institutions that played a crucial role in shaping their literate practices in the U.S.

Community learning centers and religious organizations, such as Elderly Care Center,

ESL classes, cultural orientations, culture, music, and literature group meetings, and

temple and church gatherings, played an influential role in their learning. These 
community institutions, as Moss (1992) maintains, deserve more attention because "[their] literate practices are powerful in the lives of [their] members shaping, in part, their identities and ways of thinking, acting, and engaging in everyday discourse" (p. 154). Therefore, in addition to observing the day-to-day cultural and literacy events at home settings, I also observed and actively participated in the group events across those literacy sites and collected my data through interviews, fieldnotes, and participation. I will describe in detail in Chapters 3 and 4 the role played by these sites in shaping the literate practices of my participants.

\section{Interview}

Using ethnographic interviewing (Seidman, 1998; Heyl, 2001), I interviewed fiftysix participants for one and one half hours on average in a way to develop a participatory and dialogic conversation with them in order to explore their literacy practices. The participants responded orally in face-to-face interviews, which were audio and occasionally video taped. Follow-up interviews were conducted sometimes via telephone and occasionally via digital media, such as Skyping and Facebooking. I first developed a set of questions for the interviews based on an interview protocol (see Appendix A), but was also considerate about participants leading the discussion. Conducted in Nepali, interviews were generally informal in nature, allowing for a more discussion-based conversation regarding conceptions of literacy and learning. Participants also shared their cultural artifacts, and other literacy materials, such as written texts or images during interviews, and also led the discussion with open-ended conversations pertaining to their experiences of reading and writing.

As I started interviewing the research participants, I realized that I was prepared 
more for a formal and straitjacketed type of interviewing, asking them formal questions and not receiving detailed explanation to my questions. I realized that I needed to make them feel more comfortable and confident regarding their ideas and the contribution they were making. I also needed to push them further, using ethnographic interviewing techniques, having them lead the discussion and develop an informal conversational type of interview. I could facilitate this process through a dialogue with the participants, for, as Conquergood (1998), considering dialogue as a performance, points out, dialogue helps a researcher resist conclusions as it is committed to keeping the meanings between and the conversations with the researcher and the Other open and ongoing. Following these strategies became more helpful as they started to reveal more about the challenges the participants faced when trying to adapt to a new home, and the ways they adopted to better utilize their resources for the purpose of living and adjusting in their workplaces.

The use of life history and oral story research approaches (Barton \& Hamilton, 1998; Brandt, 2001) also helped me more openly examine complex relationships between Bhutanese refugees' cultures and languages on the one hand and socio-political and religious conflicts leading to persecution, dislocation, and relocation on the other. Use of ethnographic methods - such as participant observation, interview, collection and analysis of cultural artifacts, and a close analysis of cultural practices and language in use to discuss the rhetorical and ideological nature of literacy practices - offered me ways to examine refugees' learning practices in their everyday contexts. I utilized the methods of life history and oral history research (Bertaux \& Thompson, 1997; Lummis, 1987), mostly based on participants' memories of learning to read, write, and use different technologies to navigate cultural, linguistic, and political contexts that shape and are 
shaped by current literacy practices. Life history research, according to Bertaux (1981), looks for ways to "a progressive elucidation of the historical movement of social relations" (p. 41). As one of the purposes of this study was also to trace the historical past of the Bhutanse refugees' literacies going beyond the "ethnographic present," the life history approach helped me develop a historical narrative to the events that the participants talked about. Another progressive impetus of life history interviews for me was its promise that the act of knowledge making becomes a shared act for both the researcher and the storyteller and listener (Bertaux, 1981). Interviewed in their homes, work places, literacy centers, and religious sites, the Bhutanese refugees recollected the memories of their learning to read, write, and appropriate their literacy skills across various locations of their migration, from Bhutan to the refugee camps in Nepal to the U.S. Aged between twelve to eighty-two, the fifty-six participants in this study included elderly citizens, house wives, highly educated professionals, and school and college going students.

\section{Data Analysis}

My sources of data mostly consisted of observation notes during my field visits, reflective field notes I prepared after the visits (Davies, 1999), interview notes, and other cultural artifacts and written documents I collected from the participants. The interviews were first coded and transcribed in order to find common ideas and interpret them along the categories, such as what's the story? What's going on here? What is the culture? (Sunstein \& Chiseri-Strater, 2012). Asking these questions preliminary to coding and transcribing helped me better understand the main stories about the people, their literacy events, and their significance in their day-to-day reading and writing. In the process of 
data interpretation, I used the collected data based mainly from six sources: interview transcripts, participants' texts (cultural artifacts or other texts, images, etc.), observation, participation, fieldnotes, and reflective notes. I coded ways that Bhutanese refugees' migration and non-citizen status from one place to another influenced their literacy identities. I also coded for literacy practices that transformed or remained the same after resettlement in the U.S. (religious, workplace, digital, and expressive writing, and other secular literate activities). Then, I also coded for the appearance of their desires for nationhood and citizenship in their oral, written, and cultural literate activities. In my further coding, I wanted to explore how cultural groups (literary/musical group, hymn group, and elderly reading group) all could constitute the elements of literacy groups like teachers, journalists, campaign people, movement people on the one hand, and women, less educated, lower class, etc. on the other.

Most of the narrative accounts and quotations from my participants in this study come directly from my translation of their conversations during interviews and other informal conversations during my visits to their locations. All of the interviews were originally conducted in Nepali, despite the fact that some of the participants were well versed in English. I wanted to elicit information about their literate activities in a more informal and conversational context so as to ground my study on their day-to-day common practices of learning and doing language. No other ways could better promote such dialogue than talking to them in their mother language. Although I had a plus point of being a native speaker of Nepali, which they spoke as their native language too, when translating the interviews from Nepali into English, I became equally mindful of the complexity of the process and power relations embedded into this process. Indicating the 
possibility of imbalanced power relations between the translator and the translated, Muller (2007) argues that translation is complex, political, and subjective. One strategy to recognize this kind of complexity, as suggested by Smith (2003), could be by carrying out the interview analysis in the original language and translating excerpts only at the final version stage, with footnotes explaining the significance of different terms. In addition to helping maintain "intellectual honesty," this strategy, according to Muller (2007), also draws attention to the "contingency of meaning" (p. 210). As most of the analyses of conversations, which come directly from the participants' conversations in their native language, i.e. Nepali, throughout this dissertation show, I have mainly analyzed the participants' ideas about literacy in relation to their social, cultural, political, religious, and economic contexts and also offered footnote descriptions about the terms that provide specific meanings for the participants based on those contexts. "The conception of translation," as Crane, Lombard, and Tenz (2009) observe, "can be further pinned down and described as making sense of and transferring meaning from one timespace context into another; beyond the translation of language, it also involves translation of the meaning of social and cultural practices and artefacts" (p. 40).

Taking this theoretical urgency regarding translation into consideration helped me see translations "not as static text but fluid in their construction and meaning" (Crane, Lombard, \& Tenz, 2009, p. 41). As I translated the participants' conversations, I paid specific attention to sociocultural and historical contexts as well as the rhetorical patterns of their communication in the context of Nepali speech acts, where geographical, temporal, and spatial references become equally important in the formation of meaning that the participants intend to share. Emphasizing the need to account for such wider 
geographical and cultural contexts of the participants' language when conducting research in multilingual and multicultural contexts, Filep (2009) states: "In essence, both tasks of conducting interviews and translating interview data in multilingual/multicultural settings represent complex situations, in which not only the language, but also the 'culture' has to be translated or 'interpreted' and dealt with" (p. 60). I've tried to exercise sensitivity to the best of my ability when translating the participants' interviews and conversations from Nepali into English. For example, reminiscing their experiences of brutality and persecution by the Bhutanese regime leading to their eviction, most of my participants referred to culturally, geographically, politically, and temporally loaded terms, such as Lhotshampas, and Ngolops. While both of these terms signified particular meanings, such as "southerners", and "anti-nationalists" in original Dzongkha, respectively, they had specific signification only within the contexts of the Democratic Movement launched by the ethnic Nepali population in the south of Bhutan.

Lhotshampas in that sense didn't simply mean southerners but only those Southerners who were ethnically Nepali-speaking population in the South, not other indigenous or mainstream Bhutanese people living in the South. Similarly, Ngolops didn't have a neutral connotation to anti-nationalists in general, but meant only those Lhotshampas that were involved in direct conflict with the government during that particular movement in the 1990s, leading to the "construction and representation of territorial identities" (Filep, 2009, pp. 60-61). Understanding such cultural, political, geographical, and temporal contexts of the original language and meanings attached to those contexts thus became a very essential part of my research process in this study. This becomes specifically more delicate, as Filep (2009) argues, "when the linguistically-geographically (re)constructed 
difference is political; when the naming of a space of place has political significance and expresses power relations, for instance, between neighboring states or between majority or minority populations" (p. 61). My knowledge and awareness about the delicate situation of my participants also helped elicit quality information from them as I could, as a native speaker of the same language of the participants, be more invested in meaningful communication with them even when confronted with "language or culture specific terminology or taboo expressions that carry political meaning(s)" (Filep, 2009, p. 59). In the next section I will talk about my own relation to these conflicts in more detail. With this understanding of the social and cultural contexts, although I am sensitive to the importance of fillers and hesitations as data/information sources for quality communication, I've removed all the fillers and hesitation markers for the purpose of clarity when translating the participants' interviews and produced them in "standard English," if there is one, in this study. While I've maintained literal translation of their conversations in most places when quoting the participants' dialogue in this study, in other contexts when the interviewees' ideas are less coherent and lengthier, I've included those ideas as overt summaries because such less coherent and lengthier quotations "can reduce the readability of the text, which in turn can test readers' patience and even their ability to understand" (Filep, 2009, p. 67) the implications of those ideas in the text. In the meantime, I was also aware of probable misinterpretations when overtly summarizing the conversations by changing the structure and by adding the fragments to make the quotations "readable." Therefore, I went over the interviews several times and analyzed other contextual cues in order to make sure that my translations conformed to the interviewees' ideas in the ways they preferred to communicate. For this, I showed the 
results to and discussed my interpretations with most of the participants in two public meetings organized by the community members in April and July 2014.

\section{An Outsider Within: My Positionality as a Researcher}

Since the Bhutanese refugees started to arrive in a Midwest town I call Panorama City from July 2008, I was contacted as a speaker of Nepali by one of the resettlement agencies to assist the newly arrived refugees with language and other adjustment issues in the City. I was glad to be a part of this process as I was closely observing the status of Bhutanese refugees since the early 1990s when they were settled in the refugee camps in the eastern part of Nepal. As a resident from eastern Nepal, I had been well aware of the Bhutanese refugees' political, social, cultural, and material conditions. I also had participated in several events related to their repatriation efforts and also other seminars and workshops on health and human rights issues in the refugee camps when I was still a student at Tribhuvan University and an activist for social justice and human rights when working as an Editor/Translator at INSEC, a human rights based organization in Nepal.

During my study in the U.S., as an executive official of the Nepali diaspora based organization, NASK (Nepal-America Society of Kentucky), I became closer with another Nepali-speaking diaspora of Bhutanese refugees coming to the same city. We organized a couple of cultural events together to accommodate a smaller number of refugees in the beginning months; in the meantime, after 2009, the number of Bhutanese refugees resettled in the City was much larger than the number of other immigrants from Nepal. As a result, there were several smaller groups of Bhutanese refugees in the City having their own community-based gatherings and events depending on which part of the City they lived in. I was in regular contact with the participants since they started migrating to 
Panorama City in 2008, and my position as an active member of the Nepali immigrant community in Louisville (serving as an executive member of NASK since 2007, getting reelected every year, and as the founding president of NSA - Nepalese Student Association at $\mathrm{U}$ of $\mathrm{L}$ ), further helped me increase my contact with other Asian immigrant communities in the City. Although I found these regular visits to be useful in the process of building rapport with the Bhutanese refugee community, my earlier assumptions about their intra-ethnic divides and literacy levels hit rough waters as I found that these situations were shifting in a new globalized and digitized context.

As I approached the community in the beginning, I was easily accepted by the educated people, who apparently could identify with me, for they considered themselves to be more educated than the average Bhutanese refugees. Like me, they had taught or been taught at the educational institutions in Nepal, and seemed to belong to the upper middle class back home. They regularly invited me to their meetings, had discussions about the ways they were developing projects and also occasionally asked for help and suggestions regarding educational and settlement issues. They also asked for my advice on various matters, such as how they could resume their further education, which location would be better for settling in the Nepali community around, how they could establish networking between the Bhutanese and the Nepalese communities in the City, how they could operate Sunday schools and other reading groups for children, how they could work together with the Nepali community to establish a community center, etc. I could easily intermingle in their circle, as they called me to be "one of us." In the meantime, their positioning of me became more contradictory because, on the one hand, they easily took me as an "insider to us," while on the other, not quite, as they also saw me as more 
firmly rooted than them in U.S. culture.

However, despite their past ordeals and hard present lives, most of the Bhutanese refugees were warm and gracious to me and welcomed with open arms my intrusions to their lives. On many occasions, sitting in their sofas, beds, and on the floor mats, I cried together with them as I spent hours listening to their stories of brutality by the Bhutanese regime, dislocation from their homeland, and hardships as they moved from place to place just for survival. They wanted their voices to be heard and stories told so, as one of the Bhutanese refugee elderly men, Harisharan, told me, "the world could understand how we suffered and what cultural, social, and educational experiences we could share with other communities in a new place." I feel that in this study I have also an investment in having these stories told because despite my different experiences regarding my past histories and relations to the conditions of the Bhutanese refugees, I became deeply engaged with the community practices not only due to my involvement with the community members for the purpose of this research but also due to my solidarity and moral support from the beginning to their causes for human rights, social justice, and democracy.

However, despite such welcoming gestures by most of the Bhutanese refugees in general, it became more challenging for me to develop relationships with other apparently lower class, less educated, and lower caste refugees, who viewed my position differently, as belonging to an upper caste ${ }^{5}$, class, and education level. For them, I was also representing an elite educational institution in the U.S. as a researcher. Moreover, I

\footnotetext{
5 Despite the younger generation's changing progressive attitudes toward caste-based discrimination among the Bhutanese refugees, there still exist traces of divides as lower-caste (Dalit), and upper-caste (especially Brahmin) within the community. Such attitudes are mostly informed by fundamental Hindu beliefs based on Manusmriti (a didactic Hindu scripture) and are still prevalent in most parts of India and Nepal (see W. Doniger, 2009, The Hindus).
} 
was already an "other" for them as I didn't belong to the Bhutanese community and didn't have the similar experiences of suffering and migration as theirs. For example, I drove to the home of a lower-caste family from the Bhutanese refugee community eight times without any success in interviewing a single member of the family. They couldn't easily confide in me the accounts of their troubled past and the feelings of isolation and difference meted out to them by their own community people in the name of caste and class, let alone the treatment by other communities in a new place, where they struggled every day to learn English and find a job. The "exigencies of coping and getting through life" (Ong, 2003, p. xvii) posed greater challenges to those less educated and lower-caste refugees.

Based on such experiences, my understanding of the ethics of representation draws from what Minh-ha (1991) calls "Othering." Minh-ha illustrates the power of Othering through a critique of the insider/outsider relationship. Her critique of this paradigm is essential for understanding qualitative and ethnographic research writing by looking at how subjects marked as Other might be identified. Traditional ethnographic writing has been criticized for fetishizing the insider's view, for the ideal insider, according to Minh-ha, is "the psychologically conflict-detecting and problem-solving subject who faithfully represents the Other" (p. 68). By virtue of such representation, those who are Othered can write about no experience but their own, while the dominant researcher, i.e. the elite academician, can write about every experience in the name of objective, scientific observation. I tried to resist the urge to take Bhutanese refugees' assertions about their experiences back home as truth and any one of their accounts as fully representative of all Bhutanese refugees' experiences, and, therefore, representative 
of all the refugees from different parts of the world. In other words, doing so would be a problem about generalizing conclusions from my interview data. These challenges called for constant (re)negotiation on my part as a researcher in order to earn their trust.

In the meantime, in the course of my study I also became more aware of my civic responsibility as an ethnographer. As Cushman (1999) stresses, we must develop a "deeper consideration of the civic purpose of our positions in the academy, or what we do with our knowledge, for whom, and by what means" (p. 377). In the course of this study with the Bhutanese refugees, I reflected on how the construction of knowledge produced through the study could help the participants better understand their situations and bring a change in their living conditions. For example, in addition to offering the participants volunteering services, such as reading and helping them understand their legal and official documents in English by visiting their homes, driving them from and to offices and hospitals, I also engaged in typing their manuscripts on my computer and networking for publication in print or other online forums. This kind of responsibility as a researcher, in the words of one of the participants, Dhan Bahadur, "directly helped us spread our words to the larger community, and you become our guide to let us spread our voices to a larger community through such support in reading, writing, and offering volunteering work whenever we call you." Williams and Brydon-Miller (2004) see participatory action research as a part of such a method with civic responsibility. According to them, participatory action research

combines aspects of popular education, community-based research, and action for social change. Emphasizing collaboration within marginalized or oppressed communities, participatory action research works to address the underlying causes of inequality while at the same time focusing on finding solutions to specific community concerns. (p. 245) 
Despite such civic activities with most of the male participants, my fixed position as a male student still posed some challenge to establishing rapport with female participants. More men would readily accept and invite me to their literacy events than women, and I had a hard time overcoming this difficulty born out of my fixed position. When I tried to approach women participants for the purpose of conversation or interview, they would easily evade my offer either by citing some work they had to do or by saying that they were not "intelligent" enough to provide any valuable information about my study. This self-deprecation by women participants, however, could have emerged from deep-seated cultural stereotypes that have existed for a long time in the community that women can't represent their community and that they shouldn't be "clever" in a way to outsmart their male counterparts. What seemed surprising during my study, however, was that the trend was shifting in the new context, as women participants in a shorter span of time started showing signs of change. For example, the same women who I approached a year ago and wanted to talk about their literate practices seemed more willing later to share their ideas and even propose other ways to improve the education of women in their community. They gradually increased their participation in Family Center activities and took up leadership to run weekly women's reading and singing groups.

Being aware of such changes in the literacy practices of my participants during the study helped me become more mindful of the issues of positionality and critical reflection. One specific example of such issues involved my participation in singing groups (both literary/musical, and hymn singing groups), cultural events, and other festive celebrations. These singing groups consisted of Bhutanese refugees in each site of their settlement, mostly led by women, who conducted weekly kirtans (religious culture 
of singing hymns, dancing, and citing mantras). I will talk about these groups in detail in Chapters 3 and 4 when discussing the significance of religious and cultural literacies in the lives of Bhutanese refugees in the U.S.

I started to reflect on the questions, such as why did the refugees become interested in my study? Why did they invite me to participate in those religious, cultural, and literary events? Would they still be interested in my participation if I were not doing this research? How would they look at my participation? The more I reflected on these questions, the more aware I became of the ethics of representation and my role in these contexts, not only as a participant observer, but as an active participant in writing and performing at their literacy events. For example, in November 2012, I went to the meetings of the community regularly, wrote a parody song, rehearsed singing and preparing for the program, and sang with the community participants in a cultural event that was organized by the Bhutanese refugees in coordination with a local public library to celebrate Deepawali (festival of lights), the second greatest festival among Hindus in Bhutanese and Nepalese communities (see the following video link for this program on YouTube: https://www.youtube.com/watch?v=8T2JSOYHuDc).

Likewise, in a recent talk program jointly organized by Nepalese and Bhutanese refugees to mark the public exhibition of a Nepali movie Jhola amidst an audience of its author and scriptwriter from Nepal, I served as an MC to facilitate the conversation between a cultural and musical group (local Bhutanese refugee youth organization) and the guest, the author of the movie. In addition to participating in such events, I helped recent high school graduates from the community prepare their documents for admissions to colleges. I also volunteered to drive them to the local universities in Panorama City 
and facilitate their conversations with the campus officials in several programs for the purpose of admissions and certification of their documents from Nepal (in case of other students seeking admissions in graduate programs).

As the above examples illustrate, my active participation in these community activities as well as other literacy events effectively made me part of the ongoing, changing culture of the Bhutanese refugee community. I was not simply studying the community and its practices but was active in reshaping the Bhutanese refugee learning experiences and culture through my participation in addition to being involved in more traditional research activities as well. For instance, interviewing the participants and meeting them across various facades of their life, ranging from everyday household chores to their workplaces to the learning centers, significantly prompted a changing understanding among those interviewed and involved in the study about their present situations and past histories.

\section{Methodology and Research Design}

As I frequented the Bhutanese refugee communities and also actively participated in their activities, I started being more intrigued by the spirits of perseverance, resilience, and community values that they regarded very highly. As a long-time participant observer of their daily practices of adjustment and learning, I was more intrigued by their use of literacies across various situations. When I designed this project, I found that the refugees' concept about identity and citizenship was shaped by the idea of what Cintron (1997) calls the "rhetorics of everyday," as their daily practices of reading and writing in different sites and institutions helped empower them. They didn't only practice what was taught to them for living and learning but also made creative use of the skills to transform 
their practices and bring a change in their ways of living and learning. The following questions primarily inspired my study as I started working more closely with the Bhutanese community in Panorama City:

1. How did the refugees use their previous literacy practices to adjust in a new context?

2. How did they navigate their ways across social, cultural, and academic spaces in new contexts? What role did technology play in their adjustment and transition process?

3. In what ways are the refugees different from other immigrants? What values do they proffer to their language and cultural resources in a way to bring change in the traditional perception about refugees as lazy and idle people, an appendage to the ailing economy of the country?

4. How do they negotiate their cultural and linguistic repertoires during the adjustment process? In what ways do they assert their differences as identity markers?

These were the questions that lingered for a long time in my mind and inspired me to take up this research as an effort to understand how we could adopt better policies and ways to help these people succeed in society and academic settings. These were also the questions that determined my research methods and the ways I present my findings in this study.

The questions above required qualitative research methods that could help me work more closely with refugees and understand how their cultural, social, linguistic, economic, and political contexts informed their reading and writing practices. While 
other studies have covered several aspects of refugee and immigrant literacies, they are more limited by their approaches either as case studies or ethnographies among select professionals and more educated immigrant populations (see Ortmeier-Hooper, 2008; Leonard, 2013; Pandey, 2006). This study aims to fill that gap by focusing on people ranging from twelve to eighty-two in age, from illiterates to highly educated professionals, and from housewives to office working women, offering a unique perspective to understand literacy practices of a marginalized community in day-to-day contexts. Of equal importance to this study are the dynamics of intra-community differences and interactions that many of the studies on immigrant and refugee literacies overlook, as they project refugee communities as more homogenous and uniform than different and diverse. I focus on the refugees' everyday experiences of self-making and being made across various domains of working life, home, church, temple, literacy centers, and cultural and religious gatherings, exploring in depth the interconnected everyday issues involved in shaping their literacy practices about what being refugees and the process of becoming American citizens might mean to them. This study allows us to look at immigrant literacy practices through the lens of ethnography, which, according to Robinson-Pant (2000), can lead to a greater understanding of the interaction between local and international discourses on literacy, culture, and language.

\section{Ethnography and the Representation of Other}

Ethnography as a research methodology has its roots in anthropology, in which researchers, mostly Western intellectuals, in earlier times were involved in doing research among non-Western people and representing the community members as the Other. Anthropologists designed the standards for the research in a way to promote their 
interests rather than those of the research participants. This is the reason why the concept of research often became synonymous with Western-based models developed with Western standards in mind. This concept of methodology doesn't only impose Western values in research approaches but also precludes the engagement of community members, further obfuscating the understanding of research participants' cultural and social values. As Tuhiwai Smith (1999) rightly pointed out, the term "research is inextricably linked to European imperialism and colonialism" (p. 1). Stressing the need for the role of a researcher to be both culturally sensitive and appreciative of the community values of the indigenous people, Tuhiwai Smith, in her study of the Maori community in New Zealand, called upon researchers to discover and develop a community-oriented research methodology: "Having been immersed in the Western academy which claims theory as thoroughly Western, which has constructed all the rules by which the indigenous world has been theorized, indigenous voices have been overwhelmingly silenced" (p. 29). As she suggested, research can be more encompassing and participatory only when its methods are derived from the local community members' perspective. I tried to reflect their perspective in my writing by sharing my findings with the participants during community meetings and presentations at public forums. Similarly, Helms et al. (2005) have reflected on issues related to the dominance of Western values within research and critiqued the general lack of thought invested in reflecting on the positions of nonEnglish speakers, suggesting how a "linguistic power imbalance occurs in the research within “international geography"” (p. 248).

The notion of representing the Other in a study in this sense becomes a precondition for silencing the voice of any community members. Such anthropological 
preconditions may, according to Sullivan (1996), affect the ethnographic inquiry because "for anthropologists, the Other invariably translates into configurations of cultural similarities and differences, yielding that cultural distance - Clifford Geertz's 'not us' that has always been 'out there' in various degrees for anthropologists to record, interpret, and explain...." (Sullivan, p. 97, citing Khare, pp. 4-5). Sullivan's suggestion is directed towards the need to make ethnographic research more inclusive and representative of the participants' real concerns about living and preserving their cultures. Ethnographic research methods as such need to foster democratic and inclusive measures when working with the Other. Khare's question as to how ethnography can survive if it doesn't stop assuming, appropriating, and representing the Other, and lets the Other speak for and by itself (Khare cited in Sullivan, p. 98) becomes very pertinent in the discussion of ethnographic research. While ethnography distances itself from such anthropological inclinations to assume, appropriate, and represent the Other, it has to define its research methods in a more explicit way to make the research more engaging and represent the voices of research participants.

Street's (1984) notion of the ethnographic research perspective is one such effort to utilize qualitative research in a more meaningful and participatory way for a better understanding of the knowledge and values of community members involved in the research process. His ethnographic research with Iranian farmers in a remote village of Cheshmeh is one research study that engages community members in a truly dialogic way to co-construct knowledge, involving both researcher and community members. During his observation of community meetings, Street openly invited his participants and let them forward their voices on various issues of cultural and religious significance to 
them. He also actively participated in the discussion by bringing his own Western-shaped ideas on religious and social issues in relation to the local Muslim religious discourse, making his position clear in relation to the local cultural values. It was through such active engagement and participation with the community members that Street could gain an understanding of the community principles in his research.

An ethnographic perspective in research, according to Rowsell, Kress, and Street (2011), helps draw out "larger implications pertaining to cultural and social practice" (p. 2). This perspective further allows researchers to become a part of a community of research and helps them place an understanding of literacy within a wider understanding of people's everyday lived experiences. Ethnography also allows researchers to explore hidden literacy skills in the society, showing their differences from "explicit technical or 'cognitive' processes” (Street, 1984, p. 222), and makes such skills explicit in a way to challenge policy makers to recognize the significance of learners' engagement and participation in the research. Herein comes the importance of ethnographic research, which makes people aware of hidden literacy skills and helps them channel such skills for their benefit. The reason local people don't usually benefit from literacy campaigns arises from the fact that such campaigns impose learning models from an outsider, i.e. etic, perspective based especially on Western-based literacy models.

Because intellectuals investigating literacy practices fail to make explicit the implications of individual measures of literacy from an emic perspective, this situation, according to Street, creates an "ivory tower distancing" (2006, p. 24) between practical and contextual work on the one hand and individual and cognitive processes on the other, represented by emic and etic perspectives, respectively. Ethnographic research identifies 
this problem and works at the local level to deal with real issues local people face in their everyday living. This approach to research as such makes "visible the complexity of local, everyday, community literacy practices and challenge[s] dominant stereotypes and myopia" (Street, 2006, p. 22), focusing on everyday meanings and uses of literacy in specific social, economic, and cultural contexts.

Another research perspective in ethnography that addresses the issues of power and representation is participatory action research, which, according to Williams and Brydon-Miller (2004), acknowledges that "all knowledge generation is embedded in systems of power and that academics have traditionally been deeply implicated in maintaining existing structures of economic and political privilege" (p. 246). This approach encourages the researcher to make explicit her positionality in relation to the research participants and adopt ways to "engage[s] members of the community as equal partners in the research process and acknowledge their right to equal ownership and control of the knowledge that is generated as a result" (p. 246). For this, as Kirsch and Ritchie (1995) suggest, researchers need to be aware of the politics of location that plays an important role to help them identify their position in relation to their research participants. Kirsch ad Ritchie maintain that researchers should clearly reflect on the issues of identity and location in a way to make sure that they don't inadvertently impose their own identitarian values in their research. I find their notion of a politics of location to be useful for ethnographers to identify their positionality, especially in terms of how their intellectual positions and personal experiences influence their research findings. Doing so allows ethnographers to become more sensitive towards the social, cultural, and religious values of their participants in a way to make the latter more motivated to 
participate in the research process. However, the researchers in the meantime should not forget the fact that despite their attempt, they can hardly fully step outside their subjective positions in order to examine their assumptions because, as Kirsch and Ritchie admit, such an attempt is "always a culturally and politically charged activity" (p. 10).

\section{Critical Ethnography and Critical Reflection}

In addition to the ethnographic research perspectives as discussed above, I used critical ethnography in my research of immigrant refugees because it values the reflective dimension of research process by making the study more engaging, representative, and democratic in terms of power relations between the researcher and the community members. Critical ethnography also encouraged me to use a more critical and reflective lens to look at the unexamined foundation of ethnography, which, as Williams and Brydon-Miller (2004) state, may otherwise become complicitous with the "colonial project of anthropology to examine and categorize indigenous and marginalized groups for the benefit of the dominant culture" (p. 252, citing Cushman \& Monberg, p. 173). Critical ethnography promotes dialogue and negotiation in a way to account for community people's social, religious, and cultural values. For Madison (2005), critical ethnography is "always a meeting of multiple sides in an encounter with and among the Other(s), one in which there is negotiation and dialogue toward substantial and viable meanings that make a difference in the Other's world" (p. 9).

Brown and Dobrin (2004) define critical ethnography as an emergent research approach that values personal, political, and social dimensions of people's lived experiences: "it is politicizing the ends of ethnographic inquiry and socializing the process of ethnographic knowledge-making, while rediscovering its own critical voice 
with which it is beginning to 'talk back' to postmodern theory to answer the fundamental questions the postmodern assault on traditional ethnographic practice raised" (p. 3). Highlighting the effort of critical ethnography as reconfigured praxis, they further argue that critical ethnography differs from traditional ethnography in that the former "shifts the goal of praxis away from the acquisition of knowledge about the Other to the formation of a dialogic relationship with the Other whose destination is the social transformation of material conditions that immediately oppress, materialize, or otherwise subjugate the ethnographic participant" (p. 5).

Horner (2004) calls attention to the need to break from the univocality of the research text in order to address the provisionality of the researcher's knowledge and the marginalization of the groups being studied (p. 23). He also suggests that such knowledge that the ethnographer goes with in the field itself is partial and historically constructed, and it is the recognition and awareness of the constructed nature of knowledge and experience, through the perspective of feminist, postcolonial, and poststructuralist theories that make critical ethnography distinct from traditional ethnography. As such, critical ethnography asks us to see the "work" an ethnographer engages in through her fieldworking as not solely that of the ethnographer's, but of everyone involved in the research. Laying bare the confusions created by the use of seductive words such as collaboration, self-reflexivity, and multivocality in research, Horner asserts that such words don't mean anything unless utilized and practiced with critical reflections on their implications. Furthermore, the research perspective that precludes labor relations can end up promoting traditional ethnography, hence less meaningful for the research participants. Critical ethnography, as he implies, should look at ethnographic work in 
terms of labor, "in the sense of material practices aimed at altering the physical and social environment, ... [so that] questions of time and commitment and pay and results would be at the forefront in how research is planned and conducted" (p. 21).

Similarly, highlighting the work of literacy research as an action work to help the community members change their material conditions, Williams and Brydon-Miller (2004) point out that we need to develop a systematic approach to working with community members, which "addresses fundamental intellectual and ethical issues of social change, power, representation, and the purposes and ownership of knowledge" ( $p$. 245). Literacy research, as Horner (2004), and Williams and Brydon-Miller (2004) suggest, becomes more a collaborative effort of learning among researcher and community members, than a one-way learning process involving the lone ethnographer. Calling it a participatory action research approach, Williams and Brydon-Miller (2004) assert that this approach doesn't only help change one-way direction from the researcher to the participants but also leads to a more "complex and truly dialogic process in which all are involved in research, reflection, and education" (p. 249). I am particularly interested in this critical ethnographic approach, which stresses not only research but also reflection and education of the research participants.

Following the tenets of critical ethnography, I see self-reflexivity as a key concept that I use in my research among the refugee community. Cintron (1997) illustrates this concept in his study of the Latino community in Angelstown. Any method used to order the collected information in the fieldsite becomes laden with some kind of perspective, and it is only with self-reflection that such a perspective can be revealed. Cintron does this by revealing such perspectives and suggesting their limitations in the process of 
research. For example, he clearly states in the beginning of his book how his research has been a limited project from a gender perspective because of his easy access to males as research participants and also because of his research crew all being males (pp. 11-12). As a critical ethnographer, Cintron talks about ambiguity - as he can't always interpret and understand his participants' worldviews - and clearly admits his limitations and biases, even admitting at times his positionality as an intellectual from a privileged academic background being insidious for his research. He makes explicit the implicit as he even openly admits his state of being embarrassed sometimes when he ends up asking insensitive and imposing questions to Don Angel, his main research participant, and takes responsibility for such oversights in his part as a researcher.

Cintron draws on the spirits of critical ethnography, helping me imagine my research in a more democratic and engaging way. Such a critical ethnographic perspective helps me utilize qualitative research in a way to see my research as "an account of literacy practices of others and accountable to those others" with an aim to "benefit those whose voices, texts, and circumstances make such understanding possible" (Sullivan, 1996, p. 96). In the meantime, even as I am talking about the significance of the self-reflexive tenet of critical ethnography, I am well aware of the fact that what matters is whether such self-reflection affects the actual conduct of the research and its outcomes, not whether the text offers representations of the researcher being selfreflective. In other words, I am equally concerned about the danger of making a fetish of textual pronouncements of self-reflexivity, which are easy enough to produce. To address this concern, I have taken my research ideas and even drafts of this study to the participants and asked them to offer their feedback as to how this study has been of value 
to them, and whether it helps raise their concerns to a wider world beyond their own communities. One such occasion was in the last week of April 2014 when I presented my findings from this research among the Bhutanese refugee community in a literacy event organized by a local public library. In addition to offering suggestions as to how their voices could be more inclusive in the research, most of the Bhutanese refugee participants in the event informed me of the urgency to vocalize their concerns, especially political, cultural, literacy, linguistic, and caste-and-caste related issues so the outside world could better understand how unique their experiences are and how they could contribute to the richness of American culture at large. They also expressed their belief that a study like mine could initiate an academic conversation about their transnational and transcultural identities as well as their issues on social justice, citizenship, and human rights, as the refugees from a Himalayan kingdom ${ }^{6}$ in South Asia. This kind of participant-oriented action research, as Brydon-Miller (2004) succinctly puts it, "requires that issues of ownership and agency be openly acknowledged and negotiated with research participants who define the issues, generate and interpret the data, and determine the action to be taken as a result of the study" (pp. 14-15).

As a revised form of traditional ethnography, critical ethnography thus offers us a more holistic approach to look at community literacies through triangulation of data - life history interviews, active participation in community activities, close observation of their day-to-day practices inside their community and at work, and fieldnotes. Unlike a traditional ethnographer, a critical ethnographer, according to Brown and Dobrin (2004),

\footnotetext{
${ }^{6}$ Bhutan promotes GNH (Gross National Happiness) in the world and which, according to these participants, ironically has a majority of its own citizens unhappy as it has persecuted more than $60 \%$ of its population (both Lhotshampas, Nepali-speaking Southerners, and Sarchops, another minority in the Eastern Bhutan) in the name of maintaining a single and stable ethnicity, religion, language and culture (see Michael Hutt, 1996, 2005 for more details).
} 
becomes "the activating agent for this analysis-into-action dialectic" and works as "the ethnographer-other dyad: [is] the emerging, peerlike partnership between ethnographer and participant in which the student-other is empowered as a coinvestigator of a problem that is critically analyzed in collaboration with the ethnographer as a precondition for evolving an action plan to meaningfully and effectively engage the problem" (p. 5). Mindful of the big gap between academic research and the community I chose to study, I tried to bridge the gap by identifying critical issues about representation and identity of the participants through my role as a critical ethnographer. Issues of social justice and ethical integrity, as promoted by critical ethnography, became serious concerns for me when working with the Bhutanese refugees. As a researcher, I produced critical conversations and social awareness both in scholarship and in local communities. For example, in one of the recent local Bhutanese refugees' community meetings I attended, the meeting participants raised their concerns about the myths of them being lazy, superstitious, living on social welfare that were mostly attributed to their community along with their libelous stigma as "refugees." They also expressed their hope that studies like mine and other public forums, such as the local library cultural salon (I presented my study in) would help a great deal in driving away such myths by letting the "world know how hard-working and socially and politically conscious genuine citizens we are in the American society." Such conversations among the community members have also triggered more interactions in their weekly gatherings, such as singing, and cultural and musical meetings in different locations of Panorama City. These approaches help the Bhutanese community create meanings aimed at raising awareness and promoting 
change, linking academic research to real-life conditions of the people who participate in the study.

To me, critical ethnography as a tool became more than a medium of representation of a community I worked with in terms of their lived experiences and behaviors of cultures, which is what traditional ethnography would be limited to. Instead, we understand critical ethnography as a research practice, primarily related to education whose purpose is to use dialogue as a cultural context to develop critical action, while remaining highly attuned to the ethics and politics of representation in the practice and reporting of that dialogue and resulting actions (Brooke \& Hogg, 2004, p. 116). According to Brooke and Hogg, "If the practice of critical ethnography is truly dialogic, culturally active, and ethically representative, then that practice necessarily implies real change in the self-conception of the ethnographer" (2004, p. 117).

As I self-conceived my role as a researcher, critical ethnography as a method encouraged me to reflect on my positionality in a way to see it as vulnerable and assertive at the same time. For example, my positionality created assertive resonance with the participants, for the degree of my membership in the Bhutanese refugee community was fuller due to my fixed position (i.e. my physical appearance, age, gender, etc.); however, my post-study access to most of the participants was still limited by my subjective and textual positions because I enjoyed a more privileged educational and academic status than most of my participants. Moreover, my direct regular access to the community may also be limited by the fact that due to my status as an international graduate student, I expect to leave Panorama City following the research, unlike my participants, who are expected to remain in the same location. Also, despite my willingness to reach out to a 
larger number of the participants with the draft of this research writing based on their community, most of them could not directly read it in original due to their limited skills of reading and writing in English. Subject positions, as Sunstein and Chiseri-Strater (2012) clarify, have to do with our educational and cultural experiences, and textual positions are based on the way we use language or other forms of writing to represent our participants. My subject position as the one more educated than most of the participants and also as a Nepali national growing up in Nepal without undergoing the sufferings my participants faced as refugees made me the Other in the eyes of most of the participants. Similarly, my textual representation of the participants would have been more colonizing had I not been more aware of the research principles of critical ethnography. Colonization of a research community, according to Sunstein and Chiseri-Strater (2012), occurs when we impose our own worldview on our research participants and analyze their conditions accordingly. For example, informed by the principles of critical ethnography, I've critically analyzed the representation of my research participants and used an emic perspective in writing, including their voices when illustrating their translingual and transcultural identities as refugees, instead of imposing my own worldview about their status and material conditions.

My perceptions and the expectations of the refugee community posed more challenges than comforts to me as a researcher "within" the community. I expected to find a great deal of similarity regarding their reading and writing practices back home when they grew up either in the isolated rural areas of Southern Bhutan or in the refugee camps in Nepal because of my understanding of their educational practices as uniform. However, through my fieldwork, I found that while there were some similarities in their 
cultural and learning practices based on the education system they were most commonly exposed to, there were more differences than similarities in their exposure to literacy events depending on which particular location of Southern Bhutan they hailed from and in which refugee camps they were resettled in Nepal. My well-conceived membership within the Bhutanese refugee community didn't provide me with sufficient knowledge about their diverse literate practices as well as social, political, economic, and caste-andclass-based experiences. My assumptions about certain ways of their learning and working practices seemed to collide against hard rocks when I realized that they operated differently than what I apparently thought about them. This situation made me more aware of the "ethnographic fallacy" (Duneier, 1999, p. 343) that could result in misinterpreted and misrepresented accounts of their experiences and practices.

To overcome such challenges, I found critical reflection and introspection to be key factors in helping me better understand my limitations and unlearn some of the practices that I otherwise took for granted when working with a familiar community. As Moss (1992) pointed out, it is only through "reflection, introspection, and triangulation" (p. 169) that we can be responsible to the community. When using research methodology, I realized the need to be critically reflective of what its motivations and consequences would be like; for example, why the people wanted to say something they might not be doing in real practice. I then critically interpreted the gap between what they said and what they did, for reflection has to do with a multiplicity of relations: language, cultural, religious, identitarian, participatory, etc. One of the examples came from the people in the singing group. When asked, most of the participants said that they had stopped doing any kind of writing since they left Bhutan or Nepal, but I saw them involved in reading 
and writing practices in their daily life. Even when they were learning music lessons, both men and women participants, including middle school girls, were writing notes and also reading them every day when practicing (see Chapter 4 for details). Therefore, my point was to interpret why this gap existed and how that contributed to or challenged general assumptions about reading/writing practices. Also, I wanted to find out through conversation with them as to how many of them used writing for memorization, as I could see them sing hymns by heart, and how many took down notes when new songs appeared and when others brought up new ideas and topics for conversation. Every time I revisited the community and observed the participants' everyday practices, these subsequent visits helped me revise my assumptions as I became more knowledgeable about "bottom-up research approaches" (Barton, 1995) that allowed me to respect and include literacy participants' perspectives as justly as possible.

Critical ethnography is one such methodology, which promotes dialogue and negotiation in a way to account for community people's linguistic and cultural values. For Madison (2005), critical ethnography is "always a meeting of multiple sides in an encounter with and among the Other(s), one in which there is negotiation and dialogue toward substantial and viable meanings that make a difference in the Other's world" (p. 9). Calling this form of ethnography based on dialogue and negotiation critical ethnography, Horner (2004) offers three approaches that help us integrate the perspectives of informants into the research and render our work more meaningful for the informants: collaboration, multivocality, and self-reflexivity. Multivocality in research, accordingly to Horner, contributes to empowering the "other" to "speak in the text rather than being 'spoken about' by the ethnographer" (p. 23). While literacy scholars like 
Brueggemann (1996), and Kirsch and Ritchie (1995) warn us against the possibility of slippage into a colonizing discourse of traditional ethnography through self-reflexivity, as self-reflexivity turns "the lens back to ourselves, put[ting] ourselves in the center of representation" (Brueggemann, 1996, p. 19), Horner (2004) points out that "critical ethnographers can avoid the potentially paralyzing effects of self-reflexivity by recognizing that they are not alone but part of the social" (p. 29).

Even while in the writing process, I had several chances to interact with my research participants to elicit their reaction about how they felt about their textual representations, whether they felt comfortable about certain representations in the study, and how they felt about their identitarian status as projected in the study. Sometimes by participating in literacy events and occasionally through other social organizations, such as the public library, literacy centers, and cultural and musical forum, I had ample opportunities to get back to the Bhutanese refugee community and interact with them about my findings and research methods. These opportunities offered me ways to critically examine my researcher position, going beyond the paralyzing effects of selfreflexivity to make sure that the participants could speak in the text rather than being spoken about and that their voices were fairly represented in the study.

Critical ethnography thus promotes a more inclusive social dimension of research by helping the researchers recognize that their "self-reflexivity has ideological limitations" and that "they can use those limitations as an acknowledgment that the limitations of the accounts they produce can and will likely be noted by others - not because they have been 'unprofessional' but because of the inevitability of ideological blinders" (Horner, 2004, p. 29-30). Horner thus calls for the need to "redefine self- 
reflexivity as a material social practice with specific potential use values, then we must perforce revise the imperative for ethnographers to 'be self-reflective' to the imperative to secure the material conditions that would allow ethnographers and their participants to self-reflect" (p. 30). For example, during my regular visits to the homes of two of my research participants from indigenous groups within the Bhutanese refugees, I learned through discussions that they were having a hard time coping with the new life in the U.S. and that their experiences of troubled past and brutal treatment by the Bhutanese regime caused a lot of sufferings in their life. Both of them had left their jobs in local factories in Panorama City due to their worsening health and symptoms of depression. Although they were approached by a local psychiatric clinic working with the victims of torture and conflict, they didn't readily accept the clinic's proposal to make appointments with them because of several economic and social factors. As they both revealed to me during our conversations, one of such factors was related to their material conditions, as they couldn't afford transportation to and from the clinic. The other had to do with the stigma of "backward and refugee" status they were labeled with outside their community, so they didn't want to share the bitter experiences of torture and humiliation by their own country people back home to a stranger community in the U.S. In the course of our regular meetings and dialogue about their situation, they were finally convinced that it would be better to seek medical help for addressing their problems. I also offered to volunteer their transportation by regularly driving them to the clinic and bringing them back home. After a couple of months of their regular weekly and bi-weekly visits to the clinic, I could notice some tangible effects in their life, as they became more open to the outside community, had a better family relationship, wanted to go to language and culture 
conversation classes operated by a local public library, and showed their interest to go back to work, coming a long way from the feelings of depression, ennui, and hopelessness in their lives. I was more impressed to find later that these same participants who wanted to stay reserved and hidden inside the walls of their homes before started to convince the suffering people like them to initiate a more open conversation about their situation and seek medical assistance if need be. This was the kind of change I wanted to see in my research community as one of the small but meaningful efforts promoted through self-reflexivity, whereby researchers can bring about change in the living conditions of the research participants by acting humanely.

Kirsch and Ritchie (1995) further highlight the significance of an ethical stance promoted through such self-reflexive, multivocal and innovative forms of writing. They urge us to "reconsider our privileging of certain, coherent, and univocal writing and include multiple voices and diverse interpretations in our research narratives, highlighting the ideologies that govern our thinking as well as those that may contradict our own" (p. 24). Doing so, according to Kirsch and Ritchie, "highlight[s] rather than suppress[es] the problems of representation in our writing, and expose[s] the multiple, shifting, and contradictory subject positions of researchers and participants" (p. 25). In addition to these concerns, use of self-reflexivity as a method promoted by critical ethnography also helped me highlight the importance of language and culture in examining the intersections of literacy practices between communities and schools, allowing me to address the elements of language relative to cultural identity and belonging as well as the multilayered implications when a hegemonic language displaces a people's native language (Madison, 2005, p. 49). 
Unlike traditional ethnography, critical ethnography thus not only places significant focus on the nature of participation to improve participants' abilities to develop new knowledge, create change, and empower themselves (Reason, 2004), but also helps reveal how marginalized people are situated in social and material relations and how their disempowerment is manifested in cultural arrangements (Quantz, 1994). I believe that this critically-oriented research provided a forum for the refugees to openly share and reflect on their knowledge and concerns about their situations and to raise an awareness about the social, political, religious, and cultural issues that undergirded their quality of life in a new home. My goal in using critical ethnography for this study is to employ personally meaningful strategies that would make it more likely to empower Bhutanese refugees to take initiative to express their concerns and desires, to take control over their literate practices, and become more involved within their community. 


\section{CHAPTER III}

\section{LITERACIES ACROSS BORDERS: REMAPPING THE BOUNDARIES OF

\author{
LANGUAGE AND LITERACY PRACTICES
}

Every increment of consciousness, every step forward is a travesia, a crossing. I am again an alien in new territory. And again, and again. But if I escape conscious awareness, escape 'knowing,' I won't be moving. Knowledge makes me more aware, it makes me more conscious. 'Knowing' is painful because after 'it' happens I can't stay in the same place and be comfortable. (Gloria Anzaldua, 1987)

म त के ठान्छु भने म अझै पनि केही सिक्नका लागि बांचीरहेको छु। मसँग ज्ञानका श्रोतहरु र लेखन कला पनि प्रशस्त छन्, मात्रै अड्रेजी छैन। -हरिशरण [I think I'm staying alive to learn; I only have knowledge resources and writing skills in other languages, but I've no English.] -Harisharan, born in Bhutan in 1947

I'm involved in learning and teaching of English for 32 years now, and when I want to communicate with the native speakers of English, they try to stay away from me saying that I don't understand English, and I can't talk English. This is ridiculous. My way of speaking and my accent may be different, but it doesn't mean that I don't know English.

-Gokul, born in Bhutan in 1974

\section{Introduction}

These quotations from Harisharan and Gokul remind us of the complex geopolitical, cultural, and linguistic spaces that immigrant refugees have to navigate in the process of their transition to and resettlement in the U.S. They are also suggestive of the urgency of valuing and acknowledging multicultural and multilingual resources that refugee communities bring to the U.S. While Harisharan has been actively involved in 
social work and community services in the Bhutanese refugee community for a long time, Gokul has contributed to the educational enhancement of the community as a language and sports teacher both in the refugee camps in Nepal, and in the U.S. Related to different groups of their community - one in social work and the other in educational services both Harisharan and Gokul have worked to challenge the traditional notion of refugees as unproductive and dependent people. They have been working hard to mobilize their community members for better services and better learning experiences so they can become citizens more aware of their rights and learning opportunities. However, newly arrived refugees like Harisharan and Gokul have been the victims of the traditional mindset about literacy and language that mostly stresses acontextual cognitive skills and English-only prescriptions that hinder their smooth transition to and resettlement in the U.S.

In this chapter, I analyze the literacy practices of Bhutanese refugees as they migrate to various locales, and identify the purpose of such practices in transcultural and translingual contexts in their new home in the U.S. An ethnographic analysis of the cases of these refugees helps us unmask geopolitical notions of literacy and identity across home, school, and work contexts. In my discussion, I particularly focus on how the Bhutanese refugees navigate their social, cultural, and linguistic spaces in the U.S., and how they negotiate, appropriate or transform their literate practices through their prior experiences and resources. As Gee (2000) argues, "Knowledge and intelligence reside not solely in heads, but, rather are distributed across the social practices (including language practices) and the various tools, technologies and semiotic systems that a given community of practice uses in order to carry out its characteristic activities" (p. 178). 
Such an inclusive analysis of this refugee community's literacy repertoires becomes especially helpful for depicting the contextual uses of literate, cultural, and language practices of ethnically, linguistically, and religiously diverse refugee communities in the U.S.

Through the literacy accounts of some representative participants out of fifty-six Bhutanese refugees I worked with in total for this study, this chapter argues that through their literacy practices the Bhutanese refugees are engaged constantly in forming and reforming a distinct identity for themselves as Bhutanese refugees. It suggests that the communicative practices individuals bring from their home communities to educational settings, such as schools and literacy programs, become valuable resources that we can channel towards helping refugee communities succeed in educational, social, and cultural contexts in the U.S.

\section{Construction of Identity across Diasporic Borders}

Ascribing biological or national terms to the identity of the Bhutanese refugees, as most of them illustrated through their concerns regarding identity, runs into the problem of a reified concept of diaspora, where "discussions of culture slip easily into identification by descent" (Dirlik, 2002, p. 108). As the discussions throughout this dissertation of the literacy practices of the Bhutanese refuges across various domains of social, cultural, educational, and religious lives suggest, their reading and writing activities shape and are shaped by emerging geopolitical relations and contexts. By participating in learning and creating literacy contexts in the new place, the Bhutanese refugees are not only involved in preserving and acting upon their prior cultural and literacy practices but producing a new Panorama City Bhutanese culture, and/or learning 
practices in the U.S., collapsing the boundaries of cultures and languages as marked by national borders. While most of the elderly refugees within the community seem still committed to the conceptualization of literacy learning that is deeply informed by traditional practices of reading and writing for religious purposes as they practiced it in Bhutan and Nepal, the younger generations are more concerned with literacy that can help improve their living conditions and establish their identity as newly-minted American citizens, coming a long way from their past experiences of dislocation and deterritorialization from what they may have once thought to be their own nation.

Although they are called Bhutanese after their nation of birth, most of the refugees project themselves as victims of ethnic persecution by the State, hence proffer less significance as Bhutanese for their identity. Most of the younger generations among the Bhutanese refugees, as a result, have limited their attachment of Bhutan to the vague geographical imaginary only to decry it as an oppressive regime that uprooted their identity forever. They don't want to be called Nepalese either because despite their birth (or some others' childhood at least) in Nepal, they were never offered citizenship status by Nepal during their stay for nearly two decades in the refugee camps there.

Being everywhere but belonging nowhere, the Bhutanese refugees are in search of an identity in the new homeland, where they expect to be "fully Americans," as Pramila, one of the participants, told me. So, as Dirlik (2002) suggests, "the use of a biological term as metaphor for culture and society is pregnant with the possibility of confounding cultural, social, and political with racial entities - especially where the term is divorced from its historical and structural referents" (p. 108), hence the need for historical and 
structural analysis while studying the literacy practices of a marginalized community like the refugees.

As the discussions throughout this chapter illustrate, rather than being stable and taking place in any one fixed location, literacy practices of refugees are always in flux, mobile, and traveling. Leonard (2013) notes that literacies of migrants can be better understood as "in-process meaning-making activities that encounter various social forces” (p. 17). In her study of immigrant professionals in an urban area, Leonard establishes an inextricable relationship between social forces in various locations of migration and literate practices of immigrants as shaped and informed by the issues of politics and globalization. While Leonard's (2013) study addresses a crucial issue about the fluidity and mobility of multilingual literacy practitioners in various professional levels and offers us a valuable insight into the fluid and mobile nature of the literate practices of the immigrants, the research is more focused on professional people, either highly skilled immigrants or students who have had several years of formal education and training in English and other languages in their countries before their arrival in the U.S. My study, however, explores traveling literate practices of the refugees, who are mostly deprived and underprivileged people due to their status as refugees. These refugees are also the involuntary migrants deeply affected by forced migration and persecution bearing the brunt of brutality and long experiences of what Appadurai (1996) calls deterritorialization and rootlessness. In this sense, these literacy accounts of the Bhutanese refugees as presented in this chapter offer us a unique perspective to look at the differences in terms of multilingual and multicultural learning practices across 
communities and help us adopt useful strategies for teaching, research, and other educational programs.

While my discussion of the literacy practices of the Bhutanese refugees is primarily based on their home settings, I also include here the participants' involvement in learning through such centers and gatherings to the extent of complementing their practices of reading and writing at home. In the discussion that follows, I study the relationship between lives and learning through a detailed examination of the participants' lives across various geopolitical locations and contexts. Such an examination helps us expose the diversity in people's lives and the complex relationships between lives and learning. All the names used here for these participants are pseudonyms, which are created in line with the Nepali naming tradition by taking into consideration the participants' culture, age, gender, and social structures. Along with literacy accounts of the participants in relation to theories of language and literacy to shape these accounts, I also include brief introductions to the participants, who appear more prominently throughout Chapters 3 and 4 , and who have been involved in informal learning opportunities in several literacy centers such as Elderly Care Center, ESL classes, cultural orientations, and music, arts, and culture group meetings.

\section{Migrating Literate Practices}

As discussed in Chapter One, official literacy sponsors often assume that their clients are completely illiterate and even unintelligent, that traditional school literacy is what they need, and that any failure to complete the program is owing to the individual's lack of motivation. Horsman's (1990) interviews with twenty-three women enrolled in literacy programs and ten workers in the programs suggest, to the contrary, that learners 
have varied abilities and a variety of personal and career goals related to literacy. They want to end their dependence on social service agencies. They are often hampered in their efforts by the complex demands of life in disadvantaged socioeconomic settings and by the debilitating links between many literacy programs and the very social agencies the learners wish to escape. Literacy programs need to listen more to learners' selfdefinitions of their needs and to encourage the use of literacy for social criticism. Two of my participants, Gokul's and Sekhar's examples of learning and teaching across various locations, offer us a unique perspective to look at how refugees' literate practices are constantly punctuated and shaped by their transnational migration and shifting geopolitical connections.

Born in 1974 in Bhutan, Gokul had most of his primary education in Bhutan. He was still in high school in 1990 when the Democratic Movement in Bhutan began. He was briefly at home in the south during school vacation in the summer of 1991 when his father was arrested and tortured by the Bhutanese army over allegations that he was an anti-nationalist. Like many other southerners in Bhutan, Gokul's family also was forced to leave the country after his father was released from the jail. His father's release came on the condition that the family had to leave the country within a week. Gokul's family then left for the refugee camps in Nepal. Gokul's literacy in Bhutan was mostly shaped by local educational, economic, cultural, political, and language contexts. Instead of doing his middle schooling in his own village after graduating from primary school, he had to go further north to assimilate with the northern Bhutanese students. As Gokul believed, the mandatory move of the ethnic Nepalese students from the south to the north for middle and high school education as forced by the Bhutanese government was also a 
political machination to eliminate the ethnic, linguistic, cultural, and religious features of the Lhotshampas, ethnic Nepalese living in southern Bhutan. The notes of Hari Chhetri, one of the government higher officials from the ethnic Nepalese community in Bhutan at that time, also confirm the government policy to sideline ethnic Nepalese people from Bhutan's mainstream national politics. Reminiscing about the purpose of the Bhutanese government in apparently promoting national integration, Chhetri (2013) writes: "Integration was promoted not so much with the idea of accommodation and assimilation of ethnic diversity and building a nation state but by a specific, narrow and selfish objective of limiting the Lotshampas' ... influence in national life" (p. 22). Integration in a true sense, in the words of Chhetri,

calls for tolerance, diversity, broad-mindedness and respect for ones as well as the rights of others who do not look, speak and dress-up like you. But here integration was conjured up as a mechanism for oppression, subjugation and total obliteration of the belief system and values of those ethnically different. It was devised with all the wit in the government to perpetuate subordination. (p. 24).

Gokul said this kind of integration might have been promoted because by doing so the government could also put the southern students under the surveillance radar of the school administration that worked under the direct control of the government. The regime's purpose was that the Nepali students from the south could be easily intermixed with the Drukpa ${ }^{7}$ students in the north and become well versed in the latter's religion and language through their English-medium middle school and high school education.

\footnotetext{
7 Ngalung, the people from Tibetan origins who mostly live in the northwestern part of Bhutan are often collectively called 'Drukpas'. However, it is clear that 'Drukpa' is used without a clear delineation of whom the term applies to. In fact, the word 'Bhutanese' is associated almost exclusively with the 'Ngalung' ruling group. Third, Nepali-speaking Lhotshampa people, who are largely Hindus, make up about 43 per cent of Bhutan's total population (See Giri, 2005 for further details).
} 
Being mostly groomed in the Bhutanese education system, Gokul recalled the legacy of the system, which was mostly characterized by restrictive features that were largely binding to the allegedly "anti-nationalist" ethnic communities like Lhotshampas. Gokul needed to go far away to either the northern or eastern part of Bhutan for middle and high school education, and had to take compulsory courses on Dzongkha (Bhutanese national language) and English in addition to Science and Math courses. He could, however, study Nepali only up to the fifth grade, and had to stop after that despite his interest in Nepali language and literature. He could resume his academic interests in Nepali only after he came to the refugee camps in Nepal and started correspondence courses in an Indian high school in order to complete grades 11 and 12. The worsening material conditions in the camps kept him from continuing his education. He then had to depend on some slim funds through charity and scholarship to be able to complete his bachelor's degree in India. When the third-country resettlement process started in the refugee camps in Nepal in 2007, Gokul was working in a local boarding school as an English and sports teacher. He came to the U.S. in August 2010, and started teaching ESL and citizenship classes at the Elderly Care Center from September 2012. At the time of my interview with him, Gokul lived with his wife and two children in the southeastern part of Panorama City.

Like Gokul's, Sekhar's experiences of migration and learning are compounded by his constant move and negotiation across several domains of life in both home country and the other countries of resettlement. Born in 1969 in the southeastern part of Bhutan, Samdrup Jongkhar, Sekhar completed his high school by moving to different schools in the northwestern part of Bhutan. Sekhar's learning situation was mostly similar to that of 
Gokul's. Like Gokul, Sekhar did everything to learn and excel in Nepali, even after middle school, for which he had to travel a long distance from his home in the south to various parts of western or northern Bhutan. Despite his considerable achievement in English and Science courses, Sekhar continued to pursue Nepali reading and writing on his own by sometimes finding books outside schools and sometimes buying them when he was in the border city to India. Sekhar also translated several Nepali novels into English to preserve both language skills in addition to maintaining his knowledge of Dzongkha, which, along with English, was a mandatory language in schools. While Sekhar groomed himself for his career as a dentist, he had to give up his dreams due mostly to his status as an ethnic Nepali and partly to the ongoing political movement in the South. Unable to receive an NOC (No Objection Certificate) from the government, a mandatory requirement for ethnic Nepali students from the South for further education and training, Sekhar was forced to leave his country for the refugee camps in Nepal. Due to the scarce material conditions in the refugee camps, Sekhar couldn't continue his studies there for a long time. He kept on reading and writing on his own in a new environment, however, mostly teaching in boarding schools for his living and occasionally making to campus when he had some break from teaching. Sekhar received a master's degree in education that way and kept on working as an English language teacher in local boarding schools. Upon his arrival in the U.S. in 2010, he first worked in a wood factory for one year before he started to work as an ESL teacher with a refugee resettlement agency in Panorama City. He lived in the western part of Panorama City with his wife and two sons. 
In my discussion below, I further analyze the learning practices of other elderly refugees across various locations of learning. I've included detailed discussions regarding the literacy practices of Gokul and Sekhar on the one hand and Harikala/Nandalal and Loknath/Bedmaya on the other because they mostly represent intergenerational members - the former being middle-aged literacy workers ${ }^{8}$ and the latter elderly members of the community - of the Bhutanese refugee community who are actively involved in the learning process in the new land. Although it is hard to put all of their experiences under the same basket of analysis given the intra-community dynamics of their experiences of growing up and learning, the discussions here at least offer us an insight into looking at the general trends of learning experiences and challenges facing the refugees' literacy development in the new context.

Married for forty-eight years, Harikala and Nandalal both were born in southern Bhutan in 1951 and 1944, respectively. While Nandalal lived too far away from the school's location to attend it, Harikala was not sent to school, although there was a primary school in her village, because of the general tradition in the village not to send girls to schools. Both Harikala and Nandalal were deprived of formal education in Bhutan. It was only after they arrived in the refugee camps in Nepal that they had a chance to attend adult literacy classes. It was in these adult literacy classes run by the Community Development Center that they learned to read and write in Nepali. After their children were born in Bhutan, Harikala and Nandalal wanted to educate their children, as they learned lessons from their own experiences of deprivation and scarcity. They even

\footnotetext{
${ }^{8}$ By literacy workers, I mean those members of the refugee community who have had at least a college or university degree and who have actively worked in the community, both in Nepal and in the U.S. either by teaching/running some literacy classes or by promoting literacy learning of the community by utilizing community resources.
} 
migrated from a remote village in Bhutan to an urban area for the education of their children. Unfortunately, the Bhutanese government Census in 1988 divided their family by labeling Nandalal as category one, Harikala as two, and all their children as four. Only the people who were labeled as category one were entitled to Bhutanese citizenship, and all others were ineligible to stay in Bhutan because the government branded them as noncitizens. As they were labeled four, Harikala and Nandalal's children couldn't go to schools. The situation became worse when Harikala's family was constantly threatened with torture by the army. The army's persecution got to the extent that they severely beat Harikala's father and dumped him into a gutter nearby for dead. That incident terrorized and traumatized Harikala's family, forcing them to immediately leave Bhutan to head for an unknown destination toward the refugee camps in Nepal.

After arriving in the temporary camps on the banks of Mai River in the eastern part of Nepal, Harikala's family had to face very heart-rending situations and miserable living conditions there, as an average of thirty people died each day on the banks of Mai River. The deaths, from cholera, pneumonia and other diseases, primarily affected infants and the elderly. As the living conditions in better managed camps improved after 1993, Harikala and Nandalal sent their children to school and raised the family of ten. They came to the U.S. in February 2010. Both Harikala and Nandalal started to attend the Elderly Care Center together from September 2012.

Loknath and Bedmaya were both born in southern Bhutan in 1942 and 1948, respectively. Trained to work in the farms since their childhood, they could never attend school in Bhutan. They couldn't read and write until they went to the adult literacy classes in the refugee camps in Nepal, where they mostly learned to read and write and 
count numbers in Nepali. Loknath and Bedmaya had left Bhutan in 1992 with their four children for the refugee camps in Nepal after the army raided their village. The army would turn up any time and brutally sabotage the whole village, setting houses on fire, beating the men, and raping the women from their neighborhood alleging them to have sided with the Ngolops (a derogatory term in Dzongkha used to refer to Nepali-Bhutanese in the South) and supported the agitating Lhotshampas (Southern people of Nepalese ethnic origin). Bedmaya recalled with sadness one summer afternoon of 1991 when the army cordoned off their home:

The whole village was terrified, as the army had come the other night and arrested some youth from the village; they beat other family members and also raped daughters and daughters-in-law from various families in our village. I had only arrived home after planting some vegetable saplings in the nearby farm when the army came and started to inquire me about my son and husband. Luckily, my husband had gone directly from the farm to a nearby water tap for bath and my son was away on an errand. I was so scared that my lips started to shiver like the leaves of peepal and nostrils twitched. I only told them that the men were away from home and that it would be a bad omen to enter the house by crossing the hanging dhyangro ${ }^{9}$ over the stairs on the way to the second story of the house. The army got scared when I talked about the dhyangro and left immediately. I can never forget that day in my life.

Loknath confirmed what Bedmaya said and recalled that since then, the army reappeared several times to the village, marauded the whole village repeatedly, wreaked havoc among the whole Nepali community by beating the family members and even raping women from Acharya, Magar, and Rimal families in their neighborhood. The army even arrested Loknath once and kept him in a nearby Dzongdha (District Chief) office prison for one night. Luckily, as they couldn't find any records to indict him, the army released

\footnotetext{
${ }^{9}$ A drum-like instrument made of goat leather, which shamans or witch doctors use for the purpose of spiritual practices. Also, this instrument is played by the shamans for exorcising bad spirits and offering shamanic treatment to the sick people assumed to have been suffering from bad spirits and the bewitched spells of witches as believed by some people in most parts of Bhutan and Nepal.
} 
him the next day with a threat to kill him and his whole family in case they found any evidence against him in the future. Loknath's family could hardly stay a year after that due to the repeated barbaric treatment of the army in the village and decided to collectively leave their houses in a group of fourteen households, consisting of nearly 122 members in total from their neighborhood. After spending eighteen years in the refugee camps in Nepal, their family came to the U.S. in 2010 under a refugee resettlement program. At the time of my interview with them, Loknath and Bedmaya were living in Panorama City with a family of seven.

\section{Literacies in Everyday Contexts}

Gee (2007) argues that reading and writing practices are not simply mental acts or cognitive achievements. Literacy instead is something "that happens out in the world of social, cultural, and institutional activities" (p. ix). Similarly, marking a difference between academic literacy and critical literacy, Morrell (2002) notes that while academic literacy is limited to classroom teaching through traditional texts, reading, writing, and discussing, critical literacy refers to the ability to read and write, and also think critically about how the world, society, and our communities have influenced the text. Critically literate people thus can better understand the "socially constructed meaning embedded in texts as well as the political and economic contexts in which texts are embedded" (Morrell, 2002, p. 73). Our efforts as teachers and educators should be directed towards helping our students and learners develop a sense of critical literacy so they become more aware of social, cultural, economic, political, and language contexts that undergird their literate practices. 
To show how literacy practices of the Bhutanese refugees are deeply affected by these contexts, I first analyze their everyday reading and writing practices across various spaces, such as Elderly Care Center, ESL classes, Music, Arts and Culture group gatherings, and other learning activities at their homes. These analyses are mostly based on fieldnotes, interviews, collection of cultural and literacy artifacts from the research participants, and my observation and participation in most of those activities.

\section{Literacy Practices at the Elderly Care Center}

Literacy is not only for the facility of reading and writing but also for the purpose of arousing people's consciousness about their citizenship rights and social justice. I found during my observation of teaching and learning activities at the Elderly Care Center that this Center has taken an initiative to promote literate practices among elderly Bhutanese refugees in Panorama City. Located at the northeast side of Panorama City, Elderly Care Center was first established in 2003 as a business to offer help to elderly people from the Russian immigrant community. Only those people who had reached 65 and were receiving Medicaid or those who could be eligible for Social Security benefits could join the Center for healthcare facilities and other social activities. It was only in summer 2012 that two literacy workers from the Bhutanese refugee community negotiated a deal with the Center in order to run elderly care for Bhutanese elderly people. Started on September 12, 2012 under the initiation of Gokul and Jeevan with eight participants in the beginning, this Center has attained a much larger organizational shape today, consisting of eighty-two Bhutanese elderly participants as of May 2014. In addition to offering a leisure time for elderly people to spend with their peers, this Center also offered ESL and citizenship classes to the elderly people as preparation for their 
oncoming citizenship tests. The refugees were allowed to apply for their citizenship five years after their arrival in the U.S. In addition to these learning sessions, there were a great deal of other fun activities and games designed for the elderly refugees.

Figure 3.1. Elderly Learners at the Center

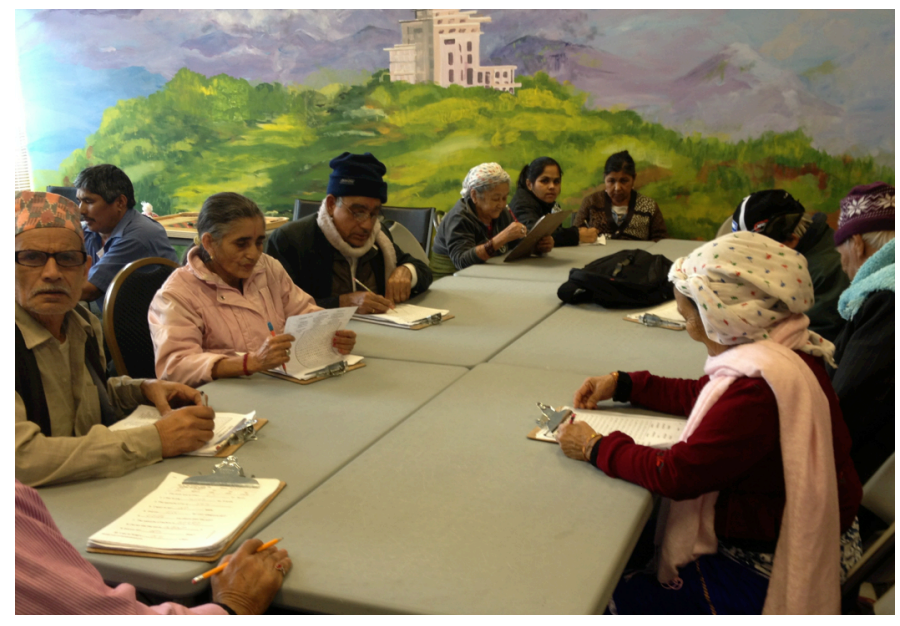

When I reached at the Center for the first time in November 2012, I was amazed by the energy and commitment the senior Bhutanese people showed in learning and promotion of other cultural activities. While more than half of the Bhutanese elderly refugees were inside a

classroom taking lessons on the U.S. Constitution and citizenship rights, others seemed busy in the outer space laughing with each other about their daily chores, playing board games and cards as per their interests. It looked like an adult school with all the learning and playing activities in a school environment.

As I observed most of their activities throughout the day, I was intrigued by the way the elderly people showed their interest in learning and other activities that would keep them more sound physically and mentally. Their engagement in such mental and physical activities reminded me of a famous saying in Latin "mens sana in corpore sano" (a healthy mind in a healthy body). When I asked Gokul, who taught ESL and citizenship classes in the Center from 10 am to $1 \mathrm{pm}$, how the facilities worked in the Center, he told me that the participants remained in the Center for six hours (from 10 am to $4 \mathrm{pm}$ ), taking 
classes in the morning hours, and socializing and doing some physical exercises in the afternoon. There were five buses to pick them up in the morning and drop off to homes in the afternoon. The Center provided all the participants breakfast in the morning and lunch in the afternoon. In addition to a teacher, the Center also employed three other Bhutanese-Nepali facilitators, who helped the participants in their learning process, by offering interpreter services during the participants' office and hospital visits. The facilitators also engaged the elderly participants in other learning and play activities in the Center when the latter were not taking classes.

Every Friday, they also organized a small socializing cultural program, mostly singing bhajans (religious songs) and dancing in tune with some of the popular Nepali bhajans. These programs not only helped the elderly learners stay sound physically, but also offered a spiritual solace in a new home thousands of miles away from their country of birth. During my several visits to the Center, I noticed almost all of the participants enjoyed such opportunities and forgot other day-to-day chores and sufferings for a short while during their stay there. In addition to learning English, the elderly people also participated in conversations about citizenship issues, legal rights as refugees, and other cultural activities that extended their connections to their home country and the country of their flight, i.e. Nepal. At the request of the participants, the Center also created a large wall painting with natural elements reminding the refugees of their home countries, which, most of the participants said, were both Bhutan and Nepal.

\section{Multilingual and Multicultural Literate Practices of the Elderly Refugees}

In this section, I analyze how people's literacy practices make inroads to their means of language, and whether such literacy practices help them to articulate their 
differences through language. The study of literacy within linguistic domain of people becomes more relevant in the context of refugees, who have found ways to create their identity based on their language choices that are informed by their literacy practices in the past as well as in the present. In my discussion below, I highlight the learning processes of four elderly participants at the Elderly Care Center I introduced above. What the participants learn there has also been the consequence of constant negotiations between the multiple language and literacy repertoires that the participants and their teacher possess.

Nandalal and Harikala had been to other ESL classes run by the resettlement agencies for elderly refugees immediately after their arrival in the U.S. However, they couldn't understand the native English-speaking teachers at all, and their learning process took a halt as they continued to go to the class but without much learning. They were hopeless about their possibility of learning further, and had decided, grudgingly, to join the classes just as a formality. In the beginning days of their arrival, both Harikala and Nandalal became more depressed about their condition in the U.S. because they thought that all they could do was to stay home and live on the memories of their past social, cultural, and religious life in their birth land.

However, the situation took a positive turn when they started to regularly attend the Elderly Care Center, where two multilingual Bhutanese-Nepali teachers, Gokul and Jeevan, taught ESL and citizenship courses. Nandalal and Harikala's hope for learning rejuvenated when they made it to the Center and took a class with Gokul. In their role of out-of-school community mediators of literacy (Baynham, 1995), both Gokul and Jeevan supported the elderly learners by providing them with a more homey and motivational 
environment where they encouraged guided participation for learning. Harikala openly appreciated the opportunity to learn with Gokul at the Center: "What Gokul teaches is very impressive. We actually started learning A,B,C,D here with Gokul, and now can write our names in English and read a few words and sentences in English." Unlike in her earlier citizenship classes run by the resettlement agency, Harikala felt less intimidated to ask questions as she became confident that Gokul would help her even if she answered something wrong. Gokul was also very appreciative of Harikala's learning process in particular and assured me that she would be able to pass citizenship tests if she continued to learn the same way. My extensive observations in the field have generally verified this position in relation to other participants in the Center.

The notion of repertoires as an intersecting point becomes useful to analyze such learning practices, for it contributes to examining translingual relations to literacy between a particular language community and literacy practices attached to the community based on their use of repertoires in the sense of what Blommaert and Backus call "the means of language" (2011, p. 4). The learning of elderly participants like Harikala was heavily influenced by all of such social, cultural, and linguistic repertoires they could accumulate across various locations of migration. Repertoires in this sense become an amalgam of multiple sources of language and other learning practices that people adopt in the learning contexts as offered by the Center. Such use of repertoires is precipitated, according to Blommaert and Backus, by superdiversity - tremendous diversifying of diversity - as a response to or consequence of the changing nature of immigration, labor, and education along with the rise of the Internet and mobile telephones in recent decades. This repertoire model as a means of language, however, 
doesn't account for the fact that the semiotic resources themselves are subject to transformation in the process of being activated, hence no question of treating superdiversity alone as a stable entity. For most of the Bhutanese refugee participants in this study, languages and literacies were extended across social, cultural, linguistic, religious, and political contexts in a way to enable them to build upon and transform their range of linguistic and cultural repertoire for a meaningful communication rather than simply reproduce a particular context.

Harikala's history of learning, as such, didn't only stem from her training at the Elderly Care Center but also emerged as rooted in integrating her learning experiences since her childhood when she started to self-teach Nepali alphabets while cow-herding in Bhutan. She also enhanced her literacy learning further by attending Nepali language and literature classes for elderly and adult people in the refugee camps in Nepal. She could go to those classes after completing all of her household chores in the evening and learn to read and write in Nepali. In those adult literacy classes, teachers from the refugee camps taught them to write their names, read Nepali storybooks and religious scriptures, and share their learning experiences with other participants in the class. This, according to Harikala, helped them substantially in their learning process, as she started to feel confident about reading and writing in Nepali and continued the trend of reading Nepali bhajans (religious hymns) and chanting religious slokas (verses) when observing puja ${ }^{10}$ every morning. This idea of religious literacies as a practice in which we engage as a society is connected to the concept of situated cognition (Lave \& Wenger, 1991). According to Lave and Wenger, situated cognition describes learning as an integral part

\footnotetext{
10 Religious members of the Bhutanese community who follow Hinduism offer this ritual early in the morning by chanting prayers and slokas to the gods based on Hindu scriptures.
} 
of generative social practice in the lived-in world (p. 35). It is a way of thinking about learning as a process that is co-created with others in real world practices.

Harikala and Nandalal's daily chores started with making preparations for going to the Elderly Care Center after they offered daily services in their puja room. When they went to the Center, they felt like being at home as they could meet most of their longtime friends. The class in the Center helped them noticeably in the learning process, and along with this class, they would also be occupied through other social, cultural, and wellness activities.

Both Nandalal and Harikala agreed that they were very motivated to learn, especially the ideas related with citizenship and other legal issues. I wanted to explore some of the reasons as to why the elderly refugees were so deeply involved in the learning process. Most of the participants I interviewed revealed that primarily they wanted to be able to pass the citizenship tests and become American citizens. Next, they wanted to learn English in a way to help them read the signs and addresses so they didn't get lost when they got somewhere outside of their homes.

Harikala and Nandalal, for example, had a very positive experience of taking classes with Gokul at the Center. Although they were having a hard time due to their "advanced age to remember most of the rules of grammar" (in Harikala's words), they learned by engaging in language activities in various modes designed for the class. They also could get better explanations by Gokul in Nepali whenever they faced problems learning English words and sentences. For example, when I asked Harikala whether the learning experiences in the refugee camps helped her any way in the U.S., she said that although they didn't learn much of English in those Nepali literature classes under adult 
literacy programs in the refugee camps, they were at least able to learn signs, cultural symbols and their meanings in Nepali. She gave me an example of how the sign of crossbones and a skull means danger, and learning that sense, regardless of language, could definitely help her decipher the common sense that where there was this sign, she couldn't approach it, as it could pose danger. Moreover, Gokul, as a teacher sharing the common dispositions of languages and cultures of their background, used many such examples in the class to help the participants better understand such concepts.

I see such a practice of learning of English by the Bhutanese refugee elderly participants by using prior knowledge and identifying common features that help them decipher the sense in a new context as a translingual practice. As the discussions above show, utilization of a translingual approach functions as a tool to connect meaningful concepts to the learners' repertoires. Moreover, this approach supports the teaching and learning process of immigrant communities, helping the English language learners make sense of their multilingual repertoires and appreciate their primary languages and cultures as meaningful resources that they can transfer towards learning in the new contexts.

Literacy as such seems to be deeply related with mobility and utilitarian needs. According to Beck (2005), while borders are wide open to financial capital, people who wish to utilize their labor and educational resources are labeled or "criminalized" as migrants, immigrants, or refugees (p. 188). The Bhutanese refugees have challenged such labels by actively utilizing their previous resources for learning in the new contexts, especially when they find more favorable learning environment like the Center. Actively involvement in the learning process in the new environment, as all of the four elderly 
participants claimed, helped the Bhutanese refugees not only enhance their ability to move but also realize change in their self-identity, confidence, and even daring.

\section{Mandatory vs. Motivational Citizenship Classes}

In this section, I compare and contrast between citizenship classes in two facilities - one run by a refugee resettlement agency, and the other by the Elderly Care Center - to highlight some of the substantial teaching and learning practices and the levels of participants' motivation in their learning. Refugee resettlement agencies in Panorama City offered mandatory citizenship classes to the newly arrived refugees to familiarize them with their basic citizenship rights and other U.S. laws. The goal of these classes was to help the refugees prepare for citizenship tests that they could take five years after their arrival in the U.S. These weekly classes mostly focused on rules and regulations that refugees were supposed to learn about the U.S. system on the way to citizenship. Despite the translation services provided to the participants in their own languages, most of the refugees I talked to expressed their confusion about the information, as they had difficulty figuring out the legalese about the U.S. system without any references or examples from their own contexts or systems that they were more familiar with. Loknath, an elderly refugee born in 1944 in Bhutan, was very frustrated when he went for three months to a citizenship class offered by the resettlement agency. He only became a passive participant without being able to understand a single point and contribute to the discussion in the class taught by a native English-speaking teacher. Loknath had

a hard time learning anything in that class because I didn't understand a single word of English then, and the teacher spoke only in English. She could never bring up any contexts and resources that I was familiar with, and I had no chance of understanding any other American contexts that she talked about. I couldn't even write my name in English in three months, let alone understand other issues on citizenship and U.S. laws that the class 
was supposed to teach us about. There was no point in attending that class. However, the teacher in my new class at the Elderly Care Center is a Bhutanese Nepali teacher who understands our problems, and brings up examples from political, social, religious, and cultural contexts that I am more familiar with. He first explains every issue in English, and switches to Nepali to elaborate the concept further. I learned most of the English words and even sentences to be able to communicate with non-Nepali speakers in nearly four months after I started taking this class with Gokul. I learned to write my name in English within a very short period of time. I am so happy and excited about what I am learning in this Center.

Loknath also excitedly related to me a story of his English language adventure last year when he was traveling to a Midwestern town. There was nobody else to travel with him but his wife, who couldn't communicate in English either. However, the communication skills he learned in this multilingual class came in handy when he needed to ask for assistance when changing buses or asking for directions. After getting off Greyhound in every new station, he would go to the security official nearby and ask for help: "We going to Akron, but no English (with a gesture to "no" by moving his head and hands); need help." He laughed heartily as he said this and added that the official then would take them to the right bus and assist with finding seats in the bus. Loknath used his previous resources in order to adjust to a new situation by utilizing not only his bodily gestures but also verbal communication skills that he learned during his stay in Bhutan and Nepal. This effective learning situation of the refugees in the new context challenges the assumptions the sponsors of literacy like the resettlement agencies carry in general about the refugees and recent immigrants in the U.S. These sponsors mostly overlook the fact that literacy practices of the minority communities like refugees are complex and therefore need to be evaluated in a close context by also taking into consideration other social, cultural, economic, and linguistic factors that contribute to the holistic learning of these marginalized people. Because they entirely attribute the literacy skills, sophisticated 
systems, and knowledge about the complexities of learning to the education system, training, and cultural orientations offered in the U.S., the literacy sponsors lose the larger picture about how people learn in other contexts by assuming as though there were no literacy, sophisticated political, cultural, and philosophical systems, and structures and knowledge about them, oppressive or otherwise, in the non-Western world before the refugees' arrival to the U.S.

In addition to offering citizenship classes twice a week, the resettlement agency in Panorama City also conducted cultural orientations with a similar objective to teach the newly arrived refugees some of the legal and practical issues about living in the U.S. In most of these cultural orientation sessions I observed, the presenters mostly used scare tactics in a more pressing way for the refugees to understand than exemplifying through supportive and more understandable contexts. For example, a police officer talking about traffic education started his presentation with a story of a "burka woman from Africa" run over by a vehicle a couple of months ago. When interpreters translated the story into the languages of the refugees from several Asian and African countries, the refugees seemed very scared and started clicking their tongues in fear. The presenters often created binary oppositions between what it could have been like for the refugees back home and how things were entirely opposite in the U.S. For example, one of the issues on security was addressed through an anecdote of a house robbery in a nearby apartment. Toward the end of the session, when the officer provided participants with his cell phone number for contact, another agency staff stressed the difference between the system in the U.S. and that in other countries the refugees hailed from. He asked the participants if they could ever imagine police personnel providing them with private cell phone numbers to report a 
robbery at their homes and stressed that it could be possible only in the U.S. The refugees' level of motivation in such classes seemed to be fed mostly by those scare tactics than by the participants' desire for learning. As some refugee participants talked to me after the session, although the participants seemed to be keenly interested in learning new cultures and legalities to fare better in the new contexts, they also became more worried that those teachings came at the cost of their (mis?)understanding of their prior practices as binary to the new ones they were going to face in the U.S. contexts. Such worries might also have arisen due to the noticeable power dynamics between the newly arriving refugees and the agency organizers of the orientations.

Unlike in those mandatory citizenship and cultural orientation classes offered by the refugee resettlement agency, elderly Bhutanese refugees seemed more relaxed, motivated and engaged in learning at the Elderly Care Center. At the Center, Gokul designed and taught materials by inviting participants to contribute to the discussion based on their understanding of the similar systems and terms in their home country as well as other adjoining neighbors in South Asia. Moreover, the participants seemed more engaged in the learning process as they could speak their ideas in Nepali and also translate the terms into English for better understanding of the concepts attached to the words.

Gokul was an experienced English teacher who had long taught in the refugee camps as well as other secondary schools in various parts of Nepal. He designed his teaching materials not only with American contexts in mind but also Nepali, Indian, and Bhutanese contexts that the participants had been more familiar with. Not only did he translate the materials into both languages for the participants but also talked about them 
by bringing in contexts from Nepal, Bhutan, and India whenever he had discussions on political terms and other issues related to citizenship and politics. In one of the sessions, Gokul took the participants to task by asking them to identify the speaker of the legislative body in U.S. parliament. He first explained about this concept to the class in English but noticed that the whole class seemed confused. Then he used some Nepali phrases and sentences by also bringing references and contexts from Indian and Nepalese parliamentary houses to help the learners better understand concepts about the parliament and the speaker.

Gokul later talked about difference in the participants' ability to understand the meaning of such political and social terms; when I asked Gokul how he facilitated the learning process of these elderly participants with such a difference, he explained to me about the significance of multilingual repertoires and the whole gamut of knowledge making as represented by such repertoires. Gokul utilized his multilingual, multimodal, and multicultural skills when designing the activities for the class. As most of the learners agreed, his use of audiovisual and other Internet resources was quite helpful for them to better understand the concepts. To familiarize the elderly participants with some of the conversational contexts in English and other question patterns during the citizenship interview process, Gokul used YouTube materials and other audio-visual resources for the participants to listen to, watch, discuss, and also helped them become familiar with the terms in several contexts. Through the use of mp3s on citizenship issues, Gokul also helped the learners gain an experience of the native speaker way of pronouncing the words. He showed me the teaching materials, such as citizenship preparatory audio clips from U.S. Citizenship and Immigration Services, and pictures and videos of the Senate 
and the House of Representatives in Washington D.C. He also showed me the sample activities on word formation, matching words and pictures from the list, and tally activities to show words and their meanings that some of the participants completed in his class. He used most of these audio-visual support materials when explaining the concepts to the participants and helping them learn these concepts and their meanings in relation to the pictures and images they represented. For example, when the participants said that they had never heard the word "bat" before, Gokul wrote on the whiteboard "BAT" and showed different birds on the projector screen. Then, he asked the class what the word referred to and where they would find the bird. In addition to pronouncing the word in English, when he explained in Nepali the term by giving them clues within a context of caves and dark places, the participants easily understood the meaning and identified the image of bat on the screen as chamero (Nepali word for bat).

During my observation of this class at the Center for several times, I found that the participants were very active. They shared their ideas with each other and participated in the discussion by trying to come up with "right" answers for the activities that were mostly about combining letters, words, finding short answers to questions about the U.S. Constitution and history, and so on. Bedmaya, Harikala, Loknath, and Nandalal were among the elderly participants who promptly responded to most of the questions that the teacher asked and actively participated in the learning activities. For example, in one of the sessions I observed, Gokul asked the participants about the U.S. Senate and the House of Representatives. He first explained about this concept to the class in English only to get a sense that the participants were having a hard time understanding in exact terms what these two legislative bodies referred to. Then he quickly switched his explanation to 
Nepali by also bringing references and contexts from Indian and Nepalese parliamentary houses; the whole class seemed to quickly catch on the meaning as they instantly started to respond to the questions by using the terms mathlo sadan and tallo sadan (two legislative bodies in Nepal) to refer to the Senate and the House of Representatives, respectively.

\section{Learning Through Physical Exercise, Yoga, and Games}

Harikala and Bedmaya talked about physical exercise as another appeal of the Center. When asked if they were also learning during those exercise moments, they said that exercises were good only for the physical body and that their learning would occur only during class time between 9:30 am to 1:00 pm. However, unlike what Harikala and Bedmaya acknowledged, during my regular observation of these exercise sessions after 1:00 pm, I found that the learning process continued even during the moments of physical exercise. For example, a physical training teacher, a Ukrainian-born woman, whom I call Olivia (aged 25), working for one year in the Center, had familiarized herself with most of the exercise-related Nepali words. She counted the elderly participants' stretches by using Nepali numbers as the people lifted their hands and bent their bodies. She asked people to raise their hands up and down at the count of numbers that all the exercisers repeated. Olivia also asked them to keep track of their movements at the count of numbers. Later on, I found after talking to most of the participants that they were able to learn numbers in both Nepali and English through these regular exercises.

In the same vein, during their break hours, especially after lunch break, the participants engaged in playing games. When I asked about what they were learning through these games, Bedmaya and Nandalal simply denied that any learning was taking 
place in those daily practices. However, unlike what the participants claimed, I noticed that there were substantial literacy practices developing through such everyday activities at the Center. I observed their bingo games several times and noticed that the elderly participants, such as Nandalal, and Bedmaya, who claimed themselves to be "illiterate", used their numerical sense and spatial understanding of the numbers when matching cards and numbers every time Jeevan, another literacy worker at the Center, announced new numbers for the participants to match.

Moreover, the less educated elderly people also very often communicated with their physical training instructor by using English words, and occasionally even sentences, that they repeatedly used during those exercise sessions. Loknath also credited these sessions for his fast learning of English words and sentences for casual conversations with Olivia and other English-speaking staff in the facility. Such practices of learning by the elderly refugees even through these small daily activities, such as physical exercise and bingo games, suggest/support the notion of learning as located in the body as much as the disembodied mind. And where else could we see better translingual and transcultural practices of learning language and literacy skills than in those small, otherwise unnoticed activities like these daily exercises and games? For example, the Ukrainian ESL teacher herself became an active participant in this translingual learning process by not only inculcating in the participants her knowledge about diverse languages and cultures but also receiving ideas and knowledge from the participants about their rich cultural and language resources. Her pronunciation of Nepali words and numbers with Ukrainian inflections and translation of them into English in turn and giving specific meanings to those words and numbers would offer not only 
Olivia but also her students an effective learning environment in translingual and transborder contexts. Similarly, the Bhutanese elderly participants too gave specific meanings to those English numbers offered by the Ukrainian teacher along with the stretches of body and circulation of ideas in mind during those moments of exercises and games. Such literacy practices of the Bhutanese refugees across various domains of learning highlight the fluid and emergent nature of literacies, as they get constantly changed and transformed as displayed by the elderly learners and their ESL teachers at the Center. Despite the participants' lack of affirmation about their daily learning experiences as practices of reading and writing in the sense of what formal school training would look like, literacy practices are changing and reshaping along with the daily practices of the participants. These examples further manifest how literacy practices become discursive, situated, transformative, contradictory, and emergent, more so in the context of non-privileged communities like refugees.

\section{“He Don't Speak English; Don't Talk to Him in English": Conflictual Practices of Production and Circulation of Languages in the U.S.}

Canagarajah (2009) suggests that Plurilingual English offers ways of negotiation to the speakers of English, as "each contact situation is a unique context, with a different mix of speakers and languages, raising its own challenges for negotiation" (p. 9), which makes users of language "competent enough to be able to monitor each others' moves at a high level of awareness" (House, 2003, cited in Canagarajah, 2009, p. 9). For Canagarajah, multilingual competence emerges out of "local practices where multiple languages are negotiated for communication" (p. 1). The socio-cultural contexts of communication along with the language user's ability to assess the contexts are important strategies that multiple language users utilize for rhetorically effective communication. 
Canagarajah thus offers a helpful practice to promote multidirectional transformation in the process of communication, whereby "English continues to be negotiated and appropriated in plurilingual tradition" (2009, p. 6). However, as the following discussion demonstrates, the way English is produced and circulated among the newly arrived immigrants from across the non-native speakers of English countries is heavily informed by an English-only mindset that privileges a certain variety of English as the "standard" and uniform practice to be learned and circulated.

Although Gokul started to learn English when he was six and had been teaching English for the last twenty years, some of the native English speakers dismissed his English because of his difference in speaking, mainly his accent. He related to me a "pleasant" experience of how a native English speaker denigrated his English skills during his conversation with another American friend:

When I was responding to one of my American friends' question about my work experience at the Center, another person who knew my friend, but not me, pulled away my conversation partner and told him in aside: "he don't speak English, so don't talk to him in English." I happened to overhear that conversation and felt so disappointed by this disparaging remark that I turned back to that person and said, "Please, correct your English: it's not 'he don't speak English,' but 'he doesn't speak English."'

Gokul said that this was only one example of several other incidents he faced on various other contexts in the U.S. So, instead of getting irritated by such remarks, Gokul started to take them as "pleasant" experiences to share with family and friends so they could not only mock a disappointing situation in the face of their struggle to learn "actual English" (Gokul's words), but also made other English learners like themselves aware of the plight facing them. I noticed that being involved in this practice, Gokul gave a new contextual meaning to "pleasant", i.e. in the sense of mocking, that only those people who knew 
about the contexts of his presentation could make a sense of what it actually meant in the context of Bhutanese-Nepali English.

This situation of disparaging treatment to the use of other varieties of English is reflective of how English monolingualism has affected the general mindset about the uses of English based on a particular and privileged variety of English and an accent attached to it, and how that transfers directly to the academic contexts in most of U.S. universities. According to Lu and Horner (2013b), such “monolingualism's ideological identification of language difference strictly with the language of those already marked as socially different from the dominant places a double burden on members of subordinated groups: not simply the burden of the actual linguistic challenges they might face, but the perception of this burden as evidence of deviant lack-in a word, trouble" (p. 584). Most of the schools, despite the increasing number of non-native English speaker students from around the world, don't generally acknowledge and recognize the legitimacy of the differences they bring to English, whether that be in terms of accents or rhetorical patterns in writing. Highly recognized by several literacy agencies in Nepal for his effective teaching, Gokul's status as an English teacher is respected not only among the refugee community but also with the administration of the institution running the Center. During my last visit to the Center, I noticed that Gokul had been awarded the best employee award in the institution, and a framed photograph was hanging on the wall in the corner of the Management office. Gokul believed that what he learned in the contexts of Bhutan and Nepal became directly useful to what he had been able to utilize in the process of teaching in the U.S.:

When I first taught in lower grades in Nepal, I learned so many teaching skills that I have been using when teaching the elderly people today. My 
ability to teach this level of people largely depends on the teaching skills and strategies I learned during my teaching in various places in Nepal, including the refugee camps in Jhapa and Morang. My teaching in upper grades later has added more to my confidence to teach English at any level now. Not only that, even my children are excelling in the school here just due to their strong skills and resources they learned during their education in Nepal. We have carried with us from our countries of birth and second resettlement almost ninety percent of the necessary resources and skills we need to adjust in the U.S. The tragedy for we refugees, however, is that these skills are rarely recognized in the contexts of the U.S.

Well versed in several languages (Nepali, English, Dzongkha, Hindi), Gokul could share with his participants the diverse resources of learning that he said were proven very effective in teaching and learning.

In order to further explore how the Bhutanese refugees' learning practices are shaped and reshaped by official literacy sponsors' interventions and policies, the discussion below focuses on two other literacy sites - ESL classes, and Cultural Orientations - that are run by one of the refugee resettlement agencies in Panorama City. The discussions illustrate how promotion of the refugees' multilingual and multicultural resources can help their smooth transition in the U.S., and how multilingual teachers are better prepared to help the refugees channel such resources for their meaningful learning experiences.

\section{Multilingual vs. Monolingual Teaching Practices at ESL Classrooms}

In this section, I offer a comparative teaching scenario between an ESL class taught by a multilingual teacher, Sekhar, and that taught by a monolingual native speaker of English teacher, Brad. Both of these classes were offered by a refugee resettlement agency in Panorama City. I start with an analysis of Sekhar's class, and compare his teaching strategies with that of another ESL class to see how multilingual repertoires can be used as resources for enhancing teaching and learning experiences of the refugees. 
Sekhar was a Bhutanese refugee ESL teacher who taught a basic level ESL class to refugees from different parts of the world.

Sekhar's class was full of images and pictures all around the wall, especially of flowers, images of all four seasons with blooming flowers, rainfall, snow, and vapor rising through the ground with captions, such as winter, spring, summer, fall written under them - all representing different seasons. The learners could see the pictures and the representative words below them and guess the meaning of those pictures while also learning English words to signify the pictures. There were also a couple of pictures of English alphabets and numbers hanging on the walls. Among twenty-four refugees in the class, ten were from Cuba, eight from Bhutan, four from Burma, and two from Somalia. Nearly half of the learners seemed middle-aged, four were in their early-60s, and the rest were between 18-28. In the session I observed, Sekhar was teaching the class to fill out a job application form. He first wrote on whiteboard his own first and last names and asked how the participants could use the slots on the form to write their own names. The participants started to complete the slots for their first and last names. Sekhar then explained to the class how they would write their addresses and where they could find the slots for them.

As Sekhar tried to communicate each context of the job application process to the students from different language backgrounds, he mostly worked through non-verbal gestures, signals, and facial expressions. As Rymes (2010) eloquently states, the notion of a communicative repertoire or "the collection of ways individuals use language and literacy and other means of communication (gestures, dress, posture, or accessories) to function effectively in the multiple communities in which they participate" (p. 528) offers 
us an insight to see how bidirectional inclusion of repertoires by interlocutors can foster pride when communicating across cultural and linguistic differences. I noticed an intriguing example of learning in this class when an issue came up about how these refugees had traveled to their workplaces from homes in their countries of origin. Most of the participants said that they went on foot, or by bus. One of the Spanish-speaking students said, "I went car red." Sekhar wrote that sentence on whiteboard and asked the student to rewrite that sentence in his own language. Sekhar later told me that he was intrigued by the way the adjective "red" was used after the noun "car." When the student wrote "coche rojo," Sekhar identified the rhetorical choice the student made in English by conforming to the grammatical structure in Spanish, where the adjective "rojo" was used after the noun "coche," hence "car red" instead of "red car." Then he gave an example of how Nepali sentence structure was similar but only in the case of verbs, as he would write "I car rode" instead of "I rode a car." When I asked him what inspired him to adopt those different strategies and how his students could better learn through them, Sekhar replied:

Because I am an immigrant, I can see myself into other immigrants' shoes and see what becomes more effective for my students' learning. What is different with my strategy is that unlike what other native speakers of English teachers do, I am not concerned and limited merely with an accent or pronunciation, but with the use of vocabulary and literacy that my students bring to my class from their previous backgrounds. I have been using English for 35 years, but the bitter reality about my English is that although it is grammatically correct and competent, I have been suffering in the U.S. just because people evaluate my English based on my pronunciation alone, not on what literacy level I bring to it. Also, I don't forget the fact that whatever level of difficulty my immigrant students are facing are the kinds of problems I had to face myself in the beginning of my arrival in the U.S. The native speakers of English teachers here emphasize too much on accent and fluency without any regard for students' other resources. I also understand that language is for communication, and most of the immigrants here are assumed to have 
failed to communicate not because they don't know English but because they don't speak in the accent that most of the native speakers of English consider to be normal and standard.

Sekhar seemed to be mindful of the differences in other languages and helped the learners understand those differences through similar examples and explanations. His references, for example, were instrumental in helping not only Nepali or Spanish speaking students in the class but to those speaking other languages as well to understand the similarities and differences in writing and communication patterns.

Pennycook (2008) underlines the pedagogical significance of translation and activism that help language teaching practices "contest current pedagogical discourses in a number of ways" (p. 44). Seeing language as a translational process, according to him, equips a non-native teacher with the tools to "oppose the many interests and complicities that have supported the use of English and only English in classrooms" (p. 44). Doing so, for Pennycook, will strengthen the teaching of English language not as a native model "in its own presence" but as a vehicle in the traffic of meaning that presents many possibilities for an English language teacher.

However, as discussed in Chapter One, there are few sponsor institutions that recognize and respect such differences in the use of English in order to help learners channel such language resources for meaningful communication. More often, the official literacy sponsors are concerned only with the prescribed regulations in their teaching and learning activities. They are guided by the curricular policies prescribed by the dominant institutions without considering the foundational realities of the people learning them. In my discussion below I offer an example of an ESL class that I observed at the same statesponsored refugee resettlement agency. 
In this class taught by Brad, a native speaker of English who taught ESL classes at the agency, refugee learners were always encouraged to learn the "standard" English in order to be able to find jobs and also get admissions to U.S. schools. The instructor didn't seem to be informed about the varieties of rhetorical structures students brought from their previous countries to the classroom. Nor could he comfortably facilitate the newcomers' learning process by helping them transform their previous knowledge into the new context. When teaching the use of polite structures in English, Brad showed examples that were very formally constructed sentences. In this advanced level ESL class I observed, Brad first wrote several formal sentences for polite requests and asked students to follow the rules when constructing their own sentences. He wanted them to imagine an urgent situation at their workplace and ask their boss whether they could go home earlier on that day. One of the students in class, Mangal, a Bhutanese refugee, made sentences consisting of an imaginary question and its answer (the question was written on board by the instructor): "Can I go home earlier today? I have stomach sick." The instructor outright dismissed the answer by saying that the sentence construction didn't match the particular way he had taught them to make sentences in the last class following the correct request structures. Brad also called Mangal's sentence wrong and wanted the student to follow the standard rules of English sentences. For example, the correct structure he demonstrated to the class by writing on the whiteboard was: "May I go home earlier today ....?" He stressed that the students could follow only the formal ones as given in the example.

Mangal had used the sentence based on his home country rhetorical style. For example, sentence structure in Nepali follows the same "subject-object-verb" pattern as 
Mangal's sentence in English. So, "I have stomach sick" is the Nepali way of saying "I have stomach ache." Even the choice of word "sick" instead of "ache" has Nepali rhetorical inflection that communicates a more appropriate meaning in the conversational tone of Nepali speech context. If the instructor had taken a multilingual and multicultural approach, he could have asked the student to offer an explanation for writing that sentence structure and tried to better understand the context of the difference. Instead of taking a more participatory and situated literacies approach and working from where the students were, the instructor seemed to be quite domineering and dismissive of the difference. As Gee (2000b) observes, situated and sociocultural view of literacy "demands that we see meaning in the world and in texts as situated in learners" experiences, experiences that, if they are to be useful, must give rise to mid-level situated meanings through which learners can recognize and act on the world in specific ways" (p. 204). Taking such a situated and sociocultural approach could have helped the instructor not only to help the students understand the concept better but also utilize this as an opportunity for learning a different rhetorical style from the other part of the globe. Such an opportunity has rarely been utilized in the context of school literacies as an opportunity for teaching and learning cross-cultural and multilingual contexts in multilingual students' writing. The teaching context here also glosses over the fact that most NES employers would have no difficulty understanding "I have stomach sick" despite its deviation from "standard" sentence construction, for the purpose of this class was to mostly familiarize the refugees with the workplace English contexts.

The multilingual teachers like Gokul and Sekhar have contributed significantly to Bhutanese refugees' understanding of cultural, social, and political issues in the new 
context, in addition to helping them learn English. During my observation of ESL classes taught by multilingual teachers, I noted several multilingual and multicultural teaching strategies and patterns that contributed to better learning practices of newly arrived refugees. It might have been not only due to their exposure to multiple cultures and languages but also due to their own experiences of being victims of the monolingual ideology in Bhutan that the multilingual teachers like Gokul and Sekhar might have developed a translingual approach to teaching. Although the monolingual teachers at the resettlement agency may not have those experiences and exposure, they could at least have adopted a translingual and situated literacies approach in order to more effectively help learners like Mangal, for a translingual approach, as Horner, Lu, Royster, and Trimbur (2011) note, "call for more, not less, conscious and critical attention to how writers deploy diction, syntax, and style, as well as form, register, and media” (p. 304, emphasis the writers'). Such an approach further acknowledges that "deviations from dominant expectations need not be errors; that conformity need not be automatically advisable; and that writers' purposes and readers' conventional expectations are neither fixed nor unified" (Horner, Lu, Royster, \& Tribmur, 2011, p. 304).

In the following section, I explain with examples as to how English is taught by adopting narrowly defining cultural contexts that become more restrictive than liberating for the newly arriving learners like refugees in the U.S. The discussions are based on my observations of cultural orientation and job preparation classes offered by one of the refugee resettlement agencies in Panorama City. 


\section{"No Bees, No Honey; No English, No Money": Challenging the Assimilationist Approach}

The way the resettlement agencies groom the newly arrived refugees for learning English and other cultural elements underlying the language helps us see stereotypical images of monolingualism and its reinforcement of American culture through everyday literacy practices offered to the refugees. Based on my observation of most of the sessions offered by sponsors of literacy, especially the refugee resettlement agency and other participant organizations, in the first part of this section I will analyze the assimilationist approach promoted through monolingualism in terms of a politics of assimilation and a politics of language implicit in the resettlement process. In one of the cultural orientation sessions I observed at the refugee resettlement agency, the underlying theme was assimilation. Although the topic of the session was transition, most of the discussion that the presenter focused was on assimilation and learning of English. The speaker, Erika, started her presentation by saying that the refugees' journey to the U.S. was an incomplete one and that it would be complete only with their learning of English and other American ways of life.

The presenter, Erica, in the beginning was able to establish a rapport with the refugee community by sharing her own experiences of working in Africa for some time, and learning new languages and cultures there. She also noted that she had to spend a considerably longer time in the process of adapting to the new contexts. She turned this sympathy into a rhetorical tool to convince the audience that it was only through their integration to the American ways of life that the refugees could be entitled to education, jobs, health, comfort, and safety. She said that English was the only vehicle that could help the refugees make their journey faster and safer. I noticed some kind of pin-drop 
silence in the room when Erika announced this as an eternal truth and continued that this journey for the refugees, therefore, was all about changing themselves. Reminding the refugees of the long struggle and conflict they endured in various locations of migration before they arrived in the U.S., Erika stressed that that the refugees had landed in the U.S. free and safe, it was time for them to learn English and get integrated into "the" American life. Erika seemed more declarative when she ended the session by saying that the refugees were stuck and needed help because they might have their previous cultural and language imprints too heavy to erase from their minds.

What becomes obvious from this observation is that sponsorship of literacy in refugee communities is offered as a unidirectional process of transformation. Wallace and Ewald (2000) challenge this kind of unidirectional assimilationist approach and argue that notions of "assimilation and resistance" should "take on new meaning" within a framework of mutuality (p. 139). They see both concepts as requiring participation and participant agency. Without participation and participant agency as practiced in the assimilation of refugees, the programs like cultural orientations and language teaching to the newly arriving refugees merely contribute to erasing language and cultural traces of the refugees' past in order to force them to adapt to the newly imposed literacy through English than towards helping them negotiate and cultivate their different language and cultural identity in a new home. This kind of assimilationist approach merely focuses on one-way integration of the refugees by enforcing English-only and other American values through orientations, and other trainings offered through sponsorship agencies. Such an assimilationist view emerges out of the consistent efforts for integration of the refugees through various channels of literacy sponsors that stress resettlement measures, ESL 
classes, and other cultural and citizenship orientations for institutional reinforcement of dominant American culture and values without much regard for cultural diversity.

Similarly, in another job preparation class for refugees, offered by the same resettlement agency, the focus was more on learning of "standard" English than understanding the job situations and the process of identifying jobs for the newly arrived refugees. Martin, the instructor, started the class by stressing the importance of English in finding jobs. He began his lecture by writing the phrase on the whiteboard: "NO BEES, NO HONEY: NO ENGLISH, NO MONEY.” Martin then asked the participants what that would mean for them. The participants collectively answered that they could not earn anything unless they learned English.

While the effort of these sessions seemed to help the refugees with their transition to the U.S., the implicit undertone of integration and English-only policy dominated the discourse in a way to shape the newly arrived immigrants to conform to dominant American standards at the cost of their previous resources in terms of language, culture, and other social forces. This view of unidirectional transformation of refugees is informed by the assumption that the education these refugees have received in the various locations in and outside the camps is deficient and hence needs to be purged through English language education in the U.S. Canagarajah (2009) talks about multilingual students' ability to negotiate their linguistic repertoire in a new communicative context to suggest that they do not do so by sacrificing their social, cultural values that are deeply rooted in the language they speak. Instead, as Canagarajah points out, "Students negotiate their different Englishes for intelligibility and effective communication" (p. 5). The goal in this context is to make the multilingual learners' communication effective and 
intelligible. It is with this anticipation that multilingual learners are prepared to offer a different perspective through the practice of negotiation.

Despite their seemingly interactive and inclusive perspectives and strategies to help the refugees succeed in the new place, the agency teachers and workers seemed to inadvertently maintain the monolingualist and monoculturalist ideology in their real practices of teaching and assimilation. In the meantime, I also inferred from my observations and fieldnotes that some of the strategies both monolingual and multilingual teaches practiced in their teaching were not absolute and all-serving. For example, some students in the multilingual teachers' classes talked about their interests in improving their accent and preferred native English speaking teachers to the NNES ones. While these newly arriving refugees liked the fact that the multilingual teachers were more sensitive to their real needs in learning, they also wanted more to be able to succeed in the English-dominated world. Similarly, the NES teachers in the ESL classes did have positive impressions to the learners because of their direct access to the "standard" features of English and cultural capital attached to it. In the meantime, some students in their classes also expressed their frustrations over how the NES teachers could not better understand their prior cultural and rhetorical patterns of learning to effectively help them transition in the new context. These situations in the teaching and learning practices of the refugees at the centers like refugee resettlement agency more vividly reflect on the situated, contradictory, discursive, and emergent context of literacy learning, which can't be defined as fixed, stable, and one-fits-all in nature.

To understand this complex nature of literacy better, I examine the practices that advocate fluid, discursive, and situated contexts in language and literacy practices. Unlike 
what the monolingualist sponsors of literacy believe, "the ideal user of English," as Lu (2006) argues, “ “.. is someone who is not only acutely aware of the pressure to function as an English-only user but also attentive to the capacities, rights, and necessities of change in all living things: people, their lives, society, culture, the world, and the language itself' (p. 608). In order to help these refugees smoothen their transition, we need to first promote their cultural and language practices. To preserve diversity, according to Pennycook (2008), we cannot view English as a stable language - we must "understand diversity outside those very frameworks that are part of the problem" (p. 40). As both Lu and Pennycook point out, it is important to recognize the ability and need for users of English to subject it to change rather than assuming English as a uniform and stable entity. In the meantime, it is also important to see the value in the different perspectives, and knowledges that immigrants bring along with different languages.

Because of their profound experiences about the impacts of constant mobility on their social, cultural, religious, and linguistic lives across various locations of transnational migration, an exploration of everyday literacy practices of the refugees across these locations becomes more useful in the contexts of shifting literate practices of the recent immigrants and refugees. Learning experiences offered through their encounters and participation in cultural gatherings, festive celebrations, rituals, and other religious ceremonies become specifically more meaningful to the refugees than to other recent immigrants because of the former's experiences of exclusion and marginalization in the mainstream discourse by the dominant regimes and elite members of the society. Because the Bhutanese refugees are persecuted for their differences in terms of ethnicity, language, culture, and religious affiliation, any activities that are involved in the 
promotion of these literacy experiences become instrumental in defining their identity as diverse and subject to change. Their participation in these activities is entirely different than that either in Bhutan or in the refugee camps because of the differences in social, cultural, and geopolitical contexts. For example, while their celebration of and participation in these cultural events would be marked by restrictive features as imposed by the Bhutanese regime in Bhutan, in Nepal the refugees simply saw those festive and cultural moments as routine performances because those were also the moments other Nepali communities surrounding the refugee camps would observe. However, those similar cultural and literate activities in Panorama City carried a different significance for the participants because they found it more necessary to stick to their collective cultural endeavors in the new contexts to maintain their distinct cultural and linguistic identity.

However, what becomes intriguing in this context is the tensions the Bhutanese refugees create when performing their identity because, although they claimed those performances to be for the purpose of preserving their cultural and language heritage/identity, I found them to be far different than what they claimed to make of their identitarian practices in Panorama City. By participating in those cultural, social, and religious events as discussed above, the refugees were instead creating an entirely different culture, i.e. Panorama City Bhutanese-Nepalese culture, instead of replicating what they believed to be cultural identity of Bhutanese or Nepali origin, a new translingual and transcultural identity inflected by the culture of Panorama City.

In the first part of this chapter, I analyzed in detail the learning experiences of the Bhutanese refugees at the literacy centers run by several sponsor institutions. The second part of this chapter discusses in detail other literacy activities, which are initiated and 
promoted by the members of the Bhutanese refugee community themselves. The

following discussions offer detailed accounts about such learning experiences in a way to suggest how organization and participation in everyday literacy events in the communities help the Bhutanese refugees enhance their learning practices as well as promote their language and cultural heritage in the U.S.

\section{Music, Arts, and Culture Group (Triveni): Mobility of Cultural Literacy in Imaginary Homelands}

Rich in its connotation of a context and meaning deeply rooted in Sanskrit and Nepali cultures regarding the promotion of cultural heritage, the name Triveni inculcates a useful meaning in the Bhutanese refugees in Panorama City, who have established and run this local community of artists, musicians, and Bhutanese-Nepali cultural ambassadors. The term Triveni in both Sanskrit and Nepali means a confluence of three elements - here arts, literature, and music. In addition to producing a regular program to broadcast twice a month through its own website and other social networking sites, such as YouTube and Facebook, Triveni was established only in October 2013 as a torch bearer of another cultural group that met every week informally at Balgopal's home, hence mediated through this new venue in Panorama City.

Some young enthusiasts among the Bhutanese refugees set up this group first as a cultural group under the initiation of Balgopal with a view to raising awareness across communities about their culture, music, arts, literature, identity, and social recognition. The members of this group are self-motivated people organized to "do something for preserving our cultural and musical heritage and sense of belonging" (personal communication with Balgopal). They used to meet almost every week in a basement, teach and learn music, sing songs, recite poems and ghazals. Doing so, as the 
participants, including Himal, and Dinbandhu, voice together, helps them remember the lost home and heritage through the memorabilia, and other related semiotic practices. In my discussion of reading and writing practices as adopted by this group, I particularly focus on the narratives of two members of this group: Balgopal, and Himal. Born in 1979 in Bhutan, Balgopal has only some memories about his birthplace of playing around the farm, going to primary school, and merrily roaming around the prairies with his siblings. Driven out of his homeland when he was just eleven, Balgopal didn't even understand why his family along with numerous others had to leave their birthplace. He completed the rest of his education in the refugee camps in Nepal, and was a well-known musician and singer around the camps when he was still in high school. He pursued his dream to complete a Bachelor's degree in music from a university in India and started playing music and singing at various programs in and outside of the camps. His popularity catapulted so much so that he released a couple of music albums (especially of bhajans) within six months and started teaching at a local music academy as a music teacher.

When the resettlement process to a third country started, he hardly had any option but to "join the bandwagon and follow the decisions of IOM (International Organization of Migration) to arrive in the U.S" (Balgopal's words). While he spent most of the time working in a local factory located in a Midwest City, Balgopal managed to save some time at the weekend for meeting with his friends, playing music, reading and writing songs, poems, and ghazals ${ }^{11}$.

\footnotetext{
${ }^{11}$ The ghazal is composed of a minimum of five couplets - and typically no more than fifteen - that are structurally, thematically, and emotionally autonomous. Each line of the poem must be of the same length, though meter is not imposed in English. The first couplet introduces a scheme, made up of a rhyme followed by a refrain. Subsequent couplets pick up the same scheme in the second line only, repeating the refrain and rhyming the second line with both lines of the first stanza. The final couplet usually includes the poet's signature, referring to the author in the first or third person, and frequently including the poet's own
} 
Although his family gained financial benefits and enjoyed a better living condition as a result of resettlement in the U.S., like the other families, the emotional toll accrued by such constant movements from place to place became devastating. In response to this deep sense of loss, Balgopal regularly writes songs and ghazals. Balgopal described the need to not only preserve his home culture and national identity in the cultural imaginary but create new sense of belonging and identity in the new context, sometimes by expressing such emotions through writing and sometimes by creating harmonious melodies and crooning them in the "lonely chambers of my musical penance."

This process of putting "words on the rough paper," as shown in the figure above, is a metaphor for the use of literacy as a means of coping with the emotional loss suffered as a result of the forced migration. Balgopal composes poems, lyrics, and music and sings them on several occasions in the cultural programs, social and religious events, and literary gatherings. He has also maintained a blog in his name, which he uses as an online platform for exhibiting his creations and sharing them with his friends and communities across several other social networking sites. The blog compositions as well as the songs, ghazals, and musical compositions Balgopal composes mark his participation as necessarily different from what would have been previous common practice in the tradition he was used to participating in. Balgopal and his friends did not have an easy

name or a derivation of its meaning. Traditionally invoking melancholy, love, longing, and metaphysical questions, ghazals are often sung by Iranian, Indian, and Pakistani musicians. The form has roots in seventh-century Arabia, and gained prominence in the thirteenth- and fourteenth-century thanks to such Persian poets as Rumi and Hafiz. In the eighteenth-century, the ghazal was used by poets writing in Urdu, a mix of the medieval languages of Northern India, including Persian. Among these poets, Ghalib is the recognized master. (retrieved from http://www.poets.org/poetsorg/text/poetic-form-ghazal, on June 29, 2014) 
access to the Internet and other forums for such composition in the past when they were living in Bhutan and in the refugee camps in Nepal. By the same token, by participating in those literacy practices, such as writing poems, composing music, singing cultural and religious songs, with new opportunities and access to new material conditions, Balgopal and the other refugee participants engaged in remaking their culture as they attempted to "preserve" it.

In this handwritten manuscript shown in Figure 3.2, Balgopal has used a folk style of writing in Nepali in order to help all the commonplace readers from his community understand the poem and its spirit of collectiveness and cultural richness. Through this song, Balgopal glorifies the folk life back home in Bhutan and recalls with fondness the

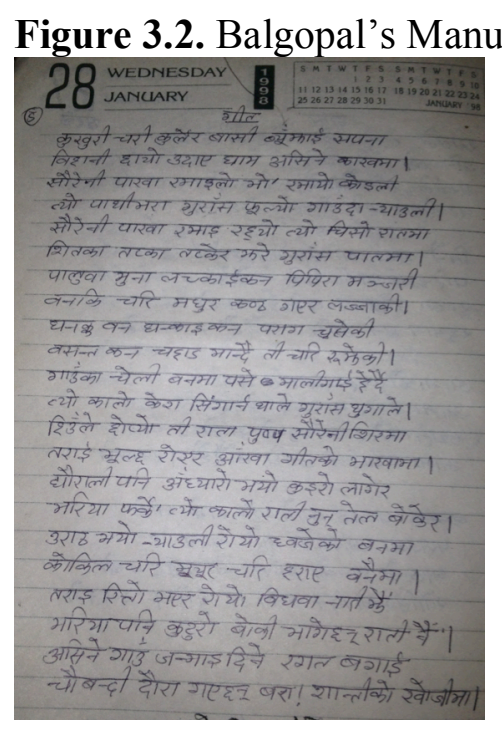
rustic and natural life there. I have translated the last stanza of the song below:

Upset and pale was the Dhwaje forest, and so did weep nyauli

Lost were cuckoo and peacock amidst the vastness of the forest

And wept the Southern plain like a widow, sans its bustling life

With their ragged paraphernalia

The porters shuffled across the borders in the blackness of the night

And Asine village with its blood-smeared façade Disappeared along with Chaubandi and Daura ${ }^{1}$ in search of peace

Balgopal's use of writing in this way mirrors what Vygotsky (1978) describes in terms of the use of psychological tools (p. 55). Writing becomes the tool through which Balgopal makes sense of his world and the experiences he gains "when struggling to live in a distant land from his birthplace" (Balgopal's words). Through the use of symbols, natural 
elements, and animal imagery, this poem reflects on the plight of the southern people in the face of the escalating violence during the democratic movement in the 1990s. Coming a long way facing this plight of "Bhutanization" in the name of language and cultural difference, the Bhutanese refugees in the U.S. underwent sufferings caused by one form of monolingualist ideology (in Bhutan) to another (in the U.S.) as illustrated through the literacy accounts of the participants like Balgopal and others.

Himal, another active member of the cultural group, also wrote about the trials and tribulations of the Bhutanese refugees as they got separated from their own kith and kin during the forced migration. Born in 1984 in Bhutan, Himal hardly remembered anything about this birthplace except glimpses of his home and surrounding farmland. $\mathrm{He}$ completed his high school in the refugee camps in Nepal. Working as an English teacher in a boarding school located in a remote part of Nepal, Himal in the beginning was opposed to the decision of third country resettlement because he thought that he would have to undergo very difficult stages for adjustment in a new place and that he would lose his identity along with the loss of culture, religion, and language. Himal, however, seemed happy about the religious freedom and other open ways of American society as he got more accustomed to the life in the U.S. after his arrival. Yet, he worries that excessive stress on American ways of living in the sense of being pushed to adopt different cultural attitudes and practices and English Only situation in both educational institutions and workplaces in the U.S. will soon inundate his cultural and language values. It is out of such fear that Himal is actively involved in Music and Culture Group regular gatherings and other weekly bhajan/kirtan observances in his apartment community. During his interview, Himal revealed that the activities organized during the 
regular culture and bhajan/kirtan group meetings would help his community better understand the value of their language and culture. He was particularly happy about the ways small school-going children seemed to actively participate in these activities by singing, dancing, and reciting religious songs in Nepali language. In his efforts to "preserve these cultural and language values that they long held dear to them" (Himal's words), Himal kept records of events that he encountered and wrote poems, and short plays about those events in a way to arouse awareness to the community people about their culture, religion, and language.

When I asked him about the reception of his writings and ideas in the community, Himal told me that people had great appreciation for his works. He also laid out his plan to have one short play performed in an upcoming festival of Hindus in November. Himal mostly wrote in Nepali, and based most of his writings on small incidents or events he noted down when at work or other places. He showed me some of his works that he had collected in a small notebook. All of the poems, mostly ghazals, were written in Nepali, and had themes related to culture, identity, love between people separated by migration, plight of refugees in different places, and the natural beauty of Bhutan and Nepal. The first manuscript I collected from Himal is an example of his composing process; he first handwrites his ideas in rough papers, whatever comes in handy when ideas strike in his mind, revises them later, and types them on computer. In the second manuscript he recited to me, Himal talks about the plight of the Bhutanese refugees due to their low status and uncertain future across several locations of their migration. Here is my translation of a small excerpt from a poem composed by Himal:

Leaving behind my soil and culture deeply rooted in it 
Trailing legs to the unknown with uncertain tomorrows

With deeply-felt tensions inside the heart

Like an uprooted radish on the surface

Blanketed with disgrace, I am living an eternal refugee life.

As both Balgopal's and Himal's writings illustrate, literacy learning for the Bhutanese refugees is intimately connected to the experience of migration on several levels. Both Balgopal and Himal maintain rough papers and blogs, whereby they use writing to cope with the loss they so deeply feel. Literacy, for most of the refugees like Balgopal and Himal, is a means by which they navigate their life through the lens of the displaced, persecuted, and lost refugees, struggling to adjust to a new home, which becomes vital to their very existence. Unlike what most multilingual literacy scholars (Norton, 2000; Sarroub, 2005; Cenoz \& Gorter, 2011) have argued for in terms of how literacy works to define people's identity as belonging to particular group or ethnicity, literacy and language practices, as the above discussions show, are always emergent, traveling, and as Garcia (2011) says, "fluid codes framed within social practices" (p. 32). Moreover, such view of literacy as fluid and emergent helps us to see notable distinctions between seemingly purely instrumental understanding of English and literacy as encouraged by the English only teachers the refugees encounter at the resettlement agencies' ESL classes and the concept of literacy and English as promoted by other multilingual teachers like Sekhar and Gokul. The latter's promotion and practice of literacy and learning pits instrumentalism against concerns of social/cultural identity and issues of emotion in problematic ways. In the meantime, it is also equally important to note that in their desires to combat the monolingual/monocultural ideology in the U.S., the refugees also involve in similar kind of Bhutanese-Nepali monolingual and monocultural practices. The difference, however, arises from the fact that the Bhutanese 
refugees' literacy practices are mediated by Panorama City cultures, as they encounter various other languages and cultural practices of many other communities. The practices I've described show that the refugees' identities are translingual, but in their understanding and defense of such identities they seem to be guided by another set of monolingualist ideological beliefs, i.e. Bhutanese-Nepali identity. My analysis of the refugees' translingual and transcultural identity is informed by such contradictory practices of the refugees in a way to show that literacy practices of the refugees are always situated, discursive, and changing along with their encounters with other cultures and language practices in various locations of their migration. The literacy centers like the Elderly Care Center, promoted by multilingual teachers with transcultural and translingual understanding of literacy and English, by contrast, treat all of these concerns related to social/cultural identities and issues of emotion and literacy learning in an integrated way.

The sponsors of literacy may thus become inadvertently complicitous to the dominant ideology of literacy and language if they don't carefully design teaching and other intercultural communication strategies that can help foster ethnic ties in refugee cultures and recognize their resourcefulness underlying multiple languages, and collective efforts at establishing social and financial stability. In the section below, I will further discuss how such literacy institutions function as ideological apparatuses of the State for hegemonizing the literacy practices of the refugees.

\section{Sponsors of Literacy: Schools as Ideological Apparatuses}

Brandt (2001) calls the sponsors of literacy "those agents who support and discourage literacy learning and development as ulterior motives in their own struggles 
for economic or political gain" (p. 26). By the same token, Brandt argues that because sponsorship focuses on broader systems of resources for literacy operating in students' world, schools, as public sponsors of literacy, "might include among their measurements of performance how well they redistribute their considerable material powers and intellectual resources to equalize life chances" (p. 45). In this section, I will include the literacy accounts of some middle-aged participants based on their experiences at the schools in Bhutan as they relate to how the Bhutanese government functioned to curb their learning practices under its radar in a more limiting way.

For most of the participants of this study who had formal schooling in Bhutan, schools functioned as paternalistic Big brothers that supervised the students' daily practices of reading and writing to curb their understanding of educational resources beyond the liminal categories as sanctioned by the State. Althusser's (1994) theory of the ideological state apparatus becomes particularly useful here in examining how the State implicated the education system into channeling its "schooled" citizenry into systemic agents to promote educational and cultural agendas conforming to the State ideology. According to Althusser, ideology is "the expression of the relation between men [sic] and their 'world', that is, the (overdetermined) unity of the real relation and the imagined relation between them and their real conditions of existence" (1994, p. 8). For Althusser, a state exercises power through its apparatuses, violently through repressive forces, such as army, police, courts, and prisons; and ideologically through benign-looking institutions, such as schools, churches, and the mass media. The school assists the state in maintaining and exercising its control implicitly through the education system in an apparently innocuous way. 
The Nepalese students from the south were implicated in the imaginary relation between them and the real conditions of existence in such a way that they unconsciously became the victims of their own oppression. For example, Sekhar, who was born in Bhutan in 1969, and who currently teaches ESL to refugee students at a resettlement agency in the U.S., believes that literacy is not merely about reading and attaining a certificate, it is also about our culture, consciousness and understanding of the world as a citizen aware of one's rights and duties. When the students from the South moved to the North for their middle and high school education, they were supposed to fully integrate to the principles of Buddhist nationhood that was implicitly endorsed by the government through Dzongkha, cultural and social behaviors, and even other Buddhist religious observances. Sekhar sadly spoke about the ideological measures adopted by the school administration to curb the ethnic Nepali students' access to learning Nepali and also observing other Hindu festivals, such as Dashain/Tihar, as the schools never offered them vacations; even if they did, it would be impossible for the Nepalese students to go home to the far South just for celebrating their festivals and religious observances. There were no other cultural and social activities promoted by the school in order to help them preserve their cultural heritage. Sekhar seemed to be fully aware of the aims of the school as ideological state apparatus, but he refused to accept the official state ideology.

In their Introduction to Multilingual Literacies, Martin-Jones and Jones (2000) observe how the acquisition and use of languages and literacies are inevitably bound up with asymmetrical relations of power between ethnolinguistic groups. According to them, the power relations in different settings are rooted in specific historical processes, in the development of a post-colonial order, in international labour migration, in the movement of refugees, in minority rights movements or in global changes of a social and political nature, but in the 
contemporary world, there are broad resonances in the ways in which these power relations are played out in local sites. (Martin-Jones \& Jones, 2000, p. 1)

The Nepalese students from the south were thus disciplined under the power of the state apparatus, i.e. the school. The only recourse the students saw would be to turn to the school library. The library and other community literacy events in the day-to-day contexts offered most of the school goers in Bhutan platforms for gaining knowledge about the outside world and literacy learning in general. However, almost all of the participants who attended high school in Bhutan - Sekhar, Gokul, Jeevan, Nirajan, and Sashi - told me about their experiences on how books and other scholarly publications in the school libraries were all sanctioned and those that were collected in the libraries would be limited to textbooks and other national newspapers published by the State. Despite such control, school libraries also signaled the cultural value of reading beyond classroom reading and assignments. As almost all of these participants recalled, such libraries used to offer them scholarly venues that they could utilize to enhance their literacy learning beyond the limited knowledge provided through the textbooks. Reading "extra supportive books," according to Nirajan, helped him substantially to understand the political and cultural conflicts that they were facing in the face of the raging democratic movement in the south.

Despite the restrictions by the school administration of gatherings of more than two students, the Nepalese students from the south used to gain much of the political and cultural whereabouts through recent news bulletins or government newspapers in the school by secretly informing each other about such news. Also, because of the limited resources in school, teachers used to be other reliable resources of reading materials on 
culture and politics for most of the southern students. For example, Sashi, who was born in southern Bhutan in 1972 and high schooled in northern Bhutan, recalled making frequent visits to his teachers' residences and borrowing books that he thought were instrumental in enhancing his knowledge about literature, culture, and the outside world beyond the borders of Bhutan. Sashi said he still followed that trend in the U.S. in a more spirited way because in either Bhutan or Nepal, the access to resourceful reading materials in the library would be limited due to the limited material conditions and also due to the surveillance of the State (in Bhutan). Following the trends he developed in both Bhutan and Nepal, Sashi mostly collected his sources from several public libraries and prepared his presentation materials during his recent workshop presentation on Himalayan culture and literature organized by a local library in the U.S.

The literacy training of southern students in the northern public schools of Bhutan mainly served to introduce them to the values of the dominant culture, preparing them to think and act as mainstream Bhutanese by adopting the discursive practices of the regime. Moreover, the northern schools also introduced the Southern students to academic resources and skills that encouraged them to study, read, and write in the ways that directly conformed to the principles of Buddhist religious nationhood as envisioned by the State through its enforcement of Driglam Namzha among the ethnic Nepalese in the south. Forceful eviction of the ethnic Nepalese from the south by denationalizing and deterritorializing their identity made them eternal refugees, bereft of the rights of citizenship and belonging. The following section discusses ideas about such desires for belonging and citizenship that the participants showed during interviews, observations, and general conversations in course of this study. 


\section{Literacies for Belongingness and Citizenship}

For many of the Bhutanese refugees interviewed for this study, memories of learning to read and write in Bhutan involved not only schools, books, religious scriptures, and teachers, but also memories of racism, isolation, and outsider status within their own country as non-citizens. The narrative of marginalization and discrimination vs. assimilation still plays out effectively in Harisharan's longing for belonging in the Bhutanese-Nepali diaspora in the U.S. Born in a remote farmhouse in the southern village of Bhutan in 1947, Harisharan didn't have access to any kind of reading and writing at home because of the tiring work at the farm and at school because there was no any school in his village when he was born. He was already twelve when there opened a primary school in his village. However, as he had to work on the farm all day, Harisharan could not join this school. Fortunately, as a literate person in the village, his father taught him Nepali alphabets; later, Harisharan learned to read and write in Nepali on his own. While he was still a farmer, Harisharan also occasionally worked as a subordinate to the Karbari, the village headman. He was a conscious citizen who understood the political movement for democracy. Although he didn't actively participate in the movement, the government army raided his home one October evening in 1990 to arrest him; he luckily survived the raid by hiding inside a grains container. Overnight, he ran away to a bordering city in India through a forest and loitered there for two years before he could join his family in July 1992 to leave for the refugee camps in Nepal.

Harisharan is still very conscious about how language is deeply related to people's identity, culture, and ethnicity at large. However, the way he talked about the identity of his community in relation to language and culture seems to be monolingualist 
in the sense of understanding it as uniform and stable. As a writer to promote Nepali culture and language, he explained to me about his experiences of how the Bhutanese regime tried to uproot Nepali language, culture, and identity by first closing Nepali Pathashalas $^{12}$ in the southern belt of Bhutan, then by imposing Driglam Namzha ${ }^{13}$, and by driving them out of the kingdom ultimately:

The government well knew that once the language was erased, everything would be erased about people's identity, culture, and ethnicity. That was the reason they first started by burning Nepali books in schools and closing Nepali pathashalas in 1989. I will give you an example of how the government would erase everything related to Nepaliness. It may be in the $18^{\text {th }}$ century that the government of Bhutan took for workers some people from Kuch Bihar, India and settled them in Wangdue area, the midwestern part of Bhutan. Then gradually the government imposed their own culture, language and everything the Drukpa ways; now they still live in the area as farmers with everything but their own language and culture. That is exactly what the government wanted to do with the Nepali people in the South by erasing everything Nepali.

Therefore, Harisharan continued, it is necessary to make the world aware of what actually happened to the Bhutanese refugees and why they were living the migratory life like gypsies, moving everywhere but belonging nowhere. With such a sense of responsibility in his mind, Harisharan started to write in Nepali, after his arrival in the refugee camps in Nepal, about his experiences of suffering, desires for home and citizenship, occasionally publishing them in daily newspapers in Nepal. He also released a small booklet from the refugee camps. I collected some of his writings to find that they mostly talked about citizenship issues, cultures, and political awareness about their rights as human beings. In this short poem in Nepali titled "Plight of the Bhutanese People," from his booklet

\footnotetext{
12 Sanskrit word meaning schools for learning Nepali and Sanskrit; there were many Nepali Pathashalas in southern Bhutan until 1988 when the government army closed all of them and stopped the primary school education in Nepali.

${ }^{13}$ The laws for enforcing the spirit of "one nation one people" requiring all the nationals, especially the southerners, to wear Gho and Kira (Bhutanese national dresses), which also forced Nepali women to cut their hair short.
} 
published in 2005, Harisharan expresses his desire for freedom while indicating the plight of the Lhotshampas in the hands of the Bhutanese regime. I've translated below the first part of this poem into English:

The plight of Bhutanese people remained with them forever, Neither could they ever enjoy freedom as citizens; Talk about freedom and the whole of a Bhutan is a prison house, Without any respect for the gentle, the learned, and the elderly, Caste, class, and nepotism prevailed everywhere instead;

The Lhotshampas at service of the nation got deported somewhere else; And the plight remained with them forever.

Harisharan even maintained a blog with the help of his sons and posted his writing and updated the blog when he wrote something new. In the last November, I also helped him type in Nepali one article about a Nepali cultural festival, which was published in a weekly column of a daily newspaper in Nepal. Entitled "Tihar," this writeup, written especially in the context of a Hindu festival, Tihar, mostly discussed the significance of Nepali culture and language in preserving Nepaliness among the Bhutanese refugees in the U.S.

Such a condition of desire and longing for identity compounded by their (mis?)fortune due to uncertain cross-border migration across distant lands in the geopolitics has emerged as a dominant theme in my findings about the literacy learning of the Bhutanese refugees in the U.S. In the present globalized context, the condition of border crossing, as Giroux (2005) writes, not only invokes

those borders that confine experience and limit the politics of crossing diverse geographical, social, cultural, economic, and political borders, it also calls for new ways to forge a public pedagogy capable of connecting the local and the global, the economic sphere and cultural politics, as well as public and higher education and the pressing social demands of the larger society. (Giroux, 2005, p. 6) 
Nirajan, a literacy worker who is actively involved in the Bhutanese refugee community in Panorama City for promoting language and cultural resources of the refugees, highlighted the need to connect the local with the global in a way to develop a harmonious relationship among various diverse communities as well as between students and academic institutions in the City. Currently working in a local public library, Nirajan mostly contributed as a liaison between the Bhutanese community and the world outside in order to help the latter understand about Bhutanese culture, language, and identity of the people coming from a reclusive South Asian country. Born in 1972 in the southwestern farming area of Bhutan, Nirajan was still in high school when the democratic movement started in 1990. Living on school in the northwestern part of Bhutan, Nirajan was a bright student entrusted with a responsibility to edit and publish a high school student wall magazine written in all three languages: English, Dzongkha, and Nepali. Well-versed in all of these three languages, Nirajan was well loved and respected in the school community for his brilliance, hard work, and perseverance. However, this warm regard couldn't last for long when the school authority started to keep a close eye on all the Nepalese students in the school long before the movement in the south started. It was in 1989 that the school authority asked them to stop the publication of the magazine in Nepali and continue to publish it only in Dzongkha and English. Nirajan explained to me the overall milieu of the school and its Panoptican surveillance against the Nepalese students from the Southern Bhutan:

It was a suffocating atmosphere on school for Nepali students. This was the time when the movement leader Tek Nath Rijal was arrested and the people in the South were agitated against the regime's forceful imposition of Driglam Namzha and the injustices put upon Nepalese population in the South by the 1988 Census. Even the cultural artifact like Lahure, a Nepali film, was banned in Bhutan just because it was in Nepali language and 
endorsed a message about the significance of Nepali cultural heritage to a larger Nepali community in the world.

The agitating people's voice would be mostly reflected only in Nepali literature, so whatever was written in Nepali and whatever circulated through the south would be strictly supervised and sanctioned by the school authority before it was passed to the Nepalese students. The language that connected students from all over Bhutan and that was also formally the language of instruction for other subjects except Dzongkha was English. When the process of "Bhutanization" started in 1988 along with the imposition of Driglam Namzha, all the ethnic Nepalese people were deprived of their language, dress, and cultural celebrations both inside schools and outside in the Nepali communities in the South, forcing Nirajan to flee the country after a severe persecution of the army started in his own village.

When he arrived in Nepal, Nirajan first completed his high school and actively participated in promoting Nepali language and literature by helping to form the Nepali Language Council in coordination with other community learning centers in the refugee camps. Together, these organizations helped a larger number of adults learn to read and write in Nepali as well as in English, and Nirajan became a part of this literacy movement in the refugee camps. More important to the learners, as Nirajan recalled, was an opportunity for many adults to learn to read literary and religious texts that raised their awareness about the political situation and their rights and deprivations as Bhutanese citizens. These literacy activities also provided opportunities for housewives and middleaged people in the camps to connect themselves to the larger world socially, politically, culturally, and economically, as they became more capable of controlling their lives and taking ownership about their practices. Primarily attracted to writing for freely expressing 
his own ideas about the conditions of the Bhutanese refugees in Nepal, Nirajan started to write and publish mostly in daily and weekly English newspapers about these issues when he was a bachelor's student. Such regular writings led to their start of an online news portal that regularly publishes articles, stories, and reports about the Bhutanese refugees and their activities around the world. Nirajan is still working as an active executive member of this Bhutanese news online portal.

As a writer and community worker, Mahesh told me that he wanted to preserve the spirit of nationhood through memorabilia and metonymic relations to the country and people of Bhutan. Born in Samchi, Bhutan in 1981, Mahesh spent his childhood in a rural farmland. He went to a primary school in a nearby village by walking every day for two hours on foot for four years and completed his $5^{\text {th }}$ grade in Sengten, Dorkha, in the northern part of Bhutan. He recalled a poem he wrote in English entitled "Take Us Forward" when he was in $6^{\text {th }}$ grade in the refugee camps in Nepal. It was about the pangs of non-belongingness and feelings of sadness for being deprived of nationhood and citizenship and called for a progressive initiation to take the refugees home. Having three published books (one collection of essays, next a collection of literary criticisms on Nepali literature, and the other a collection of short poems) and some other articles in Nepali to his credit, Mahesh said that writing in Nepali made him feel more expressive and vocal, and doing so would bring his ideas forth naturally. While he also writes occasionally in English and says that he loves English literature too, Mahesh's understanding of his mother tongue, Nepali, as being more natural than others is also aligned with monolingualism and the notion of one "mother tongue" for each group. In a collection of essays, which he published in Nepal right before his departure to the U.S. in 
2013, Mahesh has written extensively about love for his birth country. In one of the

poems dedicated to his birth land, Mahesh writes:

In case I perish in a distant unknown land,

I wish I could have a handful of soil from my birth land

That my friends could offer my burning pyre;

So even if I lost everything, my soul would join my own soil

Or my soul would linger in the purgatory, soilless for ever.

(my translation of an excerpt from his creation entitled "A Keepsake of Soil")

As expressed in most of his writings, Mahesh still believes that Bhutanese people's struggle for social justice has not finished yet; their

Figure 3.3. Mahesh's Poem

\footnotetext{
Living the Days of Robinson Crusoe

The brown, the dark, the one with Zebra

Stripes

-these cats, the stray cats-I give the name

wild cats

They come to greet me, outside the door

Whenever I come out of apartment

They would wait my arrival for welcome

back

I like them, I would embrace them but I

cannot

They run- in the winter snow or chill

My friends, my neighbors in the solitude-

Don't fear, I have love but I cannot take you

inside either

My daughter-she wants some friends

O cats! don't run-

But when I take near, she fears, so the cats

My daughter-she wants some friends

$O$ birds! don't run-

But when she runs to hold them, they fly off-

I see birds- I don't know the names

I See trees- I don't know the names

I see people- I cannot talk to them

Many things-undefined and segregated

I live solitude in the multitude-

No people, no tress, no roads, no bushes-

familiar
}

resettlement is only a temporary one, and is very

different from that of other recent immigrants,

who are voluntary migrants. Unlike those

migrants, as refugees, they have sacrificed

much of their social relations, political

movement, religious and cultural values,

attempting to define themselves in terms of

political, religious, cultural values as

Bhutanese-Nepalese. Such a definition helps

the refugees challenge the notion of an

imagined nationhood beyond their reach. Such

imagined nationhood, according to Malkki

(1995), tends to externalize refugees

ideologically, whereby refugee identity is

established without any regard for "the ever-growing scale and frequency of violent mass 
displacement, routine measures of the de facto sealing of borders, the criminalization of migrant labor and foreignness, and reactionary rhetorics of indigenousness and so-called just principles of exclusion," which, unfortunately, "are the contemporary phenomena that are creating vast, important fields for new political, scholarly engagements and for well-thought-out subversions of the national order of things" (p. 512).

In addition to such exclusion on the level of citizenship and nationhood, refugees are also ideologically excluded from the academic domains. For example, Mahesh regretted that despite his academic achievements and scholarly experiences abroad, his master's degree in economics had no value in the U.S. at all unless he could receive a degree from here:

I was a lecturer in a university back in Nepal, but the value of my education here in the U.S. is zero, and I merely become a laborer, a factory worker. I am so frustrated that we refugees are never recognized based on our language and academic skills. One of such many examples, I will tell you, is about a hospital official's treatment to me recently when I took my daughter for a check up. I could easily understand what the nurse told me and was able to answer her questions in English. However, she called for an interpreter saying that she couldn't understand me at all. I have been speaking English for 25 years, and all of a sudden I am treated like an illiterate.

Mahesh also showed to me a poem he composed in English after this experience in the hospital. I have included the poem he showed to me in Figure 3.3. In this short poem, Mahesh talks about how he would rather be friendlier with birds, animals, and other natural elements, which could at least understand his language and empathize with him. He compares his and several other refugees' life with stray cats and other natural elements that seem to belong everywhere, but, in reality, have nowhere as their own. Such feelings of loneliness and non-belongingness have inspired most of Mahesh's writings in both Nepali and English. In addition to their status as refugees, Bhutanese 
communities in the U.S. are mostly looked at through the lens of what Ong (2003) calls "American 'orientalism'," which, in turn, "has also influenced concepts of belonging" (p. 72). In the mean time, despite news accounts and

Figure 3.4. Balgopal's Ghazal in Nepali माटो संग प्रीति बस्यो भुल्न पनि सकिएन। जन्मभूमि बिर्सिएर खुल्न पनि सकिएन।।

स्वभिमानी गोर्खालीको जात मात्रै भयो मेरो। गर्व गर्दे गोर्खे भनी फूल्न पनि सकिएन।।

काला गोरा लेटिनो र फेलिपिनो हरु संग। स्वाभावैले गर्दा मिल्न जुल्न पनि सकिएन।।

बिलासिमा साथीहरू अभावको गाँस बिर्सी। रक्सिएर सबै सामु झुल्न पनि सकिएन।। ethnographic studies on literacy practices of the refugees in the U.S., little scholarly attention has been paid to their experiences of displacement, regulation, and resettlement abroad before their arrival in the U.S.

Almost all of Balgopal's ghazals, songs, and poems are fraught with the pangs of living refugee life in a distant land with such experiences of displacement and persecution, "migrating from one place to another like a domestic cat transferring its kittens from one habitat to the other." ${ }^{, 14}$ Born in Geleyphug, Bhutan in 1981, Balgopal preferred to call himself a Nepali musician and writer despite his bachelor's degrees in music and English. He completed a Bachelor of Music from an Indian university and Bachelor of Arts in English from Nepal. He became politically conscious and active and wanted to raise political awareness among the Bhutanese refugees through music, arts, and literature. With this view in mind, Balgopal not only organized regular weekly gatherings for the promotion of music, arts and literature, but also started a concerted organization called Triveni (a Nepali term meaning confluence) for the promotion of three genres in Nepali: Music, Arts, and Literature. Advocating for a deep awareness about ethnic identity as Bhutanese-Nepalis in the U.S., Balgopal wrote a

\footnotetext{
14 This expression by Balgopal is based on a typical Nepali saying that refers to the way a village cat, which belongs not only to a single house but to the whole village, keeps on moving from place to place, carrying its kittens by its mouth to several places, being everywhere but belonging nowhere.
} 
poem about how he couldn't easily assimilate into the melting pot by losing his transnational and transcultural identity. I've translated the original Nepali poem (see Figure 3.4) as follows:

I could hardly forget the soil so deeply in love with it as I was

Neither could I sprout open by being oblivious to my birth land

Sovereign became merely a moniker to my Gorkhali ethnicity

Neither could I bloom with pride as a Gurkha

Amidst multiple colors - black, white, latino, and filipino

Neither could I assimilate with my color difference intact

With luxury as a dream and compatriots trailing to live

Neither could I stun with inebriation in front of all.

All of the participants I discussed in the section above - Balgopal, Himal, Mahesh, Harisharan, Nirajan - engage in writing and publishing their articles, poems, and ghazals across forums, both print and online. Despite these participants' differences in terms of age, political, cultural, and religious orientations, whatever they write has common goals: to promote Bhutanese Nepali culture, language, and politics in a way to help them establish their identity in the U.S. and help spread their voices across communities so that they get recognized for their efforts to accommodate in the new place. What is manifest from these discussions about the Bhutanese refugees' reading and writing practices across various modes and forums is that they have been mostly under an impression of the imagined nationhood based on their own cultural, linguistic, and religious identity. On the one hand, this notion of collective Bhutanese/Nepali nationhood remains as something imagined in their minds, hence as a fixed and stable kind of identity that they seek to reinforce in their cultural imaginary; on the other hand, their knowledge and learning practices are deeply shaped by their migration to the refugee 
camps in Nepal and in the U.S., where they come across shifting practices of identity guided more by transborder and transcultural encounters than by their seemingly monocultural practices, hence transnational, translingual, and transcultural identities shaping and being shaped by their daily practices and encounters with other cultures and languages in the new contexts.

In my discussion thus far I have mainly focused on the practices of reading and writing among the Bhutanese refugees by selecting participants across various literacy centers and community organizations in Panorama City. In the discussion below, I explore learning practices of the community members as regards to their intra-community distinctions based on class, caste, religious orientation, and status inside and outside the refugee community.

\section{Intra-community Dynamics: Outsiders within}

In his analysis of Chinese diasporic communities in the U.S., Dirlik (2002) raises important points about the multiplicity of situations within the same diasporic population or between different diasporic communities, differences based on economic status, gender, educational level, political affiliation, and social position in the new land. Pointing out the need for reconfiguration of migrant societies and their political and cultural orientations in terms of diaspora and transnationality, Dirlik suggests that "diaspora and transnationality as concepts also are discursive or, perhaps more appropriately, imaginary; not only do they have normative implications, but they also articulate - in a very Foucauldian sense - relations of power within populations so depicted, as well as in their relationship to societies of origin and arrival" (Dirlik, 2002, p. 94). Warning against the general tendency in ethnographic and diasporic studies to 
affirm the cultural identity of a particular diaspora based on the origin of their nationality and cultural orientations, Dirlik (2002) writes:

The anti-assimilationist mood (expressed most fervently in liberal "multiculturalism") itself has contributed in no small measure to such cultural reification by a metonymic reduction of the culture of the Other to "representative" ethnographic elements or texts divorced from all social and historical context that may then serve purposes of self-representation by the diasporic population or self-congratulatory consumption in the carnivals of the society at large. (p. 97)

In a different study on Chinese diaspora, Ong and Nonini (1997), showing some similarities in the diasporic experiences of African diaspora and Chinese diaspora in the U.S., observe that "they [Chinese diaspora] face many directions at once - toward China, other Asian countries, and the West - with multiple perspectives on modernities, perspectives often gained at great cost through their passage via itineraries marked by sojourning, absence, nostalgia, and at times exile and loss" (Ong \& Nonini, 1997, p. 12). What runs into problems with their generalization of diasporic experiences as uniform though is that they lose sight of the social and political complexities deeply embedded in the intra-community differences, paving the way for new forms of domination and commodification from both within and outside the diasporic community. Such a reification of diaspora, furthermore, helps blur the differences. In his account of ethnoscapes, Appadurai (1996) points out such problems caused by domination or reification:

the central paradox of ethnic politics in today's world is that primordial (whether of language or skin color or neighborhood or kinship) have become globalized. That is, sentiments whose greatest force is their ability to ignite intimacy into a political sentiment and turn locality into a staging ground for identity, have become spread over vast and irregular spaces as groups move, yet stay linked to one another through sophisticated media capabilities. This is not to deny that such primordia are often the product of invented traditions or retrospective affiliations, but to emphasize that 
because of the disjunctive and unstable interaction of commerce, media, national policies and consumer fantasies, ethnicity, once a genie contained in the bottle of some sort of locality (however large), has now become a global force. (p. 41)

A close analysis of the diasporic identity of the Bhutanese refugees helps us deconstruct the claims to national cultural homogeneity in the face of proliferating transnational migration of peoples. The apparent homogenous collectivities that general discourse on refugees and recent immigrants underlines inadvertently covers up the differences between the well-placed social elite and ethnically marginalized and members of the same ethnicity further incapacitated by their class, caste, and gender locations, further confounding the identity of culturally dispossessed with the culturally privileged, who travel with ease across cultural spaces.

In my discussion below, I explore literacy practices of three marginalized members within the Bhutanese refugees to see how intra-community differences play into the cultural imaginary of society at large regarding the construction of identity across marginalized domains, such as caste, class, gender, and religious orientation. Although there are numerous such participants to offer such differences from among those I have interviewed for this study, I particularly include three representative literacy accounts of these participants in order to examine the existing intra-community heterogeneity within the Bhutanese refugee community. Moreover, these participants also represent three different subject positions within the Bhutanese refugee community based on differences in terms of caste, class, ethnicity, and religion.

Born in Chirang District, Bhutan in 1968, Ramila was raised in a Dalit family in a remote farm. When I asked her whether she went to school, Ramila replied: 
I had a very difficult life as a child growing up in a remote village of Bhutan. When my brothers went to school, I had to take care of my younger siblings at home; I cried a lot asking my parents to send me to school too, but with no avail.

As a daughter born in a Dalit family, Ramila was doubly victimized, first because of her status as a daughter and second because of her being a Dalit girl; there was no question about her family sending her to school. Ramila deeply deplored this traditional mindset of the society that treated similar human beings so differently. It was only in the adult literacy classes in the refugee camps in Nepal that she got a chance to read and write in Nepali and also learn English alphabets. In her twenty-year stay in the refugee camps in Nepal, Ramila underwent a drastic progress in terms of literacy learning, which was not limited to reading and writing skills but also expanded to social, cultural, and religious consciousness, helping to uplift her living and literacy conditions. As she was able to read the Hindu scriptures and critically examine the painfully discriminatory attitudes the upper-caste people promoted based on those old scriptures against the lower-caste people in her community, Ramila was frustrated with Hinduism and decided to convert to Christianity when she was still in the refugee camps in Nepal. Ramila credited her rebellious nature against the caste-based discrimination, Christian literacy and social consciousness encouraged by it for leading her position from an oppressed Dalit woman to a Deputy-Secretary of the camp. Although she had to face constant challenges and oppositions from her community people, especially from the dominant class and caste, when working as a leading social worker in the camps, she fought against all sorts of injustice and discrimination and maintained her position in the camps until she left for the U.S. in 2011. 
Currently living with her husband and two college-attending children in Panorama City, Ramila worked as an active social worker and organizer of weekly gatherings at a local Nepali church. I observed Ramila and other Bhutanese Christian participants several times in their weekly evening Sewa gatherings at their homes and also church congregation several Sundays. Ramila actively participated in those meetings and offered to sing psalms and deliver speeches based on the Bible, which is translated into Nepali. She mostly prepared her speeches by first taking down notes from the Bible and later writing the whole script in Nepali. Ramila acknowledges that Christian literacy has helped her improve her living and learning conditions in the U.S. She could have never moved beyond the limits of a housewife and uplifted her life in the U.S. had it not been for her religion. Ramila argued that because of her contact with churches and other local native speakers of English through them, she could learn so much about communication skills and ways to live a better life in the new context. She could perhaps never enjoy this freedom if she was not a Christian. She also credited Christianity for discarding any kind of discrimination based on caste and cultural difference.

In addition to actively participating in almost all of the church community events, Ramila was currently working in a local food-packaging company. She told me that she had a good working relationship with her coworkers and supervisors and that she had no problem communicating with them in English. She went to ESL classes run by the resettlement agency for a couple of months in the beginning and learned some basic communication skills in English that she said she could polish further during her regular church visits and also at her work by conversing with her English-speaking churchgoers and coworkers. 
In contrast to the story of success after a long and trailing struggle of Ramila as a Dalit woman is the story of challenges faced by a nearly the same aged upper-caste man from the same community. Dinbandu was raised in a well-to-do upper-caste farmer's family in a remote part of Bhutan. When he (born in 1965 in Sarbhang District, Bhutan) arrived in the U.S. in 2010, Dinbandhu didn't have any idea about how to communicate with people in English. What he had learned as a child in Bhutan was only sufficient to read and write in Nepali. Despite his primary school literacy in English in Bhutan, he had never used English for the purpose of writing and communicating with others, as he could mostly get by with Nepali in both Bhutan and Nepal. Dinbandhu recalled his childhood as one of the hardest because of his location in probably one of the remotest parts of Bhutan, from where he had to walk a whole day to reach the nearest school. He remembered his primary schooling thus:

I was already 12 when I first stepped into a school and saw the face of a school. I went to that far away school as a residential student staying with students from other remote areas. Although my father had taught me to write Nepali alphabets by holding my fingers on the leveled dust on the floor with the help of Vernamala, I knew nothing about English and Dzongkha before I got admitted to the primary school.

When I asked Dinbandhu what he remembered about his first experiences of reading and writing, he replied:

I especially remember my Dzongkha learning; as I had not any background, I struggled a lot learning this language in school. The Lopen (Dzongkha teacher) was so strict and irascible that he played his tantrums any time we could not deliver the lessons in Dzongkha as exactly as he taught them. Once he asked me to stick out my tongue and brandished the elastic rubber of a slingshot in my mouth, crushing my tongue badly. I couldn't pass this subject later and had to transfer my admissions to another school. 
After he completed his primary schooling from another school closer to his home, Dinbandhu started working in a local health post office as a compounder. He continued this government job until he was arrested on October 25, 1990 for his alleged participation in the Democratic Movement and his "crime in forgetting to wear bakkhu (Nepali term for national dress of Bhutan) during his brief visit to a local Dzongh" (Dinbandhu's description about his allegation). He was kept in prison for seven years until April 1997, when he was released. He left Bhutan for the refugee camps in Nepal only in 1999 when he got inkling from one of his confidants in the government that he was warranted for a re-arrest with an allegation that he was politically active among the ethnic Nepali community in Bhutan.

During his eleven-year stay in the refugee camps in Nepal, Dinbandhu could do little to improve his level of education because of the hardships related to refugee life; instead he worked in a local boarding school for several years to support the education of his children. When recalling the beginning days in the U.S., Dinbandhu told me that he suffered a great deal due to the lack of English language skills and other cultural conflicts everywhere he went. He even became a victim of depression for some time; with the help of some of his friends in the community when he started working at a local supplier of electronic goods, he started to adjust in the working community. Dinbandhu said that he also learned English significantly by practicing at home and at the workplace. This helped him a lot in his communication at the workplace; gradually, he felt better about his life. Despite this apparent improvement, Dinbandhu said that he was just trailing for survival in the U.S. and was still in the phase of struggle for adjustment. 
Similarly trailing but in distinct ways from that of both Ramila and Dinbandhu is the story of Mukti. "When others translated for me into English what I spoke in Nepali, I felt like losing my voice. Others spoke for me; although I enjoyed the fact that I could speak in Nepali, I felt helpless not being able to communicate directly my ideas to the officials in the government office and doctors in the hospital," said Mukti, recalling his experiences in the beginning days of his arrival in the U.S. Mukti had a hard time in the beginning to adjust in a new place, mostly because of language issues and partly because of the cultural conflicts. Born in Sharbhang District, Bhutan in 1977, Mukti had to leave his country before he could complete his primary schooling due to the Democratic Movement in the early 1990s. Despite various language and culture-related challenges in the beginning days of his arrival in the U.S., his middle school education in the refugee camps in Nepal helped him somehow get by in the U.S. As I observed several church gatherings and other religious meetings that Mukti attended, I noticed that Mukti could make preparations for his speech and songs during those meeting by first taking down notes in his notebooks, and then preparing bulleted points for this presentations. When preparing for such presentations, he first took notes in Nepali and then translated them into English in a way to "make it understandable to the non-Nepali speakers in the gathering, although I can't make it in a good English.”

Although he regretfully acknowledged that he couldn't continue his education in the refugee camps beyond the middle school due to several family obligations and poor conditions of living, Mukti was proud that he developed necessary communication skills as he started to intermingle with this church-goer friends and other colleagues in the workplace. He sharpened his reading and writing skills further when he became a regular 
churchgoer and Bible reader during his initial days in the U.S. Mukti related to me a family history about their religious affiliation. As a family belonging to an indigenous animistic religion called Kirat, they mostly followed the principles of Kirat until much later when they were in the refugee camps in Nepal. Although considered to be a branch of Hinduism, the observers of Kirat followed their own rituals and observed festive ceremonies in specific ways entirely different from those followed by the Hindus.

Mukti left Kirat for Christianity while in the refugee camps in Nepal when he became dissuaded and disillusioned by the sacrificial ritual of the former, as it sacrificed animals for appeasing the spirits of the gods. He was more attracted by the opportunity to sing psalms and pursue a religion that didn't believe in sacrificing animals to appease the supreme power. He said that after a continued effort and persistence in learning English at ESL classes and church gatherings, he could now work not only as a presenter and speaker at the mass gatherings but also as a translator and interpreter.

Mukti felt proud that despite his middle school education due to the bad material conditions in the refugee camps, he could now adjust in the new context by learning English, finding a job on his own, and communicating in both Nepali and English with his church compatriots. Mukti became equally conscious about the need to preserve his native language, Nepali, and his distinct identity as Bhutanese Nepali. While he talked about preserving Nepali as his mother tongue, Mukti also stressed other languages, such as English and Spanish, to be essential for his kids to learn. Although he could not learn more than two, Nepali, and English (which he said he was just literate with), he wanted to teach his children as many languages as they could come to terms with. Such attitudes that Mukti carried about language learning are indicative of his translingual dispositions 
toward literacy learning, whereby he didn't fetishize any one of the languages that he wanted his kids to learn. Whatever he practiced during his preparations for church gatherings and evening services also said much about his own practices of translingual identity as a refugee, for he mostly wrote his songs and lecture notes in Nepali and also translated them into English to get a sense of how they would sound and feel in a different language and how he could communicate with his English-speaking friends in the community. Mukti spent at least two hours every Saturday teaching Nepali to his children. Although he became optimistic about his future in the U.S., Mukti was also aware of the hardships and challenges his family had to face inside the community as well as outside at the workplace, due to his identity as a non-Hindu individual from an indigenous group within his refugee community, and due to limited skills in English at the workplace.

With their different cultural, gendered, and caste-based subject positions in the Bhutanese refugee community, Ramila, Dinbandhu, and Mukti led completely different lives, had distinctive educational experiences in the process of learning, and had different experiences of struggle for survival, although they all belonged to the same community. General assumptions about the equivalency between privileged caste/class-based positonality and success get challenged and interrogated in the context of transnational migration and geopolitical relations. The experiences of the differences within the Bhutanese refugees like that of Ramila, Dinbandhu, and Mukti make them Other within their own community, necessitating an imaginary affinity with the society of their origin. Regardless of their widely different cultural and social trajectories internally, the people like Ramila and Dinbandhu are expected to "bridge the gap between places of arrival and 
places of origin by presumed cultural legacies that are more imagined than real" (Dirlik, 2002, p. 100), resulting in the cultural rehomogenization of Bhutaneseness. However, the tides of such differences are rising up higher in recent times in both Bhutanese refugees and other diasporic Nepalese communities because the recent pro-constitutional movements in Nepal based on caste, religion, language, and political rights of the indigenous communities have deep implications to these Nepalese and Bhutanese refugee communities across various diasporic locations in the world.

This chapter calls into question the ordinary treatments of diasporic peoples and identities of the people as either Bhutanese or Nepalese to argue that through their engagement in literacy practices in the new contexts, the Bhutanese refugees create a conglomerate of fluid and emergent translingual and transcultural identities rather than simply reproduce either an essentialist version of their prior cultural identity as Bhutanese Nepalis or replicate a different version of it by imitating the U.S. culture. Instead, the Bhutanese refugees, as illustrated throughout this chapter, exercise an agency over their literacy practices in a way to suggest that their creations, compositions, and literacy events are all shifting and shaping along with their encounters with language and cultural practices in the context of transborder migration and geopolitical relations. 


\section{CHAPTER IV}

\section{GLOBALLY DIGITAL, DIGITALLY GLOBAL: MULTILINGUAL AND MULTIMODAL LITERACIES IN THE MAKING}

The greatest challenge of studying new media in the context of transnational family relationships is that the technologies themselves are constantly changing and research often seems to be chasing a moving target of technological developments and innovative appropriations on the part of the users.

(Mirca Madianou \& Daniel Miller, 2012)

I usually write in both Nepali and English, and have also been running an online forum for discussing cultural and academic issues among a younger generation of Bhutanese refugees in the US. However, when I write for my classes in college, the professors always penalize my grades saying that I write in a different English, and that my grammar is bad. I don't know what that means, but I sometimes feel frustrated and worry that I can't succeed academically. -Bijaya, born in

1990 in Bhutan

I have only a different accent, but I still believe that I speak a good English. However, every time I spoke either in class or outside, my middle school friends made a laughingstock of me. They tried to imitate my speech disparagingly. They didn't only make fun of me but also bullied me all the time just because I came from a different culture and spoke with an accent. The teachers didn't help me either. There were not many non-native speakers of English in the school until then, so the teachers probably weren't prepared how to deal with the students like me. Then I decided to stay shut all the time both inside and outside the class so nobody could make fun of me. -Priya, born in 1995 in

Nepal

\section{Introduction}

These vignettes from Bhutanese refugee students in Panorama City suggest the complex ways in which refugee families and communities negotiate uses of and cultivate 
competence in both languages of the resettled society and that of their cultural inheritance. Such negotiations on their part enable these refugee youth to foster valuable knowledge across generations by engaging in academic practices in U.S. schools, involving them in economic activities within the new territory, maintaining religious affiliations and identities, and participating in communal activities and activism to improve the conditions of their families and communities. Digital literacies have eased this process of integration and knowledge-making in diasporic landscapes by helping the refugees form part of a community that is characterized by recognition of the importance of social relations and differences dependent on new geopolitical and transnational relations.

The individuals from the Bhutanese refugee community transcend and reframe ordinary social and cultural life by recourse to new technologies, refiguring and transforming their social, cultural, and linguistic lives in the new context. They also appropriate new media for the purpose of both learning and pleasure, for "where there is consumption, there is pleasure, and where there is pleasure, there is agency" (Appadurai, 1996, p. 7). Similarly, as suggested by some prominent multilingual/digital literacy scholars, the Bhutanese refugees' participation in social and digital contexts fostered multilingual and multicultural competencies to manage shifting networks of relationships in the globalized and digitized contexts of learning (Lam, 2006; Jayakumar, 2008), going beyond structural diversity, which, otherwise, leads to "racial balkanization when an institution fails to foster a positive racial climate" (Jayakumar, 2008, p. 641). The literate activities that the Bhutanese refugees involved in provided access not only into multimodal and multilingual literacy practices but also insight into their cultural and 
social worlds. While this chapter adds to emerging research on refugee communities' multimodal and multilingual literacy practices by focusing on intergenerational learning practices outside and inside school contexts as well as across transnational spaces, it, in the meantime, extends beyond these research contexts by moving the study outside fixed learning locales (e.g., classrooms, literacy centers), indicating their possible overlaps in Third Spaces (Bhabha, 1994) that account for the learning experiences of the immigrants as shaped by postcolonial migration and geopolitical relations.

In this chapter, I focus attention on the multilingual and multimodal literacy practices of the Bhutanese refugees across generations - elderly and middle-aged on the one hand, and school and college going adults on the other - in the U.S. by specifically exploring the following questions: When growing up in transnational territories marked by global electronic mediations, what kinds of literacies do the Bhutanese refugees develop to engage with such global and digital conditions of their transborder movement? How are these digital and multilingual literacy practices shaped by cultural, social, political, linguistic, economic, and religious landscapes they inhabit in a way to establish relationships with families, friends, and communities with whom the individuals of this community associate? I discuss the ways in which the refugees negotiate their differences in terms of language and culture in order to enhance their learning practices in the U.S.

While multilingual literacy in the context of this study means any learning experiences of the participants in multiple languages across several locations of their migration, multimodal literacy attends to multiple modes of learning, whereby such modes create "meaning as it is made through the situated configurations across image, gesture, gaze, body posture, sound, writing, music, speech" (Jewitt, 2008, p. 242). 
Drawing on the New London Group (1996), I use "multimodal" in this chapter to indicate the range of modalities - printed words, still and moving images, sound, music, speech, and color - that users combine as they create and design texts. Instead of being limited to any one mode of communication, multimodal literacy in this chapter refers to multiple technologies of communication that the Bhutanese refugees in the U.S. use for learning as well as for maintaining their transnational affiliations. Their engagement in specific multilingual and multimodal literate practices helps the participants challenge deficit discourses about immigrant refugees in several ways. Based on their experiences of speaking more than one language, most of my participants, as discussed in Chapter 2, are multilingual, so I refer to their language identity as multilingual or translingual based on the theoretical concepts developed in both Chapters 1 and 3.

In the first part of this chapter, I mostly focus on refugee youth and their use of multimodal resources for the purpose of learning at home as well as at school. In their use of such resources, these youth shuttle between their home cultural practices and schooled literacy practices in the process of learning, collapsing the boundaries between schooled and unschooled sets of learning experiences. Instead of organizing this chapter by responses from each generation group, I will discuss them together as they fit the larger overarching theme.

In the first part, as I discuss the youth's transition from their home literacy contexts to the U.S. academic settings, I particularly analyze two main findings: First, as they write in the U.S. schools using English mostly inflected by their home culture rhetorical structures, the refugee students feel that they are penalized for their "different English"; and second, they have started to take recourse to the use of specific multimodal 
forms of composing because such forms have helped these students showcase their multilingual and multicultural repertoires in order to develop $21^{\text {st }}$-century skills as well as academic identity.

Instead of including a separate section for the introduction of the participants that appear more prominently in this chapter, I will introduce them as they fit into a particular framework of analysis based on their learning experiences. I also provide brief biographical narratives of some of my participants that are featured more prominently throughout this chapter. Giving family and educational background of the participants before and after their flights from the country of their origin helps us understand their conditions of access to literacy resources in their life trajectories. These histories help me frame their engagement in specific multilingual and multimodal learning practices in the context of their resettlement in the U.S. Temporally and spatially organized beyond their current context, the Bhutanese refugees' subjective accounts of their lived and learning experiences across distinct nation states suggest that their identities and learning practices are influenced and shaped by their multiple memberships in communities located beyond national borders. The development of digital communication technologies and their more accessible affordances in recent times have helped these participants express their transnational and transcultural identities both locally and globally across digital spaces through literacy practices that take place beyond their school classrooms.

\section{Literacies Beyond School Classrooms: Changing Technologies of Communication}

Recent decades have witnessed a considerable increase in the research of minority communities' literacy practices beyond school classrooms. Street's (1984) ideological model of literacy through ethnographies of different meanings out of people's lived 
experiences has been useful in examining the literacy practices of peripheral and marginalized groups in society, leading to direct implications for school literacy. Barton and Hamilton's (1998) study of "vernacular" literacies of Lancaster communities has been widely received in literacy studies. Similarly, Gregory and Williams's (2000) research on two communities in Spitalfields and London presents an intergenerational study of living, learning, and reading as it has taken place throughout the twentieth century in homes, clubs, churches, synagogues, mosques, theatres, and of course, school classrooms. While these studies on literacy practices focus on reading and writing activities within local communities and as located in immediate social, political, and cultural contexts, recent studies of language and literacy (Pahl \& Rowsell, 2006; Baynham \& Prinsloo, 2009; Warriner, 2009; Cope \& Kalantzis, 2009) have moved toward examining literacy practices within intersecting local and global contexts and in relation to changing technologies of communication. As such, the challenge of studying new media in the context of "transnational family relationships is that the technologies themselves are constantly changing and research often seems to be chasing a moving target of technological developments and innovative appropriations on the part of the users" (Madianou \& Miller, 2012, p. 7). However, at a local level, such innovative practices and appropriations of new media by the community members contribute to their rich learning experiences across various social domains, such as community gatherings and religious institutions. That these participants are involved in such innovative local practices indicates the fact that they are not merely doing this for preserving their traditional cultural values but for manifesting agency over their construction of knowledge, for, as Pennycook (2010) argues, "the notion of local practices needs to be 
carefully disentangled from the notion of preservation, tradition, and maintenance" ( $\mathrm{p}$. $103)$.

Along the same line, community institutions like church and temple play a significant role in enhancing the learning experiences of the Bhutanese refugees in Panorama City. Through their production of videotexts and use of multiple languages when preparing notes and scripts for their performance, the refugees are also showing an agency over their work. During their meetings in church every Sunday, the Christian members of Bhutanese community prepared their scripts for speech, singing, and any other cultural presentations. Resham and Melina, born in Nepal in 1995, and in 1990 in Bhutan, respectively, talked about the significance these informal writings they prepared for church meetings had for their academic writing in the school. For example, they learned to respect their audiences, and see how they could write something more persuasive to them. Without formal training on rhetorical situations, they seemed to be already involved in communicating across various audiences by using rhetorically effective writing both in school and in church. The boundary between academic writing and non-academic writing got blurred in their communicative practices across both printed and digital forums. Heath's (1983) ethnographic study of three different communities in the Carolina Piedmont for nearly a decade suggested sharp distinctions between the ways with words of Roadville, Trackton, and mainstream and school communities. Heath demonstrated that each community's people learned and used language in ways different from that of the people from other communities and that these differences showed up in school classrooms. Although children in Roadville and Tracton 
were not very successful in school (compared to those middle-class children in town), they were quite successful communicating with their respective communities.

Similarly, what Bhutanese refugee youth wrote and created in the communities only drew negative responses in the beginning days of their schooling in the U.S. when they tried to utilize similar writing and production skills in their classrooms. Bijaya and Binaya, born in Bhutan in 1990 and in Nepal in 1995, respectively, shared with me their bitter experiences of being punished in U.S. schools for their "incorrect and messy" use of English in their writing when they prepared their assignments based on their previous academic experiences and on their knowledge about technology. Active inside and outside classroom literacy activities, such as poetry writing contests, and youth leadership skills, from his early school days, Bijaya learned to read and write simultaneously in both languages, Nepali and English. Bijaya remembered his beginning days in a U.S. high school after his arrival in Panorama City:

In the beginning, when I responded to my teachers' questions in the class, most of my classmates used to laugh due to my accent because I didn't come from a native speaker of English background, although I had my schooling until grade nine in English medium. I was good in writing and always scored an A in Nepal, but I had a hard time in the beginning, especially in college writing, to receive grades beyond C and B although I had good grades in my high school in the U.S. too. Although I struggled in the beginning in grade ten, I quickly picked up the pace and improved my reading and writing scores later in the high school. Most of my writing in college, however, was graded on the basis of small grammar mistakes rather than other contents, and my grades suffered a lot because of this.

Such widespread beliefs about implementing language correctness approach to achieve academic and economic mobility, as Canagarajah (2011) suggests, often situate students to abandon their own cultural and social realities. 
Both Bijaya and Binaya actively participated in online communication across their community and other friends from high school and college. Sometimes through social networking sites, such as Facebook, blog, and websites committed to the promotion of Bhutanese literature and music, and mostly through their own website, both Bijaya and Binaya communicated to the outside world through poems and music. However, Bijaya talked about his frustrations that community people on those social networking sites mostly talked about daily chores, and fun activities more than other literature, music and promotional events of their culture and language. He used these social networking sites for learning language and being conscious of the nuances of English as the users negotiate meanings through their regular comments across those sites. Bijaya was also active in the Music, Literature, and Arts group and helped produce regular programs for Triveni, a local organization to promote Bhutanese culture, literature, and music, and posted those programs to the sites, such as Facebook and YouTube. Bijaya also composed some lyrics in Nepali and sang them to his own music, as he invested a lot of his time in learning music, especially harmonium and piano. He is a good musician as well as a writer.

Binaya talked about a limited access to computers before in Nepal and also in the U.S. in the beginning days of their arrival. The only way he could use computer was by going to the public libraries in Panorama City. Although he had a deep interest in using computer for his writing and learning new things, Binaya could not use it very often. He remembered the early days of his computer literacy in this way:

When my father first bought a computer long after we arrived in the U.S., he made a time schedule for three of us (siblings) to use it. I felt like using it all the time myself, but it was beyond imagination. In addition to learning to type and using social networking sites, such as Facebook, 
MySpace, I used computer for everything. Even today whenever I struggle with any concept, English vocabulary, geographical knowledge, or math problems, I resort to computer and learn by finding solutions there.

When he got to buy his own computer by working in a store, Binaya learned most of the computer skills on his own. To address the interests of the youth like himself, Binaya created a website (http://www.kynepal.com) and regularly updated it by embedding links to new releases of Nepali comedy serials, news reports, and literary and cultural events that took place in the Bhutanese refugee and Nepali communities inside and outside the U.S. Binaya explained that those links and posts were well received by all generations from his refugee community and other Nepali communities because they were mostly about comic skits, current news, and other musical and movie events that were mostly popular among the elderly as well as the youth in Nepal and the U.S. Binaya also recited to me a poem titled "Exile" that he wrote when he was in grade ten on the experiences of exile and sufferings in the new place when living as refugees in both Nepal and in the U.S. Although he didn't get to directly encounter the experiences of persecution and sufferings in Bhutan, for he was born in the refugee camps in Nepal, Binaya based his writing on the stories he heard very often from his family and other relatives about their plight as refugees. He said that this poem was also published in his school magazine in the U.S. Binaya also used such themes arising from his family experiences of isolation and living in different places as refugees when he wrote literacy narratives for his high school English class. He showed to me a paper that he wrote in response to an assignment in an English course (see Figure 4.1 for a sample), which asked students to write about their experiences on academic and cultural development. While his contents were well articulated in the paper and ideas clearly organized, Binaya couldn't receive a good grade 
in this paper in the beginning because the teacher based her grading mostly on small

"ESL things" that she

Figure 4.1. Binaya's Writing Sample

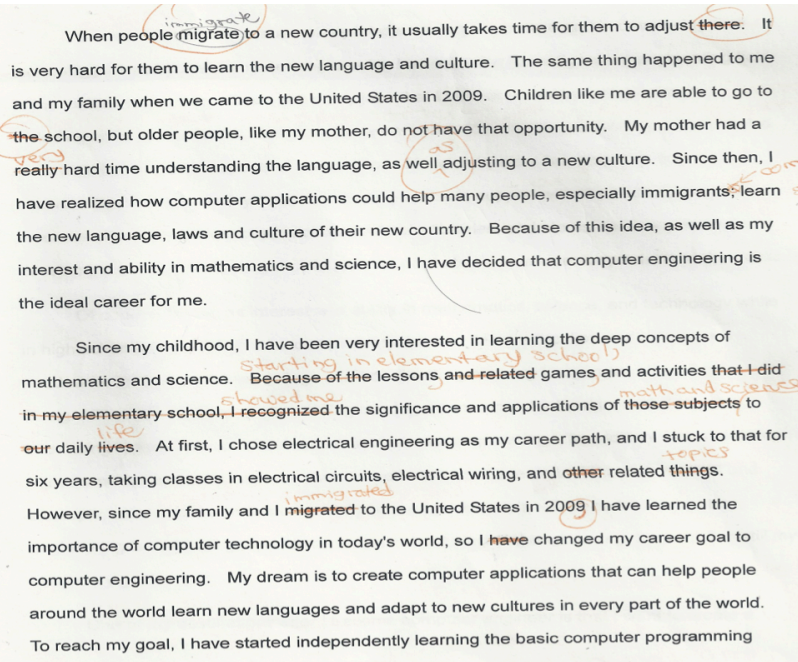

and Binaya could not help the fact that whatever they designed and learned in their home and community got directly transferred to their school classrooms. For example, when Bijaya wrote scripts or songs for his program and posted videos on YouTube, he engaged in composing several drafts of those writings, carefully selecting words, revising them for particular audiences, and recreating every piece of composition. When he followed the same methods in writing his essays for school, he did not receive encouraging feedback. He was mostly evaluated based on "small ESL issues that my teacher encountered in my writing" (Bijaya's words). Schools can help these students academically succeed by acknowledging and recognizing the skills students bring to the classroom from community learning. According to Rogoff and Correa-Chavez (2004), "literacy learning 
could be improved in schools with greater recognition of the everyday language and literacy practices that children engage in skillfully at home and in their communities" ( $p$. xiv). Also, as indicated by Heath's and other recent studies on community literacies, what is noteworthy in those findings is that to better understand the literacy practices of minority communities like the refugees we need to discover the usage and functions of language, digital and printed, in the community as well as in the classroom. A recent publication by Canagarajah (2013), Literacy as Translingual Practice: Between Communities and Classrooms, further establishes this continuity between learning practices in the communities and that in the school classrooms. The process of language learning and creative use of technology go together in literate actions of the students like Binaya, demonstrating what Lantolf (2000) calls the reciprocal effect of computers and humans in computer-mediated communication. Drawing on Vygotsky's notion of mediation in learning, Lantolf says:

In opposition to the orthodox view of the mind, Vygotsky argued that just as humans do not act directly on the physical world but rely, instead, on tools and labor activity, which allows us to change the world, and with it, the circumstances under which we live in the world, we also use symbolic tools, or signs, to mediate and regulate our relationships with others and with ourselves and thus change the nature of these relationships. (Lantolf, 2000, p. 1)

As we continue to face challenges regarding literate practices beyond the walls of schools, we need to first understand how social practices of literacy work; then we will be able to identify the ways hidden social skills implicitly contribute to people's knowledge construction based on their lived experiences. Such hidden literacy skills at the same time develop in conflictual relationship with notions of school literacy, and of literacy more generally, which is based more on an autonomous model of learning. Schooled literacy 
becomes a particular form of literacy without which people are deemed to be illiterate despite their reading and writing skills. On the other hand, hidden literacy skills, according to Street, are "seldom addressed in schools" (1984, p. 222). His grasp of hidden literacy skills in Western-based studies provided Street a keen insight into the hidden literacy practices of the Cheshmehi people in Iran when he was involved in an ethnographic study of this community in the 1970's. The nub of Street's ethnographic study lies in his manifestation of the discrepancy between people's home learning experiences and their school literacies. So, the job of teachers and researchers investigating literacy practices is to make explicit what is hidden in the society, and create an awareness among students about how hidden skills contribute to people's meaning making practices in relation to schooled literacy (p. 223). The latter, however, is hyped to be the only recognized kind of literacy that helps social improvement and social mobility, and which, according to Harvey Graff, only perpetuates the literacy myth (Graff cited in Street, 1984, p. 10). In my discussion of the multilingual and multimodal literacy practices of the Bhutanese refugees in this chapter, I draw from theoretical perspectives that consider the situated, contextual, and ideological nature of reading and writing in the context of transnational migration.

\section{Multilingual Repertoires among Refugee Youth}

Issues related to language elicit an important theme in my study's findings. Bhutanese youth speak many languages, including Nepali, English, Dzongkha, and Hindi, but most are literate only in English. The participants in this study described English as a language of education and career, but they also expressed strong beliefs about the need to become literate in their mother language in order to preserve their 
cultures and communities. These refugee youth maintained ties to their countries of origin while they became incorporated into the country of their resettlement. Many studies of language and literacy have started to explore the relation between language practices and multilayered relationships that the speakers of other languages develop across academic settings. In my discussion below, I first establish the significance of multilingual literacies in the life of speakers of other languages by drawing on language theories and then discuss my participants' literacy practices across multilingual and multimodal spaces.

Horner and Trimbur (2002) point out that "reified notions of students' cultural identities and language habits have also misled teachers into attributing to the influence of a particular foreign culture on particular writing practices" (p. 619). Consequently, they suggest that "such categorizing can also lead us to overlook direct and indirect interaction between cultures" (p. 619) because as they posit, quoting Zamel, these reified notions reinforce the idea "that each [language and culture] is separate from, even in opposition to, the other and keeps educators from understanding the complex ways in which the two intersect, mingle with, and give shape to one another" (Zamel qtd. in Horner and Trimbur, 2002, p. 619-620).

Drawing on a translingual approach to literacy, I analyze the literacy practices of Bhutanese youth through the notion of repertoires in the sense of what Blommaert and Backus call "the means of language" (2011, p. 4). Such means of language as discussed below in relation to the use of multiple languages by the Bhutanese refugee participants affirms the linguistic diversity the minority communities struggle to legitimize when comingling their versions of English to compose a text. Talking about the changing 
attitudes toward the use of English in the post-diasporic communities, Rushdie (1991) stresses the need to "remak[e] [English] for our own purposes." According to Rushdie,

Those of us who do use English do so in spite of our ambiguity towards it or perhaps because of that, perhaps because we can find in that linguistic struggle a reflection of other struggles taking place in the real world, struggles between the cultures within ourselves and the influences at work upon our societies. To conquer English may be to complete the process of making ourselves free. (1991, p. 17)

Similarly, Rushdie subjects to criticism the ideals that proclaim to glorify the use of English in its original form, failing to make relevant the new configuration of power relations within the globalized context.

Against the backdrop of such repertoires, Bhutanese youth's literacy practices make inroads to their means of language, and such practices help them to articulate their differences through language. The study of literacy within the linguistic domain of a people becomes more relevant in the context of Bhutanese youth, who have found ways to create their identity based on their language choices that are informed by their literacy practices in the past as well as in the present.

Matsuda (2006) notes that "the policy of containment and the continuing dominance of the myth of linguistic homogeneity have serious implications not only for international second language writers but also for resident second-language writers as well as for native speakers of unprivileged varieties of English" (p. 648). According to Matsuda, such policy paves the way for perpetuation of the "policy of unidirectional English monolingualism which makes moving students toward the dominant variety of English the only conceivable way of dealing with language issues in composition instruction" (Horner and Trimbur paraphrased in Matsuda, 2006, p. 637). 
Horner and Lu (2007) suggest that a multilingual approach to teaching language is more useful than eradicationist, SLA, and accomodationist approaches in that it does not only reject the monolingual reification of language but also "challenges both the power of $\mathrm{EAE} / \mathrm{SWE}$ and the sociopolitical relations maintaining its status as either correct or the 'power language"" as well as "reject[ing] the politics of English Only to engage a progressive politics of language focused on valuing difference and fostering change" ( $p$. 150). The multilingual approach in comparison to the other three approaches appears to be a more inclusive and democratic one to address student diversity and language differences in the classroom, and the ways it can be implemented in the classroom. Moreover, in spite of the academy's tacit policies of monolingualism and linguistic containment, multicultural, postcolonial and transnational programs continue to grow in popularity. As opposed to monolingualism, translingual practices become crucial in accounting for the development of literacy practices among Bhutanese refugees in the U.S. While monolingualism is linked not just to language but culture as well and treats language, culture, and identity as indelibly linked, uniform, singular, and stable, the translingual approach offers potential for change because it "insists on viewing language differences and fluidities as resources to be preserved, developed, and utilized" (Horner, Lu, Royster, \& Trimbur, 2011, p. 304). That seems to be the larger sense in which the monolingual teaching practices are limited in denying the possibility of change to the home brought on by the introduction of different elements of language and culture to that "new home" by the refugees themselves - a reworking of what it means to be American, to speak English, and so on. Therefore, a translingual approach not only takes "English" 
as always subject to change, or "translation" as Pennycook (2008) puts it, but also looks at difference as the norm of language use.

For instance, although Bhutanese youth struggle to conform to the "standard" American norms, they find ways to negotiate their cultural and language situations. Bhutanese youth are constantly under pressure to conform to what are defined as American linguistic and cultural values because the literacy sponsors always stress the "American ways" of living by reinforcing the dominant notions of these at the cost of the refugees' linguistic and cultural differences. As some of the participants have revealed, Bhutanese youth are always pressured to learn "standard" English and communication practices by doing away with their "thick accent," and also by learning "American ways of life" (Shrestha, 2011). The major goal of education that the mainstream discourse imposes on non-traditional communities like Bhutanese refugees is to reinforce the dominant language and cultural practices by removing all traces of their linguistic and cultural resources as barriers to their success in American society. So, the problem here lies in considering a notion of "American ways" of language as uniform and stable as much as in "preserving" the Bhutanese culture as a uniform and stable practice as suggested by some of the Bhutanese refugee participants. What I see happening instead in the daily literate actions of the refugees is that their literacy practices are diverse and always changing. The real cultural and literate practices of the Bhutanese refugees are thus diverse and changing in the context of Panorama City culture, whereby such practices render recognizable differences the refugees bring to the new context as resources rather than threats as assumed by some of the literacy sponsors of the refugees. 
Despite such challenges they face in the course of their adjustment to a new cultural and language environment, Bhutanese youth found creative ways to respond to those challenges and use them instead as opportunities for learning. For example, in an open forum they created on Facebook, they mostly communicated their ideas about cultures, social gathering, sports, and language learning. During our conversation, Binaya, who was born in 1995 in Nepal, explained to me the significance of such a forum for offering them a common platform for not only engendering their ideas about the major events and activities they regularly organized but also for helping the participants improve their language skills. As Binaya explained to me during the interview:

I have found these online forums to be very creative for younger generation. The people who feel shy and reserved during physical meetings take advantage of such forums like Facebook. They post their interests and immediate reactions about any activities created online. If there are any learning or sports opportunities, they openly interact about such topics in a way to help us reach to a decision sooner. I have been so excited about having more people pipe in the discussion and openly express their views. 
Figure 4.2. Facebook: Multible Languages in Action

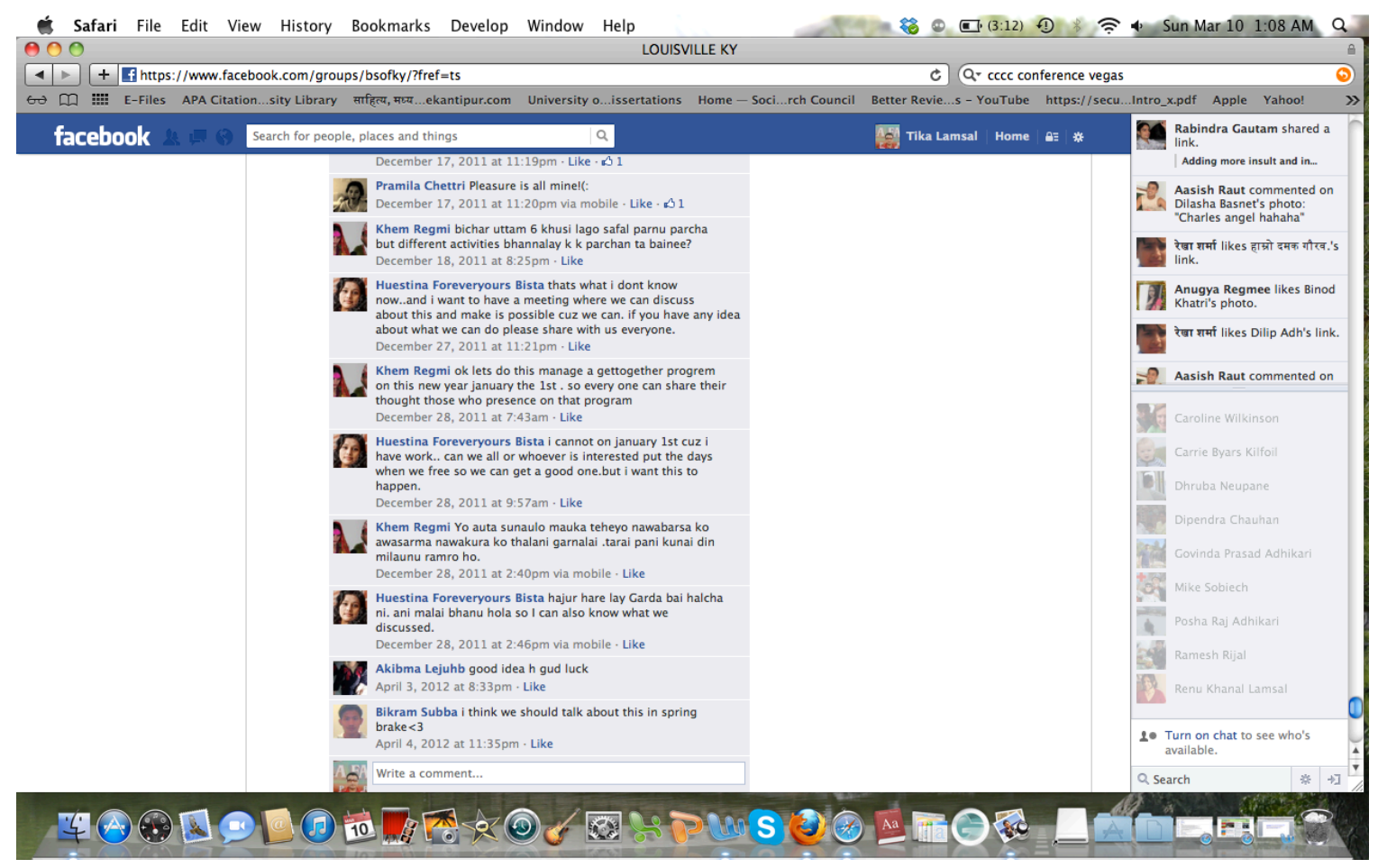

Such collective encounters online have not only functioned as digital spaces for intercultural communication, they have also contributed to learning English by including participants' own cultural and language resources. English thus becomes fraught with richer resources as the multilingual participants like Bhutanese youth bring newer constructions in English mixed with their own cultural and social nuances. As shown in this Facebook interaction (Figure 4.2), most of the participants used Nepali, English, and sometimes Hindi constructions of sentences and communicated their ideas in a situated way by weighing in which language expression would suit better for the context by positioning themselves as agents of language and culture as opposed to positioning themselves as "refugees" who must passively accept new ways or remain locked, equally passively, in old ways. They found their own ways to create changing cultural and communication patterns to suit the new contexts. 
Such language constructions help the participants learn and improve their intercultural communication in a new context. Expanding what counts as text in the classroom, beyond print form, as digital literacy scholars (Wade \& Moje, 2001; Kirkland, 2004) suggest, has the potential to influence student motivation. The following screen shot of a post on Facebook (Figure 4.3) informing Bhutanese youth in Panorama City about initiating a youth group indicates the ways youth become interested in helping out others in need and also utilizing the discussions as learning practices.

Figure 4.3. Priya and Her Group Facebook Interface

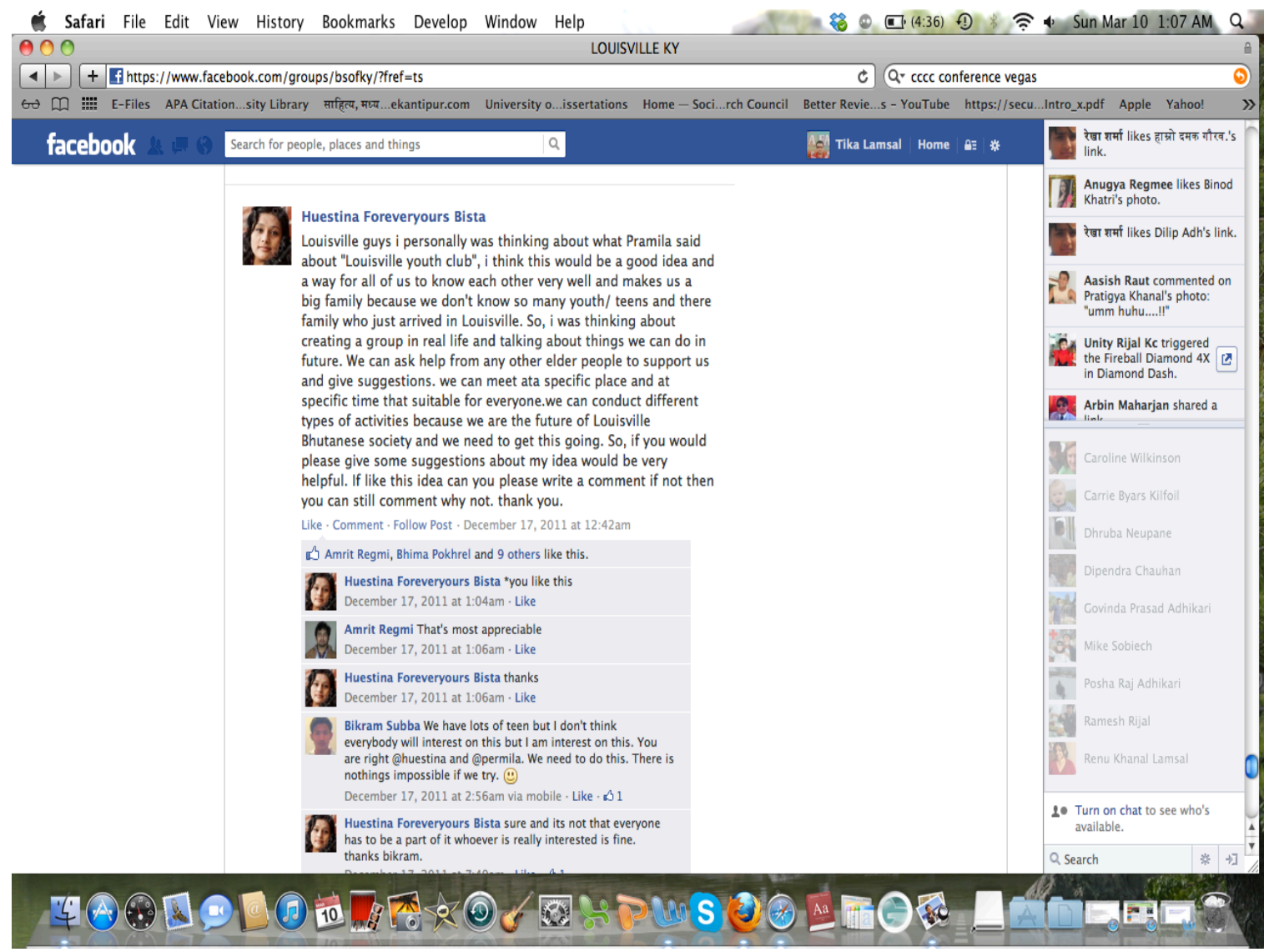

What is more intriguing to me about this forum is that school-going teenage girls have taken an initiative to start a youth group online. During group discussions online, 
Priya proposed to start a new forum in order to involve a community of youths to participate on various cultural, social, and other learning activities (see Figure 4.3). Priya was born in 1995 in the refugee camps in Nepal, but was mostly raised in the outskirts of the refugee camps, where her parents taught in a boarding school for many years until they came to the U.S. in 2008. Raised and educated in an English-medium boarding school until grade 8 in eastern Nepal, Priya considered herself very knowledgeable and competent in both written and spoken English. However, when she came to the U.S. and started to go to a middle school in Panorama City, she was made to realize for the first time that she didn't know anything about English and that she could never succeed in the new school environment. Priya shared with me a bitter experience about how she was marginalized socially and academically in a middle school in her beginning days in the U.S. When she spoke, her friends made fun of her, as they said that they couldn't understand her and that she spoke something else, not English:

I have only a different accent, but I still believe that I speak a good English. However, every time I spoke either in class or outside, my middle school friends made a laughingstock of me. They tried to imitate my speech disparagingly. They didn't only make fun of me but also bullied me all the time just because I came from a different culture and spoke with an accent. The teachers didn't help me either. There were not many nonnative speakers of English in the school until then, so the teachers probably weren't prepared how to deal with the students like me. Then I decided to stay shut all the time both inside and outside the class so nobody could make fun of me. I started to open up little bit more when I went to a private high school, where, although the treatment of white American friends and teachers was not that different, there were a couple of friends from minority ethnic communities like Latin America and Middle East, who I could count in as my friends and who helped me a lot with learning and socializing.

In the beginning, Priya thought that by starting a new online forum, she could make more friends and stay in touch with more girls from her own community. As a girl who was 
raised and educated outside the refugee camps by her parents teaching in a boarding school in the outskirts of the refugee camps in eastern Nepal, she didn't have many friends from the camps that came together to the U.S., making her feel isolated and lonely in the resettled location in the U.S. This means that Priya was creating a different community subsequently, rather than attempting to somehow preserve a pre-existing community. Given the participants' engagement in such practices of producing new learning practices in the U.S., it is important to understand the fact that the participants used their literacy skills in the new context to produce culture and society, not simply to join or reproduce an existing one.

When I asked Priya what motivated her to start such a group, she spoke about the need to start one for the preservation of their culture and language. However, during my observation of their use of social networking sites, I saw that Priya and her friends were not merely involved in preserving their language and culture but also transforming their literacy practices to fit the new context and motivate other community members for active participation and learning. For example, Priya explained to me about the ways they used Facebook for learning English and other literacy resources attached to the usage of English. Most of the participants in her group used to read English novels, such as Huckleberry Finn, Emma, Harry Potter series, etc., and posted their responses to these novels online by interpreting these books to understand their own cultural and social experiences about ethnic diversity, marriage, the role of social institutions in promoting women empowerment. Doing so didn't only help them openly discuss issues on women empowerment and gender equity in relation to the new cultures in the U.S., but also boosted their morale about learning English. One example of such learning Priya gave me 
was the way they learned English and transformed knowledge making practices through its implications to the larger world. When the participants posted online some passages or quotes from any novel they read from, they were supposed to be well knowledgeable about the vocabulary and rhetorical contexts of that passage so when asked about that particular passage, the writers could respond to those queries about such issues clearly and effectively. That way the participants were not only limiting their learning experiences to whatever was given in the text, but also expanding and transforming their implications to the new contexts of learning language, culture, and other social and political implications they had in their own society. That was one of the best learning experiences through digital literacy practices for Priya in the beginning of her arrival in the U.S.

In addition to using them as a resource for networking with their community youth online, Bhutanese youth like Priya were utilizing these forums for developing leadership opportunities and improving their language skills. Writing often both in Nepali and English, and occasionally in Hindi, most of the participants jumped in without solicitation to offer their suggestions and views about any event or learning opportunity posted online. Not writing otherwise for any other purposes, participants became more active users of English including other languages. Priya told me that they had started to improve English and also preserve Nepali and Hindi through their regular discussions online, as shown above in their Facebook interaction (the first screenshot). For example, when Priya posted about library resources for learning, people quickly jumped in to talk about the benefits to the community and whether they should participate in visiting the library and utilizing these resources. Other participants also joined the conversation by 
posting other similar offers and scholarship opportunities for college-seeking students. While Priya was excited about the online forums used for the purpose of physically meeting her friends to rehearse any cultural programs and plan and organize them on several occasions, she became more intrigued by the opportunity to use such forums for learning and improving communication skills. Moreover, such forums, as she asserted, offered opportunities for girls to become active participants in the discussion. Community discussions otherwise became mostly boys-dominated, as girls mostly remained silent and away from such public discussions. Priya was glad that things were changing along with the easier affordances to technology. As these examples of Priya's and other refugee youth's involvement in literacy practices across various forums suggest, they are creating new communities and cultures (the "Panorama City Bhutanese community" not the "Bhutanese community") and changing language practices through their literacy practices.

However, there are few educational institutions that recognize and respect such differences in the use of English in order to help these youth channel such language resources for meaningful communication. The literacy sponsors, such as schools and resettlement agencies, are concerned only with the prescribed norms in their teaching and learning activities. They are guided by the standard norms prescribed by the dominant institutions without considering the ground realities about the people learning them. For example, Priya shared with me her experiences of emotional breakdown and grade inflation in her freshman English writing courses in a liberal arts college located nearly 65 miles northwest of Panorama City. Priya was a brilliant student, who aspired to join a medical school, and wanted to maintain perfect scores in all subject so that she could take 
preparatory pre-med classes. However, her dreams started to shatter as she received grades in her college English; they were only upper Bs and Cs despite her hard work writing and revising these papers. Her papers were bled with teacher's comments mostly based on minor grammar, punctuation, and transition errors. Priya told me about her experiences of frustration in an English class:

When I went to meet with my teacher with questions as to how I could improve the mistakes as marked on my paper, he simply dismissed my desire for learning by saying that it was natural for the ESL students like me to make those mistakes and that he could understand that because I was a refugee coming from a different background. I didn't need any word of sympathy; that merely reinforced the stereotypes that we are incompetent students coming from different culture. That only added an insult to my injury by forcing me to internalize that as a non-native speaker of English, I could never improve my writing. I literally broke down several times by coming to my dorms and felt helpless. I totally stopped visiting my English teacher since then and turned in my papers whatever way I wrote them. I was too scared to visit the teacher next time.

Priya also showed to me the papers that her teacher had commented. I've included the

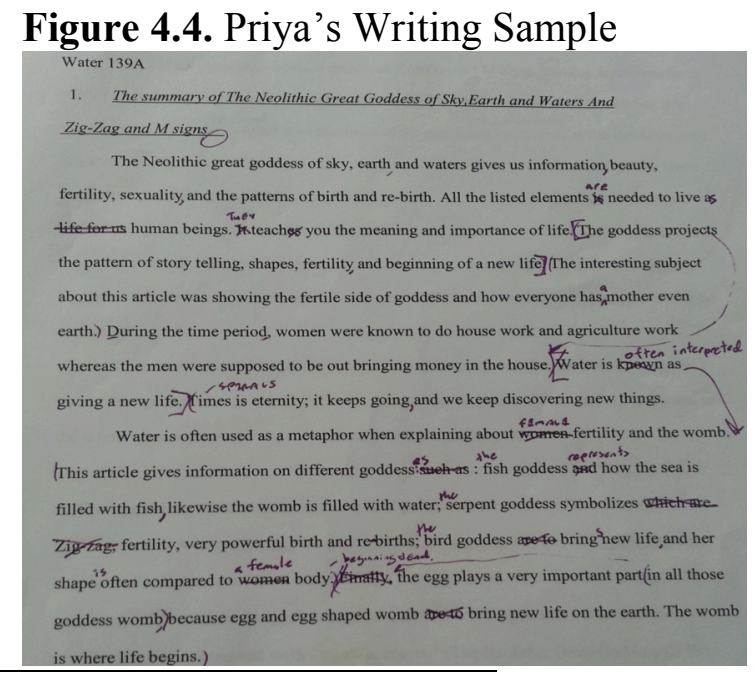
first page of this essay as an example ${ }^{15}$. I noticed that most of the comments on this essay were merely on local level errors, and Priya said that she had points reduced mostly based on those errors. Priya explained that she was okay with those marks on her paper and that she

\footnotetext{
15 Priya wrote this paper for her freshman English course in response to an assignment that asked the students to conduct a primary research on the significance of water in our world with a specific focus on how water is valued in different cultures and what stories of its origin are prevalent in those cultures to suggest the values they place on water as cultural artifact of their community. This was an expository essay they wrote in response to this assignment.
} 
wanted to learn more with clear explanation as to why they were problems on her paper and how she could improve such problems. Those errors, as seen in this example in Figure 4.4, however, are mostly based on the communicative patterns or language use Priya commonly used during her online discussions as shown in their Facebook conversation above.

Our judgment of students like Priya's language quality becomes mostly based on the quality of writing they produce in class. As illustrated by the example of Priya's writing and her response to it in my interview (the above excerpt), such discouraging and belittling attitude towards refugee students' writing provides the parallel damaging view of a stable refugee community and culture (of "refugees") that denies the possibility of change. We mainly gloss over the matters of agency students like Priya practice by utilizing multiple cultural, social, and linguistic repertoires in their academic writing. Calling this tendency a normative complex (emphasis the writer's), Blommaert (2013) notes that such complex applies "to the total semiotic fact of the 'written language'. We apply this normative complex whenever we 'read' a written text, and even if our overall judgment can be dominated by specific features such as stylistic fluency or the strength of argumentation, we appear to fold such more specific normative judgments into one total judgment of "the text'” (p. 443). Despite her willingness to learn, Priya, for example, couldn't receive any help from her teacher, as he simply asked her to revise and improve those "problems in order to receive better grades" (Priya's words) without offering any help. This kind of apathy, as transpires from this example, on the part of teacher may also have arisen due to his lack of training or strategies for supporting linguistically and culturally diverse students. However, the attitude the teacher showed toward Priya by 
suggesting that she had problems with English just because she came from a non-native English speaking and a different cultural background only reinforces what Lu and Horner (2013b) call the ideology of monolingualism that "associates language difference strictly with subordinated groups" (p. 583). Ideology of monolingualism, according to Lu and Horner, sees slight deviations in writing by those identified as belonging to subordinate social groups "as manifestations of the writers' lack of knowledge or fluency with 'the standard," while recognizable deviations in writing by those identified as and located in the "mainstream" as creative innovations (p. 583). In the meantime, if the teacher had been prepared to offer extra support and had more training working with diverse students, he could have developed a better perception of those students like Priya and also found ways to channel their multimodal, multilingual, and multicultural resources into better learning experiences of these students.

In the same vein, in one of the ESL classes I observed at a state-sponsored refugee management institution (see Chapter Three for details), the refugees were always encouraged to learn the "standard" English in order to be able to find jobs and also admissions in the U.S. schools. The instructors there didn't seem to be informed about the varieties of rhetorical structures and the variety and fluidity of those that might be used in both schools and in worksites. Nor could they comfortably facilitate the newcomers' learning process by helping them transform their previous knowledge into the new context. I have described in detail about this practice in Chapter Three with some examples from how my participants in such ESL classes tried to negotiate their multilingual resources for learning English, but without much success due to the lack of encouragement from their monolingual ESL teachers. 
Moreover, academic institutions raise the bar for such refugee students higher when taking decisions about such students' admissions. Two of my participants, Chitra and Dibya, brothers from a Bhutanese refugee family, became very vocal about their grievances regarding the provisions for admissions by local universities in Panorama City set for such students. Chitra was only four years old and Dibya two years when their family left Bhutan for the refugee camps in Nepal in 1992. Both of them came from educated family backgrounds. Both of them had completed their high school in Nepal. However, when they arrived in the U.S., they were placed in grade ten as students coming from a different cultural and linguistic background so that they could be familiar with the new educational contexts here. They had specific interests in Social Sciences and IT. Chitra wanted to pursue his higher studies in IT, and Dibya in Social Work. Their learning curve proved to be very steep in the beginning days of their arrival in the U.S. due to their difficulty in understanding "American English," both spoken and written. As they continued to work harder, they could manage their class assignments and other readings. They felt very comfortable with other Social Sciences and IT classes due to their "competent" education back in Nepal. They graduated high schools from Panorama City in good standing in 2010 .

Both Chitra and Dibya complained that despite their expertise and knowledge in Social Sciences, and IT, and their desire to continue the higher studies, they couldn't join the program of their interest just because they couldn't score the expected marks in the ESL classes. In a local community college in Panorama City, Chitra first took an ESL course as a requirement before being qualified for joining the mainstream writing course. He recalled one of his ESL teachers' comments when he turned in his first essay: 
Although my prior experiences helped little bit in coping with English classes, I was so taken back by the teacher's comments in the beginning when I turned in my first essay to ESL teacher. She told me that mine was a D paper, and she couldn't grade it above that. What seemed to matter more for her was small grammar mistakes. I thought I had written pretty well, but after seeing her comments on the paper I became hopeless that my English was so bad. I later started to use YouTube as a resource for learning English and finding instructions on other subjects as well.

As they told me during the interview, as a requirement for admissions to college, both Chitra and Dibya were asked to first attend ESL classes throughout the year and achieve certain scores before they could be eligible to take any other regular courses. These were requirements for them to get associate degrees before they could get admissions for undergrad degrees. However, they couldn't do this for several reasons: first, they couldn't afford to pay for the costly ESL classes; second, they didn't believe in the scores as they thought that the ways tests were designed made them impossible for securing the expected scores; third, they didn't have time to linger on mandatory ESL classes throughout the year when they had to work and sustain their families at the same time. When I met them the next time, both Dibya and Chitra told me that they decided to give up. I could sense a gloom of frustration rise through their faces as they sadly spoke about such restrictive provisions that had kept them from pursuing higher studies in the disciplines of their interests. Such cases are only the tip of the iceberg that we encounter in academic institutions, as very rarely do people speak about such frustrations unless they are pushed deeper because as Chitra and Dibya revealed to me during the interview, if they spoke about such realities, people might think that it was their incapability that landed them in their situation. And they didn't want to expose their weaknesses to the outside world. 
This situation of the students like Dibya and Chitra in this study parallels findings in the research on basic writing students, who are often held back and made to feel hopeless on the basis of tests that give invalid measures of their writing ability. In her longitudinal research among 53 basic writers from diverse cultural and language backgrounds at City University of New York, Sternglass (1997) analyzed the assessment practices adopted by the institution. Based on her findings from this extensive study, Sternglass concluded that

By using timed, impromptu writing tests as the sole determiner of students' placement into writing courses, the institution ignores issues of language development well-known to professionals in the field of composition. In an urban academic setting, students deserve respect for their serious attempts at mastering the conventions of written English. Their entire intellectual competence should be the basis for the assessment that is made of their ability ... . But students should not have their academic progress stifled by the appearance of language features in their writing that they demonstrate they know but do not yet control automatically. Institutional testing should be an indicator of the type of help that students need at a particular time, not a hindrance to their advancement. (pp. 160-161).

It is, therefore, "increasingly inappropriate to make simple identifications of students' languages and to categorize and place them in courses of instruction according to such identifications" (Horner, 2006, p. 571). Identities of particular communities instead are formed in the relationship and interaction between the individuals and their social and cultural environment (Giddens, 1991). In the globalized context, people's educational practices also hinge on pluralized domains of linguistic repertoires, whereby "multilingual competence emerges out of local practices where multiple languages are negotiated for communication" (Canagarajah, 2011). Writing in multilingual trends provides students with a linguistic agency capable of facilitating a resistant pedagogy in the face of institutional constraints that label their differences as deficiencies. According 
to Horner et al. (2011), a translingual approach to the teaching of writing "sees difference in language not as a barrier to overcome or as a problem to manage, but as a resource for producing meaning in writing, speaking, reading, and listening” (p. 73). As such, a translingual approach to literacy offers us ways to better understand the issues of identity and culture. Stressing the values of diverse students' resources based on their prior cultural, linguistic, and overall academic experiences, Matsuda (2002) contends that "we need to recognize that when multilingual and multicultural writers enter the US academy, they are not the only ones who need to learn the conventions and assumptions of US academic discourse practices; everyone in the US academy needs to reassess their assumptions about discourse practices in the academy as they come in contact with unfamiliar discourses" (p. 194).

In the context of rising culturally and linguistically diverse communities, Rampton's (2006) notion of crossings helps better understand how youth purposefully adopt codes from other languages or groups to navigate social and ethnic spaces. Rampton (2006) demonstrates how the multiracial youth he studied in Britain participated in language crossings to negotiate racial boundaries as they struggled to assert their identities. His study showed how Punjabis didn’t exclusively use Punjabi in their everyday practices and how Creole did not only belong to youngsters with Caribbean backgrounds. On the contrary, Rampton identified the process of language use among urban youth as less stratified given their mixing varieties of Punjabi, Creole and the English as used in the Indian subcontinent. Rampton (1995) also found that the particular ways in which the diverse youth adopted language crossings to contest racial boundaries resulted in anti-racist practices. Such a social interactivity enhances a new 
collaborative dynamic among interracial youth as they share linguistic varieties for extending their communal affiliations. As such, Rampton identifies social interaction not only as a site of linguistic exchange but also of transcultural encounter (2002, p. 12), whereby youth from ethnically diverse communities like Bhutanese refugees form their identities in relationship and interaction between themselves and the social, cultural, and linguistic environments they inhabit.

\section{Converging Literacies across Digital Spaces}

Some of the recent studies in new media have investigated the significance of digital technology to minority groups and diasporas. Technology becomes the medium by which marginalized communities negotiate their social, economic and cultural situations (Hull, 2003; Buckingham, 2003). Similarly, Gilroy's (1993) research on disadvantaged black communities points out that books and records have been vital in engendering ideologies and philosophies across the black diaspora. The way urban black youth appropriate dance and music in order to overcome their socio-economic disadvantage has drawn attention of many researchers interested in the use of technologies by crosscultural diasporas (Gilroy, 1993; Williams, 2006). The use of cable and satellite along with the exchange of video letters and Bollywood movies within the Asian diaspora has

often been interpreted as various forms of localized challenges to the dominant power of the broadcast media industries (Gillespie, 1995; Banaji, 2006). Each of these new media, however, is shifting in its usage and connotations in recent times along with the shift in some other technologies, such as mobile phones, video games, etc. that represent an alternative, opening up more avenues for socializing, communicating, and learning. 
Media convergence thus remains highly significant in the life of immigrant refugees, especially in the context of social networking migrating from computing to smart phones.

Parham (2004), and Bernal (2006) have studied the use of new media technologies by transnational immigrants. Their investigations have concentrated on the intersection of class, gender and ethnicity and how such factors become intrinsic to the identities of the minority groups such as refugee communities. Along the same line, De Leeuw and Rydin's (2007) study on the ways refugee children represent their cultural identities in the creation of their own media productions offers an insight into the ways refugee youth carve out their cross-cultural and multilingual identity in a new home. However, little has been studied about the specific importance of technology to refugee youth, who are deeply affected by issues of migration and marginalization. This chapter highlights the use of new media technologies by a marginalized refugee community in order to see how they negotiate their language and cultural differences by using such technology in both schools and communities.

Bhutanese youth construct their cultural identity through crossings in the digital space as they engage in creating multimodal productions, whereby they do not only communicate their cultural ideas within their community but also share their linguistic varieties for extending their communal affiliations with youth from other racial communities. As Rampton (2002) illustrates in his study, such activities offer a creative use of multilingual and multimodal resources for constructing their identity in addition to serving as models for others to promote anti-racist practices in the society. Kress (2010) argues that such human engagement of social semiotics functions as a cultural variable, whereby modes convey different meanings depending on the sociocultural source. 
According to Kress (2010), literacy practices are not restricted to print but also include other forms of human communication, such as body language, oral language, and visual representations. The purpose of using new media, as the participants explained during the interview, is also to educate non-Bhutanese about refugees' experiences. However, to reach other communities, they had to also use those semiotic resources, such as body language, and visual modes as used by Resham and his friends for inter-community communication. As such, Bhutanese youth's use of digital technologies reveals the importance of both becoming educated in the U.S. and also of maintaining a sense of Bhutanese identity and community among these refugee youth. The following video is created by Resham, a high school student, who graduates this summer. Resham was born into a Dalit family in 1995 in the refugee camps in Nepal and completed his middle school education there before his family moved to the U.S. Despite their lack of education, his family was more conscious about the importance of education in their children's life, so Resham and his sisters were put to school when they were five. Resham was more motivated later toward video making and music when he was still in his middle school. With better access to digital technology resources and the Internet in the U.S., Resham could see his dream coming true when he with his friends started a small local level video production group named as Timro-Mero Production. Their first production was a short movie named "Once Upon a Time in the U.S.” As Resham told me, they wanted to spread a message about how the Bhutanese community people were equal in the society in the U.S., and how people, unlike in Bhutan and Nepal, couldn't be discriminated based on their caste and class in the new land. 
Through their participation in such a digital production, Bhutanese youth extend the literate practices to their everyday functions that shape and are reshaped by their cultural contexts. When I asked Resham how he envisioned this idea and what the purpose behind the creation of this multimodal product was, he gave a long description about how some Bhutanese youth were forgetting their cultures and were enmeshed in culturally deteriorating activities, getting oblivious about their home culture calendar and festivals. Resham wanted to highlight the message about the need to spread love and family relations in the family. Although Resham prepared this short movie with a dedication to his mother on the occasion of Mother's Day, he wanted to take the message beyond the family:

I first made it for my mom; but the main idea behind this movie was that I was worried about the deteriorating condition of family relations after our people arrived in the U.S. Our culture is a collective family culture, so people should be aware of this and shouldn't totally forget their roots. When I first posted it on YouTube, I received very encouraging comments from the audiences both in the U.S. and Nepal, so I posted it on my Facebook and reached the message out further to a larger audience.

(Please see the following video on Youtube that is created and uploaded by Resham on the occasion of Mother's Day according to Nepali calendar: http://www.youtube.com/watch?v=_FHoswtO7YA\&feature=share\&list=UUMSWdHe3 QgXKP5E1F6hhdlw)

By producing this video on the occasion of Mother's Day according to Nepali calendar, and by using real mother-son characters for performance, Resham said that he wanted to raise awareness about the cultural and family values among Bhutanese communities by reproducing the cultural event in a new form in the diaspora home. However, what is intriguing about Resham's use of technology to produce this video in 
Panorama City is that he used a technology not ordinarily associated with Nepalese culture, at least when he was in the refugee camps in Nepal. And he used this digital technology in a new context attempting to shape contemporary Panorama City Bhutanese refugee life and culture. In the same vein, the video itself becomes a mediated expression of Bhutanese Nepali culture informed and shaped by new geopolitical and cultural contexts in Panorama City.

Giving such literacy events new form through the use of multimodal production, these youth participated in production and circulation of knowledge making, giving new forms to the existing practices, which, otherwise would remain unrecognized as equivalent to any literate practices by others. I was also interested to know why they used English captions for the original conversation that was in Nepali. Resham said that by using captions he could also communicate across cultures the family values he would like members of the Bhutanese refugee community to hold precious. Other communities outside the Bhutanese refugees could understand how valuable family relations are in this community.

This kind of multimodal production, as Resham pointed out during interview, also increases interracial interaction as people from other cultures could share and add to multilingual and cross-cultural discourse across digital space. The interface between community culture and language values through online networking and multimodal designs has facilitated social language development and opened new diasporic landscapes for expanding connections as well as promoting cross-cultural and multilingual practices for effectively managing transcultural relationships in an increasingly globalized and digitized world (Canagarajah, 2006; Jayakumar, 2008). Such textual designs through new 
media help the community members promote cross-cultural and cross-language practices as inevitable aspects of learning by enjoying agency over their literacy and language practices.

In their deviation from conventional language use, i.e. use of digital forms of composition instead of print and multiple semiotic resources, the refugee students like Resham, I argue, are engaged in translingual meaning making practices in all language use, including translation of scripts from their native language into English, and in the use of captions to the videotexts. Doing so not only maximizes their learning skills in several modes or languages but also establishes an agency in their work, as they become the producers of new texts and cultures through their composition instead of simply replicating the existing language and cultural norms. As shown in the videotexts the refugee youth created in their community and other composition the participants from Culture, Music, and Arts group engaged in, the participants enjoyed full agency over their work. Such agency of the learners can be best described in terms of what Lu and Horner (2013a) call a translingual framework for grasping the agency. Such a translingual framework, according to them, "sees writing, writer identity, language forms used, and writer competence as always emergent and hence writer agency as both always in operation and always in development as writers shape themselves and language forms through recontextualization" (pp. 26-27).

In such multimodal production, the refugee youth practice an integration of discourses through remixing images, sounds, and visuals. As Resham and Rewat both reiterated during the interview, their active participation in multimodal design like this has provided them with a platform to express their ideas, actively producing and/or 
changing the culture through such productions. By virtue of such practices, the refugee youth like Resham and Rewat have given a new articulation to the existing modes of communication in order to transform their practices into more meaningful communication across communities, for the reception of such creation, as Resham told me, was not limited to Nepali-speaking communities in the U.S. but also across other cultural groups that occasionally sent their feedback to the Bhutanese youth through social media, such as Facebook, and also via email. The following example of another multimodal production by Resham and his friends illustrates how these youth's engagement in multimodal literacies enables them to build upon their range of cultural and language repertoires by reaching out to the larger community rather than shifting them to only adopt the language and literacies of the dominant group. They believed that because they captured the cross-cultural and pop cultural music by integrating their own ideas and performances to the existing pop cultural remix, they could reach to the larger audiences through such production.

(see the remix song as a collage of Nepali, Hindi, and English cultural contexts: http://www.youtube.com/watch?v=1lay0ChYjqk\&feature=youtu.be)

This parody of Kolaveri song series that have inundated the Internet for a couple of years is another addition to Bhutanese youth's cultural and language resources. In addition to remixing cultural and musical contexts from Bollywood, and Hollywood, Resham and his friends, as they claimed, have used Nepali cultural symbols in order to offer a glimpse of the Bhutanese-Nepali’s engagement in building up cultural relationships across other cultures. Despite their limited access to advanced production equipment, Resham and his friends have utilized the available audio-visual equipment 
and volunteer participants for creating their multimodal designs. Selfe's (1999) concept of technological literacy helps us better understand how the users of technological literacy don't simply draw from existing technology but actively pursue change in technological environments. Therefore, in our analysis of technological literacy, we should equally be aware of the reality that agendas of technology support "social divisions along race, class, and gender and keep us from fully understanding the complexities of literacy values and practices and from defining literacy instruction in ways that could help address some of these problems" (Selfe, 1999, p. xxi). Critical technological literacy, as Selfe suggests, moves beyond academic or theoretical discussions to entail participants' community activism and the change they bring for the benefit of community people. In their pursuit of such change with a sense of agency in their technological literacy, Resham and his friends gave their group a name Timro-Mero (Yours-Mine in Nepali) Production with an intention to arouse a feeling of shared agency among all the community people. Resham believed that with this common name to indicate ownership among all, the participants would be more involved in regularly watching the videos and giving their feedback. These two videos I have referred to above are only a couple of short ones out of a gallery of short movies and other culturally significant videos that Resham says are targeted mostly for the younger generation. As a pioneer of the creation team, Resham also regularly publicizes the group production by posting trailers on social networking sites like Facebook. Through his posts, he also requests people to watch their productions and offer feedback for improvements. I actually came across his multimodal designs through his Facebook post on Bhutanese youth's Louisville group and contacted him online. The recent production Resham and 
his friends have created through their Production is a movie titled Safalta. According to Resham, this movie mostly narrates a Christian story about people's love for God and how they learn better by being aware of the principles of Christianity. This movie becomes specifically important for Resham and his friends also because, as the members of a Dalit community, they wanted to communicate the message of love and compassion to all the people regardless of their religious, caste-related, class-oriented, and ethnic backgrounds.

Rewat confirmed to what Resham said about the significance of the movie and added that this movie could be instrumental in promoting the spirit of love and equality among not only the Bhutanese community but also among other cultural groups in the society. Although born in an upper-caste family, Rewat was very vocal about his hatred toward the system of untouchability against the lower-caste members of the community still covertly operating in his society. Rewat was born in 1997 in the refugee camps in Nepal and had his primary education there before his arrival in the U.S. During our interview, Rewat raised an interesting issue he encountered when writing the script in English and finding exact terms to be translated into Nepali for dialogue in the movie Safalta. As the director and scriptwriter of the movie, Resham asked Rewat, who is one of the main actors in the movie, how he could communicate the exact meaning of Deva Doot in English. Rewat and his friends first thought about the translation and were amazed to find that the literal translation of the phrase would be Heaven milk, whose connotation in Nepali would be something like the milk derived from the Heaven. That brought a great laughter among the crew, who later decided that an angel would instead communicate a much better sense in translation. In relation to speakers' migratory 
histories and transnational ties, Saxena (2000) examines how ideological dimensions of the language and literacy practices influence people's language and script choices for usage. Saxena's analysis in turn helps us examine how the new generation like Bhutanese youth's learning practices are shaped by their cultural and religious roots in their places of origin, the connections they had in their homeland, i.e. Nepal and Bhutan, and the religio-linguistic-politico conflicts that have taken place in their countries of origin as well as that of their migration. In addition to this, as the example of Resham's attempt to combat caste prejudice through videotext illustrates, such analysis also helps us see how the refugee youth end up reshaping, remaking such conflicts through productions like these films and other videotexts.

Such community multimodal and multilingual literate practices, however, lead to questions as to whether any one other than the Bhutanese refugee community is paying attention to these videotexts, and whether other people's reception has made any impact on their reproduction and transformation of meaning. Resham told me that the purpose of such multimodal projects was to go beyond the community in a way to extend their communication with the larger audiences outside their own community. Despite their intentions, they were having slow responses in the beginning, as they took time to gain confidence and get recognized outside their own community. However, Resham shared his hope that they would be more successful, for their programs in recent times were also well received by the school communities in the surrounding area when they took similar performances to the stage. They also received good feedback for improvements. With that in mind, Resham and his friends were more encouraged to continue their work with the production of other multilingual, multimodal projects that could be easily accepted 
and shared with the outside world.

Through the use of such modes, Bhutanese youth not only learn from but also share with the outer world their cultural meanings in the contexts of what Hawisher and Selfe (2004) call the "cultural ecology of literacy" that becomes a part of "a complex web within which both humans and computer technologies coexist, and all communication takes place” (p. 644). Such individually designed documents among Bhutanese youth display their language identity through the socially and culturally responsive ways in which they arrange their dialogic texts as hybrid artforms (Bakhtin, 1981; Rampton, 1995). Also, these examples suggest that literacy practices are influenced by transnational migration, transborder family networks, and the different resources required and facilitated by these networks.

For Bhutanese youth, being literate means being able to navigate different cultural, linguistic, historical, and geo-political settings in pursuit of education and better opportunities. Most often in both academic and non-academic settings, they negotiate "the complex realities of their unique linguistic and cultural experiences" (OrtmeierHooper, 2008, p. 392). Several social activity domains, such as religion, formal schooling, and communication through community activities and participation, have contextualized most of the literacy practices in which they are engaged. Community issues shape literacy practices within these domains, with the notable exception of formal schooling, as participants go to church and temples together, maintain family and community ties through online forums, and work to organize Bhutanese refugees in the US. For these youth, the act of online interaction, as shown in their Facebook conversation, offers them opportunities to think through ideas that contribute to learning 
as well as preserving their language and cultural values. The literacy practices encountered by these youth in formal schooling, in contrast, reflect a focus on the individual, rather than community. As the multimodal approach to learning considers how students' meaning making processes are influenced by their social realities, it provides opportunities for schools to welcome the linguistic diversity and cultural knowledge that students bring to school. As Jewitt (2008) states, "multimodality attends to meaning as it is made through the situated configurations across image, gesture, gaze, body posture, sound, writing, music, speech" (p. 246), by offering the audience a collective representation of a community or cultural identity. These modes of representation, however, as Rewat complained, are not that easily recognized in school settings due to their non-print format and non-school settings for production.

\section{Religious Literacy and Transnational Identities}

Many literacy scholars have observed how immigrants negotiate transnational and transcultural identities through religious literacy education (Ek, 2009; Hones, 2001). Accounting for the influence of religious literacy in the lives of undocumented Brazilian immigrants in a Mid-west city, Vieira (2011) showed how such "transnational literate connections formed an important part of participants' religious literacies ... shaping other literacy lives in ways that invite sustained exploration" (p. 457-58). As most of the discussions throughout this chapter demonstrate, although the refugees seem to desire to preserve some imagined essence to their culture, that very culture, in fact, is at odds with the individuals' actual lived experiences.

Written out of the state, most of the participants I interviewed wrote their translingual identities across digital and printed forums, such as blogs, Facebook, on 
paper sheets, and sometimes on the covers of cigarettes. They wrote in Nepali, in Hindi, in Sanskrit, in Dzongkha, and in English, and sometimes mixed all of these languages to compose their pieces in a way to create their different ethnic identity in a new place. Such ethnic identity, according to Hall (1996), involves orientations toward common community practices, such as religions, rituals, and language practices, providing a source that people use in negotiating their identities. The notion of such ethnic identity recognizes that we are "ethnically located and our ethnic identities are crucial to our subjective sense of who we are" (Hall, 1996, p. 446).

Bhutanese refugees, in the same vein, composed religious hymns, patriotic poems, essays on their status and citizenship rights as refugees, and stories of their dislocation and cultural uprootedness. Even in the cultural artifacts they used, the refugees displayed a symbiotic relationship between spirituality and nationality. In the contexts of their religious ceremonies and cultural events, the cultural artifacts like national flags, and national anthems function as markers of Bhutanese and American nationalities, pointing to a symbolic mingling of nation, spirituality, and culture. All of such literate practices meld spiritual, cultural, and transnational meaning making, enriching the refugees' dayto-day lived experiences in the new home. Bhutanese refugees' identity is thus punctuated by contradictory beliefs and practices in the new context rather than common community practices. For example, on the one hand, they link nation, religion, and culture with their prior nationality either in Bhutan or Nepal, which sounds more like monolingualist ideology. On the other hand, through their actual practices of celebrations and ceremonies, reading and writing, and performances, they create a "new" sense of all these practices (identifying themselves as Panorama City Bhutanese, say, and merging 
Christian and other religious beliefs) that demonstrate that they are influenced by pluricultural or transcultural ideology. Most of their work as discussed throughout this dissertation can be seen as exhibiting such inevitable contradictions.

The following discussions about women's involvement in religious events in the Bhutanese communities cast light on the processes through which women negotiate their various roles, identities, and relationships. Although I met many women participants during my research and talked to them about their experiences of their involvement in singing groups, I have specifically included Amrita and Rekha as two representatives that can shed light on the importance of such literacy events in their community.

Besides oral recitation and singing most of the women participants did in connection with religious topics and hymns in kirtan gatherings, women members in the Bhutanese community also engaged in reading and writing activities in relation to these religious and cultural performances in their community. Born in 1960 in Sarbhang, Bhutan, Amrita learned to read and write Nepali alphabets at home with the help of her brother before going to the primary school. Although the general attitude in her village was not very positive about sending girls to school, her mother was a "far-sighted woman" (Amrita's description of her mom), who, despite her lack of reading and writing skills, wanted to send all of her children to school. Male members of her family were still reserved about sending girls in the family to school, but because of her elder sister and mother, Amrita started to go to school when she was twelve and completed her primary education there before she got married and started to run a family of the in-laws. She got a chance to sharpen her reading skills in Nepali in the refugee camps in Nepal through the adult literacy classes run by a local sponsor organization. Although Amrita was active in 
religious events and sang religious songs when she was in the refugee camps, she became more committed to promoting religious literacies in the communities by organizing weekly kirtans in the local settlement of the Bhutanese refugees, the northeastern part of Panorama City.

When I asked her about her role in the community literacy through religious events, she recalled that

We started religious kirtans actually with an intention to promote women's empowerment and literacy because women in general were not let free from household chores to go out of home and meet regularly. So, we wanted to meet with our women in the community in the name of kirtan. We first met to talk about family happenings, daily experiences at home in terms of whether there were any oppressive behaviors and abuses because women could very openly express their ideas and sufferings, if any, so we could collectively work in order to bring a change in the life of women. After this, we used to sing hymns to spread the message of love, kindness, and compassion to all the people. This opportunity also helped most of the women become more aware of their situations and learn through others' experiences how they could enhance their performance in workplaces both by learning English and also by sharing their experiences with each other about their working experiences.

During my observations of the kirtans, I noticed that these singing groups were mostly led by women with men playing only supporting roles, who accompanied women with songs and musical instruments. Amrita and her friends maintained their notebooks of songs, and revised some of the songs to suit the context of the ceremony; for example, if the occasion of the kirtan was a family gathering, they mostly sang songs with messages to improve people's behaviors; and if the event was on the occasion of puja, they mostly sang religious songs praising gods and goddesses. The participants selected and determined the purpose of their singing based on the contexts, i.e. social, cultural, religious, and sometimes even related to behavioral issues, especially focusing on men's attitudes towards women. Literacy practices for the women organizers like Amrita and 
Rekha embody "aspects not just of culture but also of power structures" (Gregory \& Williams, 2000, p. 11).

Like Amrita, Rekha was very active in the Bhutanese community for promoting religious literacy. Rekha was born in Chirang, Bhutan in 1984 in an area that was fertile for farming. Her village also had a primary school nearby, so she could go to school at the age of six after learning Nepali alphabets with her siblings from the joint family consisting of grandparents and thulobuwa and thuloama (father's elder brother and sisterin-law). Rekha recalled that her family was an educated family, so there were no restrictions for girls to attend schools. Having a bitter experience of being deprived of reading and learning Nepali when she was in grade two, when her Lopen (teacher of Dzongkha) snatched her Nepali book and threatened her with punishment if she carried the book next time, Rekha completed a bachelor's degree in English and political science from a college in Nepal. She was just in grade two when the impact of Lhotshampa unrest started, prompting the Drukpa regime to close down Nepali schools in the South. Her family left for the refugee camps in Nepal in 1990 after the army near her home killed her thulobuwa without any reason during a small gathering of the ethnic Nepalis in the village. As she considered teaching an ideal profession since childhood, Rekha taught in several boarding schools in Nepal before she left for the U.S. under refugee resettlement program. Currently, she is staying with her husband in the northeastern part of Panorama City and working in a child day care center.

During the interview, Rekha talked about the importance of her culture, language, and religion in a new land. She said that she became an active member of the singing group with a view to promoting religious literacy. She said that their identity could be preserved 
and transformed in the new context only when they could transfer their language and cultural heritage to their new generations in addition to teaching them English and other cultural values in the new home. During my observation of a kirtan group, which I call singing group for their active role in performing religious and

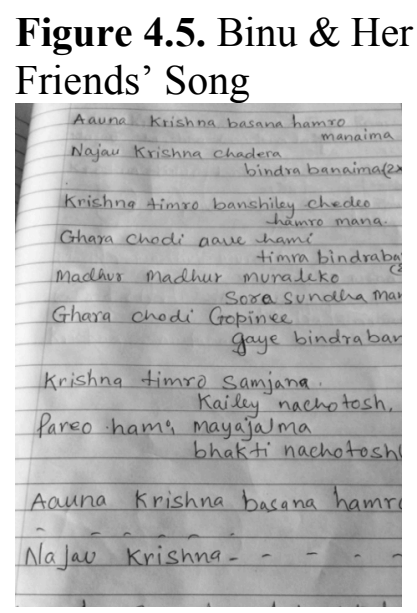
cultural songs, I found that Rekha didn't only organize weekly kirtans regularly in her community, but also encouraged the younger generation to participate in such cultural events and learn their cultural and religious heritage. Of specific interest among these kirtan events to me was the participation of three middle school girls in singing and maintaining notes on several languages.

These girls, aged 12, named Anu, Binu, and Minu, first wrote the hymns in Romanized Nepali and then sang them by following the scripts. As an example, I've included in Figure 4.5 a page from Minu's notebook, where she wrote in Romanized Nepali a hymn devoted to Lord Krishna. They also reviewed the song's translation in English in order to get a sense of how that sounded in a different language and whether that communicated different meanings of the songs in translation. Although they had started to learn Nepali script when in the refugee camps in Nepal, these girls couldn't continue learning Nepali after their arrival in the U.S., so they did whatever they could in order to practice singing by preparing a hybrid text. This practice, as Rekha told me, had motivated the girls a great deal in not only being a part of this kirtan group but also in realizing the importance of their language and culture in a new context. Rekha was happy that the new generation like Minu and her friends showed interest in their language, religion, and culture. I see 
this as a translingual practice through the use of multiple languages in order to transform the community's learning practices in the digitized and globalized context. Because composition here takes place across various modes instead of getting limited to any particular language or culture, such practice helps the community members transform meaning across various forums instead of limiting it to a monolingual script. Anu, Binu, and Minu also practice their songs by watching online their original videos and decide together how they would improvise the YouTube version in their own way to make their songs more suitable to a particular context of the kirtan. Rekha was particularly concerned that although the Bhutanese community started an initiation to run a Sunday Nepali school for a long time, it has not come to fruition due to the lack of sufficient funds and a location to run this learning center.

Rekha and Amrita, who were active members of religious singing groups in two different locations in Panorama City, talked to me about maintaining their notebooks on religious songs and job notes. The former came in handy when participating in religious and festive events in the community so they could simply review some of the hymns before singing or even update their songs based on new situations in the U.S. For example, in one of such recent religious kirtans organized at the home of Sekhar on the occasion of new home moving and initiation ceremony, I noticed that one of the singers created a parody of traditional hymns to fit the current heavy working conditions and materialistic lifestyle in the U.S. The spirit of the song went like this: don't only run like a squirrel after the job, as you may pass away while craving for the job; also, think of managing some time for spiritual practices so that you pave the way for your spiritual abode after you die. Amrita said that she would update her songs based on what appeared 
as new and improvised versions during those occasions and bring them up for singing on other occasions. Similarly, she also talked about regularly maintaining her job notes as to what new terms she encountered in the workplace and what schedule she had for a week. Although both Rekha and Amrita denied being involved in reading and writing practices in the U.S., I found that they were actively involved in such activities inside and outside their homes, constantly negotiating their ways to learning and improving their job performance by keeping track of what they were learning.

Harikala also was actively involved in promoting religious literacy in the community and wanted to start that good work from her home. Her children helped her with this by regularly organizing kirtans at home and also in the local community that they lived in. One of her sons, Balgopal, is a noted musician and composer of hymns, so Harikala asked him to sing those hymns at home during festive occasions and religious ceremonies. The advantage of having her children well versed in music, Harikala said, was that she could enjoy these hymns at home and didn't have to go to temples and other gatherings.

\section{Women and Learning: Gendering Work and Literacy}

As the keepers of home and safeguards of family culture, women in the Bhutanese community play an active role in transferring to their children the culture of the family and spiritual consciousness. However, due to their behind the curtain status for a long time in the community, women merely become intimate outsiders when it comes to the issues of education because their role in providing family education and culture to their children is hardly acknowledged. Children's success instead is measured on the basis of how fluent they become in schooled literacy so as to exchange their cultural capital with 
improved standards of living. Although the values are changing and some of the earlier assumptions about women and education are being interrogated along with their movement from rural-based agro economy to urban family economy, elderly women in the Bhutanese refugee community still talked about the brunt of the traditional family limits and the legacy carried by them in the development of their literacy. Historical displacement, as observed by Blommaert (2005), renders shifts in orders of movement "creating opportunities for voice but simultaneously causing problems of voice for those who did not 'move along' with the change, those who still spoke in the 'old' regime" (p. 78). In other words, shifts from agrarian to urban settings and movements towards both universal education and gender equality render these elders in a state of being "left behind" when it comes to educational attainment.

Most of the less educated women, who didn't get to “enjoy the schooled education," (Pramila's words), told me during the interview that they didn't have an agency in literacy works or hadn't played any role; but, in reality, unlike what they said, I saw they contributed a lot to the development of family literacy. There is also a difference between agency and sense of agency as those who enjoy agency may not see it and those who don't have actual agency may also have a sense of agency. This becomes very much applicable to the context of most of the less educated women participants in the Bhutanese refugee community. Although they directly deny having any agency in their work, the women participants' agency lies in their "socioculturally mediated capacity to act" (Ahearn, 2008, p. 95), and by the same token, their sense of having no agency over their work can be understood as affecting their exercise of agency. They seem to be overshadowed by the more powerful ones in the family, mostly due to a 
family structure to consider men as the heads of the family, and due to their assumed lack of education, social status, gender, etc., but women in the community contribute to the development not only of their individual literacy, but of the whole family and the community at large, as the examples of Harikala, Ramila, Rekha, and Pramila have shown. This shift in family literacy has paved the way for new transnational feminist literacies that help us analyze the complex relationship between gender, and the politics of local and global migrations across national borders. Family literacy development among the refugee women in the twenty-first century can thus be reflective of what Kaplan, Alarcon, and Moallem (1999) consider as the development of transnational feminist cultural studies, which "recognize that practices are always negotiated in both a connected and a specific field of conflict and contradiction and, that feminist agendas must be viewed as a formulation and reformulation that is contingent upon historically specific conditions" (p. 358). Of particular interest in this context is the literacy story of Pramila.

Born in 1970 in Bhutan, Pramila was raised in Bhutan on a farm and would remain busy working in the farm when her brothers went to school. Although she insisted on going to school, her family asked her to work on the farm and take care of her younger siblings. As the agricultural economy of her family entirely depended on the labor at the farm, as a daughter, Pramila became an easy target for farm labor, mostly due to the traditional concept of gender that limited women's role within the household and farm and deprived them of education with an argument that women didn't need any education to keep their husband's home. Despite her busy work maintaining family and sending her children to school, Pramila managed to spare a brief time to learn some vocational skills 
in weaving beads for jewelry and knitting woolen sweaters in the refugee camps in Nepal. Those skills came in handy when she came to the U.S. and stayed in touch with a local church for a long time. She admitted that she could not learn as much out of her time in ESL classes run by the resettlement agency as she could by actively participating in the community gatherings organized by local churches. Although she remained a Hindu believer, she liked the idea of compassion and fellow feeling that the church participants showed toward her and her family. Regular meetings and gatherings in the church encouraged her to practice English with her friends in everyday contexts. Pramila couldn't hide her excitement of her experiences of learning English as she energetically said: “Although I can't read and write properly in English, I can communicate with people and understand most of their conversation. Sometimes, I even use my bodily movements and gestures to communicate my message if I don't know the exact terms to articulate my ideas." Pramila now could easily communicate with the people outside her community in English and run her own small business of beads jewelry and knitwear in coordination with other community partners in the downtown in Panorama City. With the help of her children, Pramila maintained a small notebook to keep track of her business transactions. She was happy that she could contribute to her family economy as a workingwoman in the U.S. With her husband, Pramila could pay for the education of their two college going daughters, and one son and another daughter, elementary and middle school goers, respectively. She felt proud to be a supporting mother and a businesswoman with a tax paying business in the local community. Pramila also collaborated with her community friends from the church in organizing meetings and 
going to conversation clubs. With the help of her children, she also learned to use her cell phone for the purpose of texting people about the meeting time, work schedule, etc.

Although Pramila denied doing any kind of reading and writing, I noticed that she was actively engaged in learning language and also reading and writing practices regularly. When she organized meetings by texting her church friends, maintained notes on next meetings and venues, and participated in conversations with her church friends, Pramila used various modes of reading and writing, such as phone, notebook, and oral communication. These literacy activities in multimodal forms have kept her learning process active and intact in her middle age in a way to succeed in the new place. She utilized her prior knowledge and resources for negotiating across various domains of life in the U.S.

Despite such a sense of achievement, Pramila deplored the fact that she was not well educated and fluent in English. She realized this sense of lack at her workplace, a local hotel, where she worked three days a week as a cleaning helper when her partners took care of the knitwear business. As she sadly related to me, such feelings of the lack of proper education got compounded by her inability to properly communicate with her supervisors at the workplace, a hotel, as she knew most of the time that her coworkers took advantage of her gullibility and lack of language skills and forced her to work harder while others enjoyed the fruit of their cleverness and skillful maneuvering of language in reporting their work to their respective supervisors.

Pramila cherished a great hope that her children don't have to undergo experiences similar to hers and that they would receive a quality education in the U.S. to lead a better life than she did. She also wished for their children to preserve their mother 
tongue, i.e., Nepali so they could also keep intact their identity and culture as the Bhutanese people of Nepali origin. As true with most of the Bhutanese refugee participants' desire for their original Bhutanese/Nepali identity, this sense, however, is something that contributes to the contradictory nature of the participants' literacy practices. On the one hand, they are keen to preserve what they remember and claim to be their original cultural identity, while, on the other, they participate in literate and cultural activities that are clearly opposed to those practices and instead are changing, mixed, and emergent in the new context. When she participated in a local Bhutanese refugees' community meeting, Pramila even brought up this issue about starting a children's Sunday class for teaching kids reading and writing skills in Nepali. Doing so, according to Pramila, would help the kids know and use multiple languages and also be able to better communicate with the elderly members in the family. She was worried that their children might forget collective familial and cultural relationship they have long preserved in their community.

Bedmaya, Pramila's mother who was born in 1948 in Bhutan, especially recalled the time when she was ruthlessly inquired by the army at her home by threatening to kill her if they found her hiding her husband, Loknath, and offer any monetary donation or family support to the agitating Lhotshampas. Black and blue with fear and with her lips shivering and nostrils twitching as a consequence, Bedmaya could hardly talk to the army at that time. She laughed out loud remembering the way she had acted on that fated day. However, Bedmaya regretted the fact that as a daughter she was not educated by her parents and happily contrasted her present with the past, as she could now communicate more clearly and confidently with people. She gave credit for this achievement to the 
communities of learning in Nepal and in the U.S., especially the adult literacy centers in the refugee camps in Nepal and the Elderly Care Center in the U.S. Bedmaya also sadly talked about her past experiences of women's status in their community as being subservient and conforming to male-dominated structures that kept most of the women like her from being educated and taking up leadership role as guardians in the family. She also acknowledged the changing situation in the new context, as almost all of the women and daughters in the refugee families were being educated and treated more equally at the footing of their male counterparts.

Similar is the story of Harikala, who, born in 1951 in Bhutan, was in charge of her younger siblings, when her brothers carried notebooks and ran to the village school. Harikala and her sister babysat younger siblings, worked at home and at the field when their brothers went to school; the "knowables" in the village said that girls should not be sent to schools, as they would run away from the family by choosing their own grooms if they were educated. Deeply interested in reading, Harikala used to carry Gunaratnamala (a book of Nepali alphabets) and Arjun Gita (a Hindu scripture) to the forests while herding cattle, trying to learn Nepali words and read the parables there:

I had a deep desire to read books, but the village people said that women should not be taught to read. I was so much so interested in reading that I used to carry with me a Gunaratnamala and Arjun Gita to the place I went to cow herding. That way I learned some letters and words and could decipher in Nepali some short stories in Arjun Gita.

Harikala's excitement about learning English even at this age could be seen during my interview with her when she occasionally used English words, such as "regret," "success," etc. She explored the contexts through such English words as to why she was not sent to school as a child, how the social, cultural, and material conditions had kept her 
from going to schools and learning. She explained to me how her parents later deeply regretted their refusal to send Harikala and her sisters to school. Had she got a chance to go to school, she would also have been "success" like other women today.

Harikala came a long way from that situation to be able to encourage her daughters-in-law and daughters to receive education even at the cost of all household responsibilities. Harikala came forward when they were in the refugee camps and took care of all the household responsibilities so her daughters-in-law and daughters could attend school. She seemed to be a very liberal mother-in-law in a society where traditional households still have some conflicts between mothers-in-law and daughtersin-law in terms of who would run the family and who should be more responsible for household chores. Harikala did everything to make sure that their children got good education and that no girls were discriminated against in their family. Although she wasn't working outside home, Harikala actively contributed to the working conditions of the family by taking over all the household responsibility and facilitating and encouraging her daughters and daughter-in-laws to make it to schools and workplaces.

Amrita talked in detail about the experiences of self-dependency and women empowerment she helped promote even when she was in the refugee camps. Starting with knitting and weaving trainings, women in the camps got more opportunities for their empowerment as economic agents. The environment for women got more open during their stay in the camps. Amrita credited her stay during the camps for her learning leadership skills and other political ideas about their status as refugees driven out from their own birth land just for the "crime" of their demands for language, cultural, religious, and citizenship rights. She was one of the pioneers to initiate women's skill development 
and savings programs in the camps and help raise awareness about women's empowerment. Those experiences and skills, as Amrita said, came in handy even in the U.S. when she started to work in a local food packaging company. Her ESL classes (run by the refugee resettlement agency) in the beginning of her arrival helped her to some extent to learn basic communication skills in English. Such skills, Amrita told me, helped her in the workplace too, as she could easily communicate with her cohorts and supervisors by using work-related terms and expressions in English. Amrita said that she also most often watched events on computer with the help of her children and learned communication skills in English. She used these computer technologies for enhancing her English skills as well as for establishing close relationships with her religion and culture back home through the online programs produced in Nepali.

Rekha was mostly frustrated in the beginning of her arrival in the U.S. mainly because her credentials from Nepal were dismissed by the workplaces. Although a college graduate, she worked in a hotel as a sanitation maid in the beginning for one year. Luckily, she got a job at the Child Care Center that she thought would be closer to her interest in teaching. She has still been working at this Center and enjoys her work a lot, as it has offered her opportunities not only to learn communication skills but also put her efforts to a profession that she is interested in. However, she has hoped to pursue her studies further and become at least a schoolteacher later.

These accounts of women's literacy practices in the Bhutanese refugee community in Panorama City offer us an insight into the resilience and persistence of the women for learning and succeeding in the new place. Despite their experiences of sufferings and lack of education in the past, the women in the community have 
challenged the traditional roles as housewives and come forward as role models for their children and the community people. Regardless of their age and internalized "illiteracy", these participants have proven that they are the torchbearers of their community to show others that if committed and persistent, they can achieve success. They have thus challenged the preconceived notions that refugees are idle, lackluster, and dependent people feeding on social welfare. Women in the community may see themselves as noncontributors for the development of literate practices compared to their male counterparts because of the latter's visible roles as active literacy learners. However, the actual data as presented through the literacy accounts of Amrita, Rekha, Harikala, Bedmaya, and the middle school girls (Anu, Binu, and Minu) suggest, these women have significantly contributed to the promotion of cultural, religious, economic, and social literacy in their community.

\section{Everyday Discourse of Self-making through New Media Literacies}

In their daily encounters with the home of their cultural and national imaginary through electronic media, such as television shows, YouTube videos, and other Internet resources, the Bhutanese refugees recreate and transform the world of their belonging in the new homeland. As Appadurai (1996) points out, "the consumption of mass media throughout the world often provokes resistance, irony, selectivity, and, in general, agency" (p. 7, emphasis the writer's). In this section, I analyze an intergenerational participation of the refugees in new media literacies to see how they actively involve themselves in learning and transforming preexisting worlds of communication and conducts, helping them transform the everyday discourse of self-making and selfimagining through individual agency. 
When I went to his home for interview the second time, Bhakta Bahadur was watching a lok-dohori ${ }^{16}$ video on YouTube. Born in 1932 in a Dalit family in a remote hamlet of Geylegphug District, Bhutan, Bhakta Bahadur never went to school or learned to read and write, as there was no school in the whole region near his village. Only a handful of elderly men read Nepali and used to teach those interested children Nepali alphabets under a small thatched-roof shack in the village. He was not among those to be interested children due to his status as a Dalit child, as he was not allowed to enter inside the house of upper-caste Brahmins, and Dalits were not supposed to learn to read and write. Currently, he was staying with his son and daughter-in-law in one of the refugee resettlement locations in Panorama City.

Bhakta Bahadur recalled his childhood as full of both struggle and pastoral romance. As a lower-class Dalit family, they mostly earned their sustenance through sharecropping and working in the farm of other well-placed farmers in the village. He conveyed to me his memories of setting up a cowshed further north in the forests of Bhutan when he was still a child. He helped his father with the daily chores in raising cattle, hewing and tilling newly deforested plots of land for farming, and leading a pastoral life in the southern hinterlands of Bhutan. Bhakta Bahadur looked sadder as he recollected how his family later had to give up everything they had and leave the country when the Bhutanese army ordered them to evacuate their village within seven days. He didn't even know what the democratic movement was and how his family had committed treason against the king of Bhutan as anti-nationalists. He only knew that the nearby school his children went to were closed, that they had to wear gho and kira (Bhutanese

\footnotetext{
16 A popular folk song in Nepal, especially sung duet by male and female singers with musical performances, such as slapstick, humor, parody in tune with typical local style in singing, dancing, and dressing.
} 
national dresses for men and women, respectively) even when working in the farm, and that almost all of the neighbors in his village were leaving their homes one after the other at the order of the army. They left Bhutan in 1992 empty-handed, taking nothing with them but two kilos of rice and a bunch of bananas for snacks on the way. After staying in the refugee camps in Nepal for twenty years, they came to the U.S. in 2012.

Although Bhakta Bahadur didn't get to read and write in the refugee camps in Nepal, he constantly watched TV, especially for news and music programs. Now that he had Internet facilities available in the U.S. apartment, Bhakta Bahadur regularly watched Nepali news, comic skits, films, and folk songs on YouTube and kept himself up-to-date about Nepal. During my several visits to his home, I noticed him juggling through computer mouse to hit on the images of the videos on YouTube. He told me that that he didn't have any language, he mostly got by and found his programs by looking at the images and identifying which songs or serials he liked to watch. He also reflected on the immobile life in the U.S. as a non-speaker of English and contrasted it with his spirited and pleasant life back home in Bhutan and Nepal when he used to attend religious and festive occasions in the community and had a collective life as opposed to an individualistic sedentary life in the U.S. When I asked Bhakta Bahadur how he spent his days in the U.S in average, he replied:

At this age, I can't engage in other activities; the main problem for me is the problem of language. I become a dumb person when I go outside and want to communicate with English speakers. Luckily, my son has managed TV and computer for me to watch the programs I like. I am mostly fond of lok-dohoris and other Nepali comedy serials. Some of the events in these programs remind me of my own youth and take me back to my energetic life back in Bhutan and Nepal. I always recollect with fondness those times and days and live my present life on those memories. This computer has helped me so much to gain that experience in my old age. 
Bhakta Bahadur frequently took an imaginary travel to his collective homeland through new media technologies. He thus created an imaginary homeland in his host country through electronic media by constantly immersing himself into the cultural, linguistic, and musical virtual world. That homeland in the mind of Bhakta Bahadur remained imaginary too in the sense of being romanticized, since that homeland was bad enough that it drove him out.

Paralyzed both physically and linguistically in the new homeland, Damber, in his mid-eighties now, remembered his days in Bhutan as a nation builder, who, along with his other Nepali neighbors in the South, were involved in the modernization of Bhutan in the 1960s. Damber recalled that the Lhotshampas, at least a member from a household, were involved by the government of Bhutan in digging the gravel road from Paro to Thimpu, blasting the hills and turning over the rocks on the way throughout their fiveyear harsh labor on the road. Hari K. Chhetri, a long-time high-ranking government official from the ethnic Nepali community in Bhutan, has corroborated this statement in his recent book on the situation of Lhostshampas during the decades of 1980s and 90s. According to Chhetri (2013),

For a people who prided in their attachment with the land and owed total allegiance to the nation and made huge contribution to the task of nation building, it was a painful betrayal of trust by the government. Truth be told, the edifice of modern Bhutan was built on their blood, sweat and tears. If it was not in the main for the Lhotshampas, who dutifully paid their taxes and joined the conscripted labour force giving it strength, skill and number under different national programme of compulsory labour paid and unpaid - like Druk Dom and Sum Dom in the 1960s and 70s, Chuni Dom in the 1980s and Goongda Woola from 1988 - the government certainly would not have accomplished the massive programme of nationbuilding. So without them, it is doubtful if Bhutan would stand where it is today in terms of development. (p. 103). 
Self-taught to read Nepali Vernamala by writing with fingers on the dust when he was growing up in the late 1930s and early 1940s in a remote village of Bhutan, Damber could at least keep track of his wages when he worked as a laborer and read Hindu scriptures although he practiced Kirat as his main religion. He talked about harmonious relationship between Kirat and Hinduism and said that his religion was a part of Hinduism, so they celebrated all the festivals and ceremonies collectively with all other Nepalis in the South. He recalled that in the refugee camps in Nepal, his family continued to follow all the traditions the same way despite so many trials and tribulations for survival and education of his children. Now that he was very old, he could hardly do anything except to live on those past memories. Damber felt happy that the computer had become his friend at this old age:

My son and daughter-in-law leave for work in the morning and turn up only in the evening. My grandkids go to school, so when I can't go to the बुढो स्कुल (he fondly calls the Elderly Care Center as the school for the elderly as budo-school in Nepali) or even when I come back from there, I mostly watch news and other musical events on computer so I remain busy.

I saw him busily watching recent news and other folk songs on YouTube in the class at the Elderly Care Center when the class was not running. When he wasn't watching any programs on computer and not taking class, Damber mostly talked to his cohorts at the Center with much relish, reminiscing about his days in both Bhutan and Nepal.

These stories about the usage of new media by the members of Bhutanese refugee community offer us an insight to see how moving images meet deterritorialized viewers across the globe, intermingling the images of the media into local repertoires of humor and resistance. Such mobile and unforeseeable relationship between mass-mediated 
events and refugee audiences shows the shifting and transforming literacy practices of recent immigrants, whereby refugee individuals and communities seek to annex the global into their own practices of learning in the globalized and digitized contexts, creating a plurality of imagined worlds. Stressing the role of the collective imaginary in shaping the identity of transnational migrants, Appadurai (1996) writes: "It is the imagination, in its collective forms, that creates ideas of neighborhood and nationhood, of moral economies and unjust rule, of higher wages and foreign labor prospects. The imagination is today a staging ground for action, and not only for escape" (p. 7).

The elderly people, who are less educated in English, seem more at home with media and other resources in other languages than that in English. In their imagination, they create a small home inside the diaspora, where they listen to the music, watch YouTube videos, and observe religious services in Nepali and Hindi. They also use Nepali to discuss political and social issues about Nepal and Bhutan in public forums such as festive gatherings, family rituals, and outings. While the elderly and middle-aged people mostly live a small world of Bhutan, the other adults and teenagers maintain mostly Nepali mainstream culture and live in an imaginary Nepal in the diaspora all over during such occasions. Their participation in such various literacy and cultural activities in other languages in the meantime helps the refugees navigate their social, cultural, and political spaces in more meaningful ways. For example, Harisharan actively participated in multiple literate activities and utilized his repertoires in a way to gain and share both learning and teaching experiences inside and outside of his refugee community. While he shared with his community in Nepali the experiences about his works and sufferings in Bhutan, and how he gradually coped with those challenges while in the refugee camps in 
Nepal, and how he was learning English language and culture in the U.S., he used English in Elderly Refugee Literacy program to communicate with the instructors and fellow participants. Harisharan's rich experiences of fighting for language rights, rituals, and ethnic identity while in Bhutan becomes a saga of adventures that highly motivates and appeals to his audiences both inside and outside his community.

Reading and writing, as illustrated in the examples above, become translingual and multimodal practices, which can be "understood as social, economic, geopolitical, and cultural, as well as linguistic transactions across asymmetrical relations of power. In such transactions, meaning is necessarily and always the product of translation across differences, even in ostensibly monolingual settings" (Lu \& Horner, 2013b, pp. 27-28). The significance of the participants' use of literacy technologies not associated with school lies not in the technologies themselves but the agency they feel in using them for the purpose of their literate activities. In the accounts of literacy practices of the Bhutanese refugees across generations, as discussed throughout this chapter, we see that media practices, and other literacy events among the refugees substantially contribute to their identity formation, in terms of social, ethnic, cultural, national, by not only sustaining bonds with home country (Bhutan or Nepal) or by engaging with the new country, i.e. the U.S., but by engaging in the continuous process of cultural change, thereby creating their own distinct Panorama City Bhutanese-Nepali culture. Although the participants seem to be reproducing their prior culture and literacy practices and attempting to preserve them in the context of the U.S. (as most of the participants like Harisharan and Resham talked about during the interview), the practices themselves are taking technologies not associated with that culture to represent (and therefore, change) 
that culture. In many cases, as indicated in the discussions in Chapter 3 and this chapter as well, those practices are directed at changing the culture or manifest changes: changes in mother/child relations (as in the case of Harikala, Pramila, and their children), in the role of women (as the examples of Amrita, Rekha, and Ramila show), and so on. The consequence is an ongoing emergent production of a Panorama City Bhutanese culture, drawing on various resources and quite different from what in theory might be identified as the "original" Bhutanese/Nepalese culture to be found, somewhere in the past, among the Lhotshampas living in Bhutan. 


\section{CHAPTER V}

\section{RESISTING THE FINALITY OF MONOLINGUAL CLOSURES: IMPLICATIONS FOR PEDAGOGY AND EDUCATIONAL RESEARCH}

The pattern of meanings and values through which people conduct their whole lives can be seen for a time as autonomous, and as evolving within its own terms, but it is quite unreal, ultimately, to separate this pattern from a precise political and economic system, which can extend its influence into the most unexpected regions of feeling and behavior. The common prescription of education, as the key to change, ignores the fact that the form and content of education are affected, and in some cases determined, by the actual systems of [political] decision and [economic] maintenance. (Raymond Williams, 1961)

If we take seriously the idea that we can never step twice into the same river, if we start to rethink what it means to talk about things being 'the same' - the same language, the same text, the same discourse - then we can start to see that languages in general, and global Englishes in particular, do not have one point of origin but rather multiple, co-present, global origins. Global Englishes are not what they are because English has spread and been adapted but because they share different histories. English has always been local.

(Alastair Pennycook, 2010)

\section{Introduction}

Drawing on insights from New Literacy Studies, and multilingual, multicultural, and multimodal literacy research, this study argues for the need to recognize varieties of text forms associated with multilingualism, multimodality, and digital technologies. More specifically, I argue that the analysis of the Bhutanese refugees' literacy practices is, on

the one hand, a contribution to distinguishing among types of immigrant literacies (and experiences) but also, on the other hand, a demonstration of the always emergent character of literacy and language practices and identities, with the participants in this 
study presenting a more obvious instance of an emerging (translingual, transnational, transcultural) norm at odds with monolingualist norms of language, literacy, culture, identity, and nationality. In this sense, this study has implications for broadening educators' understanding of reading and writing practices that the minority communities like refugees perform beyond the classroom and for expanding what counts as literacy as shaped by geopolitical, cross-cultural, and cross-language relations. In addition to providing new conceptualizations of literacy studies, this study also offers new methodological approaches for analyzing multilingual and multimodal literacy practices of minority communities through critical ethnographic research.

This study helps uncover biases in terms of how they affect literacy practices of marginalized communities and deconstructs the many ways that an ideology of literacy becomes complicitous in tarnishing our evaluations of the literacy practices of immigrant communities like refugees and their educational (in)effectiveness in academic institutions in the U.S. An analysis of refugee literacies becomes critical at a time when curricular practices, legislations, and policies are being created to hold multilinguals and multicultural literacy learners in place regardless of the increasing number of recent immigrants and refugees in U.S. schools and universities. I started this study with an urge to understand how literate practices of the refugees are shifting in a new context, and how the refugees negotiate their prior literacy practices to create new literacies as shaped by their encounters to diverse learning practices across various globalized and digitized contexts. In this concluding chapter, I will review the arguments underlying this dissertation by accounting for its contributions to the field of literacy studies, rhetoric and composition as well as intercultural communication and education, its limitations, and its 
future directions. I will also highlight pedagogical implications of this study by offering as examples my teaching strategies and writing assignments in first year writing classes.

\section{Discursive Rhetorics, Dynamic Literacies: Contribution to the Field}

In her analysis of multicultural academic literacies, Ferris and Hedgcock (2005) establish the need for our field to expand beyond the scope of school literacy. According to them, "Professionals should approach the teaching of composition as an opportunity to build their students' academic, vocational, professional, social, and cultural literacies, which clearly are multiple and informed by numerous types of expertise.... Such literacy practices often entail operations that are inherently much more complex than the mechanical reproduction of school-based genres" (2005, p. 33). Also, as discussed in previous chapters, the immigrants like refugees utilize multiple literacy forums, ranging from traditional non-formal literacy centers to non-traditional online social networking sites, to negotiate multiple subjectivities and divergent literacy needs. Therefore, our efforts as teachers and research scholars should be directed toward promoting contact zone literacies by accounting for the ways local community practices and official literacy practices converge and clash along various contexts and locations that our students participate in.

Refugee literacy practices can offer us significant pedagogical insights by virtue of their direct implications for the academic policies and practices as designed and implemented in U.S. universities and schools. In the increasingly globalized and digitized contexts of learning, what students bring to school from their communities has direct relevance to their experiences of reading and writing development in schools as well as in communities. In the process of knowledge making, students move sedimented features 
from various literacies into contact with one another. Therefore, the growing populations of multicultural and multilingual students and scholars in the academy today precipitate the urgency of addressing and recognizing immigrant literacy practices by helping the students not only build on and add to their existing literacy practices, but also accept the fluid and emergent character of all literate practices. In light of the always emerging kinds of literacy practices I've documented throughout this dissertation, the issue seems less one of tolerance of stable, if different, literacy practices and more an issue of accepting the fluid character of all literacy practices, school included. Furthermore, as Vieira (2011) concurs, when the field of rhetoric and composition expands its scope to account for literacies in globalized and digitized contexts, it is essential to focus on immigrant literacies that move across vast spaces, "connecting readers and writers from communities across the globe" (Vieira, 2011, p. 457). This situation also further calls on U.S. educators to reorient themselves more globally to help them configure how the interaction between the local and the translocal helps shape each other in a way to developing better teaching and learning models for the diverse students in the academy today.

It becomes essential to help teachers, literacy workers, teacher educators and program planners theorize their practice in the contexts of the specific cultural differences, localities and politics they are faced with (Street, 1995, p. 136). Reframing of literacy as a critical social practice offers us a pedagogically useful perspective to account for cross-cultural, historical, and language practices of students in classroom. As this study indicates, "these often fine-grained explorations of out-of-school literacy practices provide educators with conceptual tools for bridging between the resources students bring 
to school and the different literacy practices they must learn to control - a model that is equally appropriate in adult and workplace literacy instruction" (Brandt, 2001, p. 8). Such resources, however, come to schools only as sedimented features, mixing from diverse literacies from students' communities. Only if the teachers let these features contribute to academic contexts do such features promote students' better understanding of the layered literacies they inhabit. Also, there should also be enough students interested in bringing such resources in. In other words, sedimented features of alternative literacies have no changing power in school unless there are enough teachers and students working together to make them mix with the schooled literacy for an extended period of time.

\section{Implications for Classroom Pedagogy: My Position as a Writing Teacher}

Moje and his colleagues (2008), and Beck (2009) talk about positive engagement of students in learning when the content of a lesson and the means by which it is delivered connect to their own lives. For example, when I encouraged my freshman composition students to engage in such learning practices by recognizing their multilingual and multicultural repertoires as they wrote their literacy narratives, most of them felt more comfortable talking about the role their cultural and language contexts played in their literacy development in the community. In one of my assignments on literacy narrative, students wrote essays by bringing those cultural and linguistic resources into their academic writing ${ }^{17}$. As a response to this assignment, some

\footnotetext{
${ }^{17}$ The main portion of the assignment was: Write an essay by taking an episode from your life that represents an important moment in your cultural or literacy development. This episode can be anything ranging from an early memory about a cultural event or a subcultural practice to an event at school, home, or your surrounding that was interesting, humorous, or embarrassing. You need to make clear the ways in which the event you are writing about is significant for you now. As you develop your narrative, you can address the following questions:

-How did this event change or otherwise affect you?

-What aspects of your life now can you trace to that event?

-How might your life have been different if this event had not happened or had turned out differently?
} 
linguistically and culturally diverse students in the class chose to write about linguistic, cultural, and academic tensions based on their own experiences in a way to suggest that literacy learning is shaped by their experiences of difference. Such choice to bring up issues related to their ethnic, linguistic, and cultural diversity speaks significantly about these students' agency in writing as well as rhetorical choices they make in order to negotiate tensions through dialogue and peer response. Responding to this assignment, one of the linguistically and culturally diverse students, who I call Rakesh, for example wrote an essay entirely based on his cultural and language experiences identifying his language and cultural heritage back to India during his several visits to it. Rakesh decided to write about his background of being an Indian American, how he becomes different as a student from minority culture, and how he feels hanging between his American and Indian identities. In addition to this, he uses more space of his paper to talk about cultural rituals of a wedding ceremony that he celebrates with his relatives in India. Rakesh was born of Indian parents in America, and was schooled in the American education system. But because his family was multilingual and multicultural, as his family spoke Hindi and other Indian regional languages at home, and observed almost all of the Hindu religious activities and festivities in addition to Christmas, his fixed and subjective positions always made him appear as an outsider in America. In his account of a visit to India, Rakesh also recounts about his complex identity, for by his appearance he becomes a part of the mainstream in India, but his taste and language make him an outsider in his parents' home:

My whole life I have only known what it is like to be a minority. I was now part of the majority, and I felt somewhat surreal but more so confused. In

-Why does this story matter to you? 
America I am not the norm, I was a different skin color, a different hair color, and a different culture. In India, however, I was the norm. And for the first time in my life I was able to compare what it was like to be a part of both.

This feeling of otherness and non-belongingness in either culture helps him define his identity in a different way. Furthermore, the way Rakesh performs his identity through writing indicates the contradictory and complex nature of identity; what matters most in the performative identity of the students like Rakesh, however, is an agency they manifest through such writing. By virtue of his being rooted in the mixed cultural identity, Rakesh in his personal narrative suggests that he cannot be categorized as either American or Indian. His situation is suggestive of mixed identity relations that also become representative of considerable demographics of students in U.S. universities in recent decades. Rakesh takes pride in being different and wants to assert his differential identity more openly when he says:

I enjoyed being different. I enjoyed being the minority. In India, I felt no sense of pride in the fact that I was Indian. This was due to the fact that most of the people there were of the same race. It just felt normal. In America, however, the feeling is totally different. I feel I have something that other people don't. I feel I speak for most cultures in America in the fact that they are proud to be different. So in no way am I promoting my race, or that it is better to be a minority.

The practice-based pedagogical model, which Canagarajah (1999) calls crosscultural pedagogy, became an appealing model for me to utilize in the classroom. Particularly fascinating was the way this approach encouraged students doing this assignment to participate in peer response, where both NES and NNES students actively engaged in negotiation and dialogue in a way to help each other in the process of meaning making through their writing. Doing so helped all of the students in class, both NES and NNES, enjoy agency as well as engage in meaning-making process in their 
response to the assignment. In other words, this kind of diverse pedagogy promotes translingual rhetoric, not monolingual rhetoric, where student writers from diverse cultural and linguistic backgrounds could effectively communicate with readers influenced by such cross-cultural and multilingual pedagogy, and where native speakers of English students were willing to be open to unexpected viewpoints historically dismissed in monolingual cultures. Writing in this sense is best "not treated as a unified object but rather as an agglomerate of very different resources, and each of these resources demand[s] separate attention, for access to different resources tend $[\mathrm{s}]$ to differ considerably" (Blommaert, 2013, p. 442). The diverse students like Rakesh engage in matters of agency by affecting changes in their literacy practices and learning through the use of their prior language and cultural resources. Student agency, as Fishman and McCarthy (1996) underscore, should be seen as fundamental to the construction of knowledge in our teaching pedagogy. To materialize such agency in practice, according to Fishman and McCarthy, teachers should set "the conditions for student ownership and perplexity," whereby both teachers and students engage in "cooperative inquiry" (p. 352). One of the reasons to affect these students' decisions for making such challenging choices may have arisen because of my own position as a minority instructor, culturally, linguistically, and ethnically, which not only helps culturally and linguistically diverse students acknowledge their difference as being in congruence with that of their instructor, but also encourages them to take it as an opportunity to talk about their cultural and racial difference as a resource in their writing. In the meantime, I may have some limitations too as a non-native speaker of English and as a teacher not very familiar with the popular cultural contexts of the U.S. For example, in my classes, I have encountered some 
multilingual, especially international, students, who want me to teach them grammar and standard norms of English that they want to learn for succeeding in the academy. Their assumption is that following the norms becomes a blueprint for success in their career. Such assumption is an outgrowth of the monolingualist ideology that promotes "standard English" as the only form that helps students succeed in the workplace. But, as Canagarajah (1999) rightly argues, "We should stop conceiving second language literacy as an acquisition of decontextualized grammatical structures, rhetorical skills, thought patterns, or discourse conventions. We should develop a perspective that is grounded in the broadest possible social context" (p. 148). My positioning in this sense becomes an important element in the pedagogy of my teaching. Stressing the need to recognize and value personal identity factors in our pedagogy of teaching, Holloway (1993) suggests that "we embrace to our own ends the identity politics - the perspectives of race, culture, gender, and ethnicity - inherent in language. We can claim the power of our voices, and their complexity, and their complexions to assert the dimensions of our concerns, to call attention to our successes in vitalizing the community of the university - both its faculty bodies and its student bodies" (p. 617, emphasis the writer's).

In some ways my presence in teaching first year writing subverts monolingualist cultural norms, but, in the meantime, as I have suggested above, my own pedagogy engages with the clash of norms, too, to encourage a different cultural norm for writing in the classroom, which, as identified by scholars of multicultural and postcolonial pedagogy like Karamcheti (1996), and Pratt (2008), becomes a conflictual space, a contact zone. Writing class thus becomes a location where the issues of race, class, gender, and identities get enacted. The classroom, as a conflictual cultural space, 
manifests the tension as being typical of a "contact zone." Drawing on Pratt (2008), I consider the classroom to be one of the "social spaces where disparate cultures meet, clash, and grapple with each other, often in highly asymmetrical relations of domination and subordination - like colonialism, slavery, or their aftermaths as they are lived out across the globe today" (p. 7).

In the same vein, the multilingual and multicultural pedagogy that I advocate encourages students not to maintain multilingualisms as discrete practices but to cultivate such practices to develop an agency over their academic reading and writing practices with an understanding that literacy practices are situated in broader social and cultural contexts. The dialogical pedagogy practiced in the classroom can help students develop translingual competency. How to be effective in contexts outside the classroom is still an open question. However, as teachers we can at least offer students practices that can serve as resources for their future "journey", which might be different, definitely more difficult since the dialogical model is not a dominant one. As Suarez-Orozco, Suarez-Orozco, and Todorova (2008) argue, "In order to foster higher-order cognitive skills, competencies, and interpersonal sensibilities, schools will have to accomplish more than ever before. If schooling is to be relevant and in synchronicity with the problems and opportunities of the day, it will need to prepare youngsters to deal with the increasing complexity and diversity that characterize their lives" (p. 2). This expanded context for understanding such complexity and diversity regarding multilingual literacy practices of the recent immigrants like refugees further helps us understand how much agency the learners actually wield as they change, build on, and negotiate their prior literacy practices to fit the cultural and academic contexts in the U.S. 
For teachers and scholars of literacy, such day-to-day accounts of literacy

practices in the communities, as Brandt (2001) maintains, "can shed light on how general cultural attitudes toward reading and writing affect encounters with reading and writing in schools" (p. 149). Taking an ethnographic perspective in writing and research offers opportunities for our students to explore such cultural attitudes in their writing to help them engage in meaning making practices in schools. For example, in my first year writing courses, I mostly design assignments with such an ethnographic perspective to help students see writing as a medium to better understand their own social, cultural, and linguistic experiences as resources. In such assignments (see Appendix B for a sample assignment), I challenge my students to research alternative literacies using qualitative research and multimodal textual forms, which have involved students visiting various subcultures in the community, interviewing people, and analyzing their cultural and language practices. In one first year writing class, three students created a multimodal writing project by analyzing the language patterns of an immigrant family from South Asia. The students visited this family throughout the semester, interviewed four of the family members, and wrote an ethnographic essay to explore how this family's learning of English in the U.S. was affected by multilingual and civic contexts. Building rhetorical knowledge in a variety of modes, sites, and genres of language use, the students used rhetorical and communication designs to explore the complex interactions that existed within their social and cultural contexts.

\section{Intra-Community Dynamics as Mediating Practices}

Another strength of this study is to shed light on intra-community dynamics and interactions that generally get glossed over in studies about minority community's 
literacy practices. As Bizzell (1982) acknowledges, there are as many differences within communities as there are between them. Such differences might create open areas for communication within community members and in the meantime can be implicated into the "unresolved problems of the community, experiences that remain anomalous in the community's interpretive scheme, or they may be areas the community has never even considered dealing with” (Bizzell, 1982, p. 226). An individual, according to Bizzell, may "bring one of these open areas into the range of the community's discourse if her argument for an interpretation of it is sufficiently persuasive in terms the community already understands" (p. 227). This also provides us with a deeper understanding of the social effects of literacy in a way to reconfigure the general attitude that hardly recognizes the refugees' socially constructed identities they held prior to their flight. Such normalizing attitude toward refugees affirms that "all refugees, merely by being 'refugees', are to be treated as 'equal' (read, 'identical') regardless of their vast variations in personal background, motives for leaving, reasons for escape, and plans for the future. That is, individual identities and continuities, sustained by unique biographies, are systematically neutralized..." (Daniel and Knudsen, 1995, p. 3). As such, one of the underlying arguments of this study is that literacy is not a neutral, unidimensional construct, but rather a set of lived experiences that differ not only from community to community but within a community and across time and that such intra-community dynamics offer participants opportunities to negotiate their differences through literacy activities.

As shown above in the discussion of the sample extract from Rakesh's paper, valuing interpretive agency in the classroom leads to a view of resistance on behalf of 
students that is based on their history of knowledge as it relates to social, cultural, and linguistic literacies that they recontextualize for the purpose of classroom engagement. Such a practice of recontextualization (see Pennycook, 2010) is located in classroom assignments and activities, and is situated at the intersection of disciplinary knowledge and the students' knowledge and experience. For example, "the choices for resistance," as Wallace and Ewald (2000) maintain, "will be many and part of the ongoing act of meaning making in the classroom" and may be intricately tied to "the multiple subjectivities and difference embodied in students' knowledge and experience ... ." (p. 22). Wallace and Ewald's perspective seems valuable, especially in comparison to Bizzell's (1982), which seems wary of students who resist the goals of the critical educator, and which renders student differences internally uniform rather than containing hegemonic and counter-hegemonic elements. While it may be true from a new historical and cross-cultural perspective that at any given moment students and teachers alike are subjects positioned within a specific historical time and place, it seems necessary to understand students as having higher degrees of agency in the classroom, for such a perspective implies respect for students as active agents rather than as objects involved in the dialogic process of knowledge-making. As Wallace and Ewald (2000) believe, "for mutuality to obtain in pedagogy, learning must be seen as transformational for both students and teachers ...” (p. 100).

\section{Literacies for Nationhood}

Other useful finding from this study with the Bhutanese refugees has to do with the participants' strong sense of loyalty to a new nationhood. Unlike what the studies by Guerra (2008), and Vieira (2011) present in terms of their participants' lack of 
commitment to the national spirit to the U.S. as "United Statesians" (Guerra, 2008, p. 7), the Bhutanese refugees have cherished a deep-seated patriotism to the U.S. I noticed such spirits among them when I observed their persistence in the preparation for citizenship tests and also in their organization of literacy events and religious festivals, during which they voluntarily performed and sang the American anthem and hoisted the American flag along with singing the Bhutanese national anthem and hoisting the Bhutanese national flag. This may have been caused by their sense of rootlessness for a long time and also feeling of non-belongingness and statelessness due to their ongoing political conflict against their own birth country because of its biased treatment to them as ethnic Nepalese people following different culture, language, and religion. They felt very proud to call themselves "Emericans" and tried to get citizenship as soon as they became eligible to receive one. The Bhutanese refugees thus developed and employed literacies from various cultural and social locations to negotiate multiple languages, cultures, religions, citizenship and political affiliations, and identities within and beyond their immediate communities so as to assert their identity as new citizens in the U.S. Doing so also enabled the Bhutanese refugees in Panorama City to challenge the outsiders' identification of them first and foremost as "refugees" and establish theirs as a unique Panorama City Bhutanese culture that is characterized by their emerging identitarian and literacy practices.

\section{Multiliteracies in the Making: Fluid and Emergent Literacy Practices}

With findings and arguments as discussed above, this study responds to New Literacy Studies' call for culturally and socially situated literacies in a way to promote a socially and culturally responsive pedagogy while advocating for multilingual and 
multimodal literacies beyond school classrooms. Furthermore, this study highlights the need to recognize the in-process multilingual and multicultural repertoires of recent immigrants as valuable and highly charged experiences. Implying the urgency of accounting for writing and other literate practices outside of classrooms, Williams (2010) argues that

If the claim of rhetoric and composition is to study student writing, it must be in conversation about how writing happens before and after students step on to university campuses. It is hard to make a serious claim about how pedagogy affects student writing in the brief hours they spend in the classrooms if it ignores the many hours they spend writing at home and at work, with rapidly evolving online media and technology. Understanding more about the literacy practices in which students engage outside of the classroom or before they reach college (or practices in which they may engage after college) complicate and benefit our research and our teaching. (p. 133).

There are many literacies and ways to learn about them. Only when we account for the cultural and language contexts of literacy practices can we better understand those various literacies needed for communications in globalized digital environments. As Cope and Kalantzis (2000) argue,

Literacy pedagogy now must account for the burgeoning variety of text forms associated with information and multimedia technologies. This includes understanding and competent control of representational forms that are becoming increasingly significant in the overall communications environment, such as visual images and their relationship to the written word - for instance visual design in desktop publishing or the interface of visual and linguistic meaning in multimedia. (p. 9)

Communicating in text alone is not a robust form of communication: instead, a number of different semiotic channels like audio, video, podcasts and other individual resources are integrated and utilized. There are differences and perspectives among us that help us contextualize our works in the larger world that we don't always recognize otherwise. Therefore, in addition to dealing with general reading and writing practices of a refugee 
community, this study also addresses questions that are directly pertinent to multimodal, multilingual, and multicultural teaching and learning practices in the academy: why should we pay attention to all the different media and modalities for composing meaning that students are calling to our attention? What responsibilities do we have to teach conventional academic writing and multiple modalities of composing meaning? Are university faculty - grounded by their education in the environment of print - prepared to work productively with people who may prefer works with other literacy technologies?

As discussed and illustrated in Chapters Three and Four through the literacy accounts of the Bhutanese refugees, the refugees' literacy and language experiences - the ongoing language learning at learning centers, singing religious songs and organizing other literacy events in the communities, creating multimodal texts across online forums, writing academic essays and maintaining notes for literacy events, maintaining musical, arts, and cultural groups - all prove to be fluid and emergent activities, the political, social, cultural, and academic values of which are not limited to a particular structure, setting or genre, but are largely dependent on time, location, and context. The examples and illustrations throughout this dissertation indicate the unstable and messy nature of literacy and learning practices that are highly contingent upon social and material conditions.

The role of schools has changed along with the shift in global geopolitics. Cultural and linguistic diversity has now become a norm rather than a peripheral concept, resulting in the change of meaning in the conceptualization of literacy and language. In the context of such broadening diversity of language and literacy practices, "We shouldn't return to monolingual assumptions about our students; nor should we retreat 
from writing opportunities that encourage all students to reflect upon their literacy experiences, their cultural and linguistic legacies" (Ortmeier-Hooper, 2008, pp. 409-10). The scope of literacy pedagogy needs to broaden in a way to encompass diverse learning practices facing the increasingly multilingual and multicultural populations of recent immigrants and refugees in the U.S. Such practices foster a better learning environment in those communities by envisioning a better future of literacy learning for the recent immigrants. Recognition of local diversity and global connections in academic practices, as Cope and Kalantzis (2000) note, means

not only that there can be no standard; they also mean that the most important skill students need to learn is to negotiate regional, ethnic, or class-based dialects; variations in register that occur according to social context; hybrid cross-cultural discourses; the code switching often to be found within a text among different languages, dialects, or registers; different visual and iconic meanings; and variations in the gestural relationships among people, language, and material objects. Indeed, this is the only hope for averting the catastrophic conflicts about identities and spaces that now seem ever ready to flare up. (p. 14)

Although an overarching theme of this study mainly rests on educational contexts, as this study offers insights into the learning practices of a refugee community, the implications of this research expand further to the issues of social justice, citizenship rights, and socio-political and economic contexts across various spaces that the refugees inhabit. The general conditions under which the participants in this study developed their literacy and language skills suggest that transcultural and translingual reading and writing repertoires are forged through everyday interactions across difference. As suggested by the learning experiences of multilingual refugee participants in this study, although the participants seem to share a common perspective to a difference and a shared use of negotiation to create meaning in different contexts, they engage in such practices in 
specific ways highly informed by their own histories, memories, and changing conditions of their life in the places of migration.

With such undertones throughout the dissertation, I argue that we should pay attention to our learners' identities as emergent and fluid so we could treat them not as a uniform and stable entity representing a particular region, language community, or cultural group but as agentive individuals whose literacy practices are shaping and shaped by the ongoing shift in the trajectories of globalization, digitization, postcolonial migration, and geopolitical relations. In other words, while the study focused on specific, refugee individuals, the refugees' experience is in some ways an extreme version of what all of us experience in our identities. Overall, in addition to the strengths as discussed above, this dissertation contributes to the development of studies of immigrant literacies by articulating the effects of distinctions among immigrant groups (distinguishing between "voluntary" and refugee immigrants) and the effects of intra-group dynamics (by caste, gender, generation, and religious affiliation) on the specific literacy practices of members of immigrant refugee groups. Of greater significance are the practices of those community members, who are marginalized within their communities and who appropriate the rhetorical powers of texts and positions to form and transform the norming structures that are increasingly transborder, translingual, and transcultural.

Despite the seeming alignment of many of the Bhutanese refugee participants with monolingualist, monoculturalist views of preserving an authentic culture, i.e. Bhutanese-Nepali culture, imagined as stable and internally uniform, their actual engagement with literacy practices in Panorama City through the transnational, diverse and fluid practices with language, culture, and traditions demonstrates that their literacy 
practices are more fluid, emergent, and situated in the new contexts. So, the discussions throughout this dissertation highlight and illustrate tensions between, on the one hand, dominant monolingualist views (by both some of the teachers and also some of the participants themselves) in their notions about Bhutanese/Nepalese culture/language and traditions, and, on the other, the participants' engagement in fluid, diverse, shifting, situated, and emergent practices. While there might be a need for strategic essentialism by some of the refugee community in response to the history of persecution they faced in Bhutan, that very essentialism might have informed the ideologies that led to their expulsion from Bhutan and their persecution for not conforming to a kind of pure Bhutanese essence (in their dress, language, writing, religion, etc.). The refugees seem caught between two manifestations of monolingualist/monoculturalist ideologies, Bhutanese and American, and at times respond with a different version of this themselves, though at other times working against it.

\section{Limitations of the Study}

Through an analysis and interpretation of the literacy practices of the Bhutanese refugees in this study, I don't mean to generalize the literacy practices of all recent immigrants in the U.S.; neither do the ideas expressed by the participants in this research represent generalizations about the existing literacy practices of all minority communities in the U.S. My purpose here is to illustrate cross-cultural, multilingual, multimodal, and discursive learning practices of the refugees in order to challenge misconceptions and stereotypes about refugee literacies in general and literacy practices in particular. While mainly contributory to the field through its insights into the fluid and emergent literacy practices of the newly arriving immigrants like refugees, this study also has some 
limitations. As I discussed in Chapter Two, despite an easy acceptance of me by certain quarters of the Bhutanese refugees due to some similarities in social and educational status, my position as a non-refugee and a researcher from an elite research university limited my access to a certain group of refugee members within the community. I couldn't fully access as many members of lower class, caste, and indigenous members of the community as I wanted to. For example, Bible reading groups and lower caste members of the Bhutanese refugees didn't easily accept me into their community the way other groups did because of my subjective and objective positions.

Therefore, although I collected data extensively by representing a larger number of participants with a balance of gender, profession, ethnic identity, and language diversity, my analysis could have been more encompassing had I been able to reach out to a larger non-privileged population within the Bhutanese refugee community. Similarly, I originally had planned to interview other members of the literacy sponsors within Panorama City, such as native English speaker ESL teachers, refugee resettlement managers, and other affiliate organization representatives along with the Bhutanese refugees for this study. However, given the specificity and scope of this research, I found it to be too overwhelming to include all of them at this time. I then decided to limit it within the Bhutanese refugees in Panorama City. While I see working in translation across languages (from Nepali into English, and vice versa, and also looking at dispositions of other languages, such as Hindi and Dzongkha) during this study as my strength, I also find those experiences as limiting in the sense of the inevitability of the limitations of translational practices given what is always lost in translation. 


\section{Future Directions}

The limitations I mentioned above in terms of this study, however, open avenues for future directions that the research with recent immigrants and refugees in the U.S. can take. For example, although I gave some space to talk about the issues of social justice and citizenship in Chapters 3 and 4 in the context of literacy development, that space becomes too little to do justice compared to the vastness of these refugees' expressions

and desires for social justice and political rights during my interviews and other informal conversations with them. Focused mostly on reading and writing practices of these refugees, this study had certain constraints on the way to involve all of the participants' voices and urges for freedom, political rights, and citizenship status. We can conduct substantial research on such practices on refugees' desires for belongingness, social justice, ethnic identities, and political rights, which have direct implications for literacy studies in the context of growing diverse populations in the U.S. arising as a result of postcolonial migration and globalized geopolitical relations. Furthermore, though I was not able to explore the issues of caste, class, religion in detail due to the constraints of dissertation study, such issues are of critical importance for future research. 


\section{REFERENCES}

Ahearn, L. M. (2008). Fateful literacy: New meanings, old ideologies, and some unexpected consequences of Nepali love letter writing. In M. Prinsloo \& M. Baynham (eds.), Literacies, global and local (pp. 93-116).

Amsterdam/Philadelphia: John Benjamins Publishing Company.

Althusser, L. (1994). Selected texts. In T. Eagleton (Ed.), Ideology (pp. 87-111). New York: Longman.

Anzaldua, G. (1987). Borderlands, la frontera: The New Mestiza. San Francisco: Spinsters/Aunt Lute.

Anzaldua, G. (2002, October 11). Beyond traditional notions of identity. The Chronicle Review: The Chronicle of Higher Education, pp. B11-B13.

Appadurai, A. (1996). Modernity at large: Cultural dimensions of globalization. Minneapolis: University of Minnesota.

Auerbach, E. R. (1989). Toward a social-contextual approach to family literacy. Harvard Educational Review, 59(2), 165-181.

Bakhtin, M. M. (1981). The dialogic imagination: Four essays. Cambridge: Cambridge University Press.

Balgopal, P. R. (Ed.). (2000). Social work practice with immigrants and refugees. New York: Columbia University Press.

Banaji, S. (2006). Reading 'Bollywood': The young audience and Hindi films. Basingstoke: Palgrave. 
Barton, D. (1995). Whose research? Conflicting agendas for development education research. International Journal of Educational Development, 15(4), 461-465.

Barton, D., \& Hamilton, M. (1998). Local literacies: Reading and writing in one community. London: Routledge.

Barton, D., \& Hamilton, M. (2000). Literacy practices. In D. Barton, M. Hamilton, \& R. Ivanic (Eds.), Situated literacies: Reading and writing in context (pp. 7-15). London: Routledge.

Basu, K., Maddox, B., \& Robinson-Pant, A. (Eds.). (2009). Interdisciplinary approaches to literacy and development. London: Routledge.

Bauman, Z. (1998). Globalization: The human consequences. Cambridge: Polity Press.

Baynham, M. (1995). Literacy practices: Investigating literacy in social contexts. London: Longman.

Baynham, M., \& Prinsloo, M. (Eds.). (2009). The future of literacy studies. New York: Palgrave Macmillan.

Beck, S. (2009). Individual goals and academic literacy: Integrating authenticity and explicitness. English Education, 41(3), 259-280.

Beck, U. (2005). Power in the global age: A new global political economy. Cambridge, UK: Polity Press.

Bernal, V. (2006). Diaspora, cyberspace and political imagination: The Eritrean diaspora online. Global Networks, 6(2), 161-179.

Bernard, H. R. (1988). Research methods in cultural anthropology. Newbury Park, CA: Sage Publications, Inc.

Bertaux, D. (1981). Biography and society: The life history approach to the social 
sciences. Beverly Hills, CA: Sage Publications, Inc.

Bertaux, D., \& Thompson, P. (1997). Pathways to social class: A qualitative approach to social mobility. Oxford: Clarendon Press.

Bhabha, H. K. (1992, January). Double visions. Artforum, 82-90.

Bhabha, H. K. (1994). The location of culture. London: Routledge.

Bizzell, P. (1982). Cognition, convention, and certainty: What we need to know about writing. Pre/Text, 3, 213-244.

Blommaert, J. (2005). Discourse: A critical introduction. Cambridge: Cambridge University Press.

Blommaert, J. (2010). The sociolinguistics of globalization. Cambridge, UK: Cambridge University Press.

Blommaert, J. (2013). Writing as a sociolinguistic object. Journal of Sociolinguistics, 17(4), 440-459.

Blommaert, J., Muyllaert, N. \& Huysmans, M., \& Dyers, C. (2006). Peripheral normativity: Literacy and the production of locality in a South African township school. Paper 36, Working Papers in Urban Language and Literacies.

Bloomaert, J., and Backus, A. (2011). Repertoires revisited: "Knowing language" in superdiversity. Paper 67, Working Papers in Urban Language and Literacies.

Brandt, D. (1998). Sponsors of literacy. College Composition and Communication, 49(2), 165-185.

Brandt, D. (2001). Literacy in American lives. Cambridge: Cambridge University Press.

Brooke, R., \& Hogg, C. (2004). Open to change: Ethos, identification, and critical ethnography in composition studies. In S. G. Brown \& S. I. Dobrin (Eds.), 
Ethnography unbound: From theory shock to critical praxis (pp. 115-129). New York: State University of New York Press.

Brown, S. G., \& Dobrin, S. I. (Eds.). (2004). Ethnography unbound: From theory shock to critical praxis. New York: SUNY Press.

Brueggemann, B. J. (1996). Still life: Representations and silences in the participant observer role. In P. Mortensen \& G. E. Kirsch (Eds.), Ethics and representation in qualitative studies of literacy (pp. 17-39). Urbana, IL: NCTE.

Brydon-Miller, M. (2004). The terrifying truth: Interrogating systems of power and privilege and choosing to act. In M. Brydon-Miller, P. Maguire, \& A. McIntyre (Eds.), Traveling companions: Feminism, teaching, and action research (pp. 319). Westport, CT: Greenwood Press.

Buckingham, D. (2003). Media education: Literacy, learning, and contemporary culture. Cambridge: Polity Press.

Canagarajah, A. S. (1999). Resisting linguistic imperialism in English teaching. Oxford: Oxford UP.

Canagarajah, A. S. (2006). The place of World Englishes in composition: Pluralization continued. College Composition and Communication, 57(4), 586-619.

Canagarajah, A. S. (2009). The plurilingual tradition and the English language in South Asia. AILA Review, 22, 5-22.

Canagarajah, A. S. (2011). Translanguaging in the classroom: Emerging issues for research and pedagogy. Applied Linguistics Review, 2, 1-28.

Canagarajah, A. S. (Ed.). (2013). Literacy as translingual practice: Between communities and classrooms. New York and London: Routledge. 
Cenoz, J., \& Gorter, D. (2011). Focus on multilingualism: A study of trilingual writing. Modern Language Journal, 95(3), 356-369.

Chhetri, H. K. (2013). Reminiscence: Petition and politics. Kathmandu, Nepal: Samjhana Press.

Cintron, R. (1997). Angels' town: Chero Ways, gang life, and the rhetorics of everyday. Boston: Beacon Press.

Conquergood, D. (1998). Beyond the text: Toward a performative cultural politics. In S. J. Dailey (ed.), The future of performance studies: Visions and revisions (pp. 2536). Washington, DC: National Communication Association.

Cope, B., \& Kalantzis, M. (Eds.). (2000). Multiliteracies: Literacy learning and the design of social futures. London and New York: Routledge.

Cope, B., \& Kalantzis, M. (2009). “Multiliteracies": New literacies, new learning. Pedagogies, 4(3), 164-195.

Cope, B., \& Kalantzis, M. (2010). New media, new learning. In D. R. Cole \& D. R. Pullen (Eds.), Multiliteracies in motion: Current theory and practice (pp. 87-104). New York: Routledge.

Crane, L. G., Lombard, M. B., \& Tenz, E. M. (2009). More than just translation: Challenges and opportunities in translingual research. Social Geography, 4, 39-46. Cushman, E. (1999). The rhetorician as an agent of social change. In L. Ede (Ed.), On writing research: The Braddock essays 1975-1998 (pp. 372-389). Boston: Bedford/St. Martins. 
Daniel, E. V., \& Knudson, J. C. (1995). Introduction. In E. V. Daniel \& J. C. Knudson (Eds.), Mistrusting refugees (pp. 1-12). Berkeley, CA: University of California Press.

Daniell, B. (1999). Narratives of literacy: Connecting composition to culture. College Composition and Communication, 50(3), 393-410.

Davies, C. A. (1999). Reflexive ethnography: A guide to researching selves and others. London \& New York: Routledge.

De Leeuw, S., \& Rydin, I. (2007). Migrant children's digital stories: Identity formation and self-representation through media production. European Journal of Cultural Studies, 10(4), 447-468.

Dirlik, A. (2002). Bringing history back in: Of diasporas, hybridities, places, and histories. In E. Mudimbe-Boyi (Ed.), Beyond dichotomies: Histories, identities, cultures, and the challenge of globalization (pp. 93-127). Albany, NY: State University of New York Press.

Duffy, J. M. (2007). Writing from these roots: Literacy in a Hmong-American community. Honolulu: University of Hawai'i Press.

Duneier, M. (1999). Sidewalk. New York: Farrar, Straus and Giroux.

Ek, L. (2009). Language and literacy in the Pentecostal church and the public high school: A case study of a Mexican ESL student. The High School Journal, 1-14.

Ferris, D. R., \& Hedgcock, J. S. (2005). Teaching ESL composition: Purpose, process, and practice. $2^{\text {nd }}$ ed. Mahwa, NJ: Lawrence Erlbaum Associates.

Filep, G. (2009). Interview and translation strategies: Coping with multilingual settings and data. Social Geography, 4, 59-70. 
Fishman, S. M., \& McCarthy, L. P. (1996). Teaching for student change: A Deweyan alternative to radical pedagogy. College Composition and Communication, 47(3), $342-366$.

Foster, M. (1992). Sociolinguistics and the African-American Community: Implications for Literacy. Theory Into Practice, 31, 303-311.

Freire, P. (1970). Pedagogy of the oppressed. Trans. M. B. Ramos. New York: Continuum.

Fox, H. (1994). Listening to the world: Cultural issues in academic writing. Urbana, Illinois: NCTE.

Garcia, O. (2011). Bilingual education in the $21^{\text {st }}$ century: A global perspective. New York: Wiley and Blackwell.

Gee, J. P. (1992). What is literacy? In P. Shannon (Ed.), Becoming political: Readings and writings in the politics of literacy education (pp. 21-28). Portsmouth, NH: Heinemann.

Gee, J. P. (1996). Social linguistics and literacies: Ideology in discourses. $2^{\text {nd }}$ ed. London: Taylor and Francis.

Gee, J. P. (2000). The new literacy studies: From 'socially situated' to the work of the social. In D. Barton, M. Hamilton, \& R. Ivanic (Eds.), Situated literacies: Reading and writing in context (pp. 177-193). London: Routledge.

Gee, J. P. (2000b). Discourse and sociocultural studies in reading. In M. L. Kamil, P. B. Mosenthal, P. D. Pearson, \& R. Barr (Eds.), Handbook of reading research, vol. III (pp. 195-207). Mahwah, NJ: Erlbaum. 
Gee, J. P. (2007). Foreword. In C. L. Selfe \& G. E. Hawisher (Eds.), Gaming lives in the twenty-first century: Literate connections (pp. ix-xii). New York: Palgrave Macmillan.

Geertz, C. (1973). The interpretation of cultures. New York: Basic Books, Inc.

Giddens, A. (1991). Modernity and self identity: Self and society in late modern age. Cambridge: Polity Press.

Giddens, A. (1994). Beyond left and right: The future of radical politics. Cambridge: Polity Press.

Gilroy, P. (1993). The Black Atlantic: Modernity and double consciousness. Cambridge: Harvard University Press.

Gillespie, M. (1995). Television, ethnicity, and cultural change. London: Routledge.

Giri, B. (2005). Mourning the $15^{\text {th }}$ anniversary of crisis: The plight of Bhutanese refugee women and children. Journal of Asian and African Studies, 40(5), 345-369.

Giroux, H. A. (2005). Border crossings: Cultural workers and the politics of education. $2^{\text {nd }}$ ed. New York and London: Routledge.

Graff, H. (1991). The literacy myth: Cultural integration and social structure in the nineteenth century. New Brunswick \& London: Transaction Publishers.

Graham, P. (1980). Whither the equality of educational opportunity? Daedalus, 109(3), $115-132$.

Gregory, E., \& Williams, A. (2000). City literacies: Learning to read across generations and cultures. London: Routledge.

Guerra, J. C. (1997). The place of intercultural literacy in the writing classroom. In C. Severino, J. C. Guerra, \& J. E. Butler (Eds.), Writing in multicultural settings (pp. 
248-60). New York: Modern Language Association.

Guerra, J. C. (1998). Close to home: Oral and literate practices in a transnational Mexicano community. New York, NY: Teachers' College Press.

Guerra, J. C. (2008). Cultivating transcultural citizenship: A writing across communities model. Language Arts, 85(4), 296-303.

Gupta, A. (1998). Postcolonial developments: Agriculture in the making of modern India. Durham, SC: Duke University Press.

Gupta, A., \& Ferguson, J. (2002). Beyond "culture": Space, identity and the politics of difference. In J. Inda \& R. Rosaldo (Eds.), The Anthropology of globalization: A reader (pp. 65-80). Oxford: Blackwell Publishers.

Hall, S. (1996). New ethnicities. In D. Morley \& K. H. Chen (Eds.), Stuart Hall: Critical dialogues in cultural studies (pp. 441-449). London: Routledge.

Hannerz, U. (2002). Notes on the global ecumene. In J. Inda \& R. Rosaldo (Eds.), The Anthropology of globalization: A reader (pp. 37-64). Oxford: Blackwell Publishers.

Hardt, M., \& Negri, A. (2000). Empire. Cambridge: Harvard University Press.

Hawisher, G. E., \& Selfe, C. L. (2004). Becoming literate in the information age: Cultural ecologies and the literacies of technology. College Composition and Communication, 55(4), 642-692.

Heath, S. B. (1983). Ways with words: Language, life, and work in communities and classrooms. Cambridge: Cambridge UP.

Heath, S. B, \& Street, B. with M. Mills (2008). On ethnography: Approaches to language and literacy research. New York \& London: Teachers College Press. 
Helms, G., Lossau, J., \& Oslender, U. (2005). Einfach sprachlos but not simply speechless: Language(s), thought, and practice in the social sciences. Area, 37(3), 242-250.

Heyl, B. S. (2001). Ethnographic interviewing. In P. Atkinson et al. (Eds.), Handbook of ethnography (pp. 369-383). London: Sage Publications.

Holloway, K. F. C. (1993). Cultural politics in the academic community: Masking the color line. College English, 55(6), 610-617.

Hones, D. F. (2001). The word: Religion and literacy in the life of a Hmong American. Religious Education, 96(4), 489-509.

Horner, B. (2004). Critical ethnography, ethics, and work: Rearticulating labor. In S. G. Brown \& S. I. Dobrin (Eds.), Ethnography unbound: From theory shock to critical praxis (pp. 13-34). New York: State University of New York Press.

Horner, B. (2006). Introduction: Cross-language relations in composition. College English, 68(6), 569-574.

Horner, B., \& Lu, M. (2007). Resisting monolingualism in 'English': Reading and writing the politics of language. In Ellis, V., Fox, C., \& Street, B. (Eds.) Rethinking English in schools: A new and constructive stage (pp. 141-157). New York: Longman.

Horner, B., Lu, M., Royster, J., \& Trimbur, J. (2011). Language difference in writing: Toward a translingual approach. College English, 73(3), 303-321.

Horner, B., \& Selfe, C. (2013). Translinguality/transmodality relations: Snapshots from a dialogue. Working Papers on Negotiating Differences in Language and Literacy. 
Horner, B., \& Trimbur, J. (2002). English only and U. S. college composition. College Composition and Communication, 53(4), 594-630.

Horsman, J. (1990). Something in my mind besides the everyday: Woman and literacy. Toronto: Women's Press.

Hull, G. (2003). Youth culture and digital media: New literacies for new times. Research in the Teaching of English, 38(2), 229-233.

Hutt, M. (1996). Ethnic nationalism, refugees, and Bhutan. Journal of Refugee Studies, 9(4), 397-420.

Hutt, M. (2003). Unbecoming citizens: Culture, nationhood, and the flight of refugees from Bhutan. Oxford, New York: Oxford University Press.

Hutt, M. (2005). The Bhutanese refugees: Between verification, repatriation and royal realpolitik. Peace and Democracy in South Asia, 1(1), 44-56.

Inda, J., \& Rosaldo, R. (Eds.). (2002). The anthropology of globalization: A reader. Oxford: Blackwell.

Jayakumar, U. M. (2008). Can higher education meet the needs of an increasingly diverse and global society?: Campus diversity and cross-cultural workforce competencies. Harvard Educational Review, 4(78), 615-651.

Jewitt, C. (2008). Multimodality and literacy in school classrooms. Review of Research in Education, 32(1), 241-267.

Kaplan, C., Alarcon, N., \& Moallem, M. (Eds.). (1999). Between woman and nation: Nationalisms, transnational feminisms, and the state. Durham and London: Duke University Press. 
Karamcheti, I. (1996). Caliban in the classroom. In K. J. Mayberry (Ed.), Teaching what you're not: Identity politics in higher education (pp. 215-27). New York: New York University Press.

Katz, J. (2004). On the rhetoric and politics of ethnographic methodology. The Annals of the American Academy of Political and Social Sciences, 595(1), 280-308.

Kirkland, D. (2004). Rewriting school: Critical writing pedagogies for the secondary English classroom. Journal of Teaching of Writing, 21(1/2), 83-96.

Kirsch, G. E., \& Ritchie, J. (1995). Beyond the personal: Theorizing a politics of location in composition research. College Composition and Communication, 46, 7-29.

Kress, G. (2010). Multimodality: A social semiotic approach to contemporary communication. London: Routledge.

Lam, W. S. E. (2000). L2 literacy and the design of the self: A case study of the teenager writing on the internet. TESOL Quarterly, 34(3), 457-82.

Lam, W. S. E. (2006). Culture and learning in the context of globalization: Research directions. Review of Research in Education, 30, 213-237.

Lantolf, J. (2000). Introducing sociocultural theory. In J. P. Lantolf (Ed.), Sociocultural theory and second language learning (pp. 1-26). London: Oxford University Press.

Lave, J., \& Wenger, E. (1991). Situated learning: Legitimate peripheral participation. Cambridge: Cambridge University Press.

Leonard, R. L. (2013). Traveling literacies: Multilingual writing on the move. Research in the Teaching of English, 48(1), 13-39. 
Lu, M. (2004). The ethics of reading critical ethnography. In S. G. Brown \& S. I. Dobrin (Eds.), Ethnography unbound: From theory shock to critical praxis (pp. 285-297). New York: State University of New York Press.

Lu, M. (2006). Living-English work.” College English, 68(6), 605-618.

Lu, M., \& Horner, B. (2013a). Translingual literacy and matters of agency. In A. S. Canagarajah (Ed.), Literacy as translingual practice: Between communities and classrooms (pp. 26-38). New York and London: Routledge.

Lu, M., \& Horner, B. (2013b). Translingual literacy, language difference, and matters of agency. College English, 75(6), 582-607.

Luke, A. (2003). Literacy and the Other: A sociological approach to literacy research and policy in multilingual societies. Reading Research Quarterly, 38,132-141.

Lummis, T. (1987). Listening to history: The authenticity of oral evidence. London: Hutchinson.

Madianou, M., \& Miller, D. (2012). Migration and new media: Transnational families and polymedia. New York and London: Routledge.

Madison, D. S. (2005). Critical ethnography: Method, ethics, and performance. Thousand Oaks: Sage.

Malkki, L. H. (1995). Refugees and exile: From 'refugee studies' to the national order of things. Annual Review of Anthropology, 24, 495-523.

Martin-Jones, M., \& Jones, K. (2000). Introduction: Multilingual literacies. In M. MartinJones \& K. Jones (Eds.), Multilingual literacies: Reading and writing different worlds (pp. 1-15). Amsterdam, The Netherlands/Philadelphia, PA: John Benjamins Publishing Co. 
Matsuda, P. K. (1999). Composition studies and ESL writing: A disciplinary division of labor. College Composition and Communication, 50(4), 699-721.

Matsuda, P. K. (2002). Alternative discourses: A synthesis. In C. Schroeder, H. Fox, \& P. Bizzell (Eds.), ALT/DIS: Alternative discourses and the academy (pp. 191-96). Portsmouth, NH: Boynton/Cook.

Matsuda, P. K. (2006). The myth of linguistic homogeneity in U. S. college composition. College English, 68, 637-51. (Rpt. in Cross-language relations in composition).

Mayadas, N. S., \& Segal, U. A. (2000). Refugees in the 1990s: A U.S. perspective. In P. R. Balgopal (Ed.), Social work practice with immigrants and refugees (pp. 198227). New York: Columbia University Press.

Minh-ha, T. T. (1991). When the moon waxes red: Representation, gender and cultural politics. New York and London: Routledge.

Mingolo, W. D., \& Schiwy, F. (2002). Beyond dichotomies: Translation/transculturation and the colonial difference. In E. Mudimbe-Boyi (Ed.), Beyond dichotomies: Histories, identities, cultures, and the challenge of globalization (pp. 251-286). Albany, NY: State University of New York Press.

Mohanty, C. T. (1984). Under Western eyes: Feminist scholarship and colonial discourses, Boundary 2, 12(3), 333-358.

Mohanty, C. T. (1994). On race and voice: Challenges for liberal education in the 1990s. In H. A. Giroux, and P. McLaren (Eds.), Between borders: Pedagogy and the politics of cultural studies (pp. 145-66). New York, and London: Routledge. Moje, E. B., Overby, M., Tysvaer, N., \& Morris, K. (2008). The complex world of adolescent literacy: Myths, motivations, and mysteries. Harvard Educational 
Review, 78(1), 107-154.

Morrell, E. (2002) Toward a critical pedagogy of popular culture: Literacy development among urban youth. Journal of Adolescent and Adult Literacy, 46(1), 72-78.

Moss, B. J. (1992). Ethnography and composition: Studying language at home. In G. Kirsch \& P. Sullivan (Eds.), Methods and methodologies in composition research (pp. 153-171). Carbondale, IL: SIUP.

Moss, B. J. (Ed.). (1994). Literacy across Communities. Cresskill, N. J.: Hampton.

Muller, M. (2007). What is in a word?: Problematizing translation between languages. Area, 39(2), 306-313.

Napoli, L. (2011). Radio Shangri-La: What I discovered on my accidental journey to the happiest kingdom on earth. New York: Broadway Paperbacks.

New London Group (1996). A pedagogy of multiliteracies: Designing social futures. Harvard Education Review, 66(1), 60-92.

Nyers, P. (2006). Rethinking refugees: Beyond states of emergency. New York: Routledge.

Ogbu, J. (1988). Literacy and schooling in subordinate cultures. In E. R. Kintgen, B. M. Kroll, \& M. Rose (Eds.), Perspectives on literacy (pp. 227-42). Carbondale, IL: Southern Illinois UP.

Ong, A., \& Nonini, D. (1997). Toward a cultural politics of diaspora and transnationalism. In A. Ong \& D. Nonini (Eds.), Underground empires (pp. 323332). New York: Routledge.

Ong, A. (2003). Buddha is hiding: Refugees, citizenship, the new America. Berkeley/Los Angeles, CA: University of California Press. 
Ong, W. J. (1982). Orality and literacy: The technologizing of the word. New York: Methuen.

Ortmeier-Hooper, C. (2008). English may be my second language, but I'm not 'ESL.' College Composition and Communication, 59(3), 389-419.

Pandey, I. P. (2006). Imagined nations, re-imagined roles: Literacy practices of South Asian immigrants (Doctoral dissertation). Retrieved from http://search.proquest.com.echo.louisville.edu/pqdtft/docview/305320612/68B1CD $\underline{\text { FF23EF4073PQ/1?accountid=14665 }}$

Pahl, K., \& Rowsell, J. (Eds.). (2006). Travel notes from the New Literacy Studies: Instances of practice. Tonawanda, NY: Multilingual Matters.

Parham, A. (2004). Diaspora, community and communication: Internet use in transnational Haiti. Global Networks, 4(2), 199-217.

Pennycook, A. (2008). English as a language always in translation.” European Journal of English Studies, 12(1), 33-47.

Pennycook, A. (2010). Language as a local practice. London and New York: Routledge.

Pratt, M. L. (2008). Introduction. Imperial eyes: Travel writing and transculturation. $2^{\text {nd }}$ ed. London and New York: Routledge.

Prendergast, C. (2008). Buying into English: Language and investment in the new capitalist world. Pittsburgh, PA: University of Pittsburgh Press.

Prinsloo, M., \& Baynham, M. (Eds). (2008). Literacies, global and local. Amsterdam/Philadelphia: John Benjamins Publishing Company.

Pryor, C. B. (2001). New immigrants and refugees in American schools. Childhood Education, 77, 275-283. 
Quantz, R. A. (1992). On critical ethnography (with some postmodern considerations). In M. D. LeCompte, W. L. Millroy, \& J. Preissle (Eds.), The handbook of qualitative research in education (pp. 447-506). San Diego, CA: Academic Press.

Rampton, B. (1995). Crossing: Language and ethnicity among adolescents. London: Longman.

Rampton, B. (2002). Ritual and foreign languages at school. Language and Society, 31(4), 491-526.

Reason, P. (2004). Critical design ethnography as action research. Anthropology and Education Quarterly, 35(2), 269-276.

Richmond, A. H. (2002). Globalization: Implications for immigrants and refugees. Ethnic and Racial Studies, 25, 707-727.

Robinson-Pant, A. (2000). Why eat green cucumbers at the time of dying?: Women's literacy and development in Nepal. Germany: UNESCO Institute for Education.

Robinson-Pant, A. (2005). Cross-cultural perspectives on educational research. New York: Open University Press.

Rogoff, B., \& Correa-Chavez, M. (2004). Preface. In E. Gregory, S. Long, \& D. Volk (Eds.), Many pathways to literacy: Young children learning with siblings, grandparents, peers and communities (pp. xiii-xv). New York, NY: RoutledgeFalmer.

Rose, M. (1989). Lives on the boundary: A moving account of the struggles and achievements of America's educationally underprepared. New York: Penguin Books. 
Rowsell, J., Kress, G., \& Street, B. (2012). Visual optics: Interpreting body art, three ways. Forthcoming.

Rushdie, S. (1991). Imaginary homelands: Essays and criticism 1981-1991. London: Granata Books.

Rymes, B. (2010). Classroom discourse analysis: A focus on communicative repertoires. In N. H. Hornberger, \& S. L. McKay (Eds.). Sociolinguistics and language education (pp. 528-548). Bristol: Multilingual Matters.

Sarroub, L. (2005). All American Yemeni girls: Being Muslim in a public school. Philadelphia: University of Pennsylvania Press.

Saxena, M. (2000). Taking account of history and culture in community-based research on multilingual literacy. In M. Martin-Jones \& K. Jones (Eds.), Multilingual literacies: Reading and writing different worlds (pp. 275-298). Philadelphia: John Benjamins.

Seidman, I. E. (1998). Interviewing as qualitative research: A guide for researchers in education and the social sciences. $2^{\text {nd }}$ ed. New York: Teachers' College.

Selfe, C. (1999). Technology and literacy in the $21^{\text {st }}$ century: The importance of paying attention. Carbondale, IL: SIU Press.

Shrestha, C. (2011). Power and politics in resettlement: A case study of Bhutanese refugees in the U. S. Research Paper Number 208, UNHCR. www.unhcr.org.

Smith, F. (2003). Working in different cultures. In N. Clifford \& G. Valentine, Key methods in geography (pp. 179-193). London: Sage.

Sternglass, M. S. (1997). Time to know them: A longitudinal study of writing and learning at the college level. Mahwa, NJ: Lawrence Erlbaum Associates, Inc. 
Street, B. (1984). Literacy in theory and practice. Cambridge: Cambridge UP.

Street, B. (Ed.). (1993). Cross-cultural approaches to literacy. Cambridge: Cambridge UP.

Street, B. V. (1995). Social literacies: Critical approaches to literacy in development, ethnography and education. London \& New York: Longman.

Street, B. (2001). The New Literacy Studies. In E. Cushman, G.R. Kintgen, B.M. Kroll, \& M. Rose (Eds.), Literacy: A critical sourcebook (pp. 430-442). Boston: St. Martin's Press.

Street, B. V. (Ed.). (2001b). Literacy and development: Ethnographic perspectives. London and New York: Routledge.

Street, B. V. (2006). New literacies, new times: How do we describe and teach the forms of literacy knowledge, skills, and values people need for new times? The yearbook of national reading conference (pp. 21-42). Oak Creek, WI: National Reading Conference, Inc.

Stuckey, J. E. (1991). The violence of literacy. Portsmouth, NH: Boynton/Cook.

Suarez-Orozco, C., Suarez-Orozco, M., \& Todorova, I. (2008). Learning a new land: Immigrant students in American society. London and Cambridge, MA: The Belknap Press of Harvard University Press.

Sullivan, P. (1996). Ethnography and the problem of the "Other." In P. Mortensen \& G. E. Kirsch (Eds.), Ethics and representation in qualitative studies of literacy (pp. 97-114). Urbana, IL: NCTE. 
Summary of Bhutanese refugee background and demographics (2008). Retrieved on May 2, 2014 from http://www.cdc.gov/tb/publications/newsletters/notes/TBN_4_08/tbetn_update.htm Sunstein, B., \& Chiseri-Strater, E. (2012). Fieldworking: Reading and writing research. $4^{\text {th }}$ ed. Boston and New York: Bedford/St. Martin's.

Tsing, A. L. (2005). Friction: An ethnography of global connection. Princeton and Oxford: Princeton University Press.

Tuhiwai Smith, L. (1999). Decolonizing methodologies: Research and indigenous peoples. London/Dunedin: Zed Books/University of Otago Press.

U.S. Immigration and Naturalization Service. (1997). Statistical yearbook of the immigration and naturalization service, 1995. Washington, DC: U.S. Government Printing Office.

Vieira, K. (2011). Undocumented in a documentary society: Textual borders and transnational religious literacies. Written Communication, 28(4), 436-461.

Vygotsky, L.S. (1978). Mind in society. Cambridge, MA: Harvard University Press.

Wade, S. E., \& Moje, E. B. (2001). The role of text in classroom learning: Beginning an online dialogue. Reading Online, 5(4). Retrieved on April 6, 2009 from http://www.readingonline.org/articles/art index.asp?HREF=handbook/wade/index.html.

Wallace, D. L., \& Ewald, H. R. (2000). Mutuality in the rhetoric and composition classroom. Carbondale and Eswardsville, IL: Southern Illinois University Press.

Warriner, D. S. (2009). Transnational literacies: Examining global flows through the lens of social practice. In M. Baynham \& M. Prinsloo (Eds.), The future of literacy 
studies (pp. 160-180). New York; Palgrave Macmillan.

West, C. (1990). The new cultural politics of difference. October, 53, 93-109.

Williams, B. T. (2003). Speak for yourself? Power and hybridity in the cross-cultural classroom. College Composition and Communication, 54, 586-609.

Williams, B. T. (Ed.). (2006). Identity papers: Literacy and power in higher education. Logan, UT: Utah State University Press.

Williams, B. T. (2010). Seeking new worlds: The study of writing beyond our classrooms. College Composition and Communication, 62(1), 127-146.

Williams, B. T., \& Brydon-Miller, M. (2004). Changing directions: Participatory-action research, agency, and representation. In S. G. Brown \& S. I. Dobrin (Eds.), Ethnography unbound: From theory shock to critical praxis (pp. 241-57). New York: State University of New York Press.

Williams, R. (1961). The long revolution. London: Chatto and Windus.

Young, V. A. (2004). Your average nigga. College Composition and Communication, 55(4), 693-715.

Zeppa, J. (1999). Beyond the sky and the earth: A journey into Bhutan. New York: Riverhead Books. 


\section{APPENDIX A: INTERVIEW PROTOCOL}

\section{Demographic information}

Date of birth/Gender

Place of birth and rearing/Type of household (childhood)

Parents' schooling and occupation/Schools attended

Education/Religion and Ethnic Identity

Past occupations in previous countries/Languages Spoken

\section{Flight to Nepal and resettlement in the U.S.}

Timeline of major developments in life in Bhutan, Nepal, and the U.S.

Occupations: Past, Current

Type of household (current)

\section{Early literacy exposure}

Earliest memories of seeing other people

read and write

Learning to read and write

Places and occasions of reading/ writing

People and organizations associated with reading/ writing

Materials available for reading/ writing

Kinds of materials

Technologies and their role in learning

Writing and reading at home, literacy centers, schools, and colleges

Early school reading/writing

Kinds of reading/writing

Technologies available and their role

Writing and reading with peers

\section{Language and culture}

Participants' first language, languages

other than English

Participants' sense of their facility with the English language

Participants' sense of how others perceive their

a) communicative performance, such as speech in different contexts; b) writingCurrent uses of reading and writing

In a) English b) other languages

\section{Views on literacy and learning}


Participants' view/definition of literacy

Learning

Their sense of the value of literacy

Their views on literacy transfer/ adaptation, cultural/linguistic/religious identities

\section{Changing, alternative literacies}

Participants' association with their ethnic, cultural, social or religious networks

Reading, writing, and language practices in these networks and resources they use (e.g. ethnic/language schools, publications, etc.)

Participants' view on native languages and literacies vs. those prized in the U.S.

Their views on perceived language/culture loss

Their action to prevent their language/culture loss (esp. for their children) vs. desire to succeed in the U.S. 


\section{APPENDIX B: ETHNOGRAPHIC ESSAY}

\section{Instructor: Tika Lamsal \\ English 102. Ethnographic Essay (Assignment Sheet)}

For this project, you will conduct primary (first-hand) research on a

(sub)culture, group, or community - one that you are interested in, in which you explore an unfamiliar territory of the (sub)culture, group, or community from an etic (outsider's or non-member's) point of view. Visit a site or subculture you might choose to research: a tattoo parlor, the lobby of a nursing home, a community theater, a convenience store, a fingernail salon, a group of pheasant hunters, workers on break, an airport check-in counter, a study group, a student club, a religious group, a group of employees on campus, a sports team, a Sunday school, a health club, a dance training center and so on (see Blackboard -Course Documents-for more subculture topics). If you are interested in producing a digital or multimodal work out of this fieldworking, let me know so we can figure out how to integrate such works in the assignment. You can also integrate photographs, podcasts, or any videos that you think will be relevant to the work.

Write a three-to-four-page paper in which you describe and interpret a subculture and/or a certain aspect of your fieldsite. Take fieldnotes while you study your artifact and site (see pp. 78-83 for fieldnotes). Describe details of the subculture and/or site you have chosen by observing people or cultural practices related to this subculture or site. Also, explain how your positions might affect what you will see at your fieldsite, and how you are going to mental check (see yourself as an outsider as others see you) them during your research process. You will need to do some careful thinking about what you know and what you think you know about yourself and your site. Use the following questions to guide your investigation:

- What is the subculture/site like? What are its cultural practices?

- How do your positions influence your fieldwork?

- What are your reasons for choosing this subculture? What are your research questions that guided you to do this research?

- What assumptions, myths or stereotypes are associated with this subculture or site?

IMPORTANT: Before you make any initial observations, freewrite about your concept of the community/group. The preconceived notions that you have about the community/group will make it more difficult to approach the community/group with an objective mind. If you admit your preconceived notions at the outset, you'll be more successful in distinguishing observed facts from stereotypical ideas.

\section{Goals}

The assignment is designed to help you: 
- Understand how to plan and conduct first-hand research and follow-up when necessary

- Critically examine norms and cultural stereotypes associated with difference (others)

- Arrive at original conclusions and insight into group identity, ideology, and beliefs rather than simply reproducing others' ideas

\section{Required Format}

- Use MLA style (See Blackboard - Course Documents - for the sample MLA paper)

- 3-4 pages

\section{Support and Resources}

You will be provided with sufficient support during the process of this assignment. We will discuss in class (based on daily reading materials from book and Blackboard postings) all the necessary research strategies for fieldworking. For those of you who need support to choose your topics (or subcultures), I have posted more subcultures/sites information with examples in Blackboard (see Subcultures under Course Documents). University Writing Center would be a great resource for you to get support for brainstorming your topics, reviewing your essays, and for any other help about writing your research paper. It has facilities for both virtual response and walk-in appointments (visit the Writing Center website or call them at 8522173). You can also meet with me any time during my office hours (see details about my office and time on the syllabus) if you want to discuss any issues regarding assignments.

\section{Evaluation Criteria}

Content and Rhetorical

Knowledge (35\%)
The essay presents sufficient information about the subculture/site through your observation of people's cultural practices, rituals, insider activities, language variations, cultural artifacts belonging to this community. The paper includes an analysis of some general assumptions about the subculture/site, and clarifies your positionality as a researcher. The essay develops a narrative that considerably focuses on the subculture and consistently underlines a theme to help identify them as a distinct community with their subcultural identity. The discussion informs the audience and keeps them engaged, while providing sufficient background knowledge and explaining with details unfamiliar terms and ideas.

Organization $(35 \%)$
The introduction clearly states a tentative thesis (giving an idea of what the essay is about and how you plan to forward your main idea), and research questions that guide your research. This section also introduces the subculture/site by vividly describing it. Each paragraph is clearly written and has a strong topic sentence. Transitions are used to guide the reader, and analytic section headings are used to show the clarity of ideas. The conclusion includes a reflective paragraph in which you analyze the challenges you face, and assess your strengths and weaknesses as a researcher. 


\begin{tabular}{|l|l|}
\hline Use of Sources $(20 \%)$ & $\begin{array}{l}\text { The essay correctly paraphrases, summarizes, or quotes } \\
\text { from at least two research sources. The paper includes a } \\
\text { correctly formatted source page (MLA). }\end{array}$ \\
\hline $\begin{array}{l}\text { Grammar and Mechanics } \\
(10 \%)\end{array}$ & $\begin{array}{l}\text { The essay is free from grammatical errors that interfere with } \\
\text { the readers' ability to understand the document. }\end{array}$ \\
\hline
\end{tabular}

Due: for peer response (Feb. 21), revised draft (March 6) 


\title{
CURRICULUM VITAE
}

\author{
TIKA R. LAMSAL \\ University of Louisville \\ Tika.lamsal@,louisville.edu/tika_lamsal@yahoo.com
}

\section{Education}

Ph.D. in Rhetoric and Composition, University of Louisville, Louisville, KY, August 2014

Dissertation: "Globalizing Literacies and Identities: Translingual and Transcultural Literacy Practices of Bhutanese Refugees in the U.S." Committee: Bruce Horner (Chair), Min-Zhan Lu, Bronwyn Williams, David Anderson, and Cynthia Selfe

M. A. in English (Rhetoric/Composition), University of Louisville, Louisville, KY, May 2009

Culminating Project: "Education and Fast Capitalism: Resisting the Commodification of Knowledge."

Supervisor: Bruce Horner

M. A. in English (Literature), Tribhuvan University, Nepal, June 1997

Thesis: "An Angel in the Wild: Construction of Identity in The Scarlet Letter."

Supervisor: Shreedhar Lohani

B. A. in English and Political Science, Tribhuvan University, Nepal, June 1994

\section{Academic Experience}

\section{University of Louisville}

Graduate Teaching Assistant/Composition Instructor, Aug. 2008 - present

Assistant Director of Graduate Student Writing, Writing Center, funded by School of Interdisciplinary and Graduate Studies, and Medical School, July 2012 - June 2013 
Writing Tutor/Consultant, Writing Center, Aug. 2007 - July 2008

\section{Nepal}

Lecturer of English, Central Department of English, Tribhuvan University, March 1998 - June 2007

Academic Director, Humanities Department, National Integrated College, June 2002 - June 2007

Lecturer of Business Writing and Communication, Apex College, Pokhara University, Aug. 2001 - Dec. 2006

\section{Publications}

\section{Peer-Reviewed}

"Cross-cultural and Multilingual Encounters: Composing Difference in Transnational Contexts." Journal of Global Literacies, Technologies, and Emerging Pedagogies 1. 2 (2013): 89-104.

"Beyond the Politics of Despair: Imagining the Possibilities for Change." JAC: Journal of Advanced Composition 32. 3-4 (2012): 758-767. (Co-authored with Hem Paudel)

"Global Audiences, Local Images: The Question of Exoticization in Slumdog Millionaire." Bodhi: An Interdisciplinary Journal 4. 1 (2010): 198-209.

" 'Selfing' the Other: A Colonial Reading of Jane Eyre and Wide Sargasso Sea." Bodhi: An Interdisciplinary Journal 2.1 (2008): 188-195.

\section{Other Publications}

"Mediating a Buffer Zone: Writing Center Frustration and Hope." University Writing Center Manual (2008): 40-45. University of Louisville.

"Carnivalesque Heroine in Wide Sargasso Sea." Chrysanthemum: A Literary Journal 5 (2007). Central Department of English, Tribhuvan University.

"Women's Literature as a Reflection of Women's Cause." Informal (A Human Rights Journal) 16.4 (December 2003). Informal Sector Service Center, Nepal.

"Elements of Humanism in Elizabethan Tragedies." Chrysanthemum: A Literary Journal 2 (1998). Central Department of English, Tribhuvan University. 


\section{Conference Presentations}

"Cross-cultural and Multimodal Literacies among Refugee Youth." Rhetoric Society of America Conference. May 2014. San Antonio, TX.

"Negotiating Differences through Tranlingual and Transmodal Literate Practices." Conference on College Composition and Communication. March 2014. Indianapolis, IN.

"In the Wor(1)ds of Social and Cultural Hostilities: Representations of Racial Identity in South Asian Diaspora Films." The Louisville Conference on Literature and Culture since 1900. Feb. 2014. Louisville, KY.

"Imagining Alternatives: Cross-cultural and Multilingual Mediations in Refugee Literacies." Conference on College Composition and Communication. March 2013. Las Vegas, NV.

"Politics of Displacement in Transgressive Terms: A Study of Postcolonial Diaspora Fiction." The Louisville Conference on Literature and Culture since 1900. Feb. 2013. Louisville, KY.

"Subverting Native Speaker Ideology in Composition." Thomas R. Watson Conference in Rhetoric and Composition. Oct. 2012. Louisville, KY.

"Transcultural Rhetorics, Translingual Repertoires: Literacy Practices of an Immigrant Refugee Community." Annual Meeting of Research Network Forum at Conference on College Composition and Communication. March 2012. St. Louis, MO.

"Colonial Gaze in Jack Maggs: Subverting the Imperial Projection of the 'Other'." The Louisville Conference on Literature and Culture since 1900. Feb. 2012. Louisville, KY.

“ 'Go(ing) Native': Composing Transnational Identities.” Penn State Conference in Rhetoric and Composition. July 2011. State College, PA.

"Remapping Composition in Transnational Contexts." Conference on College Composition and Communication. April 2011. Atlanta, GA.

"Messianic Anti-Pedagogy in The Ignorant Schoolmaster." Annual Conference of Kentucky Philological Association. March 2011. Frankfort, KY.

"Genre as a Discursive Practice: Cross-Cultural Mediation and Ethnographic Spectacle in Yojimbo." The Louisville Conference on Literature and Culture since 1900. Feb. 2011. Louisville, KY. 
"Teaching the 'Other': Renegotiating ELT in the Periphery." Thomas R. Watson Conference in Rhetoric and Composition. Oct. 2010. Louisville, KY.

"Global Audiences, Local Images: The Question of Exoticization in Slumdog Millionaire." Joint Conference of the National Popular Culture and American Culture Associations. March/April, 2010. St. Louis, MO.

"Blair as a Colonialist: Revisiting Blair's Lectures on Taste." Conference on College Composition and Communication. March 2010. Louisville, KY.

"Savagism and Civilization: Imperial Ideology in God's Country." Annual Conference of Kentucky Philological Association. March 2010. Richmond, KY.

"Crossdressing as a Cultural Representation: Disrupting the Finality of Heterosexual Closure in the Early Modern Consciousness." Annual Conference of Kentucky Philological Association. March 2009. Owensboro, KY.

"Cultural Identity as a Translational and Transnational Entity: Remapping the Boundaries of Teaching Writing to International Students." Annual Conference of International Writing Centers' Association. Oct./Nov. 2008. Las Vegas, NV.

“The Question of Identity: 'Calibanization' and Postcolonial Discourse."

Kentucky Philological Association Annual Conference. March 2008. Louisville, KY.

"Homosexuals in the Closet: Cross-cultural Mediation in Angels in America." Annual Conference of Literary Association of Nepal. March 2002. Kathmandu, Nepal.

\section{Invited Talks and Workshop Presentations}

\section{Public Forums/Communities}

"Global Literacies, Local Contexts: Literacy Practices of Bhutanese Refugees in the U.S” at Iroquis Public Library, Louisville, KY. July 19, 2014.

"Traveling Literacies: Refugee Literacies in the U.S.," at Cultural Salon jointly organized by Louisville Free Public Library and Nepali Cultural Forum, Louisville, KY. April 26, 2014.

\section{University of Louisville}

"Practicing Process: Peer Review and the Writing Classroom," at Pedagogy Workshop, Composition Program. Sept. 4, 2013. 
"Writing Literature Review in Dissertation," at Dissertation Writing Retreat, College of Education and Human Development. Aug. 3, 2013.

"Dissertation Writing and Literature Review: Coming to Terms," at Dissertation Writing Retreat, Writing Center. May 22, 2013.

"Constructing an Academic Argument," at a Graduate Biochemistry/Molecular Biology Seminar. March 4, 2013.

"Writing a Literature Review," for the graduate students in Health Sciences Campus. School of Interdisciplinary and Graduate Studies. Feb. 27, 2013.

"How to Help International Graduate Students Succeed Academically and Culturally," for the faculty of School of Public Health, Health Sciences Campus. Nov. 30, 2012.

"Academic Transitions and Writing Center Services," at International Center and Graduate School International Students Meet and Greet Luncheon. Nov. 13, 2012.

"Writing Literature Review in Research Writing," at a Graduate Nursing Seminar. Oct. 4, 2012.

"Citing and Paraphrasing Academic Sources," at a Graduate Nursing Seminar. Sept. 20, 2012.

"Writing Literature Review: Nuts and Bolts of Academic Research," at a Graduate Audiology Seminar, Aug. 23, 2012.

"Perspectives on Teaching," at Graduate Teaching Assistant Orientation. Aug. 14, 2012.

\section{Nepal}

"Teaching Literature and Writing to First Year B. A. Students," for College English teachers, National Integrated College. May 15, 2005.

"Teaching Technical Writing and Business Communication," for Business Communication teachers, Apex College. March 8, 2004.

"Writing and Rhetorical Strategies: Teaching Writing and Research Methodology," at First Year (M. A.) Teaching Workshop, Central Department of English, Tribhuvan University. March 5, 2000

\section{Courses Taught}

\section{University of Louisville}


ENGL 306. Business Writing

3 Sections

ENGL 102. Intermediate College Writing

14 Sections

ENGL 101. Introduction to College Writing

4 Sections

\section{Nepal}

\section{Tribhuvan University}

English 504-2. Rhetoric/Composition

6 Sections

English 503-1. Linguistics

8 Sections

English 508-2. Non-Western Studies

4 Sections

English 501-1. History of British and American Literature

6 Sections

\section{Pokhara University}

Business Writing and Communication

18 Sections

Globalization and Its Cultural Implications

2 Sections

Discourse in Disciplines: Literary Theory \& Criticism

4 Sections

\section{Professional Service}

\section{University of Louisville}

ESL and Job Readiness Assessment Volunteer Teacher, Kentucky Refugee Ministries, Louisville, Kentucky. June 2012 - July 2013.

Executive Member, English Graduate Organization, University of Louisville. Aug. 2012 - July 2013.

President, Nepali Student Association, University of Louisville. March 2010 July 2013.

Panel Chair of a session "Analysis of Cross-cultural Frames and Practices," Conference on College Composition and Communication. March 2012. St. Louis, MO.

Technology Resource Instructor at Celebration of Teaching and Learning: Envisioning Teaching and Learning in the Digital Age. Feb. 2012. University of Louisville.

Panel Chair of a session "Deconstructing the Academic/Personal Binary," Thomas R. Watson Conference in Rhetoric and Composition. Oct. 2008. Louisville, KY. 
Panel Chair of a session "Autobiographical Performances of Illness and Trauma," The Louisville Conference on Literature and Culture since 1900. Feb. 2008. Louisville, KY.

\section{Nepal}

General Secretary, Interdisciplinary Discourse for Enhancing Civic Awareness. March 2006 - June 2007.

Editor/Translator, Informal Sector Service Center. July 2000-Aug. 2003.

Founder Member, National Integrated College. Since 2001.

Chief Editor, Chrysanthemum: A Literary Journal, published by Central Department of English, Tribhuvan University. July 1997- June 1999.

\section{Professional Development}

DMAC (Digital Media and Composition) Workshop, The Ohio State University, Columbus, OH. May $31^{\text {st }}$ - June 12, 2012.

GTA Academy (a year-long interdisciplinary teaching workshop), University of Louisville. Fall 2008 - Spring 2009.

Teaching College Composition Workshop, Composition Program, University of Louisville. Aug. 18-22, 2008.

National Seminar/Workshop on Proposal and Thesis Writing, Central Department of English, Tribhuvan University. Dec. 21-26, 2006.

Workshop for English Lecturers Teaching M. A. Second Year Courses, Central Department of English, Tribhuvan University. March 15-22, 2001.

Workshop for English Lecturers Teaching M. A. First Year Courses, Central Department of English, Tribhuvan University. March 5-12, 2000.

\section{Academic Honors/Awards}

Dissertation Fellowship Award, Summer 2014, School of Interdisciplinary and Graduate Studies, University of Louisville, Louisville, KY.

\$ 500.00 Scholarship Award from Bedford/St. Martin's to participate in DMAC (Digital Media and Composition) workshop at the Ohio State University, Columbus, $\mathrm{OH}$, from May $31^{\text {st }}-$ June 12, 2012 
Mahendra Bidhya Bhusan, National Academic Excellence Award/Honor (Gold Medal), 1998, for holding first-class first position in M. A., Tribhuvan University, Nepal

Meritorious Student Scholarship for studying M. A., 1995, Tribhuvan University, Nepal

Meritorious Student Scholarship for studying B. A., 1993, Tribhuvan University, Nepal

\section{Professional Affiliation}

National Council of Teachers of English

Conference on College Composition and Communication

Rhetoric Society of America

Modern Language Association

Literary Association of Nepal

Gurukul Theater of Nepal

\section{Graduate Coursework}

\section{Rhetoric and Composition}

Critical Pedagogy, Its Discontents, and Beyond in English Studies (Bruce Horner) Teaching College Composition (Bronwyn Williams)

Writing Center Theory and Practice (Mary Rosner)

History of Rhetoric II (Carol Mattingly)

Special Topics Seminar on Pop Culture and Literacy (Bronwyn Williams)

Teaching English as a Second Language (Karen Mullen)

Politics of Language in the Teaching and the Study of Composition (Bruce

Horner)

Research Methods in Composition (Debra Journet)

Composition Theory and Practice (Min-Zhan Lu)

Narrative Theory (Debra Journet)

Re-vision: Theory and Practice (Min-Zhan Lu)

Writing in the Disciplines (Joanna Wolfe)

Film Theory and Genre (Bronwyn Williams)

Special Topics Seminar on Outside Composition (Bruce Horner)

Watson Seminar on Language and Literacy (Min-Zhan Lu, Brian Street, Suresh

Canagarajah, Ralph Cintron)

\section{Literature and Literary Theory/Creative Writing}

Victorian Afterlife (Beth Boehm)

Literature of U.S. Slavery (Carol Mattingly) 
Shakespeare (Julia Deitrich)

Creative Nonfiction: Practice and Pedagogy (Bronwyn Williams)

Contemporary Theories of Interpretation (Karen Hadley)

New Media and Cultural Theory (Aaron Jaffe)

Special Topics in Literary and Critical Theory: Sexuality and Aesthetics

(Matthew Biberman)

\section{Language Proficiency}

English (high proficiency in speaking, reading and writing)

Nepali (high proficiency in speaking, reading and writing)

Hindi (good proficiency in speaking, reading and writing)

Sanskrit (good proficiency in reading and writing)

Other local languages like Maithili, Limbu (speaking knowledge)

\section{References}

Bruce Horner, Professor and Endowed Chair in Rhetoric and Composition Department of English, University of Louisville b.horner@louisville.edu

Min-Zhan Lu, Professor and University Scholar Department of English, University of Louisville m.lu@louisville.edu

Bronwyn Williams, Professor and Director of University Writing Center Department of English, University of Louisville bronwyn.williams@louisville.edu

Cynthia Selfe, Humanities Distinguished Professor

Department of English, The Ohio State University selfe.2@osu.edu

Beth Boehm, Professor of English and Dean, School of Interdisciplinary and Graduate Studies, University of Louisville

beth.boehm@louisville.edu

Aaron Jaffe, Professor of English

Department of English, University of Louisville aaron.jaffe@louisville.edu 